Valladolid, 2021

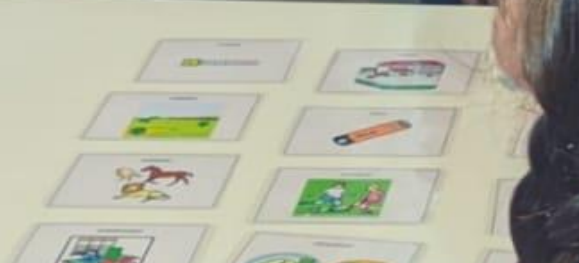

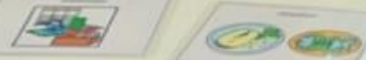

\title{
ANÁLISIS DEL PROGRAMA DE ESTIMULACIÓN LINGÜÍSTICA DE EXPRESIÓN ORAL (DELEO) Y DE SU UTILIZACIÓN CON NIÑOS CON TRASTORNO DEL LENGUAJE
}

Tesis doctoral de Alba Ayuso Lanchares

Directoras:

Inés Ruiz Requies y Rosa Belén Santiago Pardo 



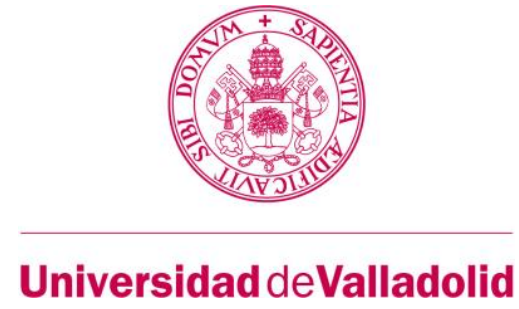

PROGRAMA DE DOCTORADO EN

INVESTIGACIÓN TRANSDISCIPLINAR EN

EDUCACIÓN

\title{
TESIS DOCTORAL:
}

\author{
Análisis del Programa de \\ Estimulación Lingüística de \\ Expresión Oral (PELEO) y de su \\ utilización con niños con Trastorno \\ del lenguaje
}

Presentada por Alba Ayuso Lanchares

para optar al grado de

Doctora por la Universidad de Valladolid

Dirigida por:

Dra. Inés Ruiz Requies

Dra. Rosa Belén Santiago Pardo 

A mi padre, que me cuida desde el cielo A mi madre, que me acompaña en todo momento 



\section{Agradecimientos}

Un proverbio africano dice: "si quieres llegar rápido ve tú solo, si quieres llegar lejos ve acompañado". No se me ocurre un punto académico más lejano que el doctorado, y no hubiera sido posible llegar hasta la meta sin toda la gente que me ha acompañado, por lo que quiero expresar mi agradecimiento infinito.

Gracias a mis directoras de tesis, a Inés por tu conocimiento, ayuda, experiencia, por tu cercanía y cariño, y por ser mi guía en toda la tesis. A Belén, por tu dedicación, por ser mi profesora de grado, mi tutora de TFG, mi compañera en la facultad, y por tus inestimables consejos, por ser mi mentora en todo este proceso académico universitario. Juntas habéis hecho un tándem perfecto y habéis logrado que esta tesis saliera adelante.

Gracias a Denisse, mi tutora en mi estancia doctoral en la Universidad de Valparaíso (Chile), gracias por acogerme en medio de una pandemia mundial, por tus consejos y por hacer fácil lo difícil.

Gracias a todas las familias y niños que han participado en el desarrollo de la tesis, gracias por vuestro tiempo y vuestra colaboración, he aprendido todo con vosotros.

Gracias a todos los centros escolares que han participado en la tesis, a las trabajadoras de la la Escuela Infantil primeros pasos, la Escuela infantil Villandrando, del Colegio Santa Clara de Asís, del Colegio Santo Domingo de Guzmán, y del Colegio San José de Palencia, gracias por vuestro apoyo, vuestro compromiso con la investigación, por aceptarme como una más y por hacerme sentir como en casa.

Gracias a las logopedas que han participado en el estudio, Nuria, Amalia, Teresa, Marta, Mar y Eva. Gracias por vuestro tiempo, vuestro compromiso, por escucharme, apoyarme y por vuestras ganas.

Gracias a mis amigas, a Sonia y a Mirella por demostrarme que "la unión no solo hace la juerga" y por apoyarme. Un agradecimiento doble a Nuria y a Amalia por enseñarme que una llamada no se puede denominar de esa manera si dura menos de una hora, gracias por hacer que la distancia no exista cuando nos necesitamos. Gracias a la otra Palencia, a Patri y 
Lara, mis amigas de siempre, gracias por hacer que el tiempo no pase. Gracias a todos mis otros conocidos y amigos que habéis colaboradora en la tesis y formado parte de mi vida durante los últimos 4 años.

Gracias a mi compañero de viaje, a Fran, por ser paciente, por confiar en que cumpliera mi sueño y por transmitirlo cuando yo pensaba que no podía hacerlo; gracias por apoyarme, por apostar por nuestros planes de futuro, por ayudarme a desconectar y a reírme, y por hacerme sentir que a tu lado estoy en casa.

Gracias a mi familia, a los Ayuso y a los Lanchares, por acompañarnos en los momentos más difíciles y por hacer que no los vivamos solos, cuando todo nos obligaba a hacerlo.

A mis hermanos: A Mario, gracias por ser tan atento, persistente, tenaz y cariñoso, gracias por estar ahí siempre, ojalá pueda acompañarte en tu sueño la mitad de bien como tú me has acompañado en el mío. A Celia chiquitina, por ser la mejor diseñadora, creadora de PowerPoint, compañera de habitación, "risoterapeuta", por ser cariñosa hasta cuando no te nace, por escucharme ensayar una y otra vez y por apoyarme en todo momento.

Gracias, mamá, por cuidarnos, por enseñarme a no rendirme nunca, a que los sueños están para el que los persigue, por tu cariño, tus besos y tus abrazos; gracias por ayudarme en todo y más, gracias por ponerlo todo tan fácil y por enseñarme todo lo que sé.

Gracias a ti papá, ojalá pudieras ver esto ahora, me llevaste a la primera reunión de la tesis, y estoy segura de que estás siguiendo desde el cielo este proceso final. Espero que desde allí puedas leer estas palabras y estés orgulloso de mí. Esta tesis es un poquito tuya, no hubiera podido llevarla a cabo sin tus trabajos de tijera y pegamento, plastificación, corrección de puntos y comas..., gracias por todo lo que me has enseñado que me ha hecho ser quien soy, gracias por quererme, por tu apoyo y por no soltarme tu mano hasta el final. Muchas gracias por luchar y por intentarlo, te echo de menos.

En definitiva, gracias a todos, lo difícil era no conseguirlo estando tan bien acompañada. 


\section{Índice de contenidos}

Capítulo 1 27

Capítulo 2 7

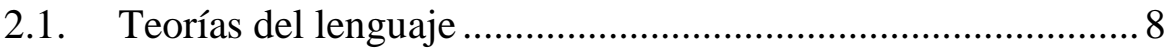

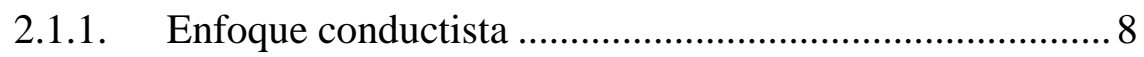

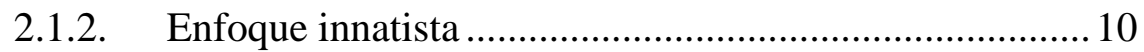

2.1.3. Enfoque cognitivo ...................................................... 11

2.1.4. Enfoque interaccionista .............................................. 12

2.2. Desarrollo normotípico del lenguaje....................................... 14

2.3. Etapas del lenguaje …........................................................ 15

2.3.1. Etapa prelingüística, presemiótica, preverbal o etapa oral

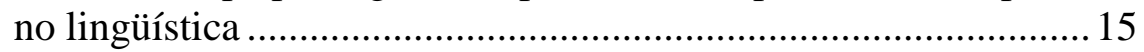

2.3.2. Etapa lingüística ........................................................ 17

2.3.2.1. El desarrollo fonológico …………......................... 18

2.3.2.2. El desarrollo del nivel morfosintáctico .................... 20

2.3.2.3. El desarrollo semántico ........................................... 21

2.3.2.4. El desarrollo pragmático ............................................. 23

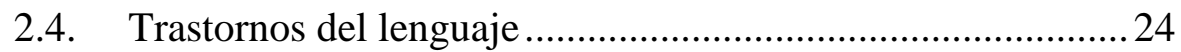

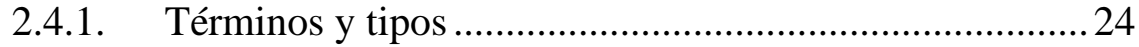

2.4.2. Identificadores y pruebas diagnósticas de los niños con

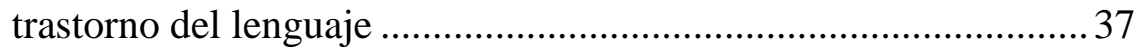

2.4.2.1. Las pruebas de inteligencia no verbal ..................... 39

2.4.2.2. Las pruebas de evaluación del lenguaje ................... 39

2.5. Intervención logopédica con niños con trastorno del lenguaje 44

2.5.1. Perfil profesional del logopeda..................................... 44

2.5.2. Rehabilitación logopédica en el lenguaje oral de los niños

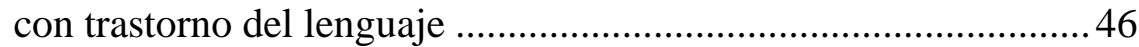

2.5.1.1. Intervención en la dimensión fonética-fonológica .. 51 
2.5.1.2. Intervención en la dimensión semántica ...................53

2.5.1.3 Intervención en la dimensión sintáctica............................55

2.6. Etapa de Educación Infantil en el Sistema Educativo Español 57

2.6.1. Integrantes de la comunidad educativa: el maestro de

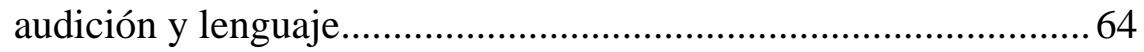

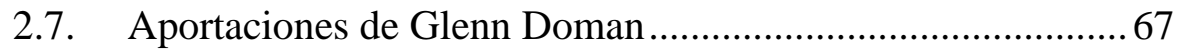

2.7.1. Los Institutos para el Desarrollo del Potencial Humano 68

2.7.2. Programa de Glenn Doman ............................................. 68

2.7.3. Programa de los bits de inteligencia ................................. 69

2.7.4. Críticas al método......................................................... 72

2.7.5. Experiencias con los bits de inteligencia ........................ 73

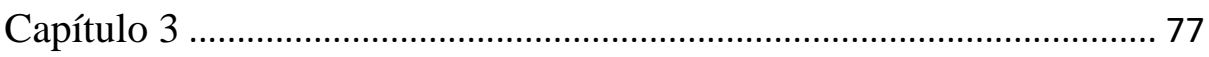

3.1 Los paradigmas en la investigación científica ............................ 77

a) Paradigma positivista o cuantitativo ...................................... 79

3.2. Estudio cuasi experimental como metodología de investigación 79

3.2.1. Tipos de estudios experimentales....................................... 80

3.2.2 Tipos de estudios cuasi experimentales ............................... 83

3.2.3 Validez interna y validez externa en el estudio cuasi

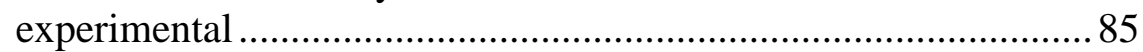

3.3. Estudio de caso como método de investigación ......................... 87

3.3.1. Tipos de estudio de caso........................................................ 89

3.3.2. Estudio de caso evaluativo (ECE) ........................................ 90

3.3.3. Criterios de utilización del estudio de caso ......................... 92

3.3.4. Fases para desarrollar el estudio de caso .............................. 93

3.3.5. Críticas al estudio de caso ................................................... 95

3.4. Criterios de rigor en la investigación del estudio de caso...........96

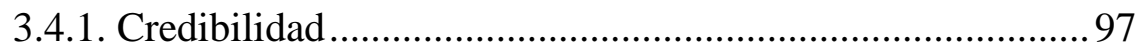

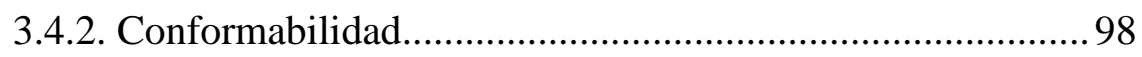

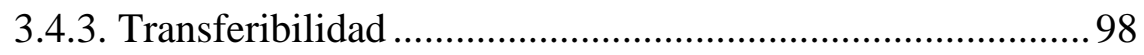




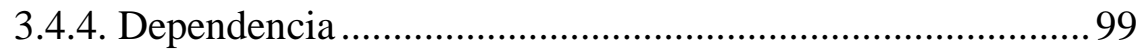

3.5 Técnicas e instrumentos de obtención de datos ........................ 100

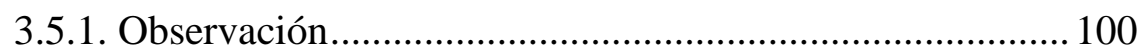

3.5.2. Pruebas estandarizadas ....................................................... 103

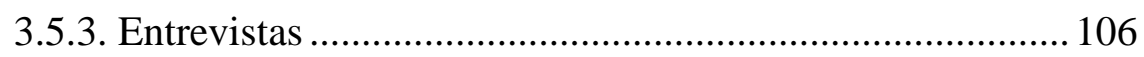

3.5.4. Cuestionario tipo Likert ..................................................... 108

3.6 Metodologías de recogida y análisis de datos ........................... 109

3.6.1. Metodología cuantitativa de recogida de datos ................. 109

3.6.2. Metodología mixta de recogida de datos............................. 110

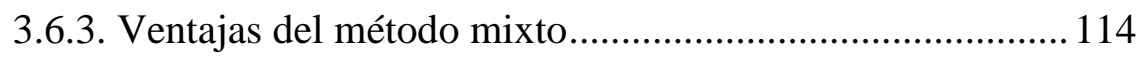

3.7 Cuestiones ético-metodológicas ............................................... 115

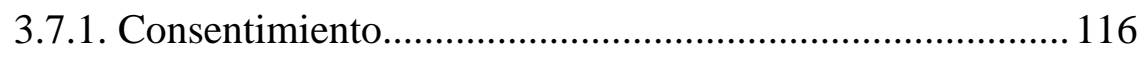

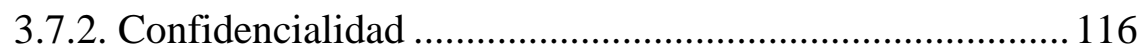

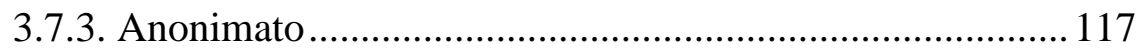

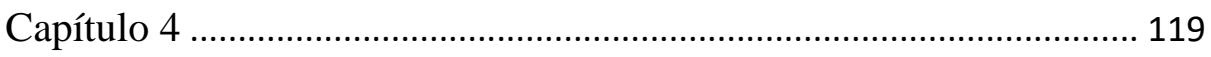

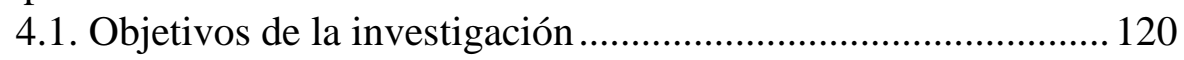

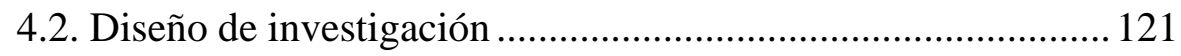

4.3. Descripción del estudio de investigación.................................. 121

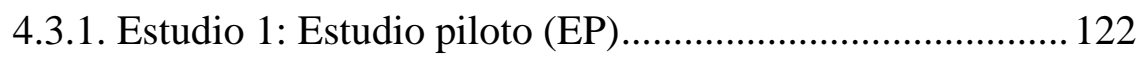

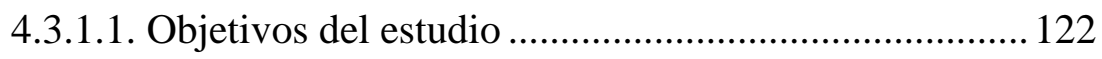

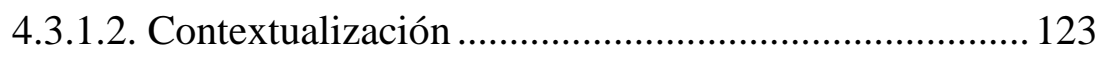

4.3.1.3. Participantes del Estudio Piloto (PEP) y criterios de

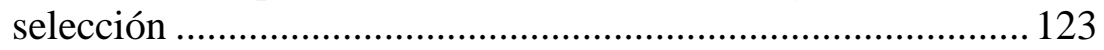

4.3.1.4. Técnicas e instrumentos utilizados ............................... 124

4.3.1.5. Fases de aplicación. Procedimiento............................ 129

4.3.1.6. Análisis de los resultados ........................................... 133

4.3.1.7. Resultados iniciales del EP y recomendaciones para

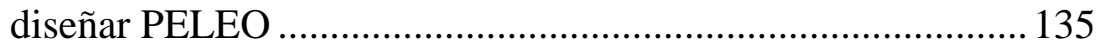

4.3.2. Estudio 2: Programa de Estimulación Lingüística de

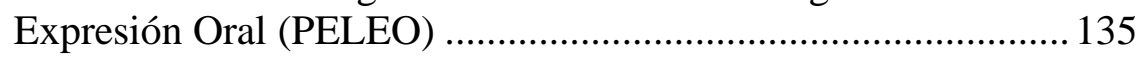

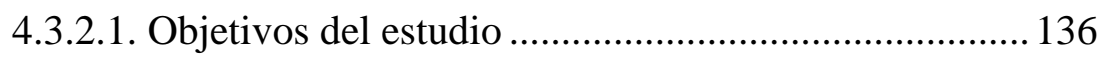


4.3.2.2. Contextualización 136

4.3.2.2. Participación y criterios de selección de los participantes

4.3.2.3. Técnicas e instrumentos utilizados 143

Fuente: elaboración propia. 155

4.3.2.4. Fases de aplicación 155

Capítulo 5 161

5.1. Resultados del Estudio Piloto (EP) 163

5.1.1. Análisis intergrupo 164

5.1.2. Análisis intragrupal 168

5.1.2.1. Grupo experimental 168

5.1.2.1. Grupo control. 172

5.1.3. Resultados del cuestionario tipo Likert 176

5.2. Discusión de los resultados del Estudio Piloto (EP) 178

5.3. Resultados del Programa de Estimulación Lingüística de Expresión Oral (PELEO) . 180

5.3.1. ¿Cómo es el diseño de PELEO en relación con la cantidad y el orden del vocabulario que se ha utilizado? 181

5.3.2. ¿Cómo es el diseño de PELEO en relación con el tipo de vocabulario que se ha utilizado?

5.3.3. ¿Cómo es el diseño de PELEO en relación a las actividades y a la motivación de los niños?

5.3.4. ¿Cómo ha cambiado el vocabulario de los niños que han utilizado PELEO? 202

5.3.5. ¿Cómo ha cambiado la articulación de los niños que han utilizado PELEO?

5.3.6. ¿Cómo ha cambiado la morfosintaxis de los niños que han

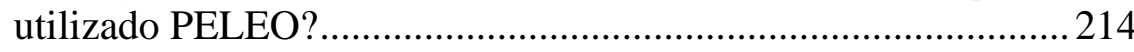

5.4. Discusión de los resultados del segundo estudio: PELEO ......218 5.4.1. El diseño de PELEO para estimular el lenguaje de niños con trastorno del lenguaje de tres a cinco años 
5.4.2. Utilización de PELEO con niños con trastorno del lenguaje

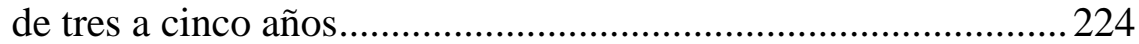

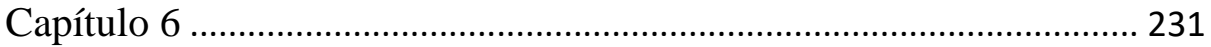

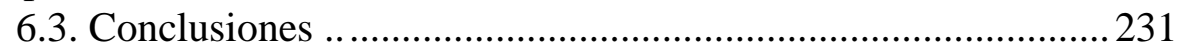

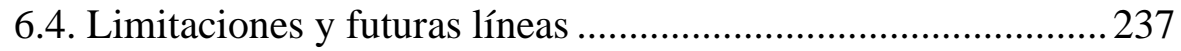

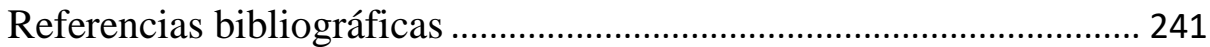




\section{Índice de tablas}

Tabla 2.1. Etapa prelingüistica e inicio de etapa lingüística ................ 16

Tabla 2.2. Edad de adquisición de los fonemas.................................... 20

Tabla 2.3. Clasificación de los hitos sintácticos en la evolución del

lenguaje de los niños ......................................................................... 20

Tabla 2.4. Criterios para el diagnóstico del trastorno del lenguaje expresivo según el DSM-IV .................................................................. 31

Tabla 2.5. Criterios para el diagnóstico del trastorno mixto del lenguaje receptivo-expresivo según el DSM-IV ................................................ 31

Tabla 2.6. Criterios para el diagnóstico del TSC según el DSM-IV (2013)

Tabla 2.7. Comparación de la terminología utilizada para determinar los trastornos del lenguaje

Tabla 2.8. Tabla de evaluación de diferentes áreas para niños con TDL adaptado de Carballo (2012)............................................................... 42

Tabla 3.1. Relación investigador e investigado en los diferentes paradigmas de investigación educativo, según diferentes autores ........78 Tabla 3.2. Diferencias entre el diseño experimental, preexperimental y el cuasiexperimental 82

Tabla 3.3. Resumen diseño postest con un grupo no equivalente ......... 83

Tabla 3.4. Resumen diseño de grupo control no equivalente pretestpostest

Tabla 3.5. Resumen diseo pretest-postest control

Tabla 3.6. Características de la Prueba de Lenguaje Oral de Navarra Revisada (PLON-R)

Tabla 3.7. Características del Registro Fonológico Inducido (RFI) ... 105

Tabla 3.8. Características del Peabody Picture Vocabulary test TVR 106

Tabla 3.9. Comparación entre las rutas cuantitativa y cualitativa ...... 112

Tabla 3.10. Esquema de los tipos de metodología mixta .................... 113

Tabla 4.1. Edad media de los participantes ...................................... 124

Tabla 4.2. Vocabulario de los PowerPoint ........................................ 126

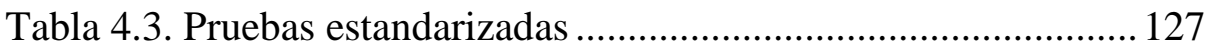

Tabla 4.4. Temporalización del estudio piloto .................................... 133

Tabla 4.5. Edad media de los participantes del estudio 2: Programa de

Estimulación Lingüística de Expresión Oral (PELEO) ........................ 136

Tabla 4.6. Logopedas encargadas de aplicar el método y su contexto 
Tabla 4.7. Relación de participantes del grupo experimental, edad al inicio de la intervención, logopedas que les atienden y contexto de intervención

Tabla 4.8. Láminas de creación propia edad tres años ..... 144

Tabla 4.9. Láminas de creación propia edad cuatro años 145

Tabla 4.10. Láminas de creación propia edad cinco años 146

Tabla 4.11. Relación de edades, lugares, participantes y cantidades de grabaciones

Tabla 4.12. Relación de entrevistas realizadas a las logopedas, fecha, hora y duración

Tabla 4.13. Relación de entrevistas realizadas a las maestras fecha, hora y lugar. 154

Tabla 4.14. Relación de entrevistas realizadas a las familias fecha, hora y duración 155

Tabla 5.1. Pruebas de normalidad para las variables del primer estudio

Tabla 5.2. Estadísticos descriptivos del análisis intergrupal .............. 164

Tabla 5.3. Prueta T-student para muestras independientes 166

Tabla 5.4. Estadísticos descriptivos de las muestras emparejadas en el

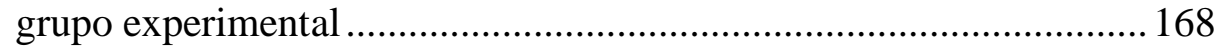

Tabla 5.5. Prueta T-student para muestras relacionadas .................... 170

Tabla 5.6. Kappa de Cohen entre los fonemas erróneos en la prueba

RFI final pretest y postest................................................................ 172

Tabla 5.7. Estadísticos de muestras emparejadas ................................ 172

Tabla 5.8. Prueta T-student para muestras dependientes .................... 174

Tabla 5.9. Kappa de Cohen de las variables de la Puntuación Típica de la evaluación inicial del PLON-R y de la evaluación final 175

Tabla 5.10. Cantidad de palabras en cada PowerPoint según la edad 182 Tabla 5.11. Respuestas de entrevistas de las logopedas en relación con el tipo y la cantidad de vocabulario que se utiliza. 183

Tabla 5.12. Conductas asociadas a motivación positiva y a motivación negativa en las sesiones con muchas palabras desconocidas 185 Tabla 5.13. Conductas asociadas a motivación positiva y a motivación negativa en las sesiones con pocas palabras desconocidas. 185

Tabla 5.14. Porcentaje de palabras conocidas según la categoría en todas las edades

Tabla 5.15. Porcentaje de palabras conocidas según la categoría en la edad de tres años. 188 Tabla 5.16. Porcentaje de palabras conocidas según la categoría en la edad de cuatro años. 
Tabla 5.17. Porcentaje de palabras conocidas según la categoría en la edad de cinco años 189

Tabla 5.18. Opinión de las logopedas sobre el tipo de palabras escogidas en PELEO 190

Tabla 5.19. Respuestas observvadas en los vídeos de las palabras que desconocen según la categoría semántica.

Tabla 5.20. Opinión de las logopedas sobre las actividades de la fase 1 y 3 (actividades relacionadas con el PowerPoint) y la fase 2 (actividades lúdicas con las palabras desconocidas) 196

Tabla 5.21. Observaciones encontradas en las listas de control relacionadas con la motivación de los niños ante las actividades ......201 Tabla 5.22. Estadísticos descriptivos de la prueba pre-postest........... 202 Tabla 5.23. Resultados de la prueba W-Wilcoxon ............................... 203 Tabla 5.24. Resultados de Kappa de Cohen ...................................... 203 Tabla 5.25. Opinión de las logopedas sobre cómo afecta al nivel

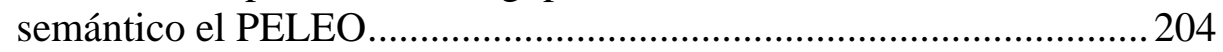
Tabla 5.26. Opinión de las familias sobre si el número de palabras que dice su hijo ha aumentado al utilizar PELEO. 205 Tabla 5.27. Opinión de las maestros sobre si el número de palabras que dice su alumno a aumentado al utilizar PELEO .................................206 Tabla 5.28. Estadísticos descriptivos de la prueba pre-postest........... 210 Tabla 5.29. Resultados de la prueba $W$-Wilcoxon ............................... 211 Tabla 5.30. Resultados de la prueba Kappa de Cohen ......................... 211 Tabla 5.31. Opinión de las logopedas sobre la articulación ................. 212 Tabla 5.32. Opinión de las familias sobre la articulación ....................213 Tabla 5.33. Opinion de las maestras sobre la articulación .................. 214 Tabla 5.34. Estadisticos descriptivos de la prueba inicial-final sobre

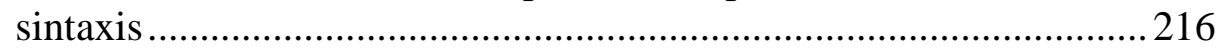
Tabla 5.35. Resultados de la prueba $W$-Wilcoxon ............................... 216 Tabla 5.36. Resultados de la prueba Kappa de Cohen ........................ 217 Tabla 5.37. Opinión de las logopedas sobre la mejora de la sintaxis de los niños que utilizan PELEO. 


\section{Índice de figuras}

Figura 2.1. Bits de inteligencia comercializados. Extraído del material comercializado: "bits de inteligencia 2: maleta roja" de Juan Ramón

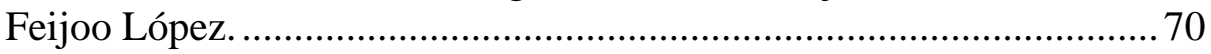

Figura 2.2. Ejemplo de bits de inteligencia. Extraído del material comercializado: "bits de inteligencia 2: maleta roja" de Juan Ramón Feijoo López.

Figura 3.1. Características del Programa de Estimulación Lingüística de Expresión Oral (PELEO).

Figura 4.2. Síntesis de los diseños de investigación que se utilizarán en esta tesis.

Figura 4.3. Ejemplo de Bit de inteligencia creado para este Estudio

Piloto. Se pueden ver el resto de las imágenes en el Anexo 12..........125

Figura 4.4. Fases de intervención del Estudio Piloto .......................... 132

Figura 4.5. Explicación análisis intergrupal e intragrupal................... 134

Figura 4.6. Ejemplo de Lámina del Programa de Estimulación

Lingüística de Expresión Oral (PELEO) ad hoc. ............................... 148

Figura 4.7. Proceso de intervención del Estudio 2: PELEO................. 159

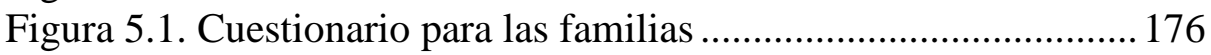

Figura 5.2. Triangulación realizada en el ECE................................... 181

Figura 5.3. Red de asociación de códigos: sesión con pocas y muchas

palabras desconocidas y motivación positiva y negativa. .................... 186

Figura 5.4. Lámina que representa la palabra "día"............................ 195

Figura 5.5. Lámina que representa la palabra "líquido"..................... 195

Figura 5.6. Porcentaje de niños de tres años que articulan correctamente los diferentes fonemas al menos en una posición................................208

Figura 5.7. Porcentaje de niños de cuatro años que articulan correctamente los diferentes fonemas al menos en una posición.......209 Figura 5.8. Porcentaje de niños de cinco años que articulan correctamente los diferentes fonemas al menos en una posición.......210 Figura 5.9. Lámina 1 del cuaderno de estímulos tres años, cuatro años.

Figura 5.10. Lámina 1 del cuaderno de estímulos cinco años 215 


\section{Listado de Anexos}

Todos los anexos se encuentran en el USB de esta tesis doctoral. El listado de los anexos es el siguiente:

ANEXO 1: Cuestionario tipo Likert creado ad hoc para conocer la opinión de las familias en relación con el EP.

ANEXO 2: Consentimiento informado de las familias (EP)

ANEXO 3: Información enviada vía email a las logopedas (ECE de PELEO)

ANEXO 4: Información enviada a los directores de los colegios con información relativa al estudio para su interés (ECE de PELEO).

ANEXO 5: Información enviada a los directores de los colegios con información relativa al estudio para el interés de las posibles familias de los niños con RL o TDL (ECE de PELEO).

ANEXO 6: Entrevista semiestructura creada ad hoc destinada a las logopedas (ECE de PELEO)

ANEXO 7: Entrevista semiestructurada cread ad hoc destinada a las maestras (ECE de PELEO)

ANEXO 8: Entrevista semiestructurada creada ad hoc destinada a las familias (ECE de PELEO)

ANEXO 9: Lista de control (ECE de PELEO)

ANEXO 10: Consentimiento informado de los logopedas (ECE de PELEO)

ANEXO 11: Consentimiento informado de los niños y los centros donde se ha realizado (ECE de PELEO)

ANEXO 12: Imágenes utilizadas en el EP

ANEXO 13: Imágenes utilizadas en las láminas de ECE de PELEO para los niños de tres años

ANEXO 14: Imágenes utilizadas en las láminas del ECE de PELEO para los niños de cuatro años

ANEXO 15: Imágenes utilizadas en las láminas del ECE de PELEO para los niños de cinco años

ANEXO 16: Informe de exclusión del candidato del estudio el PELEO 


\section{Listado de acrónimos}

Estudio de Caso (EC)

Estudio de Caso Evaluativo (ECE)

Estudio Piloto (EP)

PLON (Prueba de Lenguaje Oral de Navarra).

Programa de Estimulación Lingüística de Expresión Oral (PELEO)

Retraso del Lenguaje (RL)

Retraso Simple del Lenguaje (RSL)

RFI (Registro Fonológico Inducido)

Speech Language Impairment (SLI)

Trabajo de Fin de Grado (TFG)

Trastorno del Lenguaje (TL)

Trastorno del Desarrollo del Lenguaje (TDL)

Trastorno Específico del Lenguaje (TEL) 


\section{Publicaciones relacionadas con esta tesis doctoral}

Partes de esta tesis doctoral han sido publicadas en diversos congresos, artículos y capítulos de libro que se detallan a continuación:

\section{Congresos}

Ayuso-Lanchares, A., Santiago-Pardo, R. B. y Ruiz-Requies. (mayo de 2018), Los bits de inteligencia en niños con trastorno del lenguaje. X Congreso Internacional de la Asociación de Logopedas de España: Nuevas tendencias terapéuticas y de intervención en la logopedia. Asociación de Logopedas de España, Facultad de Ciencias Empresariales de la Universidad CEU San Pablo de Madrid.

Ayuso-Lanchares, A. y Ruiz-Requies, I. (octubre de 2019), Descripción de una intervención educativa con bits de inteligencia en niños con retraso del lenguaje. Congreso Universitario Internacional sobre la comunicación en la profesión y en la Universidad de hoy: Contenidos Investigación, Innovación y Docencia. Grupo de Investigación Complutense en Comunicación Concilium, el Fórum XXI y la SEECI, online.

Ayuso-Lanchares, A., Santiago-Pardo, R. B. y Ruiz-Requies. (septiembre de 2019), I. Adaptation Of The Doman's Flash Cards As An Educational Proposal For Children With Language Delay. Congress ECER 2019 Hamburg - The European Conference on Educational Research. European Educational Research Association, Universitat Hamburg, Germany.

Ayuso-Lanchares, A., Ruiz-Requies, I. y Santiago-Pardo, R. B. (diciembre de 2020), Déficits fonéticos en niños con retraso del lenguaje o trastorno del desarrollo del lenguaje. XIV congreso internacional de educación e innovación. Asociación para la promoción de la educación en la sociedad digital (PromoEDUCA), la Escuela Superior de Educación del Politécnico de Coimbra y el Departamento de Didáctica y 
Organización Escolar de la Universidad de Granada, Coimbra, Portugal.

Ayuso-Lanchares, A., Santiago-Pardo, R. B. y Ruiz-Requies. (septiembre de 2019), Déficits semánticos en niños con retraso del lenguaje. Twenty-seventh International Conference on Learning. Universitat de Valencia, Illinois Research Park, Common Ground and Media Lab. Valencia, España.

Ayuso-Lanchares, A., Ruiz-Requies, I. y Santiago-Pardo, R. B. (diciembre de 2020), La evolución del término Trastorno Específico del Lenguaje hacia Trastorno del Desarrollo del Lenguaje. XI Congreso Internacional de la Asociación de Logopedas de España bajo el lema: logopedia clínico-educativa basada en la evidencia científica. Asociación de Logopedas de España, online.

Ayuso-Lanchares, A., Ruiz-Requies, I. y Santiago-Pardo, R. B. (diciembre de 2020). La motivación ante actividades lúdicas o actividades de repetición en niños con Retraso del Lenguaje (RL) o Trastorno del Desarrollo del Lenguaje (TDL). I Congreso Internacional Nodos del Conocimiento. Universidad, Innovación e investigación ante el horizonte 2030. UNAM, Universidad de Sevilla y Universidad Zaragoza, organizado de manera online.

Ayuso-Lanchares, A., Pérez-Herrera, D., Santiago-Pardo, R. B. y RuizRequies, I. Análisis de los errores fonéticos de los niños chilenos y españoles con Retraso del Lenguaje (RL) y Trastorno del Desarrollo del Lenguaje (TDL). Primer congreso anual de estudiantes de doctorado de la Universidad Miguel Hernández, Universidad Miguel Hernández de Elche (España).

Ayuso-Lanchares, A., Ruiz-Requies, I. y Santiago-Pardo, R. B. (septiembre de 2021), I. Effectiveness of the Oral Expression Linguistic Stimulation Program in the Syntax of Children with Language Development Disorder. Congress ECER 2021 - The European Conference on Educational Research. European Educational Research Association, Online.

Ayuso-Lanchares, A., Santiago-Pardo, R. B. y Ruiz-Requies. (mayo de 2021), Evaluación logopédica de los hablantes tardíos durante la crisis de la COVID-19. XXIX Congreso Internacional INFAD 
Confianza en tiempos de crisis. Asociación INFAD, Instituto politécnico de Coimbra

Ayuso-Lanchares, A., Santiago-Pardo, R. B. y Ruiz-Requies. (mayo de 2021), Academic performance of children with language disorders users of a language intervention program. The $14^{\text {th }}$ Panhellenic and $1^{\text {st }}$ International Congress on Speech and Language Therapy: Building bridges. Panhellenic Association of Logopedists-Logotherapists. Digital Conference.

Santiago-Pardo, R. B., Ayuso-Lanchares, A. y Ruiz-Requies, I. (julio de 2021). Socialización de niños con trastorno del lenguaje usuarios de un programa de intervención lingüística (PELEO). XXXII Congreso Internacional AELFA-IF 2021, Asociación Española de Logopedia Foniatría y Audiología e Iberoamericana de Fonoaudiología, modalidad online.

\section{Artículos}

Ayuso-Lanchares, A., Santiago-Pardo, R. B., y Ruiz-Requies, I. (2019). Método Doman para la inclusión e intervención de niños con Trastorno del Desarrollo del Lenguaje. Revista Internacional de apoyo a la inclusión, logopedia, sociedad y multiculturalidad, 5(3), 91-105. https://doi.org/10.17561/riai.v5.n3.9

Ayuso-Lanchares, A., Santiago-Pardo, R. B., y Ruiz-Requies, I. (2020). Déficits semánticos en niños con retraso del lenguaje. Revista Internacional de Aprendizaje, 6(2), 89-101. https://doi.org/10.18848/2575-5544/CGP/v06i02/89-101

Ayuso-Lanchares, A., Santiago-Pardo, R. B., y Ruiz-Requies, I. (en prensa). Aplicación de un programa de estimulación lingüística en niños con retraso del lenguaje o trastorno del desarrollo del lenguaje. Revista Española de Orientación Psicopedagógica (en prensa).

\section{Capítulos de libro}

Ayuso-Lanchares, A. y Ruíz-Requies, I. (2020). Intervención lingüística en niños con retraso del lenguaje utilizando los bits de inteligencia. En Felipe, A., Peña, B. y Bobkina, J. (Ed.) Estudios 
sobre innovaciones educativas (pp. 87-98). Colección: Ediciones Universitarias. Ediciones Pirámide.

Ayuso-Lanchares, A., Santiago-Ruiz, R.B. y Ruiz-Requies, I. (2021). Dificultades en la articulación de los niños con retraso del lenguaje o trastornos del desarrollo del lenguaje. En Tomás Sola, M., Mariano G. y Juan Carlos C. (Ed.) Estudios sobre innovación e investigación educativa (pp. 139-149). Editorial Dykinson.

Ayuso-Lanchares, A., Ruíz-Requies, I. y Santiago-Ruiz, R.B. (2021). La motivación ante actividades lúdicas o actividades de repetición en niños con Retraso de Lenguaje (RL) o Trastorno del Desarrollo del Lenguaje (TDL). Nuevas formas de aprendizaje en la era digital: en busca de una educación inclusiva. Editorial Dykinson. (en prensa). 


\section{Capítulo 1}

\section{Introducción}

La logopedia es una disciplina universitaria joven, ya que comenzó su andadura universitaria en 1991 tal como se establece en el Real Decreto 1419/1991, de 30 de agosto, en ese momento aparecieron las titulaciones de Diplomado en Logopedia en Valladolid y Madrid. La investigación en logopedia no es tan rica como en otras disciplinas, por lo que cuando en 2014 terminé mis estudios de graduada en logopedia, no contemplé la idea de dedicarme a investigar, sino que directamente comencé mi periplo laboral, trabajando como logopeda y continúo completando dicho bagaje en el día de hoy.

Mi primera investigación consistió en la realización de mi Trabajo Fin de Grado (TFG) titulado "Intervención logopédica en pacientes con implante coclear" cuyo trabajo fue presentado mediante comunicación oral en el XXIX Congreso Internacional de la AELFA celebrado en Murcia en septiembre de 2014. Este inicio en la investigación unido a la búsqueda de la mejora en mi práctica profesional, me condujeron a explorar más el campo de la investigación, buscando información sobre la práctica basada en la evidencia, entendiendo esta como el uso consciente, explícito y juicioso de la mejor evidencia existente con el objetivo de tomar decisiones en relación con el cuidado y la intervención logopédica (American Speech-Language and Hearing Association, 2005, 2006). La búsqueda de esta práctica logopédica basada en la evidencia en hablantes tardíos y en niños con Trastorno del Desarrollo del Lenguaje (TDL) me llevó a comprobar las aún escasas investigaciones que se llevaban a cabo. Los programas existentes no eran siempre eficaces y consideraba que no eran suficientes. Por este motivo comencé a elaborar un posible plan de investigación para emprender este reto personal y profesional iniciado en el curso escolar 2017-2018. Gracias a él voy mejorando mi práctica laboral diaria como logopeda, diseñando y posteriormente poniendo en práctica el Programa de Estimulación Lingüística de Expresión Oral (PELEO) con los pacientes 
que acudían al gabinete y enseñándoselo a otras logopedas, que tan amablemente han participado utilizándolo con otros niños. De esta manera, PELEO se ha convertido en un gran instrumento diario en el centro laboral donde trabajo.

Los objetivos generales de esta tesis doctoral son principalmente tres:

a) Diseñar el Programa de Estimulación Lingüística de Expresión Oral (PELEO).

b) Evaluar el diseño de PELEO en niños con trastorno del lenguaje de tres, cuatro y cinco años.

c) Valorar y analizar la aplicación de PELEO en niños de tres, cuatro y cinco años con trastorno del lenguaje.

Pero para poder llevar a cabo estos objetivos debemos pautar otros objetivos específicos que son los siguientes:

a) Comprobar la eficacia de los bits de inteligencia del Método Doman en los niños con trastorno del lenguaje y valorar si son útiles para el nuevo programa que vamos a crear.

b) Valorar qué características de los bits de inteligencia del Método Doman, podemos utilizar para crear PELEO.

c) Proponer una serie de recomendaciones y sugerencias que realizar en el diseño de PELEO, tras realizar una evaluación exhaustiva al diseño y a la utilización de este.

d) Comprobar cómo ha cambiado la articulación, el vocabulario y la morfosintaxis de los niños que han utilizado PELEO.

La presenta tesis doctoral se ha estructurado en dos partes: una teórica, comprendida por los capítulos 2 y 3 , y otra empírica que se desarrolla en los capítulos 4, 5 y 6.

En el capítulo 2 se enmarca el marco teórico, en este capítulo describimos las teorías del lenguaje existentes (enfoque conductista, innatista, cognitivo e interaccionista), además de describir el desarrollo normotípico del lenguaje. Esto es muy importante ya que los niños que van a participar en este estudio tienen dificultades en todas o algunas de las dimensiones del lenguaje (Andreu-Barrachina et al., 2014), por lo que conocer el desarrollo normotípico nos ayudará a comprender lo que debemos esperar de ellos, por otro lado, se describen los términos y los tipos de los trastorno del lenguaje (retraso del lenguaje, hablantes tardíos, trastorno específico del lenguaje, TDL...), además se definen los identificadores y las pruebas diagnósticas. En el proceso de aplicación describiremos las tres pruebas que utilizamos: El Registro Fonológico 
Inducido (Juárez y Monfort, 1996a), el Peabody Picture Vocabulary Test, TVIP (Dunn et al., 2006), y el PLON-R (Aguinaga et al., 2004).

Posteriormente comentamos cómo son las intervenciones logopédicas con niños con trastorno del lenguaje y describimos el perfil profesional del logopeda, ya que son seis logopedas los que aplican PELEO en los niños. Además, también se describe la etapa de Educación Infantil, ya que los participantes del estudio tienen entre 3 y 6 años, que es la edad que abarca el segundo ciclo de Educación Infantil. Asimismo, también señalamos los diferentes integrantes de la comunidad educativa y de los maestros de Audición y Lenguaje, que son los encargados de tratar a estos niños en los centros educativos. Por último, explicamos las aportaciones de Glenn Doman describiendo las críticas al método y las experiencias previas existentes.

En el capítulo 3 se describe el marco metodológico de la investigación, analizando los diferentes paradigmas en la investigación científica (positivista, interpretativo y sociocrítico), para centrarnos en dos tipos de estudios: el estudio cuasi experimental y el Estudio de Caso Evaluativo (ECE). Esto es así porque en el Estudio Piloto (EP) se utiliza un estudio cuasi experimental y en segundo estudio, que consiste en la evaluación del Programa de Estimulación Lingüística de Expresión Oral (PELEO), recurrimos a ECE. Dentro del estudio cuasi experimental se describen los tipos de estudios experimentales y cuasiexperimentales, la validez interna y externa de este tipo de estudios; y dentro del estudio de caso se describen los diferentes tipos, centrándonos en el ECE y las diferentes fases que se deben desarrollar para llevarlo a cabo, además de las críticas y los criterios de rigor de éste. Conjuntamente con estos dos tipos de estudios, se han explicado las diversas técnicas e instrumentos de obtención de datos existentes, centrándonos en las que hemos utilizado en el proceso de recolección de datos. También se han descrito las dos metodologías de recogida y análisis de datos que se han manejado en esta tesis doctoral; la metodología cuantitativa que se emplea en el EP y la metodología mixta, en la que nos apoyamos para desarrollar el estudio posterior. Por último, se han detallado los criterios ético-metodológicos que incluyen el consentimiento, la confidencialidad y el anonimato.

En el capítulo 4 describimos la metodología de investigación de la tesis doctoral, este capítulo se divide en dos subapartados claramente diferenciados, el correspondiente al EP, que sigue una metodología cuasi experimental, y representa los antecedentes del segundo estudio. En este primer subapartado, correspondiente al EP, nos centramos en los criterios de selección de los participantes, la contextualización de la 
recogida de datos, los objetivos del estudio, las técnicas de análisis de datos e instrumentos que se han utilizado y las fases de aplicación que se han seguido, para finalizar con la explicación del análisis de los errores cometidos, para poder diseñar el segundo estudio en el que nos centraremos en el siguiente subapartado.

El segundo estudio consiste en la aplicación y evaluación del Programa de Estimulación Lingüística de Expresión Oral (PELEO); a este segundo estudio lo denominaremos ECE por el diseño de investigación que utilizamos. En este subapartado vamos a profundizar en los criterios de selección de los participantes, en la contextualización de la intervención, en los objetivos del estudio, en las técnicas de análisis de datos e instrumentos, y, por último, en las fases de aplicación.

En el capítulo 5 analizamos e interpretamos los resultados. Por un lado, del Estudio Piloto, en el que se analizan los resultados dividiéndolos en resultados intergrupales e intragrupales, interpretando los resultados obtenidos en cada prueba estandarizada y en cada estadístico. Por otro lado, analizamos el Estudio de Caso Evaluativo de PELEO, en él respondemos a una serie de preguntas en relación con el diseño de evaluación y a la utilización del programa, a saber: ¿cómo es el diseño de PELEO en relación con la cantidad, el orden y el tipo del vocabulario que se ha utilizado?, ¿cómo es el diseño de PELEO en relación con las actividades y la motivación de los niños?, ¿cómo ha cambiado el vocabulario, la articulación y la morfosintaxis de los niños que han utilizado PELEO?

En el capítulo 6 discutimos los resultados obtenidos, teniendo en cuenta otras investigaciones similares, o que realizan estudios que pueden dar respuesta a nuestras preguntas; esta discusión se realiza en dos subapartados: en el primero, se realiza la discusión del EP y, en el segundo, se realiza la discusión del ECE; posteriormente, explicamos las conclusiones, dando respuestas a los objetivos de la tesis, haciendo hincapié en las recomendaciones que hemos diseñado para mejorar PELEO, en las limitaciones y líneas futuras de trabajo.

En la siguiente Figura 1.1. incluimos una infografía sintética del proceso llevado a cabo. 


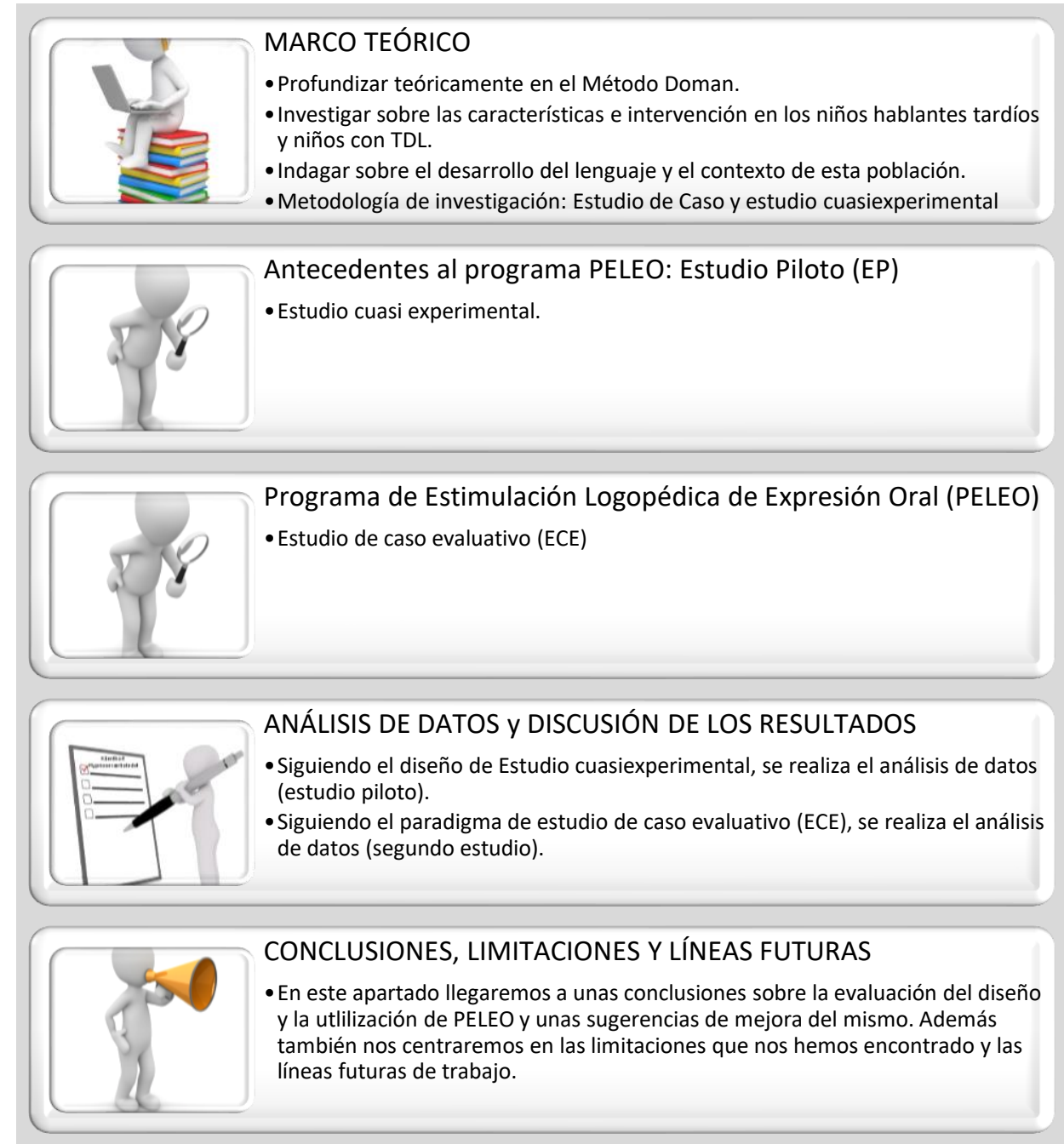

Figura 1.1. Proceso de la investigación de esta tesis doctoral. Fuente: Elaboración propia. 



\section{Capítulo 2 Marco Teórico}

En este capítulo se van a explicar las teorías del lenguaje. Conocer las teorías del lenguaje y el desarrollo del lenguaje es de vital importancia para poder comprender a los niños ${ }^{1}$ que tienen dificultades en este. Por ello vamos a centrarnos en un primer apartado donde detallaremos las diferentes teorías del desarrollo del lenguaje: el enfoque conductista, innatista, cognitivo e interaccionista; además también describiremos las etapas de desarrollo normotípico del lenguaje incluyendo en estas la etapa prelingüística y la etapa lingüística. Los participantes de este estudio padecen trastornos del lenguaje (entendiendo por niños con trastorno del lenguaje, a todos los niños que presentan Trastorno del Desarrollo del Lenguaje y los hablantes tardíos), es por ello, por lo que introducimos un subapartado sobre los términos y los tipos de trastornos del lenguaje, otro sobre los identificadores y pruebas diagnósticas que se utilizan con estos niños. Asimismo, vemos necesario explicar la intervención logopédica que se realiza con ellos, y el perfil profesional del logopeda. No nos podíamos olvidar de describir la Etapa de Educación Infantil en el Sistema Educativo Español, ya que parte de nuestro estudio se ha llevado a cabo en colegios, de manera específica en el segundo ciclo de Educación Infantil, por consiguiente, es necesario introducir información sobre los integrantes de la comunidad educativa. Por último, abordamos las aportaciones de Glenn Doman, comenzando por los Institutos para el Desarrollo del Potencial Humano, sobre los bits de inteligencia, las críticas al método y las experiencias existentes con los bits de inteligencia que van a ser cruciales para el desarrollo de esta tesis doctoral.

\footnotetext{
${ }^{1}$ A lo largo de todo este documento se utiliza el género gramatical masculino para referirse a colectivos mixtos, como aplicación de la ley lingüística de la economía expresiva. Tan solo cuando la oposición de sexos sea un factor relevante en el contexto se explicitarán ambos géneros.
} 


\subsection{Teorías del lenguaje}

El desarrollo del lenguaje suscita interés en diferentes culturas y en diferentes países. Es un logro humano sorprendente que se produce en todo el mundo. Según Goodman (1990) el aprendizaje del lenguaje está directamente relacionado con el significado, es decir, los niños aprenden el lenguaje cuando encuentran sentido al mundo, de la misma manera en la que lo hace el resto de su entorno y su cultura. Este logro se vuelve extremadamente significativo, ya que el desarrollo cognoscitivo y linguiístico es interdependiente, uno depende del otro, y el otro del uno.

Las teorías que postulan el desarrollo del lenguaje son varias: conductista, innatista, cognitiva y la interaccionista. A continuación, expondremos sucintamente cada una de dichas teorías.

\subsubsection{Enfoque conductista}

El conductismo o movimiento behavorista no es sólo una teoría explicativa del lenguaje, sino que también es una corriente de pensamiento psicológico que gracias a su repercusión teórica y práctica ha conseguido dar una explicación del aprendizaje y del desarrollo del lenguaje. Watson, Mowrer, Pavlov y Skinner han influido en las teorías de la adquisición del lenguaje explicando, a través de las leyes y principios del aprendizaje, el inicio y el desarrollo del lenguaje humano (Jiménez-Rodríguez, 2010).

En este apartado nos vamos a centrar principalmente en dos autores, Watson y Skinner, ya que son los dos autores principales de este enfoque. Watson (1970) utilizó el condicionamiento clásico para relacionar directamente el pensamiento y el habla, intentó rechazar las concepciones mentalistas de la psicología introspectiva y subjetiva; en la concepción que tenía la psicología de la conciencia, Watson explica la asociación entre los estímulos y las respuestas, y afirma que se puede predecir y controlar el comportamiento de esta manera. Watson comenta la estrechez que existe entre el pensamiento y el habla, y dice que el pensamiento ocurre cuando los hábitos verbales se producen sin hablar. Denominar objetos y situaciones era muy importante ya que permitía el desencadenamiento de conductas verbales y no verbales. De esta manera las palabras podían provocar una reacción en nuestra conducta comparable a la del objeto que sustituye cada palabra.

Según Yela (1996), Watson tuvo una investigación intensa pero corta: 
Watson apenas tuvo tiempo para hacer otra cosa que enunciar el programa de la nueva psicología, iniciar una traducción apresurada de los conceptos mentales en términos físicos -por ejemplo, el pensamiento no sería más que el lenguaje subvocal- y realizar unos pocos experimentos. [...] Su vida académica fue demasiado corta (p. 170).

Y en ese momento Skinner (1957) comienza a tener mucha importancia; él postula, a través del condicionamiento operante, que las intenciones del lenguaje oral son inobservables, y dice que las observaciones que se hacen de dichas intenciones son paráfrasis del comportamiento verbal, que no aportan nada nuevo. Skinner también rechaza que todas las palabras tienen una significación. Explica que hay algunas palabras que no tienen un referente claro y que, por lo tanto, esto es inobservable. "Skinner se esfuerza por reducir el lenguaje a un comportamiento objetivable hic et nunc, o al resultado de un comportamiento" (Bronckart, 1980, p.26). Para Skinner (1957) existe solamente el comportamiento verbal y su funcionamiento. Por otro lado, sigue apoyando la idea de estímulo respuesta, e incluye la importancia de la acción del medio sobre el sujeto después de que se haya producido una respuesta, y de esta manera es como incluye el refuerzo en el esquema inicial.

"Skinner propone realizar un análisis del comportamiento verbal en dos fases. La primera será de nivel descriptivo [...] una vez contestada esta cuestión, [...] se tratará de analizar las condiciones de aparición del comportamiento" (Bronckart, 1980, p.27). Según Owens (2003), Skinner explica que cualquier acontecimiento que aumente la probabilidad de un acaecimiento precedente será denominado reforzador de esa conducta. Cualquier hecho que disminuya la probabilidad de ocurrencia se llamará castigo. Las conductas más complicadas se aprenden a través de encadenamiento o modelado. El encadenamiento consiste en esquematizar el aprendizaje de una secuencia de conductas, actuando para que cada una de ellas estimule a que ocurra la siguiente. En cambio, en el modelado, hay una sola conducta que se rectifica poco a poco mediante reforzadores que ayudan a que se vayan acercando la conducta final deseada, esta es la idea que subyace en el método que exponemos en esta tesis. Por ejemplo, Skinner podría ejemplificar el desarrollo fonológico-fonético de la siguiente manera: cuando los niños comienzan a decir todos los fonemas, sus padres o referentes suelen reforzarle los fonemas propios de su lengua natal, y de esta manera los sonidos del lenguaje que menos se refuerzan llegan a desaparecer. Este proceso en el que se eliminan los sonidos sin castigo se llama extinción (Owens, 2003). 
Como hemos visto, las leyes del condicionamiento -clásico y operanteintentan explicar el lenguaje basándose en la asociación entre estímulo y respuesta, además de utilizar los refuerzos, los castigos, el modelado y el moldeamiento. Hoy en día se siguen utilizando estas técnicas y parámetros tanto en las teorías como en las prácticas educativas y de rehabilitación del lenguaje. Según Jiménez-Rodríguez (2010), es muy simplista reducir el lenguaje a una conducta observable, sin tener en cuenta la genética, aspectos individuales, cognitivos o de relaciones sociales.

\subsubsection{Enfoque innatista}

A partir de los años 60, Noam Chomsky -autor perteneciente a la teoría innatista o biolingüística- se opone a las teorías que se postulaban en ese momento, entre ellas a la teoría de Skinner, y propone la existencia de una estructura mental innata que posibilita la adquisición y el desarrollo normalizado del lenguaje en cualquier lengua, además esto permite que con muy poco input lingüístico se pueda desarrollar un dominio del lenguaje de manera casi automática (Berwick et al., 2011; Chomsky, 1972). Todo ello gracias al uso de unas reglas gramáticas internas con las que nacemos, que van evolucionando y enseñan al niño a cómo utilizar la lengua de su contexto social (Chomsky, 1972).

Chomsky razona que existe alguna universalidad o algunos elementos que son comunes en todas las lenguas, ya que todas las lenguas tienen sujetos, formas para realizar la negación, para construir frases... Y todos los seres humanos compartimos algún tipo del lenguaje, y además dan por hecho que es una cualidad únicamente humana, y que no compartimos con los animales (Owens, 2003).

Chomsky (1957) desarrolla la idea de la existencia de dos niveles de procesamiento lingüístico. El primero interviene mediante reglas que afectan a la estructura de la frase -encuadran las relaciones en la organización de la frase, y son universales; mientras que el segundo opera mediante reglas de transformación- delimitan la organización de los elementos estructurales de cada lenguaje, es decir, no son universales (Owens, 2003). Chomsky (1957) aplica sus investigaciones matemáticas a la estructura de todas las lenguas y propone la gramática transformativo-generativa.

Chomsky (1975), en su libro Aspectos de la teoría de la sintaxis, realiza una revisión de la teoría de la gramática transformacional. Postula que en caso de continuar investigando se descubrirá que todas las lenguas del 
mundo comparten propiedades estructurales de base común. Este autor cree que existen unidades fonológicas, sintácticas y semánticas universales innatas, los denomina universales sustantivos de la teoría lingüística.

Chomsky (1978) desarrolla la idea de un dispositivo de adquisición del lenguaje denominado en inglés: Language Acquisition Device (LAD), con $\mathrm{LAD}$ podemos generar un enunciado en cualquier lengua conectando significados y sonidos. El LAD va a empezar a funcionar ante estímulos lingüísticos durante la etapa crítica de adquisición del lenguaje y, de forma involuntaria, será el responsable de la comprensión y de la expresión en esa lengua a partir de ese momento.

Pero Chomsky se centra en el lenguaje adulto, y está claro que el lenguaje del niño no es una copia exacta del lenguaje adulto, sino que muestra algunas características especiales. Cuando Chosmky describió las reglas que hemos explicado sobre la lengua adulta germinó un gran interés por las propias del lenguaje infantil (Owens, 2003). Existen otros autores innatistas que sí se centraron en el lenguaje infantil, como Lenneberg (1985), que propuso un periodo crítico para la adquisición del lenguaje, que se correspondía con la pubertad; según él, la causa de esto era debida a la finalización de la lateralización hemisférica, por la plasticidad y el desarrollo cerebral.

\subsubsection{Enfoque cognitivo}

Piaget no estaba en total desacuerdo con Chomsky, pero tampoco totalmente de acuerdo con él, por eso plantea la teoría cognitiva. En ella, como prerrequisito para desarrollar el lenguaje, el niño tiene que dominar la estructura cognitiva y social del mundo que le rodea, establece la importancia del pensamiento sobre el lenguaje, por lo que la adquisición del lenguaje es el resultado del desarrollo cognitivo. Esto se observa en los momentos en los que los niños hablan con ellos mismos, lo que Piaget define como el pensamiento egocéntrico, cuando este pensamiento desaparece -descentralización cognitiva-, aparece el lenguaje socializado o comunicativo (Piaget, 1923).

Este autor observa cómo algunos "enunciados de los sujetos más jovencitos se emiten en la ausencia de un interlocutor, y constituyen monólogos [...] que acompañan la acción o el juego. Piaget llama este tipo de producciones verbales lenguaje egocéntrico y lo opone al lenguaje socializado" (Bronckart, 1980, p.42). 
Piaget (1973) explica que los niños desarrollan la función simbólica como una actuación más de su inteligencia, cuando están a punto de finalizar el periodo sensomotor y que es entonces cuando aparece el lenguaje. Por lo que el conocimiento lo expresan a través de imágenes mentales, imitación diferida, juego simbólico, dibujo y lenguaje.

Piaget (1946) profundiza sobre la adquisición del lenguaje en un libro donde podemos comprobar que, para él, la característica más específica de los humanos no es el lenguaje sino una capacidad cognitiva superior que hace posible que desarrollemos éste; también considera que el lenguaje no es más que una manifestación simbólica más.

Pero ¿qué es la función simbólica? La "función simbólica o función semiótica son presentadas de modo general y bastante vago, el concepto $[\ldots]$ esencial es el de representación [...] es decir, con toda inteligencia que no se apoya simplemente en las percepciones y los movimientos" (Bronckart, 1980, p.51).

A pesar de su gran aportación, no estudia sobre el efecto de la interacción sobre el lenguaje como sí lo hacen los autores interaccionistas.

\subsubsection{Enfoque interaccionista}

Entre otros, Vygotski y Bruner fueron algunos de los autores que aportaron sus conocimientos y sus ideas a este enfoque.

Vygotski fue un psicólogo que estudió la adquisición y el desarrollo del lenguaje y propuso un modelo sociocultural. El desarrollo humano se produce gracias a procesos de intercambio en un entorno social y comunicativo. Es decir, a través del lenguaje. La adquisición y el desarrollo del lenguaje están conceptualizados dentro de la internalización, que es el curso del desarrollo en el que los procesos sociales en pequeños grupos internos van cambiando en procesos individuales.

El desarrollo de los niños se produce a través de procesos de intercambio y transmisión de conocimiento en un contexto comunicativo y social. Es decir, el lenguaje es el motor que hace que la mente se desarrolle. Las funciones sociales son normas sociales que se han interiorizado al ser consciente de estas. El lenguaje se va desarrollando, logrando que el pensamiento se verbalice y el habla se racionalice. Se regula y se planifica el pensamiento $\mathrm{y}$, por consiguiente, las acciones venideras (Vygotski, 1979). 
Las funciones mentales son normas sociales inconscientes; el lenguaje y el pensamiento, aunque son independientes a lo largo de la evolución del niño, se va produciendo una interconexión entre ellos, ya que el pensamiento se va apoyando poco a poco del lenguaje, y con el tiempo el lenguaje se va volviendo más racional, ya que se regula y se planifica la acción que se quiera llevar a cabo. Por lo que el pensamiento no está por debajo del lenguaje, sino que están conectados y están influidos el uno por el otro. Para Vygotski, el lenguaje de los niños es social y, poco a poco, los niños lo interiorizan pasando por un periodo egocéntrico con una expresión externa y con una función interna- llegando al último paso que es el pensamiento verbal, que este ya tiene una expresión interna (Vygotski et al., 1995; Vygotski, 2010).

Bruner (1986) describe, por su parte, la adquisición del lenguaje en los niños y reconoce como indispensable la expresión correcta del lenguaje a través de la adquisición de la sintaxis y el aprendizaje del vocabulario. Reconoce este hecho en la manera en la que los niños aplican sus propias reglas gramaticales, generalizando las que ya conocen a otras que todavía desconocen. A través de esta explicación pone en entredicho la importancia que daban los modelos conductistas a la imitación. Los niños no producen frases incorrectas a nivel semántico, y correctas a nivel sintáctico. Por lo que explica que los niños desde muy pequeños adquieren una coordinación léxico-semántica.

Es imprescindible que los niños aprendan la gramática, los niños no aprenden la gramática a través de la imitación. Este hecho es observable ya que cometen errores gramaticales, o regularizan verbos que son irregulares; también es muy importante que aprendan la función comunicativa, el saber cómo comunicar. Desde los primeros momentos los niños son activos y están preparados para integrarse en las acciones de los adultos y del resto de seres humanos. Partiendo de este enfoque hemos diseñado la metodología que se va a utilizar en esta tesis.

Así pues, desde este enfoque, el niño es activo y adaptativo cuando adquiere el lenguaje, pero, a su vez, necesita a su entorno para entrar en la Zona de Desarrollo Próximo (Vygotski, 1979), ayudado por un adulto, según Vygotski (1979):

La zona de desarrollo próximo. No es otra que la distancia entre el nivel real de desarrollo, determinado por la capacidad de resolver independientemente un problema, y el nivel de desarrollo potencial, determinado a través de la resolución de un problema bajo la guía de un adulto o en colaboración con otro compañero más capaz (p.10). 


\subsection{Desarrollo normotípico del lenguaje}

El lenguaje es un aspecto más dentro de todo el desarrollo evolutivo del mismo, sería muy difícil comprender éste de manera aislada, existen una serie de procesos o desarrollos necesarios para la adquisición del lenguaje, como son el sistema nervioso -correlacionando sus avances con el desarrollo motor y el aparato fonador-, el desarrollo cognitivo incluyendo en este la discriminación perceptual del lenguaje hasta la simbolización y el pensamiento- y por último el desarrollo socioemocional -que resulta del medio sociocultural, las interacciones y las influencias recíprocas- (Castañeda, 1999).

El lenguaje sigue etapas predecibles, pero no debemos perder de vista las diferencias individuales de cada uno, por lo que los datos normativos deben interpretarse como una guía general y debemos tener en cuenta los datos de cada individuo para poder declarar si existe algún trastorno o dificultad en el desarrollo del lenguaje.

Existen una serie de generalizaciones o principios (Owens, 2003, p.68):

- El desarrollo es predecible, esto quiere decir que suele seguir un patrón de desarrollo común en todos los niños, lo podemos observar en algunas escalas de desarrollo.

- La mayoría de los niños suelen alcanzar los hitos del desarrollo más o menos a la misma edad. Por ejemplo, según MorenoFlagge (2013), a los doce meses los niños dicen tres palabras con significado.

- Es necesario que existan oportunidades para el desarrollo. Según Contreras-González y Soriano-Ferrer (2007), los niños que pertenecen a ambientes desfavorecidos socioculturalmente no desarrollan el lenguaje en igual medida que sus pares con amplias oportunidades de estimulación y desarrollo.

- Los niños atraviesan períodos o fases evolutivas, como podemos comprobar en el apartado 2.3 de este mismo capítulo.

- Los individuos pueden llegar a ser muy diferentes. "Por ejemplo, en la adquisición de la fonología algunos niños son bastante conservadores y evitan las palabras cuya pronunciación les resulta difícil; otros están dispuestos a arriesgarse" (Gleason y Rather, 2010, p.6).

Siguiendo el modelo pluridimensional de Bloom y Lahey, escrito en 1978, (citado en Fernández, et al., 2014), los niños logran un lenguaje normalizado cuando alcanzan una utilización adecuada y correcta de las palabras (tanto en expresión como en comprensión). Esto quiere decir 
que logran demostrar un desarrollo léxico de calidad y cantidad. Además, se considera que consiguen un lenguaje normalizado cuando poseen un desarrollo fonológico y fonético claro, una estructura gramatical adecuada, un ritmo y una velocidad apropiada, y cuando presentan un tono y una entonación adecuados (Fernández et al., 2014).

El estudio de la adquisición del lenguaje es abordado por los diferentes autores de maneras diversas. Puede ser tratado desde un enfoque cronológico (Bermeosolo, 2016; Reyzábal, 2001), o describiendo las etapas por las que pasa el niño sin determinar las edades a las que sucede (Navarro, 2003). Teniendo en cuenta esto, a continuación, vamos a centrarnos en dos etapas de la adquisición del lenguaje: la etapa prelingüística y la etapa lingüística (Serón y Aguilar, 1992).

\subsection{Etapas del lenguaje}

Los niños desarrollan su lenguaje por etapas, pasando de una a otra de manera constante hasta que adquieren por completo su lenguaje, podemos encontrar dos etapas claramente diferenciadas: la etapa prelingüística (Fernández et al., 2014) y la etapa lingüística (AnayaReig y Calvo, 2019)

\subsubsection{Etapa prelingüística, presemiótica, preverbal o etapa oral no lingüística}

Según Fernández et al. (2014), esta etapa ocurre entre los cero y los doce meses; otros autores, como Torres (2003), explican que hasta los dieciocho meses se caracteriza por manifestarse antes de la adquisición del lenguaje verbal, es entonces cuando los bebés aprenden las bases de la comunicación. Los bebés empiezan a comprender que las palabras representan una realidad (los referentes) y empiezan a reconocer los sonidos del lenguaje oral, en especial los fonemas de su lengua, aunque no están preparados para expresar esos fonemas. Aunque sí que realizan sonidos similares a los de su lengua materna. Se comunican a través de comunicación no verbal (miradas, gestos y expresiones faciales). Alrededor de los nueve a los doce meses se producen las emisiones de las primeras palabras. Y es entonces cuando comprende que las palabras simbolizan un significado. Según Anaya-Reig y Calvo (2019), durante estos primeros meses no se puede hablar de lenguaje sino de comunicación. En la Tabla 2.1, reproducimos un esquema de lo que ocurre en esta etapa. 
Tabla 2.1.

Etapa prelingüística e inicio de la etapa lingüística

\begin{tabular}{llll}
\hline & Prebalbuceo & $\begin{array}{l}\text { Cero a dos } \\
\text { meses }\end{array}$ & $\begin{array}{l}\text { Vocalizaciones reflejas } \\
\text { y gorjeo }\end{array}$ \\
\cline { 2 - 4 } $\begin{array}{l}\text { Etapa prelingüística } \\
\text { (cero a diez meses) }\end{array}$ & Balbuceo & $\begin{array}{l}\text { Tres a seis } \\
\text { meses }\end{array}$ & Juego vocal \\
\cline { 3 - 4 } & & $\begin{array}{l}\text { Seis a diez } \\
\text { meses }\end{array}$ & Imitación de sonidos \\
\hline $\begin{array}{l}\text { Inicio de etapa } \\
\text { lingüística (diez a } \\
\text { catorce meses) }\end{array}$ & Etapa holofrástica & \\
\hline
\end{tabular}

Fuente: Navarro (2003, p.326).

Como podemos ver en la Tabla 2.1, en un primer momento encontramos el prebalbuceo, en este momento destacan los mecanismos reflejos, que se caracterizan por dar una respuesta a estados de necesidad o de satisfacción, como pueden ser el llanto, la sonrisa y los movimientos de evitación. Se expresa displacer o placer (Secall, 1981). Según Torres (2003), el llanto se considera por algunos autores como la primera intención comunicativa, ya que los adultos le dan sentido interpretándolo como una expresión asociada a impulsos internos: hambre, incomodidad...

Durante el segundo y el tercer mes aparece la sonrisa social, ya que el niño tiene cierto control bucofonatorio que aparece en forma de sonrisas, risas, arrullos, gritos... juegos vocálicos en los que existen multitud de cambios prosódicos, de duración y ritmo tonal (Torres, 2003). Es cuando comienza el balbuceo, que consta de cuatro características, la ejercitación articulatoria y auditiva además de las identificaciones y diferenciaciones fónicas. Para conseguir la primera es necesario la segunda. La tercera función es la respuesta al entorno fónico y que incluye los ruidos de la naturaleza, de los animales, de los artilugios creados por el hombre y de las lenguas maternas (Chivite, 1998). Este balbuceo está cargado de deseo comunicativo, de relación, de satisfacción, de demanda, sorpresa y asentimiento (Secall, 1981).

El balbuceo como juego vocal (tres a seis meses) lo describen varios lingüistas clásicos, por ejemplo, Jespersen (1922) y Lewis (1951) que explican que el objetivo de este balbuceo es el ejercicio muscular afinando éste hasta realizar emisiones más sistemáticas y obtener un mayor control de las posiciones articulatorias, explorar todas las posibilidades de los órganos bucofonatorios y, por último, obtener un placer en las emisiones. 
Según Piaget (1973), en la imitación de sonidos se observan tres estadios: La preparación refleja, la imitación esporádica y la imitación sistemática:

- El primero es la preparación refleja (aunque se debería excluir al estar relacionada con los reflejos puros, algunos investigadores la incluyen) se corresponde a los momentos en los que un niño llora y el otro al escucharlo también comienza a llorar, o la misma situación cuando un niño gime y el otro lo imita.

- El segundo estadio, denominado como imitación esporádica se caracteriza porque los esquemas reflejos comienzan a asimilar elementos externos y aumentar según adquiera más experiencia. Por ejemplo, cuando los gritos reflejos se convierten en gemidos o vocalizaciones.

- El tercer estadio es la imitación sistemática de los sonidos pertenecientes a la fonación del niño y de los movimientos ejecutados por el sujeto de manera visible para él, es una imitación clásica, no intenta acomodar estos modelos a otros nuevos. Por ejemplo, los niños repiten "Ba" y "Be" de forma esporádica, y en otro momento se lo decimos nosotros y ellos lo repiten.

En esta etapa también aparecen las protopalabras, que ocurre mientras se sigue produciendo esa jerga expresiva, a los catorce a dieciocho meses aparecen emisiones más o menos constantes, que puede ser la repetición de una sola sílaba, que el bebé emplea con sentido y ya no son meras imitaciones, sino creaciones que realiza el propio niño. Implica que el niño ha aprendido que los sonidos tienen significado, y las personas que se relacionan habitualmente con el bebé empiezan a comprender esas emisiones (Mariscal, 2008, citado en Anaya-Reig y Calvo, 2019). La comprensión es mayor, pasa de diferenciar los tonos de voz y los gestos a identificar algunas partes de su propio cuerpo, y a comprender algunas órdenes únicas, las denominadas órdenes simples, como por ejemplo "no, ven, dame, toma..." (Reyzábal, 2001).

\subsubsection{Etapa lingüística}

Según Anaya-Reig y Calvo (2019) resulta muy difícil decidir en qué momento del desarrollo sucede, porque la evolución es continua, pero se puede considerar que inicia en el momento en que comienzan a emitir 
segmentos fónicos rudimentarios que existen en el entorno inmediato del niño -por ejemplo: $a b a$ en lugar de agua-. En un inicio estas situaciones están relacionadas con objetos presentes o una situación concreta, pero según aumenta la capacidad simbólica del niño, las puede producir en un ambiente más abstracto o sin el objeto presente. Al inicio los niños comprenden mucho más de lo que son capaces de producir (Anaya-Reig y Calvo, 2019). Bosch (1984) expone que este periodo de perfeccionamiento del lenguaje se extiende hasta los seis o siete años.

Este apartado lo dividiremos dependiendo de los diferentes niveles del lenguaje existentes, Anaya-Reig y Calvo (2019) priorizan los siguientes niveles del lenguaje:

- Nivel Fónico: Es el estudio de los sonidos y de los fonemas, los fonemas son los elementos de la articulación. En este mismo nivel también se estudia la prosodia (acento, entonación...). Además, también se estudian las letras y las grafías como representación de los sonidos y fonemas en la lengua escrita.

- Nivel morfológico y sintáctico o morfosintáctico. La morfología se ocupa de las palabras y sus constituyentes de primera articulación. Es decir, estudia qué clases de palabras hay y las diferencias, cómo se expresan los accidentes gramaticales, que son las variaciones en las palabras (género, número, persona...), cómo se conjugan los verbos... La sintaxis también se ocupa de las palabras, la relación entre las palabras y en las que se construyen unidades superiores llamadas oraciones.

- Nivel léxico y semántico, o léxico-semántico, la lexicología estudia las palabras en cuanto a su origen, cómo se forman y cómo llegan a formar parte del input lingüístico de cada persona.

- Nivel textual o pragmático, es relativamente reciente, considera la explicación de los hechos lingüísticos, es decir incluye los enunciados dentro de un contexto más amplio y de una situación en particular.

\subsubsection{El desarrollo fonológico}

Este desarrollo es mayor entre los dieciocho meses a los seis años, en él se pone en construcción todo el sistema fonológico que se conserva en la adultez. Ingram (1976), citado por Fikkert (2007), investigó que los 
niños no adquieren unos fonemas tras otros, sino unos con otros, de esta manera realizan los siguientes procesos y errores: sustitución, asimilación y simplificación de la estructura silábica. Una vez que los niños llegan a los cinco-seis años ya tienen adquirido la mayor parte del sistema fonológico.

El desarrollo fonético-fonológico de los niños se produce en 4 etapas (Susaníbar et al., 2013):

a) de 0 a 12 meses, se corresponde a la etapa prelingüística, comienza con las vocalizaciones involuntarias hasta el balbuceo.

b) de 12 a 18 meses, es la etapa en la que aparecen las primeras 50 palabras.

c) de 18 a 4 años, etapa fonológica de procesos de simplificación y expansión del repertorio fonético.

d) de 4 a 6 años, es la etapa final; a partir de este momento ya adquieren todos los fonemas.

La teoría de la fonología natural sugiere que los niños realizan procesos de simplificación fonológica. Se sabe que entre los 3 y 4 años es cuando más cantidad y variabilidad de procesos de simplificación fonológica existen (Coloma et al., 2010).

La adquisición de los fonemas es progresiva, alrededor del año el niño comienza a emitir sus primeras palabras, los primeros fonemas que articulan los niños son /p/, /b/, /m/, /a/, /i/; también articulan los fonemas oclusivos o nasales y una longitud no superior a dos silabas. Existe una

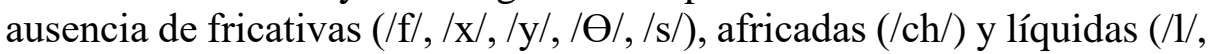
$/ \mathrm{r} /, / \mathrm{rr} /$ ) y el escaso contraste entre grados de abertura vocálica (Buceta, 2011). Los fonemas se adquieren gradualmente, existe una gran variabilidad intrapersonal, esto significa que un mismo sonido a veces se produce de forma correcta y otras veces de forma incorrecta; además, existe una mayor dificultad en la realización de grupo de sonidos fricativos y de líquidos; mientras que los oclusivos sordos $(/ \mathrm{p} /, / \mathrm{t} /, / \mathrm{k} /)$ y las consonantes nasales $(/ \mathrm{m} /, / \mathrm{n} /, / \tilde{\mathrm{n}} /)$ suelen ser fáciles de articular, sin embargo no hay un orden fijo para la adquisición de los fonemas, esto quiere decir que la variabilidad entre los infantes es alta (Perelló, 1990). Quizás por esa variabilidad, los estudios se contradicen en algunas edades de adquisición de fonemas, aunque sí que coinciden en que los fonemas nasales y oclusivos áfonos son los que articulan de manera más temprana, y los fricativos y róticos los que articulan más tarde (Torres, et al., 2016). El estudio más actual que muestra las edades de adquisición de cada fonema es el de Susanibar et al. (2013) que podemos encontrar en la Tabla 2.2. 
Tabla 2.2.

Edad de adquisición de los fonemas

\begin{tabular}{ll}
\hline Edad & Fonemas articulados \\
\hline 3 a 4 años & $/ \mathrm{m} /, / \mathrm{ch} /, / \tilde{\mathrm{n}} /, / \mathrm{k} /, / \mathrm{t} /, / \mathrm{y} /, / \mathrm{p} /, / \mathrm{n} /, / / \mathrm{l}, / \mathrm{f} /, / \mathrm{ua} /, / \mathrm{ue} /$ \\
\hline 4 a 5 años & $/ \mathrm{r} /, / \mathrm{b} /, / \mathrm{g} /, / \mathrm{pl} /, / \mathrm{bl} /, / \mathrm{ie} /$ \\
\hline 5 a 6 años & $/ \mathrm{cl} /, / \mathrm{rr} /, / \mathrm{pr} /, / \mathrm{gl} /, / \mathrm{fr} /, / \mathrm{tr} /, / \mathrm{eo} /$ \\
\hline 6 a 6.6 años & $/ \mathrm{s} /, / \mathrm{rr} /, / \mathrm{pr} /, / \mathrm{gl} /, / \mathrm{fr} /, / \mathrm{tr} /, /$ eo/ \\
\hline
\end{tabular}

Fuente: Susanibar et al. (2013, p.29).

\subsubsection{El desarrollo del nivel morfosintáctico}

Según Anaya-Reig y Calvo (2019), los niños primero adquieren los significados y después empiezan a asumir reglas gramaticales, como los procedimientos de formación de plurales, las conjugaciones verbales, utilización de sufijos, afijos...

La sintaxis se desarrolla antes que la morfología. Esto significa que un niño puede llegar a los cuatro años sin entender la separación de las palabras sin entender, por ejemplo, la separación de palabras [...], sin embargo, un niño de cuatro o cinco años puede construir una oración compuesta de relativo, aunque todavía vacile en el uso de determinados tiempos y modos verbales (Anaya-Reig y Calvo, 2019, p.114).

Acerca de la morfología es común, en niños entre dos y cinco años, los fenómenos de extensión analógica en cualquier ámbito de flexión; esto quiere decir que pueden hacer derivados, hiperregular conjugaciones verbales: he freído, sabo y un largo etcétera (Anaya-Reig y Calvo, 2019). En cuanto a la sintaxis es muy popular la clasificación de Sonsoles Fernández (Bermeosolo, 2016), que podemos encontrar en la Tabla 2.3.

Tabla 2.3.

Clasificación de hitos sintácticos en la evolución del lenguaje de los niños.

\begin{tabular}{llll}
\hline Dos años & Oraciones de una palabra. & \\
\hline $\begin{array}{l}\text { Hasta los veintisiete } \\
\text { meses }\end{array}$ & $\begin{array}{l}\text { Oraciones básicas (predominio de nombres, sin } \\
\text { determinantes, conjugaciones, preposiciones ni } \\
\text { auxiliares). }\end{array}$ \\
\hline $\begin{array}{l}\text { Hasta los tres años y y } \\
\text { seis meses - cuatro años }\end{array}$ & $\begin{array}{l}\text { Oración de cuatro o cinco palabras con poco dominio de } \\
\text { la flexión y algunas subordinadas. }\end{array}$ \\
\hline $\begin{array}{l}\text { A partir de los cuatro } \\
\text { años }\end{array}$ & $\begin{array}{l}\text { Oración completa de seis u ocho palabras, incluyen } \\
\text { subordinadas y una correcta flexión. }\end{array}$ \\
\hline
\end{tabular}


Fuente: Elaborada a partir de los datos obtenidos en Bermeosolo (2016).

A los 6 años, los niños ya tienen adquiridas las principales oraciones subordinadas (Peñaloza, 2017). Según Parada-Salazar (2019), las oraciones complejas o subordinadas son aquellas en las que uno o más verbos subordinan a uno principal. Se clasifican según la función que ejercen con respecto a la oración principal, existiendo tres grandes tipos: las de relativo o adjetivas, las nominales o sustantivas y las adverbiales.

Según Auza y Peñazola (2019), tanto las oraciones subordinadas que utilizan, como la longitud de las frases y las palabras empleadas, aumenta cuando los niños acuden a escuelas infantiles o a los colegios en educación infantil, puesto que en estos entornos las interacciones entre iguales aumentan, y por tanto la estimulación en estos ambientes se incrementa. Esto quiere decir que los niños aprenden por aprendizaje incidental.

\subsubsection{El desarrollo semántico}

La adquisición de un vocabulario básico constituye el pilar fundamental para la gran mayoría de niños, este pilar será sobre el que después se fundamente el sistema lingüístico; así pues, la adquisición del vocabulario es clave para activar otros componentes lingüísticos y para el progreso escolar de todo el alumnado con o sin problemas del lenguaje (Mendoza, 2016). El proceso de aprendizaje del vocabulario parte del almacenamiento y procesamiento de las diferentes palabras, que es lo que posibilita una posterior producción (Rodríguez-Montes, 2020).

Este lenguaje es mayor cuando los niños acuden a las escuelas infantiles o a los Centros de Educación Infantil (Auza y Peñazola, 2019), ya que las interacciones aumentan entre iguales y la estimulación en estos ambientes aumenta. Esto quiere decir que los niños aprenden por aprendizaje incidental.

Existe una serie de límites respecto a las primeras palabras de los niños, los niños pequeños suelen incluir en su repertorio palabras que hacen referencia a objetos que se mueven (transportes), antes que a palabras que hacen referencia a objetos inmóviles (semáforo), esto es porque su vocabulario refleja su vida cotidiana y es improbable que su vocabulario haga referencia a referentes distanciados en el tiempo y en el espacio. 
Cuando el niño se va haciendo más mayor, estas palabras cada vez se hacen más complejas e interconectadas y obtienen un nuevo tipo de conocimiento: la conciencia metalingüística (Gleason \& Ratner, 2010; Sentis et al., 2009), además de estos también encontramos la frecuencia en la que escuchan los niños las palabras (Goodman et al., 2008). Estos límites se extienden hasta el periodo escolar obligatorio (a partir de los seis años), cuando los niños siguen teniendo dificultades en los conceptos temporales y espaciales (Díaz-Villafáñez, 2016).

El lenguaje tiene diferencias individualizadas, pero algunos de los hitos del desarrollo son iguales en todos los niños y algunos de ellos son los que podemos encontrar a continuación:

- Etapa preléxica, de los diez a quince meses, los padres nombran las palabras que corresponden a algunas emisiones que realizan los niños, acompañadas de comunicación no verbal (Nelson, 1988), y en torno a los nueve o diez meses ya responden a su nombre, y responden a la palabra "no" (Aparicio e Igualada, 2019).

- Etapa de los símbolos léxicos, de los dieciséis a los veinticuatro meses, es cuando se produce el aumento más significativo de vocabulario. Los niños comienzan a etiquetar de forma linguística los objetos, personas y acciones de su alrededor. Cometen errores de sobreextensión, que consiste en ampliar el campo semántico de una palabra, por ejemplo, llamar "guau" a todos los animales; también cometen infraextensión, tratando de ponerle un nombre a un objeto para referirse solo a ese, y aunque podría generalizarlo no lo hace, por ejemplo "trapito" es su trapo con el que duerme, pero no son el resto de los trapos (Nelson, 1988).

- Etapa semántica, de los diecinueve a los treinta meses, el vocabulario medio de los niños se sitúa en torno a las 50 palabras y hacia el final de la etapa se incrementa notablemente (Nelson, 1988) y realizan combinaciones de palabras a los dos años los niños producen unas trescientas palabras (Aparicio e igualada, 2019).

- En torno a los tres años producen unas mil palabras (Aparicio e Igualada, 2019); a partir de los tres años desaparecen los fenómenos de sobreextensión e infraextensión y comienzan a establecerse relaciones entre los significados de las palabras (sinónimos, antónimos, reciprocidad, jerarquización de significados) (Nelson, 1988). 
- Desde los tres y los cuatro años la categoría que más aumenta es la de preposiciones, conjunciones, adjetivos y pronombres (Nelson, 1988).

- A partir de los cuatro años es más frecuente el uso de conectores discursivos, que son "una figura clave para la interpretación de la función pragmática del discurso. En la medida en la que no se trata de un nexo entre los enunciados, sino de un elemento que se encarga de conectar y canalizador de las interpretaciones y estrategias discursivas" (López, 1990, p.82).

- A los seis años la mayoría de los niños tiene un vocabulario de entre quince mil y dieciocho mil palabras (Aparicio e Igualada, 2019).

\subsubsection{El desarrollo pragmático}

Según Jiménez-Rodríguez (2010), los niños aprenden el lenguaje dentro del contexto conversacional. Desde que los niños son muy pequeños se perciben las siguientes características:

- Capacidad de expresar emociones.

- Establecer contacto conversacional.

- Adquisición y desarrollo del lenguaje comunicativo.

- Emitir información y demandarla para solicitar o preguntar por sus intereses.

La evolución es mucho más lenta cuando se trata de estas otras adquisiciones:

- Comparar información.

- Construir narraciones y razonar.

- Adaptar su forma de hablar a cada momento.

En la etapa infantil podemos encontrar formas muy primitivas de desarrollo pragmático, que serán base de evolución posterior. Los niños pequeños son hábiles para comenzar un nuevo tema de conversación, aunque no son tan hábiles para mantenerlo durante más de tres intervenciones seguidas.

A los dos años casi no tienen en cuenta a su interlocutor para proporcionarle detalles descriptivos que mejoren la comprensión del mensaje. Hacia los tres años establecen un turno de palabra relativamente largo. Entre los tres y cuatro años, toman conciencia de los aspectos sociales de la conversación, utilizan frases claras, bien construidas y 
adaptadas al oyente. Desde los cuatro años adaptan sus emisiones al interlocutor y utilizan el doble de emisiones afectivas que a los tres años. A los cinco años aún no se dan cuenta de que es más adecuado realizar peticiones indirectas que directas. Cuando tienen que hacer una aclaración realizan imitaciones y repeticiones. Hasta los siete u ocho años no realizan narraciones breves, historias largas, narraciones sin conversación o preguntas (Jiménez-Rodríguez, 2010).

\subsection{Trastornos del lenguaje}

En este apartado hablaremos de los trastornos del lenguaje, los tipos existentes y el desarrollo y la evolución de los términos para denominarlos, además de las pruebas de evaluación existentes para diagnosticarlo.

Los problemas del lenguaje son comunes en niños y niñas que están en edad preescolar, pero son diferentes las cifras dependiendo del país que realice los estudios (Law, et al., 2019), por ejemplo Vavrik (2016) estima una prevalencia del 4-5\% en Austria, en Norteamérica la prevalencia se sitúa en torno al 7\% (Tomblin et al., 1997), en Croacia la prevalencia se sitúa en menos del 5\% (Ljubešić, 1995), en Estonia alrededor del 8\% de los niños están diagnosticados con esta dificultad (Law et al., 2019), estudios españoles como el de Peralta y Narbona (1991) determinan que el trastorno del lenguaje se sitúa en torno al $2-3 \%$, en niños en edad escolar sin signos de trastornos neurológicos ni genéticos. Los problemas de lenguaje son más frecuentes en niños que en niñas y en aquellos que tienen una historia familiar de retraso de lenguaje o habla, y problemas de lectura (Moreno-Flagge, 2013). Como podemos comprobar la prevalencia no está claramente definida.

\subsubsection{Términos y tipos}

Los términos que se utilizan para denominar los trastornos del lenguaje cambian y se subdividen de diferente manera en los países de la Unión Europea (Law et al., 2019).

En España la manera de nombrar este trastorno ha ido cambiando con el tiempo, a finales del S.XIX, se utilizaron términos como "Retraso de la palabra", "afasia congénita" o "audiomudez", que se utilizaron hasta mediados del S. XX. Alrededor de la década de los 60, se reemplazó el término afasia por "disfasia" (Perelló et al, 1978), "ateniéndonos a la 
etimología de las palabras, la afasia señalaría la ausencia de lenguaje y la disfasia el trastorno más o menos grave de esta capacidad" (Jiménez, 2010, p.37).

Rapin y Allen (1983), crean la división más conocida y citada: Fonéticafonológica, léxico-semántica, morfosintáctica y pragmática. En 1987, Rapin los agrupa en tres niveles: trastornos expresivos, trastornos expresivos y comprensivos, y trastornos del procesamiento central de alto orden. Los déficits que agrupa en esos niveles son los siguientes: agnosia verbal auditiva, dispraxia verbal, déficit de programación fonológica, déficit semántico-pragmático, déficit fonológico-sintáctico y déficit léxico-sintáctico, (Carballo, 2012; Crespo y Narbona, 2006; Serra-Raventós, 1991), en la Tabla 2.7 podemos encontrar cómo se agrupan estos trastornos. De todos los tipos señalados, la agnosia auditivo verbal, la dispraxia verbal, el déficit de programación fonológica y el déficit semántico-pragmático no se corresponden con el concepto de Trastornos Especifico del Lenguaje (TEL) que se entiende en la actualidad, ya que son términos que han desaparecido o se les ha cambiado su denominación, o se han añadido dentro de otro tipo de trastornos. En cambio, el déficit fonológico-sintáctico y el déficit léxicosintáctico se mantienen en vigencia, ya que en ambos la comprensión puede estar afectada (Aguado et al., 2015). A continuación, describimos todos los trastornos ya mencionados anteriormente.

- La agnosia verbal auditiva es la afectación del lenguaje desde el nivel más básico de reconocimiento a nivel fonético. Es decir, sufren una dificultad para descifrar y reconocer los sonidos del lenguaje. La comprensión oral es menor de 3 desviaciones típicas por debajo de la media. No solo se ve afectado el nivel fonético, sino que también se ven afectados la sintaxis y la semántica de la expresión verbal. Tampoco son capaces de repetir palabras a través de la imitación. Este subtipo se corresponde con el subtipo 'agnosia auditivo-verbal' de la clasificación de Rapin y Allen (1983). Los niños que lo sufren se comunican gracias a la lengua de señas o a través de gestos naturales (Crespo y Narbona, 2006).

- La dispraxia verbal es la afectación que se caracteriza por un habla muy poco inteligible, pero cuyos gestos y expresión facial indican que quieren comunicarse (Ygual y Cervera, 2005). A pesar de existir una comprensión casi o completamente normal, son niños con una falta de fluidez enorme (Serra-Raventós, 1991). 
- El déficit de programación fonológica se caracteriza por un problema a nivel fonológico. Los procesos fonológicos son una serie de operaciones mentales sistemáticas que el niño emplea desde el año y medio de edad para simplificar el modelo adulto de habla (Ingram, 1983 y 1986). Los procesos fonológicos más comunes en niños con Trastorno Específico del Lenguaje (TEL), en varias lenguas, son los de estructura silábica, principalmente el de omisión de sílaba átona (Ingram, 1981) y reducción de grupos consonánticos (Bortolini \& Leonard, 2000). En español, los procesos de estructura silábica también son los más recurrentes en niños con TEL, específicamente los de omisión de sílabas átonas (Aguilar et al., 2002). La dificultad principal de estos niños es su expresión ininteligible e imprecisa. Su expresión no llega a ser eficaz para mantener una conversación con un interlocutor (Serra-Raventós, 1991). Aunque el nivel fonológico está afectado, no muestran dificultad en otros niveles, manteniendo una capacidad media en la vertiente comprensiva del lenguaje y una fluencia adecuada. Pueden producir fonemas y sílabas aisladamente, pero éstos se desestructuran u omiten de manera diversa al utilizarlos en el contexto de la palabra y/o frase. Mejora su articulación ante tareas de repetición. Se aprecia una mejoría articulatoria en tareas de repetición, respecto a la de emisión espontánea (Crespo y Narbona, 2006).

- En los niños con déficit semántico-pragmático se encuentra una producción importante, aunque no ligada significativamente al contexto. Algunos son denominados como "logorreicos" en el sentido de producir enunciados estructuralmente correctos, pero sin relevancia contextual. Pueden llegar a tener un amplio vocabulario, pero sin fijación cognitivo-pragmática. Pueden tener ecos y perseverancias temáticas. Su comprensión está profundamente afectada, pudiendo no saber responder o bien hacerlo sobre la base de alguna de las palabras comprendidas (Serra-Raventós, 1991).

- El déficit fonológico-sintáctico se caracteriza por una gran dificultad de articulación y fluidez, los niños con este déficit se expresan a través de frases cortas, sin palabras gramaticales (artículos, preposiciones...), tampoco incluyen marcajes morfológicos (tiempo, número, posesión...) (Serra-Raventós, 1991). También muestran dificultades de comprensión de enunciados largos, descontextualizados o con sintaxis complejas. 
En su discurso aparecen omisiones, distorsiones y sustituciones en la expresión oral. Su nivel semántico es muy bajo (Crespo y Narbona, 2006).

- El déficit léxico-sintáctico se caracteriza por un retraso en el inicio del habla, estos niños poseen un nivel fonético normotípico, pero su nivel semántico está comprometido, al presentar anomia, dificultad en la fluencia del lenguaje, debido a las reformulaciones que realizan para mantener un discurso coherente (Serra-Raventós, 1991). También presentan un nivel bajo de comprensión de vocabulario que dificultan la comprensión de enunciados. Esto puede deberse en parte a que no deducen parte del significado de las palabras nuevas a partir de las características sintácticas de la frase (Crespo y Narbona, 2006). Presentan un vocabulario muy pobre, tienen problemas de evocación lo que hace que el habla sea interrumpida, y suelen utilizar perífrasis y muletillas (Peña, 2014).

No fue hasta la década de los 80 cuando se sustituyó el término de "disfasia" por "retraso de lenguaje (RL)" y "trastorno específico del lenguaje (TEL)". Es en la década de los 90 cuando ya se distinguieron tres tipos de trastornos del lenguaje: Retraso simple del lenguaje (RSL), RL, y TEL, sin una frontera muy nítida entre ellos.

Estos tres tipos de trastornos se caracterizaban por lo siguiente:

- EL RSL en general es el más leve, se denomina como "retraso inicial" o como "retraso simple". Las dos formas están admitidas en la literatura científica. Moreno-Flagge (2013) admite que, en estos casos, el niño muestra una buena comprensión y una evolución del lenguaje similar a la de los niños sin problemas, pero los hitos del desarrollo del lenguaje los realizan de forma más tardía. En estos casos, es imprescindible descartar una hipoacusia, sobre todo en niños con factores de riesgo, infecciones respiratorias, otitis media de repetición. Se trata de un aprendizaje del lenguaje, pero más tardío que el resto de los niños, en este retraso no muestran grandes dificultades en la comunicación ni en la comprensión. Las primeras palabras aparecen entre los 18 y los 20 meses, comienza la combinación de palabras no más allá de seis meses después. El léxico que va apareciendo es homogéneo, es decir los sustantivos (50\%) y otro tipo de palabras. La evolución de su lenguaje responde a la 
intervención y a cambios en su entorno social más inmediato, ante una mayor estimulación se normaliza el progreso, a pesar de continuar la inmadurez en algún componente especialmente en lo expresivo -iniciativa y cooperación- (Serra-Raventós, 2002). Los niños con RSL no presentan un desfase a nivel intelectual, relacional, motor o sensorial, pero sí que están especialmente afectados los componentes fonológicos y sintácticos; también existe un retraso en la semántica y en la pragmática, aunque en menor nivel que la fonología y la sintaxis (Gento y Hernández, 2012).

- El RL en cambio es un poco más grave que el anterior, los errores que cometen unos y otros son parecidos. Las primeras palabras y estereotipos no aparecen hasta los 24-26 meses y todavía no superan las cien primeras palabras. Un desarrollo muy lento y demasiado básico de la sintaxis y la morfología que se puede observar en la lentitud en la combinación de dos palabras (lexemas autónomos y no estereotipos), que tardan en conseguirla más de seis meses, al igual que ocurre con la flexión morfológica productiva. La simplificación expresiva se estabiliza y la incorporación espontánea de nuevas estructuras expresivas es muy lenta. Su habla suele estar muy afectada, aunque no es el problema principal. La comprensión progresa en contextos conocidos, pero hay dudas ante novedades o contextos complejos (Ellis, 2007; Serra-Raventós, 2002). Es posible y parece ocurrir que estos niños con retraso del lenguaje evolucionen y se conviertan posteriormente en sujetos con TEL (Ellis, 2007); teniendo esto en cuenta habrá niños que gocen de un desarrollo prelingüístico normal, y que cuando cumplan un año y medio comiencen a presentar un retraso del lenguaje que evolucione finalmente en un TEL; este retraso afectará a varios componentes lingüísticos como el almacén fonológico, la memoria de trabajo, que provocará problemas de vocabulario en los niveles fonológico y morfosintáctico, lo que provocará un empeoramiento lingüístico. Además, los niños con RL necesitan de terapia, pero su pronóstico es más positivo que los niños con TEL (Acosta et al., 2012).

- El TEL o SLI -Speech Language Impairment- es una gran limitación en la capacidad del lenguaje receptivo, comprensivo y/o comunicativo, que no tiene causa definida, aunque sí que existe una importante carga de genética familiar y probable 
multifactorial. No se justifica con una pérdida auditiva, no presenta daño cerebral, la inteligencia del niño debe ser normal, no presenta un déficit motor, esta falta de capacidad en el lenguaje tampoco es debida a factores socioambientales ni al desarrollo afectivo (Aguado, 2007a; Aguado, 2004; Leonard, 1998; Leonard, 2014 y Moreno-Flagge, 2013).A veces, puede ser difícil diferenciar el TEL del RL y la gravedad del cuadro parece ser el criterio más adecuado para decidir cuál de las dos es la que está afectando al paciente. Ya que, en el RL o disfasia, además de desarrollar el lenguaje tardíamente, éste es deficiente en su estructura, forma y fonética; siendo especialmente característicos los problemas de comprensión, Moreno-Flagge (2013). Se utiliza el término TEL cuando el RL no desaparece, y a los cuatro años todavía no producen con fluidez la estructura: sujeto, verbo y objeto. Siguen apareciendo errores y omisiones en casi todas las expresiones, incluso si son capaces de emitir frases de tres núcleos. Un $10 \%$ de las expresiones pueden llegar a ser ininteligibles. La comprensión es aún peor si solamente se apoya en el lenguaje prescindiendo de la ayuda pragmática. El desarrollo semántico es muy lento sobre todo en las palabras relacionales. El nivel morfosintáctico avanza mínimamente, y es el nivel más afectado por las omisiones y los errores (SerraRaventós, 2002).

Andreu-Barrachina et al., (2014) profundizan más en las diferencias entre RL y TEL; determinan que se encuentran diferentes en ambas dificultades en cuanto a diferentes características:

- La naturaleza del trastorno: ya que el RL se basa en un desfase cronológico, mientras que el TEL se basa en una alteración intrínseca persistente del procesamiento del lenguaje.

- Grado de afectación: el RL es leve, y el TEL es moderado o grave.

- Evolución: el RL es transitorio y el TEL persistente.

- Dimensiones del lenguaje afectadas: mientras que en el RL está principalmente afectado la dimensión fonológica, en el TEL está afectado la dimensión fonológica, morfosintaxis, léxica, semántica y pragmática.

- Respuesta específica a la terapia: mientras que en el RL existe una mejoría rápida, en el TEL la mejoría es lenta y variable.

- Aprendizaje de la lectoescritura: en el RL existe poca repercusión en el aprendizaje de la lectoescritura, y en el TEL está frecuentemente afectada. 
En la actualidad, hay autores que cuestionan el término "Trastorno específico del lenguaje" no estando de acuerdo con el concepto de "específico" dado que los síntomas que presentan los niños no se centran exclusivamente en factores lingüísticos, al igual que está en desuso el término RL, y se tiende a hablar de hablantes tardíos (Carrasco et al., 2015; Mendoza, 2016; Moreno y Nieva, 2021).

Un proyecto reciente llegó a un consenso multinacional y multidisciplinario en relación con "Criterios y Terminología Aplicada a los Trastornos del Lenguaje: sintetizando la evidencia" denominado CATALISE (Bishop et al., 2016), este estudio recomendó que se use el término trastorno del lenguaje en niños con dificultades del lenguaje. Por lo tanto, se pretende eliminar los términos usados anteriormente. Se mantienen en la idea de que estos niños experimentan "limitaciones funcionales" que se ven plasmadas en un bajo nivel educativo, en problemas de la comunicación en sus actividades de la vida diaria, problemas en las relaciones sociales y en su calidad de vida según avanzan en los años escolares (Bishop et al., 2016).

En España, siguiendo la línea de CATALISE en 2015, se realizó un "documento de consenso elaborado por el comité de expertos en TEL sobre el diagnóstico" en él se llegaron a una serie de acuerdos que, aunque se asemeja a los seguidos en CATALISE, no son iguales. Se llegó al acuerdo de que, en vez de utilizar conceptos como trastorno del lenguaje, trastorno primario del lenguaje, trastorno del espectro del lenguaje, o incluso trastorno del desarrollo del lenguaje, se debía mantener el término TEL, por las siguientes razones:

“a) una mayor aceptación general, b) mayor número de entradas como término de búsqueda bibliográfico y c) parece definir mejor a la población. No obstante, considera que el término específico en algún momento se debería cambiar, porque asume que los problemas que presentan los niños con TEL no conciernen únicamente al lenguaje y que no se puedan presentar en otros trastornos del desarrollo" (Aguado et al., 2015. p. 147).

Aun así, desde 2015 hasta la actualidad, otros han comenzado a utilizar con más asiduidad el término Trastorno del Desarrollo del Lenguaje (TDL).

En el DSM-IV, el Manual diagnóstico y estadístico de los trastornos mentales (American Psychiatric Association, 2000), podemos seguir encontrando el término TEL, con los siguientes dos subtipos TEL expresivo y el TEL mixto receptivo y expresivo. Algunos autores han 
dudado de la existencia del TEL exclusivamente expresivo (Leonard, 2009) por lo que desapareció en el DSM-V (American Psychiatric Association, 2012). En este manual se encuadra en el bloque de Trastornos de inicio en la infancia, la niñez y la adolescencia, a diferencia del DSM-V (American Psychiatric Association, 2012) en el que lo encuadran en otro bloque.

A continuación, en las Tablas 2.4 y 2.5 se explica la descripción que realiza el DSM-IV (American Psychiatric Association, 2000) de los dos subtipos: Trastorno del lenguaje Expresivo y de Trastorno Mixto del Lenguaje Receptivo y Expresivo, describiendo los criterios de inclusión:

Tabla 2.4.

Criterios para el diagnóstico del Trastorno del lenguaje Expresivo según el DSM-IV

A. Las puntuaciones obtenidas mediante evaluaciones del desarrollo del lenguaje expresivo, normalizadas y administradas individualmente, quedan sustancialmente por debajo de las obtenidas mediante evaluaciones normalizadas tanto de la capacidad intelectual no verbal como del desarrollo del lenguaje receptivo. El trastorno puede manifestarse clínicamente a través de unos síntomas que incluyen un vocabulario sumamente limitado, cometer errores en los tiempos verbales o experimentar dificultades en la memorización de palabras o en la producción de frases de longitud o complejidad propias del nivel evolutivo del sujeto.

B. Las dificultades del lenguaje expresivo interfieren el rendimiento académico o laboral o la comunicación social.

C. No se cumplen criterios de trastorno mixto del lenguaje receptivo-expresivo ni de trastorno generalizado del desarrollo.

D. Si hay retraso mental, déficit sensorial o motor del habla, o privación ambiental, las deficiencias del lenguaje deben exceder de las habitualmente asociadas a tales problemas

Fuente: Recuperado de DSM-IV (American Psychiatric Association, 2000, p.61).

Tabla 2.5.

Criterios para el diagnóstico del Trastorno mixto del lenguaje receptivoexpresivo según el DSM-IV

A. Las puntuaciones obtenidas mediante una batería de evaluaciones del desarrollo del lenguaje receptivo y expresivo, normalizadas y administradas 
individualmente, quedan sustancialmente por debajo de las obtenidas mediante evaluaciones normalizadas de la capacidad intelectual no verbal. Los síntomas incluyen los propios del trastorno del lenguaje expresivo, así como dificultades para comprender palabras, frases o tipos específicos de palabras, tales como términos espaciales.

B. Las deficiencias del lenguaje receptivo y expresivo interfieren significativamente el rendimiento académico o laboral, o la comunicación social.

C. No se cumplen los criterios de trastorno generalizado del desarrollo.

D. Si hay retraso mental, déficit sensorial o motor del habla o privación ambiental, las deficiencias del lenguaje exceden de las habitualmente asociadas a estos problemas

Fuente: Recuperado de DSM-IV (American Psychiatric Association, 2000, p.64).

La Clasificación Internacional de las Enfermedades CIE-10 (OMS, 1992) sigue una clasificación parecida al DSM-IV-TR -DSM-IV revisado-, dividiendo el trastorno en dos subtipos: Trastorno de la Expresión del Lenguaje y Trastorno de la Comprensión del Lenguaje.

En la última versión del DSM, que es el DSM-V (2014), incluye todos estos trastornos dentro de los trastornos del neurodesarrollo, dentro de este apartado encontramos cinco trastornos: el Trastorno del lenguaje (TL) ha eliminado el término "específico" de la versión anterior del DSM; el Trastorno de la Comunicación Social (TCS), que incluye sobre todo alteraciones en el lenguaje en relación con el contexto y con los interlocutores; el Trastorno de la fluidez de inicio en la infancia (tartamudeo) y el Trastorno de la comunicación no especificado. En relación con nuestro estudio, nos interesa el Trastorno del lenguaje (TL) y el Trastorno de la Comunicación Social (TCS).

- El Trastorno del lenguaje (TL) presenta los mismos criterios y sustituye al trastorno del lenguaje expresivo y al trastorno mixto del lenguaje receptivo-expresivo que se explican en el DSM-IV y ya hemos explicado en el apartado anterior.

- Los criterios que establece el DSM-V (2014) para el Trastorno de la Comunicación Social (TCS) son los que se detallan en la Tabla 2.6.

Tabla 2.6.

Criterios para el diagnóstico del TCS según el DSM-V (2014) 
A. Dificultades persistentes en el uso social de la comunicación verbal y no verbal que se manifiesta en todos los siguientes factores:

1. Deficiencias en el uso de la comunicación para propósitos sociales, como saludar y compartir información, de manera que sea apropiada al contexto social.

2. Deterioro de la capacidad para cambiar la comunicación de forma que se adapte al contexto o a las necesidades del que escucha, como hablar de forma diferente en un aula o en un parque, conversar de forma diferente con un niño o con un adulto y evitar el uso de un lenguaje demasiado formal.

3. Dificultades para seguir las normas de conversación y narración, como respetar el turno en la conversación y narración, como respetar el turno en la conversación, expresarse de otro modo cuando no se es bien comprendido y saber cuándo utilizar signos verbales y no verbales para regular la interacción.

4. Dificultades para comprender lo que no se dice explícitamente (p. ej., hacer inferencias) y significados no literales o ambiguos del lenguaje (p. ej., expresiones idiomáticas de humor, metáforas, múltiples significados que depende del contexto para la interpretación).

B. Las deficiencias causan limitaciones funcionales en la comunicación eficaz, la participación social, las relaciones sociales, los logros académicos o el desempeño laboral, ya sea individualmente o en combinación.

C. Los síntomas comienzan en las primeras fases del período de desarrollo (pero las deficiencias pueden no manifestarse totalmente hasta que la necesidad de comunicación social supera las capacidades limitadas).

D. Los síntomas no se pueden atribuir a otra afección médica o neurológica ni a la baja capacidad en los dominios de morfología y gramática, y no se explican mejor por un trastorno del espectro de autismo, discapacidad intelectual (trastorno del desarrollo intelectual), retraso global del desarrollo u otro trastorno mental.

Fuente: Recuperado de DSM-V (American Psychiatric Association, 2013, pp.26-27).

El CIE-11 (World Health Organization, 2018) aporta un nuevo término: Trastornos del desarrollo del lenguaje (TDL) que se subdivide en trastorno del desarrollo con deficiencia del lenguaje receptivo y expresivo, del lenguaje expresivo, del lenguaje pragmático y con otro tipo de deficiencia específica del lenguaje. Y se mantiene el trastorno para déficits pragmáticos.

Este término TDL proporciona un lenguaje común para todos los profesionales de la salud del mundo, por lo que decididamente nos parece 
más apropiado para referirnos al Trastorno hoy en día y el que utilizaremos en este documento. A continuación, con la finalidad de aclarar y comparar toda la terminología, se presenta la Tabla 2.7 que resume de todos los términos y subtipos encontrados: 
Tabla 2.7.

Comparación de la terminología utilizada para denominar los Trastornos del lenguaje

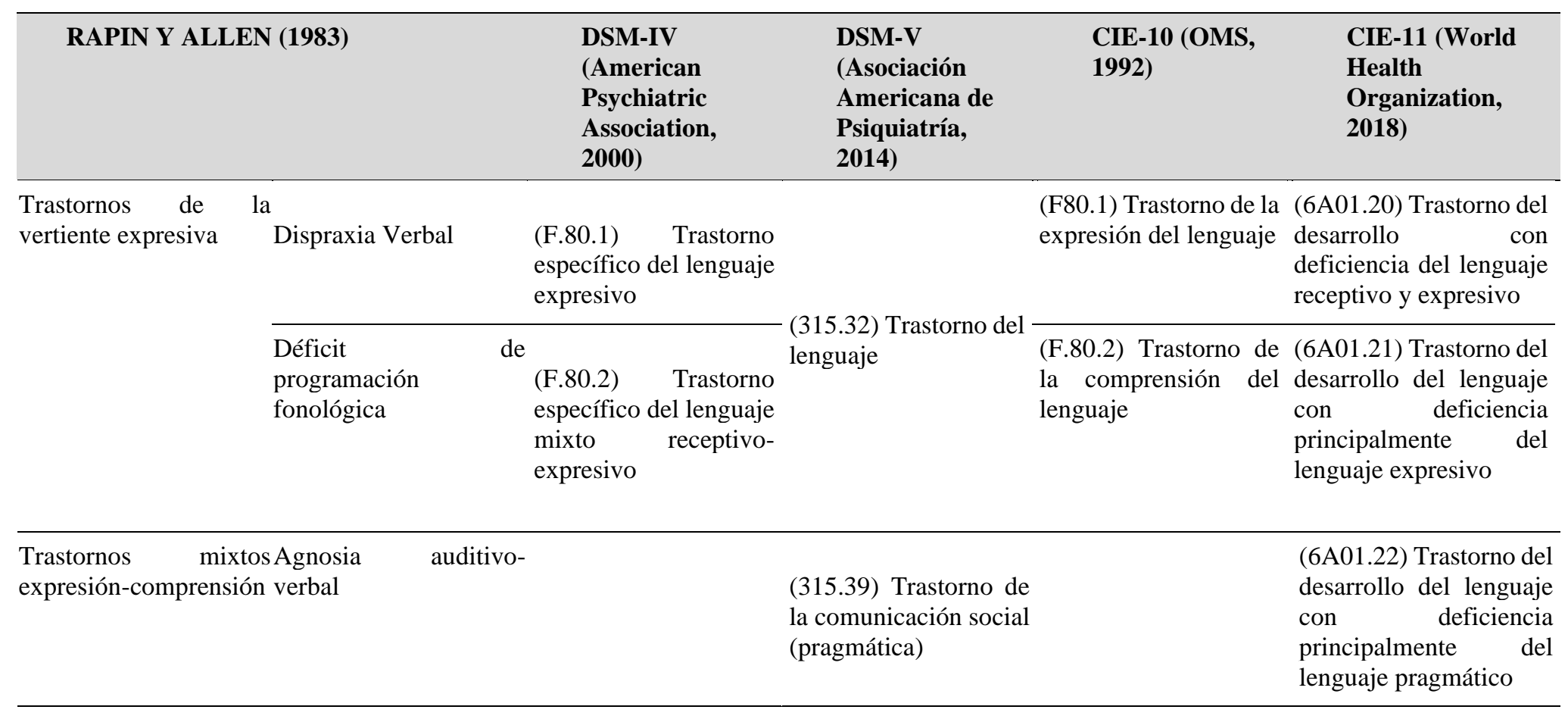




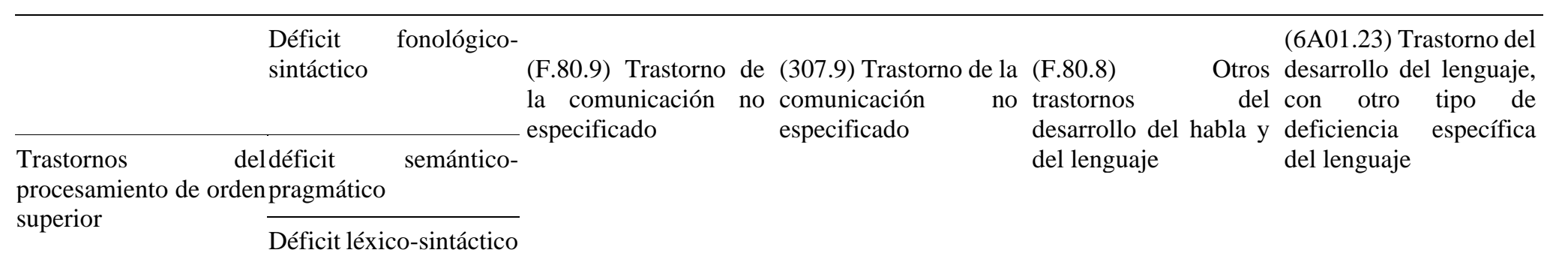

Fuente: Creación propia, basándose en la información de Rapin y Allen (1983), DSM-IV (American Psychiatric Association, 2000), DSM-V (Asociación Americana de Psiquiatría, 2014), CIE-10 (OMS, 1992) Y CIE-11 (World Health Organization, 2018). 


\subsubsection{Identificadores y pruebas diagnósticas de los niños con trastorno del lenguaje}

El proceso de evaluación del TDL no es tarea sencilla debido a su heterogeneidad a la propia delimitación del trastorno, a su abordaje multidisciplinar, a la gran cantidad de áreas lingüísticas y no lingüísticas afectadas y a la dispersión de instrumentos de evaluación que se tienen que utilizar, a veces escasos o carentes en español, por ello la generalización de protocolos de evaluación científicamente validados es un objetivo necesario para reconocer adecuadamente a los niños con TDL y para adoptar las medidas previas necesarias (Carballo, 2012; Mendoza, 2016).

También es muy complicado determinar la edad mínima para el diagnóstico del TDL, por ejemplo, a los tres años es muy difícil observar la permanencia del problema, y es muy difícil diferenciar los síntomas con los de otros trastornos. Se pueden utilizar los inventarios de comunicación o escalas para analizar el lenguaje que presentan estos niños y comprobar si está comprometido. En general, a los cuatro años ya podríamos hablar de un posible TDL y confirmar ese diagnóstico a los cinco años (Aguado et al., 2015). Mientras que en edades anteriores estaríamos hablando de dificultades de lenguaje (anteriormente denominadas RSL o RL).

Es muy difícil la identificación temprana de trastornos del lenguaje que evolucionen a un posible TDL. Para realizarlo correctamente debemos fijarnos en los predictores prelingüísticos, variables relacionadas con el retraso del desarrollo en general y con el del lenguaje en particular, referidos al balbuceo, la comprensión del vocabulario, el desarrollo de las destrezas de juego combinatorio y simbólico y el desarrollo de la función pragmática (Carballo y Fresneda, 2005).

Los principios o requisitos que guían el proceso de evaluación en los niños con TDL son los siguientes (Cohen, 2001):

- La persona encargada de evaluar debe tener un extenso conocimiento del desarrollo y el procesamiento del lenguaje, además de conocer los diferentes trastornos del habla y del lenguaje existentes y sus posibles etiologías.

- La información se debe recoger en diferentes ámbitos y contextos de manera longitudinal y desde diferentes perspectivas: psicopedagógica, socio-familiar...

- Conocer las diferentes estrategias e instrumentos de evaluación: entrevistas, test estandarizados, cuestionarios, observaciones... 
- Realizar la evaluación en un ambiente tranquilo, que inspire confianza, y que motive al niño a expresarse y comunicarse.

- Debe considerarse la conducta convencional y la no convencional para poder comprender las demandas del lenguaje en las situaciones difíciles en las que el niño intenta comunicarse y los medios con los que trata de hacerlo.

- Tiene que descubrir las características, la disponibilidad del medio y de recursos de la familia y del medio externo.

- Evaluar tanto la expresión como la comprensión.

- Los resultados de la evaluación deben ser más que una etiqueta diagnóstica. Deben proporcionar recomendaciones específicas para la intervención, y nunca perder de vista la necesidad de reevaluar o revisar el diagnóstico y la evaluación, ya que la naturaleza del trastorno, las funciones y la edad van cambiando.

Según Wirz (1993), existen dos métodos para evaluar, descriptivos y prescriptivos:

- Descriptivos: Parten del razonamiento inductivo, plasman con un gran detalle la conducta comunicativa del niño como base para poder tomar la decisión de dónde se halla el problema y para saber qué puede hacer con ello.

- Prescriptivos: Parten del razonamiento deductivo, extraen conclusiones en base a la información y a los datos disponibles, así como a las ideas que han orientado el diseño del método. Utilizan estándares y normas como base de comparación. (p. 11)

Dentro de los métodos prescriptivos encontramos los test estandarizados. Los métodos de evaluación estandarizada tienen un largo recorrido en el ámbito de la psicología. La medida formal y sistemática de la inteligencia empezó por dos psicólogos de origen francés, Binet y Simon, a principios del S.XX, con lo que se inició la era moderna de la evaluación psicológica. En los años siguientes, se crearon pruebas para medir diferentes aptitudes, personalidad y rendimiento escolar. La logopedia ha aceptado la tradición de evaluar la comunicación y el lenguaje mediante estas pruebas estandarizadas (Mendoza, 2010).

En el apartado anterior hemos detallado los criterios de inclusión del TDL según el DSM-IV y el DSM-V, en ellos aparecen dos grandes apartados que se deben analizar: las pruebas de inteligencia no verbal y las características del lenguaje de los niños con esta patología (Martínez, 2015); esto es posible evaluarlo a través de diferentes pruebas estandarizadas que se describen en los siguientes apartados. 


\subsubsection{Las pruebas de inteligencia no verbal}

Si queremos evaluar la inteligencia no verbal de los niños con TDL utilizaremos la quinta edición de la escala de inteligencia de Wechsler para niños, el WISC-V (Wechsler, 2014), es la adaptación más moderna de la prueba original que se publicó en 1949 (WISC). Esta prueba puede aplicarse a personas de entre seis años y dieciséis años y once meses de edad.

La adaptación española de la prueba WISC-V (Wechsler, 2014) contiene quince pruebas. Doce son pruebas que ya se encontraban en el WISC-IV (cubos, semejanzas, matrices, dígitos, claves, vocabulario, búsqueda de símbolos, información, letras y números, cancelación -anteriormente denominada animales en DSM-IV - comprensión y aritmética), y las otras tres forman parte de las nuevas pruebas del DSM-V (puzles visuales, balanzas y Span de dibujos).

\subsubsection{Las pruebas de evaluación del lenguaje}

Para analizar las dificultades que muestran los niños con TDL, tenemos que centrarnos en que estas dificultades se encuentran en la comprensión y/o producción en los aspectos semántico, fonológico-fonético, morfosintáctico y pragmático, además de en una conducta verbal inadecuada (Carballo y Fresneda, 2005).

Como punto de partida para comenzar la evaluación se pueden utilizar las Checklist -listas de prueba o de control- de lenguaje y comunicación del niño con un posible TDL, de los padres o de los maestros. Carballo (2012) propone una serie de Checklist sensibles para los niños con TDL con medidas con gran validez ecológica y de esta manera determinar qué prueba estandarizada es la más adecuada para el niño en cuestión:

- Lista de Comunicación y Desarrollo de Lenguaje (Wetherby \& Prizant, 2002).

- LDS -LanguageDevelopmentalSurvey- (Rescorla, 1989) sirve para detectar de manera temprana el retraso del lenguaje en niños pequeños.

- La adaptación española del inventario de Desarrollo Comunicativo MacArthur (Jackson et al., 2003), es el inventario de comunicación más utilizado a nivel internacional y sus propiedades psicométricas son bastante adecuadas para el caso 
que nos ocupa. Marca el umbral clínico en el centil 10; en los niños con desarrollo normotípico del lenguaje su edad máxima de administración son los treinta meses; en los niños con TDL, se puede aplicar periódicamente a partir de la edad del avance o para comprobar la estabilización del problema (Aguado et al., 2015).

- CCC-2 (Children's communication Checklist) (Bishop, 2003).

- Las escalas de rangos observacionales -para padres, maestros y para el niño en cuestión- del CELF-3 (Semel et al. 1997), que se utiliza para obtener información sobre las habilidades linguísticas que muestran los niños en edad escolar.

- Protocolo de observación del lenguaje (Ygual et al., 2011) para maestros de educación infantil.

En el Documento de consenso elaborado por el comité de expertos en TEL sobre el diagnóstico (Aguado et al., 2015), se determinó que el mejor instrumento para el diagnóstico de TEL -sin excluir el análisis cualitativo ni las muestras de lenguaje- es la edición española del CELF4 (Semel et al., 2006). -Actualmente ya se encuentra el CELF-5 (Wiig et al., 2013)-. En caso de no disponer de él, se recomienda utilizar test de lenguaje expresivo y comprensivo diseñados o adaptados a la población española y que evalúen varias dimensiones (fonológica, morfosintáctica y semántica) y que tengan unas buenas propiedades psicométricas. Se debe evitar diagnosticar el TEL o el TDL, evaluando al niño con una única prueba que evalúe una sola dimensión lingüística. Para poder diagnosticar a un niño de TDL es necesario que el niño muestre errores en el apartado morfosintáctico, de esta manera se necesita:

- Para el diagnóstico del TDL fonológico-sintáctico: una puntuación por debajo del punto de corte en las pruebas fonológicas y en las morfosintácticas.

- Para el diagnóstico del TDL léxico-sintáctico: una puntuación por debajo del punto de corte en las pruebas semánticas y en las morfosintácticas.

En los niños más pequeños se recomienda repetir la evaluación pasados seis meses para confirmar o descartar la continuidad del trastorno, y los efectos de la intervención logopédica si existieran.

En relación con los puntos de corte para el diagnóstico de base psicométrica, se recomienda que al menos una de las escalas centrales 
del CELF-4, tenga por lo menos un 1.5 desviación típica por debajo de la media. Aun así, es recomendable prestar especial atención a las subpruebas de estructura de palabras, conceptos y seguimiento de direcciones y recuerdo de oraciones, ya que son los que presentan mayores tamaños del efecto en niños con TDL (Aguado et al., 2015). Además del CELF-5, útiles para niños de 5 a 15 años, también existe el CELF Preschool-2 Spanish (Wiig et al., 2009), que está destinado para niños de 3 a 6 años y 11 meses.

Otros autores, como Anaya-Reig y Calvo (2019), proponen pruebas para las cuatro dimensiones del lenguaje ya explicadas en el apartado 2.3.2 de esta tesis.

En relación con otras pruebas, también es conveniente utilizar pruebas de memoria a corto plazo, memoria de trabajo fonológica, y medidas de conducta a través de inventarios o cuestionarios de padres o de desempeño académico (Aguado et al., 2015).

Carballo (2012) propone unas pruebas estandarizadas diferentes para cada nivel de lenguaje, ver en la Tabla 2.8. 
Tabla 2.8.

Tabla de evaluación de diferentes áreas para niños con TDL adaptado de Carballo (2012)

\begin{tabular}{|c|c|c|c|}
\hline $\begin{array}{l}\text { Evaluación (Ev.) de la } \\
\text { Fonología }\end{array}$ & 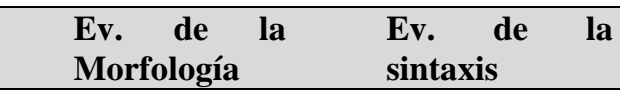 & $\begin{array}{l}\text { Ev. de la } \\
\text { semántica }\end{array}$ & $\begin{array}{l}\text { Ev. de la } \\
\text { comprensión }\end{array}$ \\
\hline $\begin{array}{l}\text { Pruebas de repetición de } \\
\text { pseudopalabras, por ejemplo, la } \\
\text { de Aguado (2007b) }\end{array}$ & TSA (Aguado, 1989) & $\begin{array}{l}\text { Test de vocabulario } \\
\text { en PLON-R } \\
\text { PPVT-III (Dunn et } \\
\text { al., 2006) }\end{array}$ & TSA (Aguado, 1989) \\
\hline $\begin{array}{l}\text { Otras pruebas más informales } \\
\text { como A-RE-HA (Aguilar y } \\
\text { Serra, 2003) o el Registro } \\
\text { Fonológico Inducido (Juárez y } \\
\text { Monfort, 1996a) }\end{array}$ & BLOC (Puyuelo et al., 1997) & $\begin{array}{lrl}\text { Escalas } & \text { Reynell } & \text { BLOC (Puyuelo } \\
\text { (Reynell y Gruber } & \text { et al., 1997) } \\
1990) & & \end{array}$ & $\begin{array}{ll}\text { CEG }- \text { Test } & \text { de } \\
\text { Comprensión } & \text { de } \\
\text { Estructuras } & \\
\text { Gramaticales } \\
\text { (Mendoza et al., } \\
\text { 2005) }\end{array}$ \\
\hline $\begin{array}{l}\text { La subprueba de integración } \\
\text { auditiva del ITPA (Kirk et al., } \\
\text { 2004) }\end{array}$ & $\begin{array}{lrlr}\begin{array}{l}\text { Subtest de cierre } \\
\text { gramatical de cierre }\end{array} & \begin{array}{l}\text { La repetición } \\
\text { oraciones con las }\end{array} \\
\text { gramatical del } & \text { subpruebas } & \text { del } \\
\text { ITPA } & & \text { MSCA, CELF-V } \\
& \text { (Wiig et al., 2013), } \\
& & \text { STSG } \\
& & \text { (Toronto, } \\
& \end{array}$ & ITPA (Kirk et al., 2004) & $\begin{array}{l}\text { MSCA o el test Token } \\
\text { (Renzi y Vignolo, } \\
\text { 2005) para evaluar el } \\
\text { paradigma forma- } \\
\text { color-tamaño }\end{array}$ \\
\hline $\begin{array}{l}\text { Pruebas para evaluar niños } \\
\text { bilingües hablantes de español- } \\
\text { inglés, o algunas subpruebas } \\
\text { que se encuentran dentro de } \\
\text { pruebas más complejas de } \\
\text { lectoescritura }\end{array}$ & CELF-V (Wiig et al., 2013) & $\begin{array}{l}\text { Test Boehm de conceptos básicos } \\
\text { (Boehm, 1990) } \\
\text { CELF-V (Wiig et al., 2013) }\end{array}$ & \\
\hline
\end{tabular}




\begin{tabular}{ll}
\hline Subtest de las \\
escalas McCarthy \\
de Aptitudes y \\
Psicomotricidad \\
para niños -MSCA- \\
(McCarthy, 2006) \\
\hline
\end{tabular}

Fuente: Adaptado de Carballo (2012). 


\subsection{Intervención logopédica con niños con trastorno del lenguaje}

En este apartado indagamos sobre el perfil profesional del logopeda, incluyendo además las intervenciones logopédicas en la población con trastorno del lenguaje y las investigaciones existentes relacionadas con ésta, además de los principios generales de intervención que se deben de seguir para poder llevar a cabo una adecuada intervención.

Los principios de intervención lingüística explicados en Roth (1996) y citados en Carballo y Fresneda, (2005) son:

- El lenguaje se adquiere y se utiliza primariamente para el propósito de comunicación, esto quiere decir que debe enseñarse en un contexto comunicativo, no aislado a él.

- La intervención es un proceso dinámico en el que el logopeda evalúa el progreso en diferentes momentos.

- La intervención logopédica debe orientarse individualmente, para especializar la intervención para el niño en cuestión.

- La intervención del lenguaje es más efectiva cuando las metas de la terapia están adaptadas.

- La meta final es enseñar estrategias para facilitar el proceso de adquisición del lenguaje.

- Es muy importante tener en cuenta las habilidades cognitivas no verbales del niño con TDL.

Todo ello lo tiene que llevar a cabo el logopeda, en el siguiente apartado profundizaremos en este profesional.

\subsubsection{Perfil profesional del logopeda}

Carballo y Fresneda (2005) proponen una intervención multidisciplinar (lingüística, psicológica, escolar, familiar...) para intervenir con población infantil, no habiendo cabida para una intervención únicamente logopédica. Aun así, como en este estudio nos vamos a centrar en el área lingüístico vamos a hablar sobre la acción de los logopedas con estos niños. Según la Ley 44/2003, de 21 de noviembre, de ordenación de profesiones sanitarias, "los Diplomados universitarios en Logopedia desarrollan las actividades de prevención, evaluación y recuperación de los trastornos de la audición, la fonación y del lenguaje, mediante técnicas terapéuticas propias de su disciplina" (p.8). 
La titulación oficial universitaria fue regulada en el Real Decreto 1419/1991, de 30 de agosto, denominaron al título "diplomado en logopedia" en el año 1992 fue cuando apareció el art. 28 de la Ley Orgánica 11/1983 de Reforma Universitaria y el Real Decreto $1497 / 1987$ por lo que se establecieron las directrices generales comunes a todos los planes de estudio de los títulos universitarios de carácter oficial. Las diplomaturas tenían una duración de tres años. Se vuelve a regular en la Orden CIN/726/2009, de 18 de marzo (BOE del 26 de marzo) por la que se establecen los requisitos para la verificación de los títulos universitarios oficiales que habiliten para el ejercicio de la profesión de Logopeda. Se implanta el Grado en logopedia, para obtener el título será necesario invertir cuatro años, y se adaptan los estudios al Espacio Europeo de Educación Superior (EEES), extinguiéndose el título de Diplomado en logopedia. Este Grado acredita a trabajar con la población que nos ocupa en la práctica privada y en instituciones públicas. La gran mayoría de intervenciones logopédicas se llevan a cabo en clínicas privadas (Law et al., 2019). La logopedia se apoya en bases de la psicología, la medicina y complementa estas con la pedagogía, además de necesitar formación específica (Sánchez-Delgado et al., 2015).

La logopedia es una disciplina sanitaria, como podemos observar formalmente en el apartado 2 del artículo 2 de la Ley 44/2003, de 21 de noviembre, de ordenación de profesiones sanitarias. En este artículo equipara la logopedia a otras profesiones sanitarias como son la Enfermería, Fisioterapia, Podología...

En España no existen decretos que expliquen las competencias profesionales de esta profesión, y se encomienda a los colegios profesionales que regulen sus funciones, sin embargo, el Real Decreto 1277/2003, de 10 de octubre, por el que se establecen las bases generales sobre autorización de centros, servicios y establecimientos sanitarios, en su anexo II define la unidad asistencial de Logopedia con el siguiente texto: "U.61 Logopedia: unidad asistencial en la que un logopeda es responsable de realizar la prevención, el estudio y la corrección de los trastornos del lenguaje" (p.15).

En el libro blanco del título del grado en logopedia (Gallego, 2004, p.52), expone que el plan de estudios del grado en logopedia debe incorporar los siguientes bloques de contenido:

a) Logopedia ciencia y profesión.

b) Bases biológicas, lingüísticas, psicológicas y pedagógicas de la Logopedia. 
c) Alteraciones y trastornos del lenguaje y la comunicación.

d) Evaluación y diagnóstico en Logopedia.

e) Intervención logopédica.

f) Practicum.

Podemos comprobar como existe un bloque en el que se incluyen las alteraciones y trastornos del lenguaje y la comunicación, donde se sitúa la enseñanza de las características e intervención con los hablantes tardíos y los niños con TDL.

En todas las definiciones que hemos encontrado se detalla que el logopeda es el especialista encargado de los trastornos del lenguaje, audición, voz, habla y funciones orales no verbales, y por eso creemos que es necesaria la actuación del logopeda con esta población.

\subsubsection{Rehabilitación logopédica en el lenguaje oral de los niños con trastorno del lenguaje}

La eficacia de la intervención logopédica con los niños con trastorno del lenguaje está más que demostrada, y hoy en día el enfoque de esperar y no tratar a los niños para comprobar si evolucionan positivamente de manera espontánea está obsoleto (Singleton, 2018). Existen diversas aproximaciones en la intervención en niños con trastorno del lenguaje. A menudo se recurre a una clasificación clásica en la que se diferencian modelos naturales (que emplean metodologías menos intrusivas) y modelos directos y focalizados (que usan procedimientos más precisos y estructurados); y otros autores en la misma línea, diferencian entre métodos funcionales (los objetivos se ajustan a la propia iniciativa del niño) y formales (se realiza un trabajo individual con actividades más restringidas). Según Acosta (2012a) y Mendoza (2006), existe una gran evidencia científica para todos los métodos, lo que es tranquilizador para los logopedas, ya que hoy en día los logopedas buscan aplicar estrategias basadas en la evidencia que lleven a lograr una gran cantidad de objetivos en un periodo corto de tiempo (Eisenberg et al., 2020).

Independiente del enfoque utilizado, se tienen que incluir una selección de conductas para utilizarlas con estos niños, según Hedge y Davis (1995), citado en Carballo y Fresneda (2005), el contenido de estos tratamientos incluye la selección de una serie de conductas, palabras, estructuras y destrezas que son las siguientes:

- Seleccionar las conductas que tengan un mayor impacto o una mayor importancia en las destrezas comunicativas del niño, como 
son las que mejoran la comunicación social y el rendimiento académico.

- Seleccionar las conductas que sean más útiles, más frecuentes y naturales; es decir, las que mayor probabilidad tengan de realizarse tanto en casa como en otros ambientes.

- Seleccionar las conductas que amplíen las destrezas comunicativas del niño; es decir, palabras que se integren de forma más fácil en una frase.

- Seleccionar las conductas que sean lingüística y culturalmente más adecuadas para el sujeto.

- Seleccionar las palabras, estructuras gramaticales, y modelos más usuales y valorados por la familia y por su entorno social.

Pero para trabajar este tipo de contenido, se utilizan una serie de técnicas. Acosta, (2012b), diferencia varios tipos de intervención dentro de la estimulación del lenguaje oral en los niños con trastorno del lenguaje, y entre otros incluye los siguientes: imitación, modelado, intervención familiar, intervención basada en la estimulación general del lenguaje, intervención basada en la estimulación focalizada, intervención a través de recast conversacional y respuesta diferenciada por niveles de prácticas que explicaremos a continuación:

a) Imitación

La imitación ha sido muy utilizada, y aunque un gran parte de los investigadores cree que la imitación por sí sola no es un mecanismo suficiente para conseguir un desarrollo del lenguaje correcto, sí que es cierto que la imitación es muy importante para el desarrollo cognitivo y social (Meltzoff \& Williamson, 2013). Fey \& Proctor-Williams (2000) recomiendan el uso de la imitación para tratar a niños con trastorno del lenguaje, y explican que la imitación tiene que ser instruida, es decir que el profesional tiene que explicar al niño cómo realizar esta imitación. Fey \& Proctor-Williams (2000) explican cómo es recomendable el uso de esta imitación sobre todo cuando se introducen nuevas formas, porque da la posibilidad a los niños de practicar, además les da la opción de mejorar su gramática a través de la imitación (Eisenberg et al., 2020). Paul \& Norbury (2012) explican que es positivo el uso de la técnica de imitación con niños con trastorno del lenguaje, ya que de esta los logopedas incluyen un mayor número de palabras desconocidas y un gran número de respuestas (imitaciones) en un corto periodo de tiempo. 


\section{b) Modelado}

Existen dos tipos de enfoques dentro del modelado, el primer enfoque consiste en que el niño observe a alguien producir las emisiones que contienen la forma lingüística que tiene que aprender (ya sean palabras o una forma gramatical...). Al niño se le pide que mire al logopeda y que atienda, pero no se solicita una repetición. En el segundo enfoque se repite la misma acción que en el primero, pero además se pide al sujeto que repita la acción (Morton, 2008). Esta técnica es similar a la imitación, pero con la diferencia de que en este caso lo que se imita es una regla de combinación, inserción o secuencias de morfemas, no la emisión completa del modelo (Leonard, 2014).

c) Intervención familiar

Según Pappas \& McLeod (2009), existen cuatro modelos de intervención en cuanto a la participación familiar y cómo participa estas en las sesiones de logopedia: a) la aproximación basada en el logopeda, que es el modelo tradicional en el que el logopeda asume toda la responsabilidad; b) aproximación basada en los padres como terapeutas, en esta ocasión los padres son coterapeutas y realizan actividades complementarias en casa; c) la intervención centrada en la familia, los padres son participantes activos en la toma de decisiones y se realizan propuestas individualizadas y diferenciadas; y d) aproximación centrada en la familia como colaboradores, en esta situación bajo la tutela del logopeda se solicita a la familia la participación en la intervención.

Independientemente del modelo elegido, el trabajo con las familias en la intervención de los niños con RL es primordial. Roper \& Dunst (2003) explican unas estrategias básicas para facilitar y mejorar la comunicación en un entorno familiar natural: (a) ayudar a las familias a comprender la necesidad de facilitar muchas oportunidades de uso de las habilidades comunicativas aprendidas y también facilitar distintos tipos de oportunidades; (b) ayudar a identificar las actividades y situaciones en las que el niño está más motivado; (c) ayudar a identificar las señales comunicativas que emite el niño, y responder a los intentos de interaccionar con sus iguales; (d) utilizar la imitación para facilitar la comunicación; (e) utilizar el modelado; (f) ayudar a que utilicen un estilo interactivo no directivo; y (g) ayudarlos a identificar las situaciones de su vida familiar que brindan una gran oportunidad para el fomento de la estimulación del lenguaje. Todas estas estrategias son importantes y básicas, ya que los enfoques de intervención basados en aumentar la 
interacción de las familias con los niños son claramente eficaces (Falkus et al., 2016).

d) Intervención basada en la estimulación general del lenguaje

Este enfoque consiste en estimular y reforzar de manera sistemática y regularizada el lenguaje de los niños (Acosta, 2012b). Existen multitud de programas cuyo objetivo no es centrarse en mejorar un área o una dimensión específica, sino en mejorar todo el lenguaje general de los niños con trastorno del lenguaje, como el programa diseñado por Cuevas-Miranda et al. (2019), en el que se trabajó el léxico pasivo, la conciencia fonológica y la comprensión y producción de narraciones. Dentro de este enfoque se encuentran las actividades en las que se realizan conversaciones regulares con los niños, ya sea sobre un tema en común, una lámina o una vivencia (Juárez y Monfort, 1996b). Es común recurrir a la conversación y a la entrega de un feedback adecuado (Acosta, 2012b).

e) Intervención a través de recast conversacional

El recast son respuestas que da el adulto inmediatamente después de la emisión del niño. Comparten el contexto en el que se está hablando y la mayor parte de palabras que se repiten, se mantiene el significado original que quería dar el niño, pero la frase se repite de forma correcta (Andreu-Barrachina et al., 2014). Existe evidencia de que el recast resulta efectivo en niños con trastorno del lenguaje (Camarata \& Nelson, 1992; Nelson et al. 1996). Fey et al. (2003) también señalan esta evidencia, remarcando que con los niños con trastorno del lenguaje debe hacerse más cantidad de recast que con los niños sin dificultades o con otro tipo de dificultades.

f) Respuesta diferenciada por niveles de prácticas

Este modelo parte del supuesto de que la intervención puede llevarse a cabo dentro del contexto educativo (Acosta et al., 2012), por lo que es muy probable que dicha intervención sea desarrollada por el maestro de audición y lenguaje. Esta estrategia aparece recogida en el año 2004, en el Acta para la Educación de los Individuos con Discapacidad (IDEA²).

\footnotetext{
${ }^{2}$ Este Acta, es el renombre de la Ley de educación de todos los niños discapacitados en 1975 (Ley pública 94-142) que se promulgó en el congreso de Estados Unidos. Con los años, esta Ley ha sido enmendada varias veces y ha sido renombrada. La Ley fue revisada por última vez en noviembre de 2004 y entró en vigor el 1 de julio de
} 
Esta estrategia se divide en tres niveles: a) el tutor, con el asesoramiento y apoyo del logopeda o del maestro de audición y lenguaje, trabaja con todos los niños en el aula, teniendo un mayor seguimiento con los niños con trastorno del lenguaje, se utiliza material de apoyo al lenguaje (libros, teléfonos, cartas, sellos) y se realiza role-play; b) se ejecuta una enseñanza intensiva en el aula, mediante estimulación focalizada tanto del lenguaje oral como de la lectura, se implementa de manera multi e interdisciplinar por el logopeda y el profesor; y c) si los niños no progresan en las dos etapas anteriores se pone en marcha un programa más intensivo de manera individual fuera del aula (Acosta, 2012b).

g) Intervención basada en la estimulación focalizada

Con esta estrategia facilitamos a los niños estímulos lingüísticos específicos relacionados con una dimensión del lenguaje, o con la forma, contenido o el uso (Acosta, 2012b). Dentro de este tipo de intervenciones, encontramos programas que buscan unos objetivos muy concretos, como, por ejemplo, el estudio de Acosta et al. (2020) que pretende mejorar la gramática de los niños con trastorno del lenguaje, y la investigación de Pavez et al. (2008) que realiza un Plan de Estimulación del Desarrollo Narrativo.

Todas estas técnicas explicadas anteriormente se pueden simultanear para ofrecer una mayor estimulación a los niños con trastorno del lenguaje, por ejemplo, algunos autores como Acosta et al. (2020), utilizan a la vez el modelado, la imitación y el recast para su intervención lingüística.

Además de las estrategias anteriormente explicadas, es conveniente cuidar de otros aspectos, por ejemplo, Brito-Torres (2018) destacan la importancia de realizar procedimientos más sistemáticos, estrategias verticales y situaciones más estructuradas, además de pautar una intervención intensiva con una alta frecuencia con los niños con trastorno del lenguaje. Gallardo (2016) expone la conveniencia de revisar y monitorear periódicamente a los niños, con el fin de reestructurar el plan de intervención de acuerdo con las necesidades individuales de cada uno de ellos. En cuanto a la duración del tratamiento no existe una definición establecida (Madueño y De Sebastian, 2018); Alt et al. (2014) afirman que no se encuentran diferencias significativas entre el número de sesiones semanales, pero por otro lado, Khamis-Dakwar \& Khattab (2014) explican que cuanta más terapia siempre es mejor. Nye et al.

2005. Esta ley ahora se llama El Acta de Educación Para Individuos con

Discapacidades de 2004 (IDEA 2004). 
(1987) explican que se produce un mayor progreso entre la cuarta y la doceava semana de intervención logopédica en niños, y estos beneficios disminuyen a partir de la decimotercera semana. Por todo ello, podemos concluir que no existe un consenso en la comunidad científica en cuanto a la cantidad de sesiones necesarias en los niños con trastorno del lenguaje.

Existen diversos programas o intervenciones específicas para cada dimensión del lenguaje. A continuación, vamos a presentar diferentes intervenciones o consideraciones para trabajar la dimensión fonéticafonológica, semántica y morfosintáctica. No hemos incluido la dimensión pragmática, al no ser una de las dimensiones que PELEO incluye en su programa.

\subsubsection{Intervención en la dimensión fonética-fonológica}

Los niños con dificultades en el nivel fonético presentan menos verbalizaciones, articulan correctamente menos consonantes y vocales y tienen un habla más ininteligible que los niños de su edad. Los errores que más se encuentran son la omisión de sílabas átonas y de consonantes finales, y las reducciones de grupos consonánticos. Comenten errores articulatorios y los más frecuentes son en los fonemas /d/, /l/ y /r/. Los niños con TDL tienen dificultades en las oclusivas, nasales y las semiconsonantes (Andreu-Barrachina et al., 2014). Entre un 33 y 54\% de los niños con dislalias tienen dificultades para pronunciar los fonemas $/ \mathrm{s} /, / \Theta /, / \mathrm{r} /$; entre un 17 y un $28 \%$ cometen errores en los fonemas $/ \mathrm{g} /, / \mathrm{k} /$, $/ \mathrm{n} /, / \mathrm{r} /$; y entre un 1 y un $11 \%$ cometen errores en los fonemas $/ \mathrm{b} /, / \mathrm{p} /, / \mathrm{f} /$, /d/, /t/, /l/ y /n/ (Perelló, 1990).

En este sentido Rivera (2009) y Rodríguez (2010) establecen dos tipos de intervenciones cuando hablamos de la dimensión fonética y fonológica:

a) La intervención directa que tiene como objetivo enseñar al niño a articular correctamente todos los fonemas e integrarlos en su expresión espontánea, realizando actividades de generalización.

b) La intervención indirecta que se orienta en las bases de que la articulación y las habilidades motoras de los órganos fonoarticulatorios están interrelacionadas con otras funciones como la masticación, succión, respiración...

Ha existido un gran cambio en la intervención logopédica en la articulación, sobre todo en la intervención indirecta mencionada, ya que 
anteriormente se pensaba que para lograr una correcta articulación del habla era necesario realizar una serie de praxias linguales correctas, además de tener una discriminación auditiva correcta (González, 2003). Existía una creencia de que para mejorar los sonidos del habla era necesario realizar praxias fonoarticulatorias entendiendo estas como "la realización de movimientos programados y organizados de forma intencional y coordinada dirigidos a controlar los músculos faciales y los órganos activos de la articulación, como son lengua, labios y paladar blando". (Parra-López et al., 2016 p.77). Esta creencia existía debido a que pronunciar implica un dominio práxico (Ygual y Cervera, 2016), diferentes estudios utilizaban rutinas de este tipo de ejercicios con niños con dificultades en la articulación (Brumbaugh \& Smit, 2013; Mackenzie et al., 2010; Oliveira et al., 2015). Pero, recientemente se ha demostrado que realizar ejercicios oromotores no verbales con el fin de mejorar la articulación de los niños no tiene ninguna evidencia científica (Susanibar, 2015; Susanibar et al., 2016), ya que los estudios de Steeve et al. (2008) y Steeve (2010) explican que el habla, al contrario de lo que pensaban hasta ese momento, se desarrolla independientemente de las demás funciones motoras orofaciales. Susanibar et al. (2016) detallan que debemos concebir el habla como un acto motor, que involucra diferentes aspectos psicolingüísticos, auditivos, y que requiere de una variedad de habilidades cognitivas superiores, y no solamente las funciones orofaciales.

Según estas nuevas evidencias, debemos desterrar los ejercicios que proponían realizar praxias articulatorias. Ramírez (2011) y Rivera (2009) establecen una serie de principios para intervenir sobre la articulación:

- Trabajar por medio del juego.

- Enseñar a la vez las consonantes, teniendo en cuenta el desarrollo fonético normotipico del lenguaje, y el grado de madurez de cada niño. Realizar una enseñanza de forma análoga ya que presentar el mismo mecanismo de ejecución puede facilitar el aprendizaje.

- Evitar enseñar en una misma sesión fonemas que tengan el mismo punto de articulación como puede ser los fonemas $/ \mathrm{k} / \mathrm{y}$ $/ \mathrm{x} /$.

- Los ejercicios articulatorios no se deben realizar de manera brusca o exagerada dando lugar a una articulación poco natural, pues pueden crear malos hábitos lingüísticos en el niño.

- La duración de los ejercicios debe ser corta, para evitar la fatiga del niño.

- Es necesario incluir actividades de discriminación auditiva. 
- Es interesante grabar el habla del niño, para realizar una comparación de los avances posteriormente.

Jiménez-Rodríguez (2010) incluye la necesidad de orientar y ofrecer pautas a las familias, para lograr una mejor intervención.

\subsubsection{Intervención en la dimensión semántica}

La adquisición de un vocabulario básico constituye el pilar fundamental para la gran mayoría de niños con RL, este pilar será sobre el que después se fundamente el sistema lingüístico; así pues, la adquisición del vocabulario es clave para activar otros componentes linguísticos y para el progreso escolar del alumnado con trastorno del lenguaje (Mendoza 2016; Marulis \& Neuman 2010). Los niños con trastorno del lenguaje desarrollan su léxico de una manera más lenta, y con más imprecisión que los niños con un desarrollo normotípico (Rice \& Hoffman, 2015).

Andreu-Barrachina et al. (2014) explican que estos niños tienen un retraso en la adquisición de las primeras palabras (sobre los 24 meses), enlentecimiento de la explosión léxica: de los 18-24 meses muestran un vocabulario reducido, dificultades de acceso al vocabulario realizando circunloquios y sustituciones semánticas, uso de palabras comodín o generales en vez de utilizar palabras específicas y dificultad para utilizar palabras que ya comprenden.

Estas dificultades en el caso de los niños con TDL se extienden hasta la adolescencia, donde se sigue notando esta brecha de desigualdad en su vocabulario en relación con los niños con desarrollo normotípico del lenguaje (Rice \& Hoffman, 2015).

Andreu-Barrachina et al. (2014) explican las características relacionadas con el léxico de los niños de tres a cinco años con TDL:

a) Los niños de tres años: tienen una menor longitud media del enunciado por palabras, realizan producciones sin verbo, tienen un alto uso de enunciados menores (si y no), estereotipos (ya tá), palabras sociales (hola, adiós...), poco uso de oraciones simples, realizan omisiones de palabras y errores morfológicos en palabras, entre otros.

b) Los niños de cuatro años: menor longitud media del enunciado por palabras (aproximadamente 3 palabras de media), presencia de enunciados incomprensibles por múltiples omisiones, poco uso de oraciones simples y compuestas y omisiones de palabras. 
c) Los niños de cinco años: menor longitud media del enunciado por palabras (aproximadamente 4-5 palabras de media), poco uso de oraciones simples y compuestas, omisiones de palabras.

Estos niños tienen claramente menos capacidad que sus homólogos para recordar palabras dentro de un listado (Mainela \& Evans, 2005), su vocabulario es mucho más reducido basándose en objetos de su entorno más cercano, y presentan grandes dificultades para la asimilación de conceptos abstractos (colores, formas, tamaños y conceptos espaciotemporales) (Alegre y Pérez, 2008). Los niños con trastorno del lenguaje no tienen la misma capacidad para nombrar objetos o imágenes con la misma frecuencia ni a la misma velocidad que los niños de su misma edad (Thal, 2000), hay un desfase en cuanto a su nivel de comprensión y el de expresión: su nivel de comprensión del vocabulario es cercano a la normalidad y, en cambio, el nivel de producción suele ser muy bajo, aunque es verdad que este desfase puede ser modificable con el tiempo (Jackson, 2004); también tienen dificultades para manejar artículos, pronombres, plurales y el uso de diferentes tiempos verbales (Peña, 2014).

Cuando comenzamos una intervención lingüística con ellos, podemos advertir graves dificultades en el aprendizaje del vocabulario, especialmente en el aprendizaje incidental (Oetting et al., 1995). Cuando se compara el aprendizaje incidental por vía rápida, que es como se denomina al aprendizaje en la interacción natural de estos niños, y la vía de aprendizaje lento, que no es una simple interacción natural y requiere de una mayor dificultad para el interlocutor, podemos observar que los niños con dificultades del lenguaje aprenden mejor el lenguaje a través de esta segunda vía de aprendizaje lento (Mendoza, 2016).

Las estrategias de intervención en la enseñanza de vocabulario a niños con trastorno del lenguaje que puedan ayudarles a aprender palabras (especialmente verbos) incluyen lo siguiente (Gray, 2005; Good et al., 2015; Nash \& Donaldson, 2005; Riches et al., 2005; Weismer \& Hesketh, 1996):

- Proporcionar más presentaciones que incluyan palabras nuevas para los niños.

- Una tasa de presentación más lenta del estímulo.

- Aumentar la presentación de verbos (dándoles dentro de frases o de forma aislada).

- Enseñar las diferentes terminaciones morfológicas para diferentes palabras y resaltar la raíz común de esta. 
- Mostrar explícitamente los significados de las palabras.

- Usar las palabras en oraciones.

Los niños con TDL tienen diferentes puntos fuertes y debilidades con respecto al aprendizaje de palabras comparado con los niños con desarrollo típico del lenguaje (Wright et al., 2017).

El número de palabras que aprenden los niños puede variar según diferentes estudios:

- Una o dos palabras después de 10 horas (Spencer et al., 2017).

- Dos palabras después de 18 horas (Lubliner \& Smetana, 2005).

- Cuatro palabras después de 30 horas (Snow et al., 2009).

Existen muy pocos estudios que tengan como objetivo mejorar el vocabulario de los niños en edad escolar con TDL. Los pocos estudios que hemos encontrado son solo para niños de Primaria y muestran que la intervención logopédica en semántica es efectiva. Todos los estudios tienen en común la repetición continua de las palabras a intervenir. Algunos de estos estudios, al trabajar enseñando palabras, también mejoraban la conciencia morfológica u otras áreas (Good et al., 2015).

En relación con las palabras que enseñan a los niños, podemos observar que Mendoza (2016) recomienda seleccionar el siguiente léxico básico para intervenir con los niños con TDL: palabras concretas que nombren objetos o acciones específicas; nombres de objetos y personas familiares; nombres de animales y mascotas; verbos; adjetivos para describir objetos y personas; palabras relevantes cultural y socialmente; en cambio Wright et al. (2017) utilizan un listado existente de las palabras que más veces se utilizan en las personas de habla inglesa, al igual que vamos a realizar nosotros en esta tesis doctoral.

\subsubsection{Intervención en la dimensión sintáctica}

Existen multitud de estudios que muestran diferentes enfoques para el tratamiento de los niños con RL o TDL con dificultades en su sintaxis, y todos ellos ponen de manifiesto la dificultad de los niños con trastorno del lenguaje en su expresión oral, ya que realizan frases más cortas y simples (Zwitserlood et al., 2015). Crespo-Allende et al. (2020) afirman que los niños con TDL tienen un mayor número de errores en su sintaxis, pero que su perfil de adquisición es similar al de los niños con desarrollo típico del lenguaje y que la mayoría de las desviaciones y de las dificultades en la sintaxis no son exclusivas del grupo TDL, sino más 
abundantes. Estos errores son muy variados, algunas investigaciones como la de Sanz-Torrent et al. (2011) señalan la dificultad en el uso de los complementos del verbo, como pueden ser los complementos directos o indirectos, cuando en algunas ocasiones su utilización es obligatoria, y se observa que estos niños suelen omitir estos complementos; además, el estudio de Aguilar-Mediavilla et al. (2007) afirma que los niños con TDL tienen dificultades y suelen omitir palabras función, estas palabras función son preposiciones y conjunciones entre otras. Además, Norbury \& Bishop (2003) afirman que los niños de habla inglesa con TDL muestran un retraso en la semántica y muestran dificultades en la longitud media de la frase. En relación a esta longitud media de la frase, Andreu-Barrachina et al. (2014) lo incluyen dentro del patrón de dificultades de los niños con TDL según su edad de la siguiente manera: los niños de tres-cuatro años tienen una menor longitud mediana del enunciado por palabras, situándose en menos de una palabra de media; en los niños de cuatro años esta longitud se encuentra en una o dos palabras de media; mientras que los niños de cuatro-cinco años con TDL dicen aproximadamente tres palabras de media; y, por último, los niños de cinco-seis años dicen aproximadamente cuatro-cinco palabras de media.

Para profundizar en el estudio de la sintaxis se pueden realizar diferentes actividades como pueden ser: narraciones guiadas por un estímulo, utilizar una secuencia de imágenes, realizar una entrevista con adultos o una toma de producción libre (Slama-Cazacu, 1981; Jisa \& Kern, 1998; citados en Silva, 2010). Según Demuth (1996), realizar estadísticos con una muestra de producción libre es difícil y problemático, ya que es complicado contar con un volumen considerable de habla infantil y realizar un análisis estadístico adecuado. Son incalculables las diferentes categorías que se pueden evaluar dentro de la sintaxis de los niños con RL y TDL. En el artículo de Crespo-Allende et al. (2020), utilizaron un corpus de habla de toma de producción libre, por lo que pudieron comprobar seis categorías de desviaciones en los niños con TDL y lo compararon con niños con desarrollo normotípico del lenguaje; estas categorías fueron la discordancia gramatical, la elisión, la sustitución, el hipérbaton, la hiperregulación verbal e incorporación. Todas ellas se pueden observar al tener un corpus de lenguaje amplio. En cambio, en otros estudios como el de Domínguez y Martínez (2015) se utilizan diferentes categorías como son la oración (unidades que contengan sujeto y predicado), la no-oración (pueden ser sujetos separados, predicados separados, objetos o complementos sin verbo), y la 
formulación (falsos arranques, marcadores no incluidos en el segmento y que aparecen solos).

La intervención en la sintaxis incluye como objetivo principal, en la gran mayor parte de ocasiones, ampliar la gramática de los niños con trastorno del lenguaje (Ramírez-Santana et al. 2018). Ebbels (2014) y Mendoza (2016) señalan diferentes maneras para mejorar la gramática de los niños con TDL: aproximación, modelado, estimulación focalizada y recast, todos ellos explicados en el apartado 2.5.2.

Proctor-Williams (2014); Swanson et al. (2005) añaden a las anteriores el empleo combinado de formas, colores y líneas para señalar distintas partes de la morfología y de la sintaxis, con el propósito de conseguir objetivos gramaticales. Algunos estudios como el de Sanhueza et al. (2021) explican que para comprender elementos gramaticales como puede ser el presente y el pasado, pueden utilizarse ejercicios motores, es decir mover el brazo hacia atrás cuando hablen en pasado y el brazo hacia delante cuando hablen de futuro, viéndose este tipo de ejercicios como beneficiosos para los niños con TDL (Eikmeier et al., 2015; Moretti \& Greco, 2018).

\subsection{Etapa de Educación Infantil en el Sistema Educativo Español}

Los niños que forman parte de esta tesis doctoral se encuentran en edades comprendidas entre tres y cinco años, pertenecen a la Etapa de Educación Infantil que está organizada en dos ciclos: primer ciclo de cero a tres años y, segundo ciclo de tres a seis años. La Etapa Infantil comprende desde los cero hasta los seis años, por lo que las escuelas infantiles se convierten en el lugar perfecto para realizar una tarea de prevención y detección para el trastorno del lenguaje.

La Ley Educativa Española ha ido cambiando sobre todo en los últimos años, desde la Ley General de Educación (LGE - Ley 14/1970), que se promulga en el año 1970 y tiene una vigencia de 20 años, hasta la Ley actual que es la Ley Órgánica 3/2020, de 23 de diciembre, por la que se modifica la Ley Orgánica 2/2006, de 3 de mayo, de Educación (LOMLOE).

La LGE incorpora el nivel educativo denominado Educación Preescolar que atiende a los niños de dos a los cinco años. Esto es toda una novedad, ya que, hasta ese momento, en la Ley de Educación Primaria de 1945, no había un nivel establecido como tal, sino que estaba incluido en la 
enseñanza primaria como un periodo de iniciación. En esta ley también podemos ver cómo organiza la educación especial como un sistema paralelo al ordinario, especializando los colegios, y dirigiendo a los niños con dificultades a centros o a unidades de educación especial fuera de los centros ordinarios.

En 1975, se crea el Instituto Nacional de Educación Especial, que depende del Ministerio de Educación y que se encarga de velar por el funcionamiento y ordenación de la educación de los alumnos con discapacidad, lo que hace que aumenten los centros de educación especial. En 1978 se publica un Plan Nacional de Educación Especial que inspira las próximas etapas educativas, en este plan se organizan los principios básicos que sustentaban el Plan Nacional que son: la integración escolar, la normalización de servicios, la sectorización y la atención multiprofesional e individualización de la enseñanza. La integración sucede cuando "los sujetos que presentan algún tipo de necesidad peculiar son ubicados en centros y en aulas en los que conviven con alumnos que requieren atención educativa ordinaria" (Palacios y Fernández, 2009, p. 44).

Se empieza a hablar de integración a raíz del Informe Warnock (1981), donde se plantea el principio de integración en el ámbito escolar, sin perder de vista las necesidades especiales que presentan los alumnos, pero teniendo en cuenta su derecho a ser atendidos en centros ordinarios (Montero, 1991). El principio de integración propugna que todos los niños tienen derecho a acudir a una escuela ordinaria, teniendo en cuenta su edad y situación geográfica y recibir la mejor respuesta educativa que se les pueda dar según sus necesidades (Cerdá-Marín y Iyanga-Pendi, 2017).

Como comprobamos, la integración es un mecanismo mediante el cual se incorporan alumnos al aula ordinaria, pero en los últimos años ha surgido el término "inclusión" como concepto que se aproxima más a lo que se desea conseguir en educación y que se explicará más detenidamente en el siguiente subapartado.

En 1982 se crea la Ley de Integración Social del Minusválido (LISMI, Ley 13/1982) que se centra, entre otros asuntos, en la educación de las personas con discapacidad y propone integrar a las personas con discapacidad dentro del sistema educativo ordinario.

Tres años después entró en vigor el Real Decreto 334 de Ordenación de la Educación Especial, que desarrolló lo que expuso la LISMI, diseñando medidas concretas para llevar a cabo un programa de integración escolar 
de los niños con discapacidad dentro del sistema educativo general. Por primera vez en España aparece definida la educación especial dentro de un texto legal.

Finalizados esos veinte años de vigencia de la LGE, entró en vigor la Ley de Ordenación General del Sistema Educativo (LOGSE) en el año 1990. La LOGSE sustituye la educación preescolar por la Educación Infantil que comprende a los niños de cero a seis años, y los divide en dos ciclos. Esta misma ley también incluye por primera vez el concepto de alumno con necesidades educativas especiales (ACNEE), ya que en el Artículo 3 , podemos encontrar que "Las enseñanzas recogidas en los apartados anteriores se adecuarán a las características de los alumnos con necesidades especiales" (p.28930). En el Real Decreto 696/1995 de Ordenación de la Educación de los Alumnos Con Necesidades Educativas Especiales, se explican los diferentes tipos de ACNEE, teniendo en cuenta: la modalidad de intervención psicopedagógica, si tienen necesidades temporales y permanentes, su contexto social y cultural, la historia educativa y escolar o las condiciones personas de sobredotación, discapacidad psíquica, motora o sensorial o trastornos graves de conducta.

En el año 2002, aparece la Ley Orgánica de Calidad Educativa (LOCE), en ella encontramos la diferenciación por edades de esta etapa, los niños de cero a tres años se encuentran en la educación preescolar y los niños de tres a seis años en la educación infantil, esta ley no se llegó a aplicar dado que estuvo en vigor muy poco tiempo.

En el año 2006, aparece la Ley Orgánica de Educación (LOE), y se recupera el concepto de Educación Infantil de la LOGSE en el que se la considera una etapa, pero la divide en dos ciclos. En el preámbulo de esta ley se categoriza al anteriormente denominado alumnado con necesidades educativas especiales, como alumnado con necesidades específicas de apoyo educativo, incluye dentro de este alumnado a las personas con discapacidad y, como novedad, al alumnado que se incorpora tardíamente, que muestra dificultades específicas educativas, altas capacidad y también los que necesitan apoyos por circunstancias sociales. Esta ley apuesta por la inclusión de todo el alumnado. El paradigma de la inclusión educativa es relativamente nuevo, la UNESCO (2004) la reconoció como el soporte fundamental que asegure la igualdad de oportunidades para las personas con necesidades específicas, no solo en el ámbito educativo sino también en el laboral y social. La UNESCO (2008) la define como: 
Un proceso de abordaje y respuesta a la diversidad de las necesidades de todos los alumnos a través de la creciente participación en el aprendizaje, las culturas y las comunidades, y de la reducción de la exclusión dentro y desde la educación (p.11).

La inclusión es un proceso de reestructuración escolar que promueve la presencia, la participación, la respuesta ante las necesidades y el rendimiento de todos los estudiantes, incluso los que están en situación de exclusión, ya que la razón de su existencia es este alumnado. Todos deben de aprender a vivir con la diferencia y a mejorar gracias a las diferencias de cada alumno mediante una mayor participación en el aprendizaje, las culturas y las comunidades. Este concepto suele asociarse a alumnos con discapacidad o con necesidades educativas especiales y a personas que viven en contextos de pobreza (Blanco, 2014; Echeita, 2008; Moriña, 2011 y Parrilla, 2001).

Pero, ahora bien, ¿cuál es la diferencia entre inclusión e integración?, la respuesta ante esta pregunta la podemos observar en Palacios y Fernández (2009):

Entendemos que la integración, tal como la hemos definido anteriormente, alude más específicamente a los supuestos pedagógicos, mientras que la inclusión tendría que ver más con otros aspectos que guardan relación con la disponibilidad y adecuación de medios materiales y con la planificación de componentes organizativos que conducirían a la inmersión total (no solamente educativa) de los sujetos con necesidades especiales (p. 48).

En España, la ley que estaba vigente en el momento de la fase de recogida de datos de esta tesis doctoral (cursos 2017-2018; 2018-2019 y 20192020) es la Ley Orgánica 8/2013, de 9 de diciembre, para la mejora de la calidad educativa (LOMCE), es la ley que se encarga de administrar y adoptar las medidas necesarias para identificar y evaluar las necesidades de los estudiantes con el objetivo de intervenir lo antes posible. Esta ley no sustituyó, sino que modificó el texto de la Ley Orgánica 2/2006, de 3 de mayo, de Educación (LOE). Esta ley como todas las anteriores, que ya hemos explicado, considera la Educación Infantil como voluntaria y no incluye novedades en relación con la inclusión.

Pero, actualmente contamos con otra ley, la Ley Orgánica 3/2020, de 29 de diciembre, por la que se modifica la Ley Orgánica 2/2006, de 3 de mayo, de Educación (LOMLOE), y que incluye una serie de modificaciones en los objetivos y principios de la Etapa de Educación Infantil, como son la inclusión de tres principios pedagógicos: la gestión emocional y la educación para el consumo responsable y sostenible; 
además de la promoción y educación para la salud. Además, se incluye como objetivo la promoción de la igualdad de género y la compensación de los efectos de las desigualdades (ya sean de origen cultural, social y/o económico). También incluye cambios en la evaluación y orientación, como es la detección precoz y la atención temprana de las necesidades de apoyo educativo de manera prioritaria, donde se podría incluir a los hablantes tardíos y a los niños con TDL, y además se insta a los centros educativos a que cuando el alumno finaliza la etapa se emita un informe sobre su desarrollo y sus necesidades.

A nivel autonómico en Castilla y León, contamos con dos Decretos:

- El Decreto 12/2008, por el que se determinan los contenidos educativos del primer ciclo de la Educación Infantil en la comunidad de Castilla y León y se establecen los requisitos que deben reunir los centros que impartan dicho ciclo.

- El Decreto 122/2007, de 27 de diciembre, por el que se establece el Currículo del Segundo Ciclo de la Educación Infantil en la Comunidad de Castilla y León.

En el Artículo 4 de ambos decretos, encontramos dos objetivos generales de esta etapa, relacionados con las dificultades que presentan estos niños:

e) Relacionarse con los demás y adquirir progresivamente pautas elementales de convivencia y relación social, con especial atención a la igualdad entre niñas y niños, así como ejercitarse en la resolución pacífica de conflictos (Decreto 12/2008, p.3022; Decreto 122/2007, p.7).

f) Desarrollar habilidades comunicativas en diferentes lenguajes y formas de expresión (Decreto 12/2008, p.3022; Decreto 122/2007, p.7).

Lo que significa que es de vital importancia que los niños tengan un nivel de lenguaje suficiente para poder desarrollar estos dos objetivos. La relación con los demás está basada en el lenguaje y en la comunicación con los iguales, y las habilidades comunicativas dependen de una buena destreza y desarrollo del lenguaje oral.

Asimismo, la Etapa de Educación Infantil está compuesta según la Orden $\mathrm{ECI} / 3960 / 2007$, de 19 de diciembre, por la que se establece el currículo y se regula la ordenación de la educación infantil, por tres áreas de conocimiento: área de conocimiento de sí mismo y autonomía personal; área de conocimiento del entorno; y la tercera y la última área, que es la 
que más nos interesa, es el área del lenguaje: comunicación y representación.

Esta área está dividida en bloques, siendo muy interesante para esta tesis mencionar el Bloque 1, que corresponde al Lenguaje verbal: Escuchar, hablar y conversar; aproximación a la lengua escrita; acercamiento a la literatura.

En el Anexo II de la Orden ECI/3960/2007 encontramos las orientaciones metodológicas y para la evaluación, donde se menciona la atención a la diversidad y se hace hincapié en la necesidad de dar una adecuada respuesta a las diferentes motivaciones, necesidades, intereses y estilo cognitivo de cada niño. Además, se tiene en cuenta la individualización, la flexibilidad y el respeto a estas diferencias. En el Anexo II de la Orden ECI/3960/2007 viene descrito lo siguiente:

Especial atención merecen aquellos niños y niñas que presentan necesidades educativas especiales, que deberían identificarse y valorarse lo más pronto posible. Es especialmente importante la detección y atención temprana de sus necesidades por ello, maestros y educadores se coordinarán con otros profesionales, además de favorecer un ambiente, especialmente afectivo y estimulante. Se deberán utilizar con ellos los recursos más adecuados para favorecer su desarrollo, siempre prestando más atención a los procesos que a los resultados que obtengan. (p.28)

Lo que significa que, como recurso, pueden utilizar un maestro de audición y lenguaje para intervenir con los niños con trastorno del lenguaje, y trabajar con ellos, ya que es necesario identificar a estos niños y trabajar con ellos de manera temprana.

En la Orden EDU/1152/2010, de 3 de agosto, por la que se regula la respuesta educativa al alumnado con necesidad específica de apoyo educativo al alumnado con necesidades específicas de apoyo educativo escolarizado en el segundo ciclo de Educación Infantil, Educación Primaria, Educación Secundaria Obligatoria, Bachillerato y Enseñanzas de Educación Especial, en los centros docentes de la Comunidad de Castilla y León, se menciona el Plan de Atención a la Diversidad. El concepto de atención a la diversidad está muy ligado al alumnado con necesidades específicas de apoyo educativo, del que ya hemos hablado en los párrafos anteriores. Teniendo en cuenta a RuizQuiroga (2010) podemos determinar que:

La atención a la diversidad es un concepto amplio que incluye las dificultades de aprendizaje, discapacidades físicas, psíquicas y sensoriales, los grupos de riesgo, las minorías étnicas, etc. El concepto 
de diversidad nos plantea que todos los alumnos tienen unas necesidades educativas individuales propias y específicas para poder acceder a las experiencias de aprendizaje necesarias para su socialización, establecidas en el currículo escolar (p.2).

En el capítulo II del Plan de Atención a la Diversidad en su Artículo 9, se recogen todas las actuaciones y medidas educativas y organizativas para atender a los niños con dificultades en los centros educativos, tiene que ser coordinado y elaborado por diferentes profesionales:

Será responsabilidad del equipo directivo de cada centro docente la elaboración, coordinación y dinamización del Plan de Atención a la Diversidad, con la participación de todo el profesorado y el asesoramiento del orientador que atiende al centro. Asimismo, el Plan de Atención a la Diversidad será informado por el claustro de profesores y aprobado por el consejo escolar del centro. (p. 64457)

Lo que significa que en caso de que haya un niño con trastorno del lenguaje en el centro, será responsabilidad del equipo directivo la elaboración, coordinación y la puesta en práctica del Plan de Atención a la Diversidad. Por tanto, tendrán que atender a las necesidades que el niño presente.

En el capítulo III de esta Orden, podemos leer sobre la necesidad de realizar una evaluación psicopedagógica para conocer las necesidades de apoyo educativo que pueda mostrar. Para poderlo llevar a cabo realizarán procedimientos como son las pruebas psicopedagógicas estandarizadas, la observación sistemática, seguimiento de protocolos para medir la competencia curricular, cuestionarios, entrevistas y la corrección de los trabajos realizados en el colegio. Lo que significa que, cuando haya un niño con trastorno del lenguaje en las aulas de un colegio, será muy necesaria la evaluación. Lo importante es dar respuesta a estos niños, aunque ya estén diagnosticados o se les tenga que aplicar pruebas psicopedagógicas o realizar estos protocolos.

El capítulo IV se centra en que el alumnado con necesidades educativas especiales acudirá a centros ordinarios, a no ser que las necesidades educativas sean graves y permanentes y requieran adaptaciones significativas en la mayor parte de las áreas del currículo, y necesiten de recursos humanos y materiales específicos, no pudiendo ser atendidos en centros ordinarios. Lo que significa que los niños con trastorno del lenguaje acudirán a centros ordinarios, que han de ser tratados en estos centros, y que para ello se han de dotar de profesionales que puedan atender sus necesidades, tratando e interviniendo en su lenguaje, empleando métodos con fundamentación científica. 
En el capítulo V encontramos estos profesionales, son los recursos humanos que ponen a disposición del sistema educativo para atender al alumnado con necesidades en Castilla y León. El equipo está formado por el orientador, el profesor técnico de servicios a la comunidad, el maestro de pedagogía terapéutica y el maestro de audición y lenguaje del que posteriormente hablaremos.

Estos alumnos cuentan con unas ayudas que se regulan cada curso escolar, como se puede observar en el Extracto de la Resolución de 31 de julio de 2020, de la secretaría de Estado de Educación, por la que se convocan ayudas para alumnos con necesidad específica de apoyo educativo para el curso académico 2020-2021, y que se renueva cada año, los beneficiarios de estas ayudas son:

Podrán solicitar las ayudas los alumnos que no superen una determinada renta y/o patrimonio familiar y que presenten necesidad específica de apoyo educativo derivada de discapacidad o trastornos graves de conducta y que se encuentren cursando en centro específico, en unidad de educación especial de centro ordinario o en centro ordinario que escolarice alumnos que presentan necesidades educativas especiales, alguno de los niveles educativos no universitarios. (p.34414)

Lo que significa que estos niños podrán acudir a consultas privadas, pudiendo financiar estas consultas de logopedia con esta prestación.

Es muy importante entender que los participantes de esta tesis están inmersos en un contexto educativo que tiene que ofrecerles una respuesta a sus necesidades especiales y a sus dificultades, y que estos serán atendidos en este contexto por diferentes profesionales. A continuación, procedemos a detallar el perfil profesional del maestro de audición y lenguaje, como encargado de intervenir el lenguaje del niño en el contexto escolar, con quien el logopeda tiene que tener necesariamente un estrecho contacto, por lo que consideramos conveniente explicar sus funciones con esta población.

\subsubsection{Integrantes de la comunidad educativa: el maestro de audición y lenguaje}

La administración educativa debe guiar en los principios de normalización, inclusión y no discriminación. Las escuelas deben contar con profesores especializados y recursos para el alumnado con necesidades educativas especiales (Law et al., 2019), como ya hemos podido observar es lo que dictan las leyes educativas desde la LOGSE. 
Todos los integrantes de la comunidad educativa han de sentirse responsables de la atención a la diversidad (Fernández, 2009). Las familias y el tutor son los primeros en darse cuenta de las dificultades del alumnado, una vez que ellos detectan las dificultades, los Equipos de Orientación Educativa y Psicopedagógica (EOEPs) y los Equipos de Atención Temprana (EAT), diagnostican la dificultad.

A continuación, vamos a definir ambos equipos:

- Los EOEPs, en Castilla y León, responden a la Orden de 9 de diciembre de 1992, por la que se regulan la estructura y funciones de los Equipos de Orientación Educativa y Psicopedagógica, en ella se dice lo siguiente:

- Los EOEPs son un sector de profesionales relativos a la orientación que trabajan en los niveles de Educación Infantil y Educación Primaria, para lograr un desarrollo personalizado e integral de las capacidades de todos los alumnos.

- Estos EOEPs están compuestos por dos tipos de profesores: los profesores de la especialidad de psicología y pedagogía y de servicios a la comunidad. El número de profesores que componen estos equipos difiere dependiendo de si es una zona rural o urbana.

- Los Equipos de Atención Temprana en Castilla y León, se establecen en la Orden EDU/746/2016, de 19 de agosto, por la que se establecen los equipos de orientación educativa en la comunidad de Castilla y León, así como el ámbito de actuación de los mismos y se delega la competencia para modificar su ámbito de actuación, en esta orden podemos observar que existe un equipo de atención temprana con un código en cada ciudad de Castilla y León.

Después tratan a estos alumnos los encargados de la intervención que son los maestros de Pedagogía Terapéutica (PT) y los maestros de audición y lenguaje, en los que nos centraremos a continuación, porque son los responsables de la intervención directa sobre el lenguaje, en la escuela, en la población de esta tesis.

Según el Real Decreto 1440/1991 del 30 de agosto, por el que se establece el título universitario, oficial de Maestro, en sus diversas especialidades y las directrices generales propias de los planes de estudios conducentes a su obtención; el maestro de audición y lenguaje es el encargado de promover y desarrollar la prevención de los problemas 
del lenguaje, a potenciar las capacidades comunicativo-lingüísticas y a la solución de problemas específicos de lenguaje y comunicación en un centro educativo. Por lo que entre sus funciones pueden variar desde atender a niños con dificultades del lenguaje como son los niños con trastorno del lenguaje, como realizar adaptaciones curriculares, o también son servir de apoyo y orientaciones al resto de maestros y profesionales del centro educativo (Gallardo y Gallardo, 1993). Existen grandes controversias hoy en día con las funciones del logopeda y del maestro de audición y lenguaje, ya que tienen algunos ámbitos de actuación equiparables, pero son profesiones diferentes (CifuentesLardín y Martínez-Ramón, 2018).

El maestro de audición y lenguaje aparece por primera vez en el Real Decreto 334/1985 de 6 de marzo de Ordenación de la Educación Especial, donde se establecen las directrices para la integración de sujetos con discapacidades en los colegios. Para dar la respuesta necesaria a estos niños se incorpora a los profesores de pedagogía terapéutica y de audición y lenguaje.

Actualmente podemos observar cómo el título de maestro de audición y lenguaje habilita a estos profesionales a tratar a los niños con trastorno del lenguaje dentro del marco educativo. Como se puede observar en el Real Decreto 1393/2007 de 29 de octubre, por el que se establece la ordenación de las enseñanzas universitarias oficiales, es un Grado de cuatro años -Grado en Educación Primaria-con mención en audición y lenguaje.

Debemos tener en cuenta que las características de la docencia que realiza el maestro de audición y lenguaje "se apoya en la colaboración y promueve la acción directa en el aula más que la provisión individualizada fuera del aula al margen del proceso de enseñanzaaprendizaje y del currículum" (Fernández y Ganzaráin, 2004; p.55), y al incorporar al maestro de audición y lenguaje en el aula ordinaria, se consigue fomentar la inclusión del alumnado con dificultades y trastornos del lenguaje a través de estrategias y procesos colaborativos (Fernández y Ganzaráin, 2004).

En relación con las funciones del maestro de audición y lenguaje, la Conferencia Sindical de Comisiones Obreras (2009), especificó las siguientes:

- Realizar intervenciones directas de apoyo a los alumnos que presenten dificultades y coordinarse con el resto de los profesores de ese mismo alumno. 
- Participar en la elaboración y asesoramiento del currículo escolar que tenga que ver con los aspectos lingüísticos, además de las programaciones de ciclo y las adaptaciones curriculares.

- Asesorar al resto de profesorado en la programación de actividades relacionadas con la prevención y el tratamiento de dificultades en las áreas de comunicación y lenguaje.

- Evaluar y valorar la necesidad de la atención educativa especial de los alumnos con dificultades en la comunicación y el lenguaje.

- Proporcionar información, orientación, material y colaboración a los tutores y otros profesores de apoyo.

- El contacto con sus compañeros tiene que ser continuo, a través de reuniones periódicas para informar y dar pautas tanto a los profesores como a los familiares.

Por lo que vemos, los animan a tener contacto y comunicación con la familia y con los profesores del centro, pero en ningún momento se hacen eco de los profesionales externos de gabinetes como son los logopedas, por lo que no existe obligación por su parte de mantener contacto con estos profesionales.

Una vez descrita la etapa de Educación Infantil y haber descrito el equipo de profesionales que trata a los participantes de nuestro estudio, vamos a explicar el método Glenn Doman que es el pilar fundamental en el que se apoya y da sentido a esta tesis doctoral.

\subsection{Aportaciones de Glenn Doman}

Glenn Doman fue un médico e investigador estadounidense fundador de los Institutos para el Desarrollo del Potencial Humano en Filadelfia (EEUU) es el creador de los bits de inteligencia. El primer objetivo de Doman cuando creó su método hace más de 60 años, fue conseguir que los niños con lesiones cerebrales graves mejoraran de forma global, tanto física como cognitivamente. Con el tiempo, Doman amplió los posibles destinatarios del método añadiendo a niños sanos con el fin fortalecer su desarrollo intelectual y su potencial (Doman y Doman, 1998). En el momento en el que creó el método se consideraba que los niños con lesión cerebral eran incurables ya que sus incapacidades eran consecuencia de la muerte de neuronas. Doman expuso que como las neuronas muertas no podían recuperarse, las vivas tenían que aprender a realizar conexiones entre ellas para asumir funciones que desempeñaban las muertas (Estalayo y Vega, 2001). En este apartado se va a profundizar en el Método Doman, es por ello por lo que vamos a hablar sobre los 
Institutos para el Desarrollo del Potencial Humano, sobre el Programa Glenn Doman, especialmente en los bits de inteligencia, en las críticas al método y en las experiencias existentes con los bits de inteligencia.

\subsubsection{Los Institutos para el Desarrollo del Potencial Humano}

Doman creó Los Institutos para el Desarrollo del Potencial Humano (http://iahp-es.org/), una fundación que se dedicaba al tratamiento de los niños con lesiones cerebrales. Poco a poco halló métodos de acceso neurológico, restablecimiento de la vista, el oído, el tacto, el movimiento, el lenguaje... (Estalayo y Vega, 2007).

Al comprender que el tiempo jugaba en su contra, debido a que la tardanza en la intervención significaba un mayor retraso, se tomó la decisión de capacitar a los padres de los niños para la realización de terapia doméstica, con un programa intensivo elaborado en un periodo de varios meses hasta la consecución de metas precisas en varias áreas neurológicas (Doman y Doman, 1998).

Se crearon métodos especiales de lectura y de matemáticas, además del programa de bits de inteligencia, se consiguieron buenos resultados con estos métodos, y fue entonces cuando Doman fundó un centro de educación para niños de cero a catorce años, eran niños sanos que fracasaban en el ámbito académico. Publicó una serie de libros en 1986, 1998, 2008 y 2009. Hoy en día se continúan ofertando cursos para los padres en las diversas sedes del instituto que tiene por el mundo.

\subsubsection{Programa de Glenn Doman}

El programa de Glenn Doman es muy variado, este método se subdivide en diferentes programas: programa de lectura, musical, matemáticas, lectoescritura, físico y, por último, los bits de inteligencia. Doman defendía el uso simultáneo de estos programas. La aplicación consistía en que, dos veces al año, los padres con el niño asistieran durante una semana completa, al Instituto para el Logro del Potencial Humano, creado por Doman y donde realizó una labor publicitaria y de intervención masiva de su método. Durante ese tiempo, se evaluaba al niño y a sus padres, se les formaba para que continuaran con los programas en casa. Doman consideraba muy importante que los padres se esforzaran y llevaran a cabo todos los ejercicios en casa con su ayuda (Doman y Doman, 1998). 
El programa de desarrollo del lenguaje que detalla Doman conlleva una serie de principios básicos de la buena enseñanza que no se deben de olvidar en ningún momento. Doman y Doman (1998) sugiere realizar una estimulación temprana, empezar cuando el niño sea lo más pequeño posible, mostrar alegría constante, respetar a los niños teniendo total confianza en ellos, llevar a cabo el programa únicamente cuando los padres y los niños estén contentos, preparar un entorno favorable para el aprendizaje, detener la actividad antes de que el niño desee dejarla, presentar frecuentemente bits nuevos siendo organizados y constantes, no evaluar ni examinar al niño y, tener la precaución de preparar antes de cada sesión el material (Doman y Doman, 1998).

Como podemos ver, el Programa de Glenn Doman, incluye muchos apartados, pero nosotros nos vamos a centrar exclusivamente en el Programa de los bits de Inteligencia, ya que es el punto de partida de nuestra tesis doctoral.

\subsubsection{Programa de los bits de inteligencia}

Los bits de inteligencia son unidades o tarjetas que se basan en la visualización y repetición de la palabra de la imagen que aparece en las láminas en un breve periodo de tiempo. Doman et al. (2012) definen este término como "un bit de información, que se fabrica utilizando un dibujo o una ilustración muy precisa o una fotografía de excelente calidad. Tiene ciertas características muy importantes: debe ser preciso, diferenciado, exacto y nuevo. También tiene que ser grande y claro" ( $\mathrm{p}$. 70). Estos bits se pueden adaptar al formato TIC (Tecnología de la información y la comunicación). Las experiencias con los bits de inteligencia son diversas, como los bits de lectoescritura de Bautista (2010) que adaptó los bits para aprender a leer y a escribir del Método Doman, para poder implementarlo en un curso escolar a través de las nuevas tecnologías.

Doman y Doman (1998) utiliza tres tipos de programas de estimulación a través de bits: bits de palabras, bits de imágenes, y bits de números. Los primeros -bits de palabras-se realizan con una cartulina blanca DIN A3 cortada por la mitad. En la que aparecen las palabras escritas de manera grande y clara, con trazo grueso y de color rojo, sirve para mejorar la capacidad lectora. Los segundos -bits de imágenes- son cartulinas en las que aparece la imagen de la representación de la palabra que se busca, y los últimos -bits de números-son 100 cartulinas blancas 
de 30x30 (DIN A3), en las que se pegan gomets rojos de 2cm de diámetro donde se peguen tantos como números queramos representar.

En esta tesis nos vamos a centrar en los bits de inteligencia de imágenes. Estas láminas, además de mostrar el dibujo, también incluyen la palabra escrita en color rojo, ya que es el color que mejor ven los bebés. Los bits de inteligencia están diseñados para aumentar el conocimiento de los bebés y favorecer su maduración neurológica. Las pautas de procedimiento varían dependiendo de la fase de realización y de la edad de los niños, desde mostrar las imágenes con una frecuencia máxima de diez veces al día, bajando la frecuencia según los niños sean más mayores. Los bits se agruparán por categorías, enseñando las láminas de forma rápida, además de decir el nombre de lo que representa en voz alta (Doman y Doman, 1998). Podemos encontrar un ejemplo de cómo es este material comercializado en las Figuras 2.1 y 2.2.

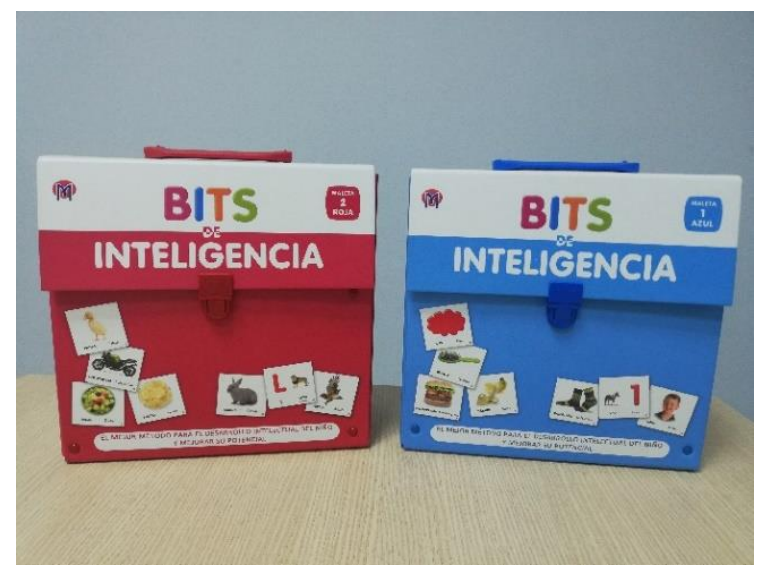

Figura 2.1. Bits de inteligencia comercializados. Extraído del material comercializado: "bits de inteligencia 2: maleta roja" de Juan Ramón Feijoo López. 


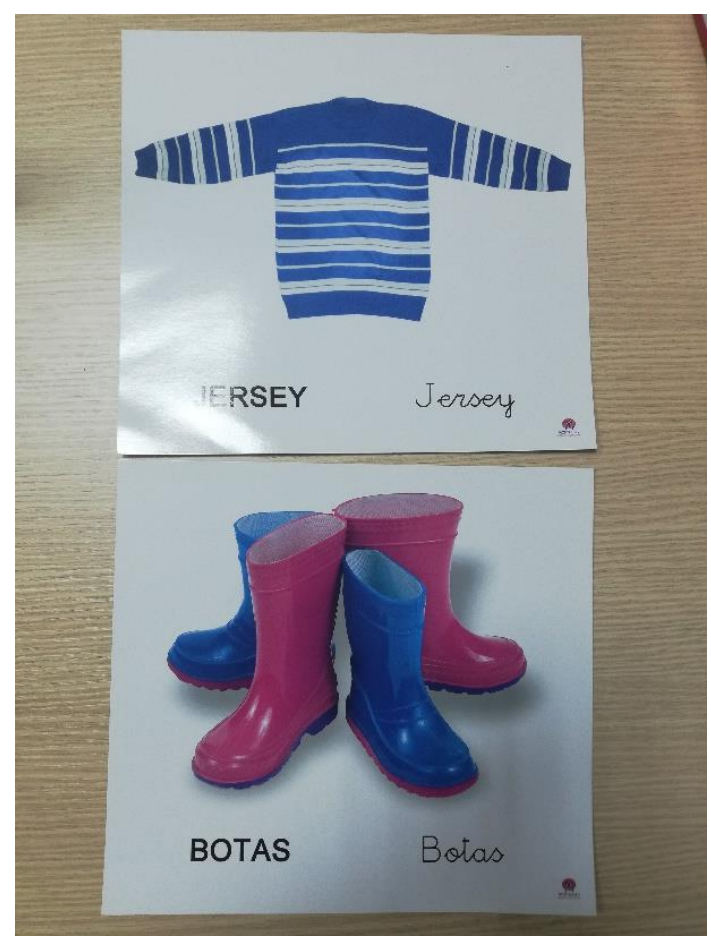

Figura 2.2. Ejemplo de bits de inteligencia. Extraído del material comercializado: "bits de inteligencia 2: maleta roja" de Juan Ramón Feijoo López.

El método de utilización de los bits consiste en ir presentando las láminas, y que una voz, vaya nombrando cada lámina. Las láminas pueden ser de una o varias categorías, dependiendo del momento de rehabilitación en el que nos encontremos. Las categorías pueden ser muy diferentes, animales marinos, terrestres, vegetales, bebidas, prendas de vestir...; según Doman y Doman (2012) estas categorías son "un grupo de diez o más tarjetas de bits de inteligencia que están directamente relacionadas entre sí" (p.73).

Doman (2000) se basa en estos bits pues, como ya hizo constar, los niños aprenden a través de una combinación de vista (V), oído (A) y tacto (T). Según Quinteros (2017), la metodología de los bits se puede resumir en tres palabras: rápido, novedoso y motivador. Para que sea eficaz, se debe mostrar un bit cada segundo para evitar la distracción de los niños y decir el nombre correspondiente con entusiasmo. Esto último se ha adaptado añadiendo voz a nuestros bits de inteligencia a través de las nuevas tecnologías. 
Según Estalayo y Vega (2001), los bits deben de presentarse de manera rápida. Además, el periodo en el que presentemos cada categoría será corto, de unos cinco días de duración. Por este motivo, como explicaremos posteriormente, es fundamental que exista una adherencia terapéutica grande para poder llevarlo a cabo en nuestras sesiones de logopedia, en la que la frecuencia en la que los pacientes acuden a la consulta no suele superar las dos sesiones semanales.

\subsubsection{Críticas al método}

Es un método que no está exento de controversia, ya que en varias publicaciones ha sido desacreditado por la comunidad científica, alegando que carece de evidencias y fundamentos empíricos (p.e. American Academy of Neurology, 1967; American Academy of Pediatrics, 1965, 1968 y 1982; American Academy for Cerebral Palsy, 1965; Canadian Association for Retarded Children, 1965; American Academy of Physical Medicine and Rehabilitation, 1968).

Además de la falta de evidencia científica, también critican que difieren sustancialmente de otros grupos que tratan problemas de desarrollo en (American Academy of pediatrics, 1982):

- La naturaleza excesiva de sus reclamos de curación pobremente documentados.

- Las principales demandas de los padres para que realicen de manera inquebrantable una técnica no probada hasta el más pequeño detalle.

Debemos tener en cuenta que la mejora observada en pacientes que se someten a este método de tratamiento puede explicarse por el crecimiento y el desarrollo de los niños, la práctica intensiva de algunas habilidades aisladas o los efectos de la estimulación intensiva (American Academy of pediatrics, 1982).

Además de la falta de evidencia científica, también encontramos otras razones por las que el uso del método preocupa a diferentes sectores científicos como, por ejemplo, la idoneidad de la función rehabilitadora que ejercen los propios padres, debido a que el método exige demasiado a la familia y se pueden descuidar otras necesidades familiares; también preocupa que aumente la ansiedad de unos padres agobiados y confundidos (American Academy for Cerebral Pals et al., 1968). 
Después de estas desacreditaciones, en 1974 y 2005 Doman escribió dos publicaciones sobre la efectividad del método en niños con multitud de problemas del neurodesarrollo, como son la parálisis cerebral, epilepsia, espina bífida, déficits sensoriales, diversidad funcional intelectual, autismo y problemas de deglución. El Instituto para el Logro del Potencia Humano, (https://www.iahp.org) en la actualidad sigue impartiendo cursos y tratando a familias y a niños con problemas, además de continuar publicando artículos que avalan la eficacia del método.

\subsubsection{Experiencias con los bits de inteligencia}

Existen pocas experiencias con los bits de inteligencia en el lenguaje, podemos encontrar la investigación de Von et al. (2013) que dictamina que, empleando los bits de inteligencia, encuentra ciertas mejoras en población con parálisis cerebral, síndromes genéticos, retraso del desarrollo, daño cerebral adquirido y niños con epilepsia, obteniendo una ganancia media en la comprensión del lenguaje de ocho meses, tras dos años de tratamiento.

En otros contextos, como en el educativo, se sigue llevando a cabo en muchas escuelas infantiles de España y de otros países, con el objetivo de que los niños realicen los hitos de desarrollo antes de lo esperado (leer, hablar...), aunque esta no fue la idea principal con la que se creó el método. Al realizar una búsqueda en Google en el que se utilicen como términos de búsqueda: método Doman escuela infantil España, encontramos 50900 resultados, y en los resultados de la primera página vemos varios colegios que lo utilizan: el Colegio Diocesano Milagrosa (Castellón), el Colegio Europeo DAOS (Las Palmas), la Escuela Infantil Municipal Zorita (Requena) entre otras. Si realizamos una búsqueda en Palencia, al ser una de las ciudades donde se ha llevado el estudio encontramos que tres escuelas infantiles lo utilizan: Escuela Infantil Campos Góticos, Escuela Infantil Villandrando, y un colegio de educación infantil: Colegio Santo Ángel.

También, en el ámbito de la rehabilitación clínica, los logopedas lo utilizan en sus sesiones de rehabilitación, siendo incluso comercializado en varias páginas de venta de material logopédico ${ }^{3}$, como el que se puede

\footnotetext{
3 Bits de inteligencia 1: maleta azul (https://www.amazon.es/Bits-inteligencia-1$\underline{\text { maleta- }}$

azul/dp/8493671843/ref=sr 1 9?keywords=bits+de+inteligencia\&qid=1584536646\& $\underline{\mathrm{sr}=8-9})$
} 
observar en la anterior Figura 2.1. En este caso, el uso es diferente puesto que este método se suele adaptar a las necesidades de cada niño, vetando a la familia el protagonismo y la responsabilidad, ya que, aunque el enfoque sea naturalista o de intervención temprana centrada en la familia, la responsabilidad final no recae totalmente sobre la familia. Esta adaptación se realiza bajo el criterio del propio logopeda, debido a que no se encuentra literatura sobre este tema. Este vacío lo observamos cuando se realiza una búsqueda exhaustiva en dos buscadores Scopus y Web Of Science (WOS).

En Scopus, cuando aplicamos las palabras clave Doman Method encontramos únicamente 5 resultados (1984, 2011, 2012 y 2018), estos cinco artículos se centran sobre todo en patrones motores y no tanto del lenguaje. En caso de añadir la palabra Language a los resultados anteriores, no obtenemos resultados.

Realizando la misma búsqueda en otro buscador, WOS, al añadir Doman method encontramos 61 resultados. Con el objetivo de delimitar los resultados, eliminamos los enmarcados dentro del área Science Technology -ya que muchos de los resultados encontrados eran sobre tecnología y totalmente ajenos a esta investigación-, la criba produce 21 resultados desde 1968 a 2015, no siendo ningún resultado de origen español. Los resultados, al igual que ocurría en Scopus, aunque tratan del método Doman, no se centran en el lenguaje, por lo que volvemos a filtrar la búsqueda con la palabra language y, finalmente, encontramos un único artículo (Von et al, 2013), en el que sí que se realiza una breve evaluación del lenguaje.

En caso de realizar la misma búsqueda con las palabras clave en español, el resultado en las dos páginas web, utilizando Método Doman, se reduce a un único resultado en Scopus, que es un artículo de fisioterapia y, en WOS, otro artículo que tampoco tiene relación directa con el Método Doman y el lenguaje.

Bits de inteligencia 2: maleta roja https://www.amazon.es/Bits-inteligencia-2-maletaroja/dp/8493671851/ref=sr 1 4?keywords=bits+de+inteligencia\&qid=1584536646\& $\underline{s r=8-4}$

Bits de inteligencia: Frutas y vegetales https://www.amazon.es/Bits-InteligenciaFrutas-Vegetales-partir-

ebook/dp/B07LCSBHWF/ref=sr 1 12?keywords=bits+de+inteligencia\&qid=1584536 $\underline{646 \& s r=8-12}$ 
Todos estos datos nos llevan a confirmar que no existe suficiente información en la literatura científica sobre el Método Doman en relación con el lenguaje. 



\section{Capítulo 3 \\ Marco metodológico de investigación}

El propósito de este capítulo está centrado en describir los planteamientos teórico-metodológicos que hemos elegido para esta investigación. En esta investigación se van a utilizar dos diseños de investigación; en el Estudio Piloto (EP) se utiliza un estudio cuasi experimental (Campbell \& Stanley, 2005) y, en el segundo estudio, el Estudio de Caso (EC) (Yin, 2009; Stake, 1995; Simons, 2011). En este capítulo se describe el diseño cuasi experimental, las características, los tipos y la validez interna y externa. También se describe el EC, sus características y los criterios y fases para un correcto desarrollo de este, así como también explicamos su tipología (Stake, 2005; Merriam, 1998); en especial, nos centramos en el Estudio de Caso Evaluativo (ECE), que es clave en el diseño de investigación y en los criterios de rigor y credibilidad en los estudios de caso. Asimismo, se hace alusión a las técnicas e instrumentos de obtención de datos y a la metodología de recolección y análisis de datos; $\mathrm{y}$, por último, las cuestiones éticometodológicas de la investigación.

\subsection{Los paradigmas en la investigación científica}

La definición de investigación es la de un conjunto de procesos sistemáticos, críticos y experimentales que se realizan en el estudio de una cuestión (Torres, 2019). La investigación es un proceso de búsqueda sistemático de algo nuevo, se realizan actividades intencionales y repetitivas que llevan al descubrimiento y a la intervención de algo novedoso (Domínguez-Montes, 2016). En este apartado se van a describir los diferentes paradigmas de investigación en la investigación educativa son el positivista, el interpretativo y el sociocrítico (GilÁlvarez et al., 2017), por lo que nos centraremos en estos tres, en el estudio de Pons-Bonals y Espinosa-Torres (2020) explican las diferencias entre la relación del investigador e investigado en las 
tradiciones de la investigación educativa, en diferentes tipos de paradigmas (Tabla 3.1).

Tabla 3.1.

Relación investigador e investigado en los diferentes paradigmas de investigación educativo, según diferentes autores.

\begin{tabular}{|c|c|c|c|c|}
\hline & $\begin{array}{l}\text { Koetting } \\
(1984)\end{array}$ & $\begin{array}{l}\text { Latorre et al. } \\
\text { (1986) }\end{array}$ & $\begin{array}{l}\text { Lincoln y Guba } \\
\text { (2000) }\end{array}$ & $\begin{array}{l}\text { Denzin y } \\
\text { Lincoln } \\
(2012)\end{array}$ \\
\hline Positivista & $\begin{array}{l}\text { Relación } \\
\text { independiente } \\
\text { entre } \\
\text { investigador e } \\
\text { investigado }\end{array}$ & $\begin{array}{l}\text { Independenc } \\
\text { ia, } \\
\text { neutralidad, } \\
\text { el } \\
\text { investigador } \\
\text { es externo y } \\
\text { el sujeto se le } \\
\text { trata como } \\
\text { objeto de } \\
\text { investigació } \\
\text { n }\end{array}$ & $\begin{array}{l}\text { Dualista, } \\
\text { objetivista }\end{array}$ & $\begin{array}{l}\text { Científico } \\
\text { desinteresad } \\
\text { o en estable } \\
\text { relación } \\
\text { cercana con } \\
\text { el } \\
\text { investigado. }\end{array}$ \\
\hline $\begin{array}{l}\text { Interpretati } \\
\text { vo }\end{array}$ & $\begin{array}{l}\text { Interrelación } \\
\text { entre } \\
\text { investigador e } \\
\text { investigado (el } \\
\text { investigador } \\
\text { genera } \\
\text { empatía), } \\
\text { relaciones } \\
\text { influidas por } \\
\text { factores } \\
\text { subjetivos }\end{array}$ & $\begin{array}{l}\text { Existe una } \\
\text { relación de } \\
\text { dependencia, } \\
\text { y una } \\
\text { implicación } \\
\text { del } \\
\text { investigador } \\
\text { que } \\
\text { establece } \\
\text { una } \\
\text { interrelación }\end{array}$ & $\begin{array}{l}\text { Interactiva/subjetiv } \\
\text { ista }\end{array}$ & $\begin{array}{l}\text { Participació } \\
\text { n } \\
\text { apasionada } \\
\text { del } \\
\text { investigador } \\
\text { en la } \\
\text { relación que } \\
\text { establece } \\
\text { con el } \\
\text { investigado. }\end{array}$ \\
\hline $\begin{array}{l}\text { Sociocrític } \\
\mathrm{o}\end{array}$ & $\begin{array}{l}\text { Interrelacionad } \\
\text { os, relaciones } \\
\text { influenciadas } \\
\text { por un fuerte } \\
\text { compromiso } \\
\text { para la } \\
\text { liberación } \\
\text { humana (el } \\
\text { investigador } \\
\text { comparte } \\
\text { intereses con } \\
\text { los } \\
\text { investigados). }\end{array}$ & $\begin{array}{l}\text { Relación } \\
\text { influida por } \\
\text { el } \\
\text { compromiso, } \\
\text { el } \\
\text { investigador } \\
\text { es un sujeto } \\
\text { más. }\end{array}$ & $\begin{array}{l}\text { Interactiva/subjetiv } \\
\text { ista }\end{array}$ & $\begin{array}{l}\text { Intelectual } \\
\text { transformad } \\
\text { or. }\end{array}$ \\
\hline
\end{tabular}

Fuente: basado en Sandín (2004) y Denzin y Lincoln (2012) citados en Pons-Bonals y Espinosa-Torres (2020). 
A continuación, explicamos cada uno de los paradigmas:

a) Paradigma positivista o cuantitativo

El paradigma positivista, cuantitativo o racionalista, sugiere su utilización para descubrir las relaciones de causa y describir los elementos teóricos-prácticos que sustentan la propuesta de investigación (Maldonado, 2018). Este paradigma se basa en una concepción del mundo único, objetivo y tangible, que puede ser dividido en partes para realizar una investigación. Existen muchos tipos de investigación que se incluyen dentro de este paradigma: experimentales, cuasi experimental y no experimental (Gil-Álvarez et al., 2017).

b) Paradigma interpretativo

También denominado cualitativo, naturalista, humanista o etnográfico, que se centra en la investigación de las acciones humanas y la vida social, en medio de una realidad dinámica, cambiante, múltiple y holística. Los investigadores cualitativos se inclinan hacia el estudio de características de fenómenos que no se pueden observar directamente (Gil-Álvarez et al., 2017).

\section{c) Paradigma sociocrítico}

El paradigma sociocrítico, surge como una mezcla de las dos anteriores, pero pretende estar entre el primer paradigma y del segundo, quiere estar entre el reduccionismo y el conservadurismo. Este paradigma considera lo teórico y lo práctico como una unidad única (Gil-Álvarez et al., 2017). La realidad social en este paradigma es construida, holística, dinámica, divergente, compartida, inductiva, flexible, transparente, tiene una validez consensuada y convergente (Maldonado, 2018).

\subsection{Estudio cuasi experimental como metodología de investigación}

El estudio cuasi experimental se ha utilizado en el Estudio Piloto (EP). Cuando un científico trata de averiguar si funciona o no un tratamiento, una metodología o un programa, como es nuestro caso, se puede utilizar 
la metodología cuasi experimental (Salkind, 1999). La investigación cuasi experimental nació en el ámbito educativo y psicológico, donde la aleatoriedad de las muestras no podía llevarse a cabo, además de otras características de los procedimientos experimentales que no podían seguir en estos ámbitos (Manterola y Otzen, 2015). No es hasta 1966, cuando Campbell \& Stanley (1966) explican los tipos de diseños cuasi experimentales en su libro.

\subsubsection{Tipos de estudios experimentales}

El diseño cuasi experimental, es un tipo de diseño experimental. Campbell y Stanley (1966) identificaron tres tipos de diseños experimentales: Diseños pre-experimentales, experimental verdadero y cuasi experimental. La principal diferencia entre los tres tipos es el control que imponen en las variables que se están estudiando, cuánto mayor es el control más fácil es atribuir la relación de causa y efecto a unos sucesos (Salkind, 1999).

- El diseño experimental fue el primero que existió y el más antiguo de los subtipos que presentamos, también lo llaman diseño experimental verdadero o real.

Es un diseño de investigación o evaluación con dos o más grupos seleccionados de forma aleatoria (un grupo experimental y un grupo de control) en los que el investigador controla o introduce una intervención (por ejemplo, nuevo programa o política) y mide su impacto en la variable dependiente al menos dos veces (medición anterior y posterior al ensayo). [...] se suelen utilizar para responder a las preguntas de investigación en la evaluación, que tratan de evaluar la eficacia de las intervenciones de un programa o política en entornos de desarrollo. (White \& Sabarwal, 2014, p.1)

Los pasos para llevar a cabo un estudio experimental son: (a) asignar aleatoriamente los participantes al grupo experimental o al control, (b) realizar la prueba pretest a cada grupo, (c) aplicar el tratamiento al grupo experimental, y no tratar al grupo control o tratarlo con otro tipo de programa, (d) realizar la prueba pretest a ambos grupos (Salkind, 1999).

El método experimental no fue del todo adecuado para disciplinas como la psicología y la pedagogía, fue necesario crear otros diseños más acordes para estas disciplinas. Según SalasBlas (2013) esto ocurrió por los siguientes problemas que se 
encontraron: (a) los objetos de estudio en estas disciplinas eran más complejos, ya que solían presentar relaciones múltiples y era difícil ejercer un control sobre ellos. (b) los primeros investigadores sociales que utilizaron el diseño experimental se preocuparon más por la estadística que por la calidad de los resultados y el procedimiento para obtenerlos. (c) Los primeros investigadores que utilizaban el diseño experimental no obtenían los resultados que buscaban, ni podían validar las hipótesis de manera contundente (validez interna), ni podían hacer generalización. (d) Los modelos univariables no daban buen resultado en la pedagogía y en las ciencias sociales, por lo que se quedaban muy limitados y expuestos a la crítica. (e) En aquel momento tuvieron problemas con la ética de la investigación en este tipo de diseños. Campbell \& Stanley (2005) sabían que parte de los problemas que se produjeron no tenían que ver con el diseño experimental, ni con el tratamiento de los datos, sino de que se producían situaciones poco controladas, por eso propusieron el uso de los diseños pre y casi experimentales que explicamos a continuación.

- El diseño preexperimental también se denomina diseño de control mínimo, aproximación experimental, diseño intrasujeto, diseño no experimental, diseño de caso único, diseño experimental débil, diseños defectuosos o de control mínimo, experimento piloto, diseño del mal experimento (Manterola y Otzen, 2015).

Los diseños preexperimentales no se caracterizan por la selección aleatoria de participantes de una población, ni incluyen un grupo control. Sin estas dos cosas, la capacidad de la investigación para descubrir la naturaleza causal de la relación entre las variables independiente y dependiente se reduce considerablemente, y casi se elimina. Estos diseños tienen poco o ningún control sobre las variables extrañas que podrían ser responsables por resultados distintos de lo que pretendía el investigador. (Salkind, 1999, p.235)

Según Salas-Blas (2013) los estudios preexperimentales se limitan como diseños causales por lo siguiente: cumplen con la manipulación de la validez interna, aunque no la controlan, por lo que no son muy útiles en la construcción científica, se aplican solamente cuando es imposible manipular esta condición de validez interna, pero sus resultados son siempre discutibles. 
- El diseño cuasi experimental se caracteriza por no ser aleatoria la designación de los participantes en cada grupo.

Hay casos en los que la aleatoriedad sencillamente no es práctica ni posible, y el uso de un grupo control es imposible o demasiado costoso, o no es razonable. Por ejemplo, no podemos decidir aleatoriamente cuáles familias que esperan un hijo van a tener varones y cuáles tendrán mujeres. Tampoco podemos decidir cuáles niños recibirán educación preescolar y cuáles no. Los diseños en los que es imposible asignar de manera aleatoria participantes a todos los grupos se denominan diseños cuasi experimentales porque no son verdaderamente experimentales. (Salkind, 1999, p.251)

Encontramos que, en este tipo de diseño, se produce una manipulación de las variables dependientes para observar o medir su efecto sobre las variables independientes, por lo que su validez interna se ve reducida ya que no se utilizan grupos asignados de forma aleatoria y por la dificultad de controlar todas las variables en contextos reales. Pero al ser una situación real, la validez externa es muy superior a las propuestas puramente experimentales (Gómez y Roquet, 2009). En el Estudio Piloto (EP) de esta tesis se va a utilizar este tipo de diseño, el diseño cuasi experimental, al no poder controlar todas las variables y no poder agrupar a los participantes.

En la Tabla 3.2 se han detallado las características de cada tipo de estudio experimental.

Tabla 3.2.

Diferencias entre el diseño experimental, preexperimental y el cuasi experimental

\begin{tabular}{|c|c|c|}
\hline ntal & imental & imental \\
\hline $\begin{array}{l}\text { Grado de control alto. } \\
\text { Validez interna mayor. } \\
\text { Validez externa menor. } \\
\text { Objetivos: predecir y } \\
\text { explicar. } \\
\text { Se manipula el fenómeno. } \\
\text { Asignación aleatoria de } \\
\text { los grupos experimental y } \\
\text { control. } \\
\text { Manipulación de la } \\
\text { variable independiente. }\end{array}$ & $\begin{array}{l}\text { Grado de control bajo. } \\
\text { Validez interna menor. } \\
\text { Validez externa mayor. } \\
\text { Objetivos: describir. } \\
\text { Actitud pasiva. No se } \\
\text { modifica el fenómeno } \\
\text { objeto de estudio, el } \\
\text { investigador registra las } \\
\text { mediciones. } \\
\text { Se produce en situaciones } \\
\text { reales, naturales. }\end{array}$ & $\begin{array}{l}\text { Grado de control medio. } \\
\text { Validez interna media. } \\
\text { Validez externa mayor. } \\
\text { Objetivos: predecir, } \\
\text { explicar. } \\
\text { Se provoca o manipula el } \\
\text { fenómeno. } \\
\text { El investigador determina } \\
\text { los valores de la validez } \\
\text { interna. }\end{array}$ \\
\hline
\end{tabular}




\begin{tabular}{|c|c|c|}
\hline $\begin{array}{l}\text { Control de las variables } \\
\text { extrañas. } \\
\text { Comparación de dos o } \\
\text { más grupos. } \\
\text { Medición de cada } \\
\text { variable dependiente. } \\
\text { Uso de estadísticos } \\
\text { inferenciales. }\end{array}$ & $\begin{array}{l}\text { No se manipulan las } \\
\text { variables. } \\
\text { No permite que se } \\
\text { establezcan relaciones de } \\
\text { causa-efecto. }\end{array}$ & $\begin{array}{l}\text { as significativas } \\
\text { ntrolar. } \\
\text { ación aleatoria } \\
\text { hdo la equivalencia } \\
\text { stica. } \\
\text { liza en situaciones }\end{array}$ \\
\hline
\end{tabular}

Fuente: basado en Gómez y Roquet (2009, p.33).

\subsubsection{Tipos de estudios cuasi experimentales}

Existen múltiples tipos de estudios cuasi experimentales: diseños transversales, longitudinales, de grupo control no equivalente, de grupo control no equivalente con medidas sólo postest, de discontinuidad en la regresión, de series temporales interrumpidas, longitudinales de medidas repetidas, longitudinal en panel y, por último, longitudinal de cohortes (Campbell \& Stanley, 2005); a continuación, vamos a explicar algunos de ellos:

- Diseño postest con un grupo no equivalente (Tabla 3.3): es un estudio en el que no se realiza una asignación aleatoria de sujetos, no se realiza evaluación pretest, se realiza un tratamiento y finalmente una evaluación postest (Gómez y Roquet, 2009).

Tabla 3.3.

Resumen diseño postest con un grupo no equivalente

\begin{tabular}{llll}
\hline Grupo & Pretest & Tratamiento & Postest \\
\hline $\begin{array}{l}\text { Grupo } \\
\text { experimental }\end{array}$ & No & $\mathrm{Si}$ & $\mathrm{Si}$ \\
\hline
\end{tabular}
(2009).

Fuente: Elaboración propia basada en Gómez y Roquet

- Diseño de grupo control no equivalente pretest-postest (Tabla 3.4): es uno de los diseños cuasi experimentales más utilizado, sobre todo cuando es imposible o muy difícil asignar aleatoriamente sujetos a grupos. Por ejemplo, en un entorno educativo no es fácil controlar todas las variables, u organizar las aulas a mitad curso y en esos casos es conveniente utilizar este 
tipo de diseño (Salkind, 1999). No hay que olvidar que este tipo de estudio tiene una mayor validez interna que el estudio anterior, ya que introducimos un grupo control, en este tipo de diseño, la principal amenaza es la validez interna ya que la asignación de grupos no es aleatoria (grupos no equivalentes) (Gómez y Roquet, 2009).

Tabla 3.4.

Resumen diseño de grupo control no equivalente pretest-postest

\begin{tabular}{|c|c|c|c|c|c|}
\hline Grupo & Asignación & & Pretest & Tratamiento & Postest \\
\hline $\begin{array}{l}\text { Grupo } \\
\text { experimental }\end{array}$ & $\begin{array}{l}\text { No } \\
\text { aleatoria }\end{array}$ & es & Sí & Sí & Sí \\
\hline Grupo control & & & & No & \\
\hline
\end{tabular}
(2009).

Fuente: Elaboración propia basada en Gómez y Roquet

Este tipo de estudio es el que llevaremos a cabo en el Estudio Piloto (EP) ya que no podemos escoger a los participantes de manera aleatoria.

- Diseño pretest-postest con grupo control (Tabla 3.5): para mejorar la validez interna, hay que seguir este tipo de diseños, pero es necesario controlar todas las variables, y asegurarnos de que todas las condiciones, excepto el tratamiento, sean iguales en ambos grupos (Gómez y Roquet, 2009).

Tabla 3.5.

Resumen diseño pretest-postest con grupo control

\begin{tabular}{lllll}
\hline Grupo & Asignación & Pretest & Tratamiento & Postest \\
\hline Experimental & Aleatoria & $\mathrm{Si}$ & $\mathrm{Si}$ & $\mathrm{Si}$ \\
\hline Control & Aleatoria & $\mathrm{Si}$ & $\begin{array}{l}\text { No / Diferente } \\
\text { al del grupo } \\
\text { experimental }\end{array}$ \\
\hline
\end{tabular}

Fuente: elaboración propia basada en Gómez y Roquet (2009). 


\subsubsection{Validez interna $y$ validez externa en el estudio cuasi experimental}

No basta con idear los diseños, sino que también es necesario evaluar estos, para juzgar su utilidad, para ello Campbell \& Stanley (2005) utilizaron los criterios de validez interna y externa.

"La validez interna es la cualidad de un diseño experimental que hace que los resultados obtenidos se deban a la manipulación de la variable independiente". (Salkind, 1999, p.238). Por ejemplo, si podemos determinar que los bits de inteligencia de Glenn Doman son un instrumento que logra mejorar el lenguaje de los niños con trastorno del lenguaje, y si podemos decir que son la única causa aparente del cambio, decimos que el diseño (y el experimento) es internamente válido. Si hay varias explicaciones distintas para los resultados de un experimento, este no tiene validez interna.

"La validez externa es la cualidad de un diseño experimental que permite generalizar los resultados, de la muestra original a otra muestra y luego por extensión a la población de la cual se obtuvo la muestra" (Salkind, 1999, p.238). Es decir, siguiendo con el anterior ejemplo, si podemos aplicar los bits de inteligencia de Glenn Doman para mejorar el lenguaje de otros niños con trastorno del lenguaje, podemos decir que tiene validez externa.

Según Rodríguez (2011) existen varios factores que influyen en la reducción de la validez interna que son:

- Historia, sucesos que acontecen en el periodo que transcurre entre el inicio y el fin del experimento; por ejemplo, la atención o la estimulación del lenguaje que puedan recibir en el colegio, en sus familias, además de nuestro experimento con los bits de inteligencia.

- Maduración, cambios que experimentan los sujetos al avanzar el tiempo, como puede ser el desarrollo normal del lenguaje que tendrían sin estimulación

- Prueba, el efecto de la aplicación de una prueba inicial sobre los resultados que se obtengan en una prueba final; es decir, que el sujeto se pueda aprender la prueba, pero en nuestro caso es muy difícil que esto ocurra, ya que no se les da la respuesta correcta en la prueba inicial.

- Instrumentación, alteraciones en las medidas por defectos en los instrumentos de medida o errores de los investigadores y/o 
correcciones de las pruebas, estos errores son más difíciles de cometer en pruebas estandarizadas que son las que hemos utilizado.

- Regresión estadística, esto se produce cuando se seleccionan los participantes sobre la base de puntajes extremos, es decir hay participantes con estadísticos muy diferentes entre sí.

- Selección, desvíos en los resultados producidos por la selección diferencial de sujetos, para ello se ha llevado a cabo una selección de unas edades específicas, y con características parecidas.

- Mortalidad experimental, o perdida diferencial de sujetos en los grupos, puede ocurrir que a mitad del tratamiento los participantes quieran abandonar el estudio, pero esto no ha ocurrido en nuestra investigación.

- Interacción de los factores anteriores.

Según Rodríguez (2011), existen varios factores que influyen en la reducción de la validez externa:

- El efecto reactivo o de interacción producido por una prueba pretest, ya que puede aumentar o disminuir la sensibilidad de los participantes para la variable que queramos estudiar; en nuestro caso no creemos que ocurra ya que son niños muy pequeños y no son conscientes de ser evaluados.

- Efectos de la interacción entre desvíos en la inclusión de participantes en el estudio y la variable experimental.

- Efectos reactivos del ambiente experimental, los cuales impedirán la generalización del uso de los bits de inteligencia; esto es posible que ocurra, ya que la muestra del Estudio Piloto (EP) es muy reducida y solo se aplica en un mismo contexto.

- Interferencia de varios tratamientos al mismo sujeto. Los efectos de los primeros tratamientos no pueden eliminarse. Nuestros participantes no habían acudido nunca a un servicio de logopedia, por lo que esto no puede ser un motivo para reducir la validez externa.

Resulta complicado cumplir con la validez interna y la externa al mismo tiempo, porque los procedimientos para aumentar una disminuyen la otra y viceversa (Rodríguez, 2011); en nuestro estudio existe una mayor validez externa que interna. 


\subsection{Estudio de caso como método de investigación}

El Estudio de Caso (EC) como método de investigación, se ha utilizado en el segundo de los estudios de esta tesis doctoral que, finalmente, constituye el estudio principal. A finales de la década de 1960 y a lo largo de la década de 1970, los métodos de investigación estaban centrados en la evaluación de programas sociales y educativos, pues necesitaban aportar información y mejorar la toma de decisiones y la actuación social y educativa. Los desarrolladores de programas necesitaban saber cómo se conseguían los resultados, querían profundizar en el proceso porque sin esta explicación los resultados no servían para nada, por ello se comenzaron a utilizar los estudios de caso (Simons, 2011) "la esencia del EC es la descripción, explicación o comprensión de un inter/sujeto/objeto, una institución, un entorno o una situación única y de una manera lo más intensa y detallada posible" (Díaz et al., 2011; p.21), en un sentido amplio también se define "como el proceso de indagación sistemática y crítica del fenómeno que se haya escogido, y de generación de conocimientos que se sumen a los que ya son públicos sobre el tema en cuestión” (Simons, 2011, p.39).

Entre la multitud de definiciones y enfoques, dentro del EC (Durán, 2012; Yazan, 2015), encontramos dos autores clásicos que abarcan la investigación del EC, estos autores son Robert Yin y Robert Stake. Stake tiene un enfoque más holístico y orientado a la evaluación de programas en el campo educativo (Alonso, 2003), tras realizar un análisis exhaustivo de los estudios de caso, encontramos que hay una tercera autora Merriam (1998), que opina que un caso también puede ser una persona, un programa, un grupo, una política... además de las muchas opciones que ofrecen Yin y Stake. A continuación, presentamos alguna de las definiciones más importantes en el EC:

Marcelo et al. (1992) explican las diferencias del EC dependiendo de la definición de cada autor; por ejemplo, algunos autores lo utilizan como una herramienta al compararlo con un examen intensivo o completo, ya que Walker (1982, citado en Marcelo et al., 1992) lo define tanto como técnica de evaluación como de investigación.

Por otro lado, Durán (2012) lo utiliza como un método de aprendizaje; en ese sentido encontramos la siguiente definición: "un EC es un método de aprendizaje, que parte de un ejemplo complejo considerado como un todo en su contexto y se basa en la comprensión en conjunto (holístico) de dicho ejemplo, a partir de una descripción y un análisis muy 
detallado" (United States General Accounting Office, 1990, p.14, citado por Durán, 2012, p.124).

Por otra parte, González (2009), explica su utilización como método de investigación:

Hoy en día es uno de los métodos investigativos utilizado con mayor frecuencia por aquellos investigadores acuciosos, dedicados a profundizar en la naturaleza de un fenómeno dado. En este sentido Grunow (1995) destaca la importancia de esta metodología al revisar 204 estudios empíricos y encontrar que en el 50\% de estos estudios se adoptó esta metodología de investigación. (p.307)

Yin (2009), en cambio, lo considera como una estrategia de investigación para estudiar otra situación más concreta, lo define como "una investigación empírica que estudia un fenómeno contemporáneo dentro de su vida real, cuando los límites entre el fenómeno y su contexto no son claramente evidentes" (p.14).

Stake (1995) entiende el EC como algo particular y complejo y, al igual que Yin, lo considera una estrategia de investigación: "el estudio de caso no es una opción metodológica, sino una elección sobre el objeto a estudiar que como forma de investigación se define por su interés en casos particulares, y no por los métodos de investigación usados" (p.236).

La definición de Merriam (1988) se asemeja a la de Yin y a la de Stake en relación con que también lo enfoca como una estrategia de investigación; lo define como una descripción y un análisis intensivo y holístico de una entidad, un fenómeno o una unidad social desde un punto de vista particular, descriptivo y heurístico y utilizando diferentes fuentes de datos que se apoyan para lograr ese razonamiento heurístico.

Autores más actuales como Simons (2011) se basan en los autores anteriormente mencionados y presentan una definición más completa que recoge múltiples posibilidades:

El Estudio de Caso es una investigación exhaustiva y desde múltiples perspectivas de la complejidad y unicidad de un determinado proyecto, política, institución, programa o sistema en un contexto "real". Se basa en la investigación, integra diferentes métodos y se guía por las pruebas. La finalidad primordial es generar una comprensión exhaustiva de un tema determinado (por ejemplo, en una tesis), un programa, una política, una institución o un sistema, para generar 
conocimientos y/o informar el desarrollo de políticas, la práctica profesional y la acción civil o de la comunidad. (p.42)

Nuestra propuesta sobre EC para esta tesis doctoral aúna dos definiciones: supone realizar una investigación en algo particular y utilizarlo como una estrategia de investigación (Stake, 1995) al proponer un programa de intervención logopédica como el caso que queremos estudiar (Merriam, 1998). Es decir, investigamos sobre un método de intervención logopédica que, al mismo tiempo, nos servirá como estrategia de investigación.

\subsubsection{Tipos de estudio de caso}

Los estudios de caso presentan diferentes variaciones teniendo en cuenta las siguientes variables: (a) cantidad de casos (simple o múltiple); (b) unidades de análisis (holístico o detallado); (c) objetivo de la investigación (descriptiva, demostrativa, generativa...) y (d) temporalidad (diacrónica, sincrónica) (López-González, 2013).

Teniendo en cuenta los tipos de EC según los objetivos, Stake (2005) considera que existen tres grandes tipos:

- Intrínseco: se desarrolla porque queremos conseguir una mejor comprensión del caso en sí mismo. No optamos por un caso porque represente a otros casos o porque sea ilustrativo de un determinado problema, sino porque tiene interés en sí mismo.

- Instrumental: el objetivo principal es proporcionar más información sobre un tema o para reformular una generalización. El caso no es el papel principal, es secundario y su utilización sirve para aportar datos para comprender otro fenómeno.

- Caso múltiple o colectivo: un conjunto de casos que se estudia de forma conjunta para investigar un fenómeno específico, población o condición general. En realidad, se trata de un estudio instrumental que lo extendemos a varios casos, que pueden ser similares o no.

A estos tres tipos podemos añadir los que señala Merriam (1998), que caracteriza tres tipos de EC: descriptivos, interpretativos y evaluativos:

- Descriptivos: no se guían por generalizaciones, ni fundamentaciones teóricas, ni hipótesis previas. Son útiles para aportar información básica en áreas educativas. 
- Interpretativo: son descripciones densas y ricas con el propósito de interpretar y teorizar sobre el caso de estudio.

- Evaluativo: envuelve una descripción, explicación y juicio para tomar decisiones, suelen utilizarse para realizar una evaluación educativa, ya que sirven para explicar los vínculos causales de las intervenciones en la vida real.

Por otra parte, teniendo en cuenta la cantidad de casos, encontramos dos tipos: el EC único y el EC múltiple. El estudio de caso único centra su unidad de análisis en un único caso (Yin, 2009); su uso se fundamenta en que el caso debe tener un carácter crítico, tiene que permitir confirmar, cambiar, modificar o ampliar el conocimiento sobre el objeto de estudio (López-González, 2013). El estudio de casos múltiples es más robusto ya que se basa en la replicación (Yin, 2009); es decir, que intenta contrastar y contestar las respuestas que se obtienen en cada caso analizado (López-González, 2013).

\subsubsection{Estudio de caso evaluativo (ECE)}

Este trabajo tiene un diseño de Estudio de Caso Evaluativo (ECE), según Simons (2011), este tipo de estudios debe:

- Discernir el valor del programa que constituya el caso: se puede basar en el juicio sobre las pruebas obtenidas o las formas en las que diversas personas y grupos de interés valoren el programa. Además, se puede implicar a los propios participantes del EC.

- Informar de la toma de decisiones y ser receptivo a las necesidades de los interesados y mantener negociaciones efectivas con los participantes.

- Incluir y equilibrar justa y equitativamente los interesantes del programa.

En nuestro caso nos centraremos en este tipo de ECE, ya que intentamos analizar el Programa de Estimulación Lingüística de Expresión Oral (PELEO) y conocer en profundizad tanto el diseño como su utilidad.

Van Wynsberghe \& Khan (2007) describen las características del ECE:

- Tamaño pequeño: se requiere un estudio intensivo de una muestra pequeña; en nuestro caso es PELEO, como único caso de estudio en el que realizamos un estudio en profundidad. 
- Nivel de análisis detallado y contextualizado: el lector debe tener la sensación de no perderse ningún tipo de información. En nuestro estudio se observa esta característica gracias a la cantidad de datos recogidos, tanto del diseño del programa como de la implementación de este, como por la descripción detallada del proceso de utilización de PELEO.

- Escaso control que el investigador ejerce: es adecuado para abordar la indagación de entornos complejos, en los que es difícil establecer relaciones de causa-efecto, en nuestro caso esta característica no se cumple, ya que sí que ejercemos control en la investigación al tratar con los niños.

- Los estudios de caso establecen límites temporales y espaciales específicos: en este estudio hemos limitado el estudio entre 2018 y 2020 en el contexto de un programa logopédico en escuelas infantiles, centros educativos y gabinetes de rehabilitación logopédica.

- Generar hipótesis de trabajo: los estudios de caso sirven para aprender de lo que se descubre analizando los datos recolectados. Esta investigación se ha basado en una hipótesis de partida, y ha generado un modelo de evaluación que ha surgido de la integración de los datos recogidos del programa de investigación.

- Uso de múltiples fuentes de datos: esto resulta de mucha utilidad y es posible realizar una triangulación para otorgar mayor precisión en los resultados. Para realizar nuestra evaluación, hemos empleado diversos instrumentos de evaluación que servirán para una futura triangulación.

- Extender los hallazgos del EC a otras situaciones: analizando interacciones para descubrir o construir factores que son elementos del fenómeno estudiado. Por ejemplo, en nuestro estudio queremos analizar PELEO para conocerlo en profundidad y poder utilizar el programa con otros niños.

Es importante evaluar todas las partes del caso para poder profundizar en el mismo (Simons, 2011), por ello en nuestro caso se ha decidido evaluar las siguientes partes de PELEO: 


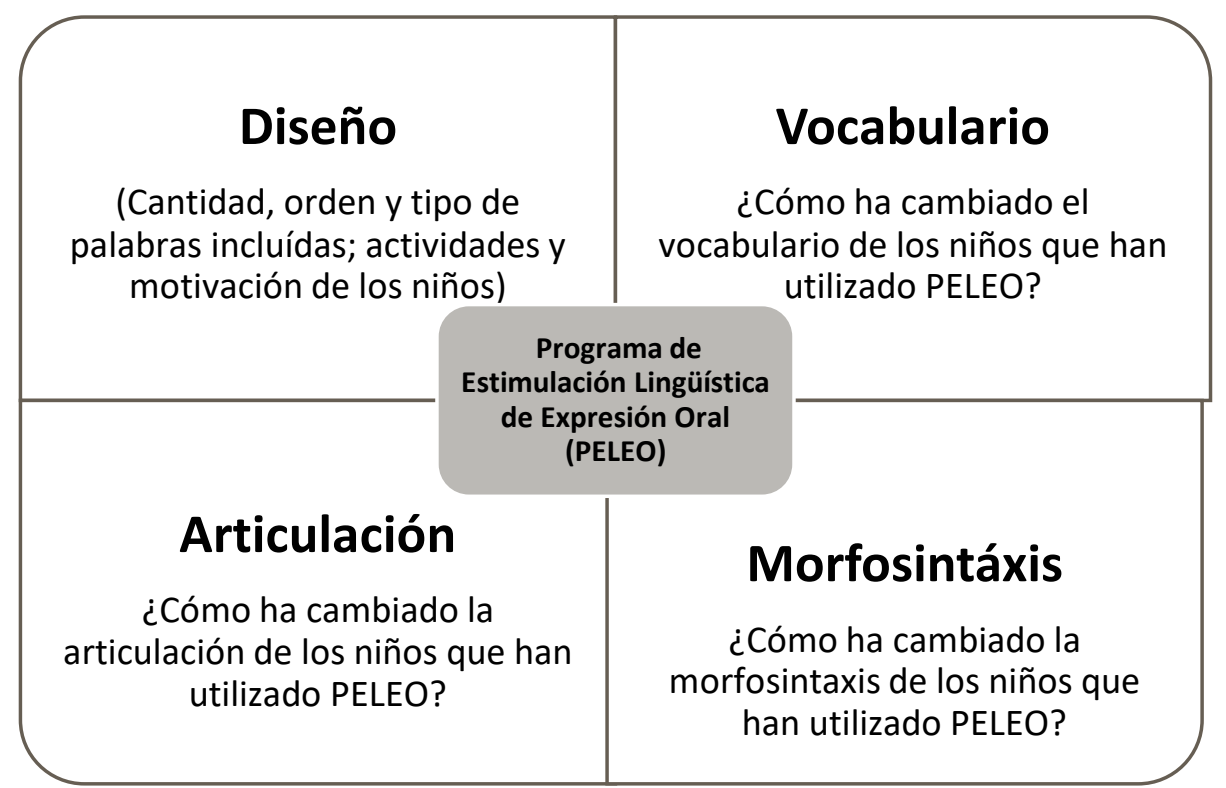

Figura 3.1. Características del Programa de Estimulación Lingüística de Expresión Oral (PELEO). Fuente: creación propia.

\subsubsection{Criterios de utilización del estudio de caso}

No existen unos criterios irrevocables para elegir el EC como metodología de investigación, pero se suele utilizar cuando lo que se pretende es explicar una circunstancia actual o realizar una extensiva y profunda descripción de un caso o fenómeno social (Gómez y Roquet, 2009).

El EC se puede utilizar tanto como casos únicos como en casos múltiples; los casos múltiples consisten en un estudio que tiene varios tipos de casos y con todos ellos se estudia el mismo fenómeno o situación. Cada EC es un instrumento sobre un hecho, que se realiza con una coordinación entre cada uno de los casos (Stake, 2005). Además de este, también existe el EC, según Yin (2009) existen cinco razones por las que podemos elegir el caso como diseño de investigación:

- El caso tiene un carácter crítico para modificar o confirmar una teoría o conocimientos sobre el objeto de estudio; por ejemplo, en el caso de esta tesis doctoral consistiría en analizar el diseño y la utilización de PELEO en los niños con trastornos del lenguaje, para proceder a su modificación si fuera necesario. 
- Representa un caso irrepetible, peculiar y especial; ya que este PELEO no existía hasta este momento.

- Es un caso típico o representativo que permite recopilar datos sobre un fenómeno, lugar, circunstancia; en nuestro caso recopilaremos datos sobre la aplicación de PELEO.

Es conveniente seguir estos criterios en el momento de seleccionar los casos (Yin, 2009): (a) el caso debe ser accesible (datos, personas, documentos...), los datos, las personas y los documentos son accesibles, ya que los colegios, los gabinetes logopédicos y las familias nos los proporcionan; (b) los procesos, programas, personas... pueden interrelacionarse y mezclarse con las cuestiones de investigación, y así ocurre en esta investigación en el que el programa de investigación se interrelaciona con todas las personas participantes en ella de una manera o de otra; (c) es posible establecer una buena relación con los informantes, como realizamos en el desarrollo de la intervención y en la posterior realización de las entrevistas en las que establecemos una relación estrecha no solo con los niños, con los que pasamos muchas horas de intervención, sino también con las familias, las maestras y las logopedas; (d) el investigador puede continuar su labor mientras sea necesario, en nuestro caso hemos continuado la investigación hasta que ésta ha finalizado y (e) la calidad y la credibilidad del estudio no están puestas en duda.

Del mismo modo, el EC plantea potencialidades educativas (Pérez, 1994): (a) lograr experiencia en el diagnóstico de problemas específicos, en este caso de PELEO; (b) una comprensión más profunda y realista; (c) adquisición de la capacidad de análisis y síntesis, puesto que realizamos una evaluación del método y para ello hace falta analizarlo y sintetizarlo; (d) integración e interrelación de conocimientos y vivencias, y (e) motivación, que en nuestro caso es la motivación de los profesionales y de los participantes.

\subsubsection{Fases para desarrollar el estudio de caso}

Las fases del proceso de investigación cualitativo en general son dinámicas y flexibles, es decir no se guían por un proceso lineal, interactúan entre ellas y pueden solaparse en algún momento; el hecho de realizar un estudio desde el paradigma de investigación cualitativo requiere que cada etapa (la definición del tema que se va a estudiar, el planteamiento del problema y los objetivos, el diseño, el trabajo de 
campo, el análisis y la interpretación de los datos, la presentación de los resultados y el informe final) deben tener una sincronía y formar parte de un todo (Noreña-Peña et al., 2012).

Si nos centramos en el EC, encontramos cinco fases descritas por Montero y León (2002), estas cinco fases son: la selección y definición del caso; la elaboración de una lista de preguntas que guíe la atención del investigador en un primer momento; la localización de las fuentes de datos; el análisis e interpretación y la elaboración del informe final. Otros investigadores como Pérez-Hoyos (2016) definen otras etapas que son las mismas que las anteriores, pero más desglosadas, estas son: (a) diseño de investigación; (b) identificación y selección de la organización; (c) consecución del apoyo de la organización, (d) documentación inicial, (e) trabajo de campo, (f) análisis de información, (g) elaboración del informe final de investigación, (h) ajuste, aprobación y difusión del EC. Y a su vez incluye algunas etapas transversales como (i) construcción de los marcos teóricos y (j) evaluación del rigor del EC.

Ortiz-Ocaña (2015) va más allá, y describe las cinco fases de Montero y León (2002):

- La selección y definición del caso: se trata de seleccionar el caso apropiado y definirlo, en ese sentido nos tenemos que fijar en que ámbitos es relevante el estudio, los casos pueden venir dados o puede seleccionarlos el investigador como ocurre en esta tesis doctoral.

- La elaboración de una lista de preguntas que guíe la atención del investigador en un primer momento, aunque no en exceso. Después de una pregunta general conviene desglosarla en un conjunto de preguntas más específicas. La pregunta general es ¿cómo es el diseño y el uso de PELEO cuando se emplea con hablantes tardíos y con niños con TDL? Y las preguntas específicas son:

- ¿Cómo es el diseño de PELEO en relación con la cantidad y el orden del vocabulario que se ha utilizado?

- ¿Cómo es el diseño de PELEO en relación con el tipo de vocabulario que se ha utilizado?

- ¿Cómo es el diseño de PELEO con relación a las actividades y a la motivación de los niños?

- ¿Cómo ha cambiado el vocabulario de los niños que han utilizado PELEO? 
- ¿Cómo ha cambiado la articulación de los niños que han utilizado PELEO?

- ¿Cómo ha cambiado la morfosintaxis de los niños que han utilizado PELEO?

- La localización de las fuentes de datos: se seleccionan los sujetos a explorar, las personas a entrevistar y las técnicas de recogida de datos, en las que vamos a profundizar más adelante.

- El análisis e interpretación: el EC sigue un análisis cualitativo la mayoría de las ocasiones, pero en algunas ocasiones se puede llevar a cabo un análisis cuantitativo, o mixto como es el caso de esta tesis doctoral.

- La elaboración del informe final en el que se expliquen las conclusiones a las que se llega con el EC. Este informe, según Enrique y Barrio (2018), debe tener la estructura que considere oportuna el investigador, pero debe reportar todos los pasos dados, desde la aproximación realizada a nivel teórico, al diseño general, hasta un análisis y la interpretación de los datos.

\subsubsection{Críticas al estudio de caso}

El EC ha sido muy cuestionado por algunos investigadores, como Enrique y Barrio (2018) por diversas razones que se pueden categorizar en: la confusión y pérdida de significados sobre su concepto; la confiabilidad; la validez y la generalización de conocimiento. En este apartado nos vamos a centrar en la confusión y la pérdida de significados sobre su concepto, y demostraremos cómo, aunque es criticado, se pueden realizar acciones para que la investigación sea fiable y válida.

La confusión y pérdida de significados sobre su concepto: se refiere a la dificultad que tiene definir el EC, como hemos podido comprobar anteriormente, ya que se puede definir como enfoque, estrategia, método o metodología o incluso diseño de investigación. El EC no debe encasillarse en ninguno de los conceptos anteriores puesto que lo consideramos multimetódico y transdisciplinario (Durán, 2012). Aun así, hemos dejado claro en el apartado anterior la variedad de definiciones existentes, y en la que nosotros nos centramos para realizar esta tesis doctoral, por lo que esta crítica no debería ser válida para este estudio.

La confiabilidad, la validez y la generalización del conocimiento: se refiere a la falta de representatividad y rigor en la recopilación de 
información y a los sesgos que pueda introducir el investigador al realizar su propia interpretación de la realidad que estudia. Sin embargo, estas debilidades se palían argumentando con solidez el porqué de la elección del método y aplicando un proceso metodológico preciso y, de esta manera, construir una base científica válida y, por tanto, unas conclusiones y resultados fiables. Un ejemplo de esto es la triangulación (Enrique y Barrio, 2018). Profundizaremos en esto en el apartado 3.4 de esta tesis doctoral.

Así pues, para paliar estas debilidades es conveniente argumentar con solidez el porqué de la elección del método y aplicar un proceso metodológico preciso para construir una base científica válida, y por tanto unas conclusiones y resultados fiables (Enrique y Barrio, 2018).

\subsection{Criterios de rigor en la investigación del estudio de caso}

La calidad de la investigación cualitativa ha estado en entredicho y ha generado amplias críticas entre diferentes investigadores, y al mismo tiempo los investigadores que comenzamos a iniciarnos en el campo de la investigación también nos hemos preocupado por estas cuestiones (Noreña-Peña, et al., 2012).

Para poder realizar una correcta investigación debemos cumplir los criterios de rigor que son: credibilidad, transferencia, fiabilidad y coherencia (Pérez-Hoyos, 2016). El rigor es un concepto transversal en cualquier investigación, gracias a él podemos realizar una aplicación escrupulosa y científica de diferentes métodos de investigación y técnicas de análisis de datos. Existen diferentes corrientes en relación con el rigor en la investigación cualitativa, unas opinan que no es necesaria la aplicación de normas de evaluación de calidad, otras opinan que depende de la ocasión, y las últimas que abogan por la evaluación con los mismos criterios que la investigación cuantitativa (Noreña-Peña, et al., 2012). Ortiz-Torres (2015) realiza un análisis de artículos publicados con EC en educación durante los últimos diez años y llega a la conclusión de que el impacto científico de estos artículos es muy alto y viene derivado de la calidad, novedad y pertinencia de estas investigaciones, siendo estas válidas. A continuación, vamos a profundizar en los criterios de rigor. 


\subsubsection{Credibilidad}

El criterio de credibilidad o autenticidad es el del valor de la verdad, es muy importante ya que permite evidenciar los fenómenos y las experiencias tal y como las perciben los participantes (Noreña-Peña, et al., 2012). Se debate sobre la confianza que es depositada en los resultados y los procedimientos de la realización del estudio de investigación (Quecedo y Castaño, 2002). En este caso es muy importante realizar una triangulación para disminuir al máximo la incertidumbre y fortalecer la credibilidad en el EC (López-González, 2013).Para garantizar la credibilidad en el EC es imprescindible realizar una descripción detallada de cómo se recogió el análisis de datos y cómo se ha analizado la información, en qué contextos se ha llevado a cabo la investigación y cómo se ha llevado a cabo el análisis, de esta manera se minimiza la posibilidad de emitir conclusiones sin fundamentación teórica o empírica (Chaverra-Fernández et al., 2019).

Hernández et al., (2006) explican los siguientes aspectos que hay que tener en cuenta en lo relativo a la credibilidad en el EC: (a) documentar la evidencia de manera sistemática, sin olvidarse de ninguna evidencia y ofreciendo detalles particulares del desarrollo de la investigación, como hemos hecho en el capítulo 2; (b) utilizar múltiples fuentes de datos e información y no aferrarse a una única fuente, eso lo hemos hecho al utilizar diferentes técnicas e instrumentos de recogida de datos; (c) realizar la triangulación de datos, nosotros hemos triangulado los diferentes datos para responder a las diversas preguntas de investigación que hemos planteado; (d) verificar los resultados con los participantes correspondientes, como hemos hecho nosotros con las familias de los niños entrevistándolas; (e) evaluar todos los detalles del caso que puedan explicar los resultados, así hemos hecho al evaluar no sólo el diseño en sí, sino también cómo han cambiado las dimensiones fonéticas, semánticas, y morfosintácticas de los niños que han utilizado PELEO y (f) documentar los procedimientos utilizados, en este sentido hemos documento los procedimientos a través de diferentes instrumentos y técnicas como es la grabación de video, de esta manera fomentaremos la credibilidad. Quecedo y Castaño (2002) explican cómo la credibilidad de los resultados puede aumentar o calibrarse a través de estrategias desarrolladas en la fase de diseño, recogida de datos, análisis o redacción del informe. 


\subsubsection{Conformabilidad}

También se llama neutralidad u objetividad, se refiere a garantizar la veracidad de las descripciones realizadas por los participantes. Permite conocer el rol de investigador durante la investigación e identificar sus éxitos y limitaciones, para después controlar las críticas que suscitan el fenómeno o los sujetos participantes. El investigador cualitativo tiene el compromiso ético de informar a los responsables de los lugares donde realiza la investigación de las actuaciones profesionales que realizará durante la investigación (Noreña-Peña, et al., 2012), así se hizo explicando a las familias (Anexo 5) y a los colegios (Anexo 4) las actuaciones que se iban a realizar. En relación con la neutralidad se propone asegurar que los resultados de una investigación están relacionados con el problema estudiado, y no entran en juego los juicios o intereses del investigador (Quecedo y Castaño, 2002), es por ello por lo que se decidió que otras logopedas aplicaran PELEO y no lo hiciera únicamente la doctoranda, de esta manera conocimos la opinión sobre el programa de otras personas. Guba (1981) describe los siguientes términos relacionados con esta conformabilidad: (a) saturación: se debe al proceso de juntar las pruebas y evidencias necesarias para asegurar la credibilidad de los resultados que obtengamos; (b) aportación de las fuentes documentales: es importante añadir todas las referencias bibliográficas; (c) descripción detallada y minuciosa de los hechos observados y lo que ocurra y percibamos de cada uno de los participantes.

\subsubsection{Transferibilidad}

La transferibilidad y la generalización son aspectos que están entre lo cualitativo y lo cuantitativo y que tienen relación con la replicación de los resultados de un estudio; además, la transferibilidad tiene un enfoque más cualitativo y la generalización un enfoque más cuantitativo (LópezGonzález, 2013). La transferibilidad o aplicabilidad consiste en poder trasferir los resultados de una investigación a otra u a otros contextos. Nos referimos a transferibilidad cuando se tiene en cuenta que los fenómenos estudiados están estrechamente vinculados a los momentos, a las situaciones del contexto y a los sujetos participantes de la investigación. La manera de lograr ésta es a través de una descripción exacta de las características del contexto en las que se realiza la investigación y la de los sujetos participantes (Noreña-Peña, et al., 2012). En nuestro caso se han descrito los distintos contextos del estudio en el 
apartado 4.3.2.1. en el que se explica la contextualización del estudio piloto y en el apartado 4.3.2.2. en el que se explica la contextualización del estudio 2: PELEO.

Algunos autores recogidos en Adelman et al. (1983) explican cómo realizar una transferibilidad o generalización en el EC: (a) en primer lugar, está la posibilidad de generalización del ejemplo estudiado; por ejemplo, en nuestro caso consistiría en generalizar el estudio de este método en otros métodos. (b) El segundo tipo es la de generalizar las características de este caso a múltiples casos, sobre todo ocurre cuando el caso se elige por su carácter de representatividad de una clase más amplia; en nuestro caso hemos elegido 33 niños a los que se ha pasado PELEO, estos niños representan a niños de tres a cinco años y siete meses años con trastorno del lenguaje por lo que podemos generalizar nuestros resultados con otros niños de las mismas edades y con las mismas dificultades. (c) Y, por último, en estudios que no se seleccionan por la relación entre el caso y su clase a la que podría pertenecer, también podría darse la generalización del caso a otros casos, teniendo en cuenta la coherencia interna del caso en vez de su representatividad. Flyvbjerg (2003) señala que el EC es ideal para la generalización utilizando la comprobación de Karl Popper ha llamado "falsación", y que en las ciencias sociales forman parte de la reflexividad crítica, que es lo que permite lograr datos desde lo observacional.

\subsubsection{Dependencia}

La consistencia o dependencia también se llama replicabilidad, hace referencia a la estabilidad de los datos. En la investigación cualitativa no siempre existe una estabilidad de los datos, al igual que en no todas las ocasiones es posible la replicabilidad exacta de un estudio en un paradigma cualitativo, debido a la cantidad de situaciones o realidades analizadas por el investigador. Sin embargo, es necesario que, aunque exista una gran variabilidad de los datos, el investigador procure encontrar una estabilidad en la información que recoge y analiza. Para lograr esto se utilizarán elementos como la triangulación de investigadores, de técnicas y de resultados; el empleo de un evaluador externo, y la descripción detallada del proceso de recogida, análisis e interpretación de los datos, además es necesario realizar una comparación constante para revisar y comparar los resultados con teorías anteriores (Noreña-Peña, et al., 2012). Quecedo y Castaño (2002) explican que la consistencia de los resultados pretende establecer el 
grado de relación entre las conclusiones o los datos de una investigación y los procedimientos de recogida y análisis de la información. En relación con la dependencia, nuestros datos son estables, y son replicables, ya que explicamos los diversos contextos en los que se lleva a cabo, siendo llevo a cabo el programa por graduadas en logopedia y con un proceso de recolección de datos muy sistemático, lo que beneficia la replicabilidad.

\subsection{Técnicas e instrumentos de obtención de datos}

Según Gil-Álvarez (2016), existe una diferencia entre las técnicas de recogida de información y los instrumentos, ya que las primeras engloban a las segundas. Las técnicas de recogida de información incluyen todos los medios técnicos que se utilizan para registrar las observaciones o facilitar el tratamiento de los datos. Dentro de estos medios técnicos se encuentran los instrumentos y los recursos (que son objetos independientes y se utilizan para obtener y registrar la información).

No existe un acuerdo en la clasificación de las técnicas de recogida de datos, pero Gil-Álvarez (2016) tras el análisis de diferentes autores, propone la división en seis grandes grupos:

- Observación

- Entrevista

- Cuestionario

- Pruebas objetivas y test

- Técnicas grupales y sociométricas

- Análisis de documentos

En esta tesis doctoral nos centraremos en la observación, la entrevista, el cuestionario y las pruebas objetivas y test.

\subsubsection{Observación}

La observación es una de las técnicas de investigación más importantes en las ciencias sociales, nada puede sustituir el contacto directo del investigador con su campo de estudio (Martínez y Galán, 2014). 
La observación es un fenómeno que forma parte de las funciones perceptivas de la persona, esenciales, de una manera tácita, para el funcionamiento cotidiano. Observar es ponerse delante de un objeto o poner la mirada en él, y supone el proceso contrario, al proceso empático, de sentir con, metiéndose dentro, poniéndose en su lugar. (p.245)

Existen diversos tipos de observación dependiendo de la función de participación dentro del entorno estudiado. De una manera amplia, podemos distinguir entre observación participante y no participante (Fàbregues et al., 2016). Nosotros nos centraremos en la observación participante, debido a que la investigadora forma parte directa e interviene claramente con PELEO sobre los sujetos, que son las acciones que van a ser observadas.

El proceso de observación se compone de una serie de hitos cuya secuencia es conveniente respetar (Gil-Álvarez, 2016):

- Determinar el propósito de la observación: tenemos que determinar el objeto a observar, por ejemplo, si se desea medir el "lenguaje" se debe determinar en qué consiste esa conducta. Existen cuatro tipos de conductas observables: conductas no verbales (expresiones faciales, conductas gestuales, posturales...), conducta espacial (colocación de las personas, distancia entre las mismas...), conducta extra-lingüista (intensidad, tono, timbre, pronunciación, falta de fluidez...) y por último conductas lingüísticas (palabras, frases...). Nosotros observaremos la conducta lingüística y la extra-lingüística.

- Precisar las condiciones en que se realizará la observación: durante cuánto tiempo se va a observar, cuántas sesiones, en qué intervalos de observación u anotación... En este caso tenemos otras cuatro tipologías: Ad libitum (todo vale, la recolección de la observación no es estructurada), de eventos conductuales (se utilizan listas de control o escalas, se observan conductas prefijadas), focal (se define un sujeto o grupo y el observador centra su atención durante un tiempo determinado), de secuencias temporales (cuando observamos estados de conducta más amplio y que duran en el tiempo, el criterio consiste en cuantificar el tiempo de ausencia o permanencia de una conducta); en esta investigación se realiza una observación de eventos conductuales, ya que se observa si el niño dice o no dice una serie de palabras, y además es focal, ya que se centra la observación 
sobre todo en el apartado de actividades, para observar las conductas que muestra el infante.

- Precisar los instrumentos de observación y análisis de datos: lista de control, registro anecdótico, sistemas de rasgos, escalas de estimación o apreciación y sistema de categorías; además de los marcados por Gil-Álvarez (2016), nosotros añadimos la grabación en vídeo.

En nuestro caso usaremos como instrumento de observación la lista de control con un sistema de categorías.

La definición de lista de control es la siguiente:

Este tipo de instrumento presenta, conforme con las directrices de una actividad o tarea, una enumeración de conductas, cualidades o características esperables/observables de los estudiantes. Estas, que se pueden agrupar en unos pocos criterios o figurar aisladas, se evalúan mediante una marca que indica la ausencia o presencia de una conducta o rasgo. (Lara y Cabrera, 2015, p.20)

Según Lara y Cabrera (2015), para realizar una lista de cotejo o lista de control o check-list, se recomienda (a) realizar una planificación rigurosa de los criterios que se van a evaluar; (b) descartar enunciados valorativos intermedios del tipo "a veces" "es posible"; (c) construir indicadores claramente observables; (d) utilizar una tabla de tres columnas: en la primera consignar los indicadores que se van a evaluar, en la segunda la respuesta de cumplimiento positivo y en la tercera la de cumplimiento negativo.

Nosotros vamos a utilizar la lista de control para valorar qué palabras conocen o desconocen los niños cuando utilizamos PELEO, y de esta manera marcaremos con un sí cuando el niño conozca cada palabra y un no cuando la desconozca; además de tener un apartado abierto de observaciones para hacer anotaciones. Esta lista la podemos encontrar en el Anexo 9.

Para dar credibilidad a la observación empleamos la grabación en vídeo, Quintana (2008) expone que se trata de:

Una herramienta de doble uso, por una parte, nos ayuda a identificar aspectos susceptibles de ser observados que pueden ser mejorados o cambiados $\mathrm{y}$, por otra parte, es útil también para realizar un determinado aspecto de la enseñanza o de una problemática concreta como parte de un proyecto de investigación-acción en el aula. Otro uso 
muy desarrollado es la implementación de esta técnica para llevar a cabo la retroalimentación formativa del profesor en prácticas, como parte de las técnicas de triangulación de resultados y de observación en colaboración entre profesores. (p.311)

Teniendo en cuenta esto, vamos a utilizar la grabación de video para identificar aspectos susceptibles de ser observados respecto a la utilización del método principalmente.

\subsubsection{Pruebas estandarizadas}

De acuerdo con Popham (1999) y López (2013), una prueba estandarizada es un test que se administra y evalúa siguiendo un proceso previamente determinado. Esto quiere decir que existe una unificación de criterios y condiciones para todos los sujetos en relación con la presentación, formato, tipo de preguntas, instrucciones, administración, la cantidad de preguntas, el tiempo necesario para cada una de ellas, y cómo se califica e interpretan esos resultados.

Por estandarización entendemos al proceso de sistematización de todos los elementos de acercamiento a una acción de recogida e interpretación de información, de manera que se utilicen los mismos: instrumentos o técnicas, criterios de corrección y/o síntesis o análisis de la información y criterios de interpretación de esta.

Estas estrategias se pueden aplicar tanto para clasificar instrumentos y técnicas de recogida de información, como para clasificar planes o programas de evaluación. No obstante, su mayor impacto, sin duda, lo tiene en el diseño de instrumentos y/o técnicas de recogida de información. (Jornet-Meliá, 2017, p.5)

Popham (1999) explica dos tipos de pruebas estandarizadas dependiendo su utilidad: pruebas de aptitud y las pruebas de logros.

Las pruebas estandarizadas de aptitud predicen cuán bien es probable que los estudiantes se desempeñen en algún espacio o nivel educativo subsiguiente [...] Pero a la hora de evaluar la eficacia de una escuela, los ciudadanos y los miembros de los consejos escolares se apoyan en los puntajes obtenidos por los alumnos en pruebas estandarizadas de logros. (Popham, 1999, p.2)

Existen multitud de pruebas estandarizadas de lenguaje, pero las pruebas que nosotros utilizaremos serán las pruebas estandarizadas de aptitud, ya que nos interesa conocer el lenguaje de los niños. Para ello seleccionamos tres pruebas estandarizadas: PLON-R. Prueba de 
Lenguaje Oral Navarra-Revisada (Aguinaga et al., 1990), cuya descripción se encuentra en la Tabla 3.6; el Registro Fonológico Inducido (RFI) (Juárez y Monfort, 1996a), cuya descripción se encuentra en la Tabla 3.7; y el Peabody Picture Vocabulary Test, TVIP (Dunn et al., 2006), cuya descripción se encuentra en la Tabla 3.8.

Tabla 3.6.

Características de la Prueba de Lenguaje Oral Navarra Revisada (PLON-R)

\begin{tabular}{|c|c|}
\hline $\begin{array}{l}\text { Nombre de la } \\
\text { prueba }\end{array}$ & V-R) \\
\hline Aplicación & Individual \\
\hline $\begin{array}{l}\text { Ámbito } \\
\text { aplicación }\end{array}$ & Niños de tres, cuatro, cinco y seis años. \\
\hline Duración & Variable, entre 10 y 12 minutos. \\
\hline Finalidad & Detección rápida o screening del desarrollo del lenguaje oral. \\
\hline Baremación & $\begin{array}{l}\text { Puntuaciones típicas transformadas y criterios de desarrollo en } \\
\text { los apartados de Forma, Contenido, Uso y Total en cada nivel } \\
\text { de edad. Estos criterios nos dan un resultado cualitativo de cada } \\
\text { apartado (forma, contenido y uso) y un resultado final } \\
\text { categorizado como: retraso, necesita mejorar o normal. }\end{array}$ \\
\hline $\begin{array}{l}\text { Instrucciones } \\
\text { generales de } \\
\text { aplicación }\end{array}$ & $\begin{array}{l}\text { El examinador deberá estar familiarizado con el manual, los } \\
\text { contenidos y los materiales que usará a lo largo de la aplicación, } \\
\text { tiene que aplicar el test al menos en tres ocasiones antes de la } \\
\text { primera evaluación real. } \\
\text { El ambiente tiene que ser silencioso, privado, ventilado y libre } \\
\text { de distracciones. } \\
\text { La relación con el niño debe ser amigable y se presentará la } \\
\text { evaluación de manera lúdica. } \\
\text { Debe estar alerta al nivel de cansancio del niño y se parará la } \\
\text { aplicación en caso de que muestre signos de cansancio o pérdida } \\
\text { de interés. } \\
\text { Se animará y elogiará al niño por el esfuerzo, y no se reforzará } \\
\text { solo cuando dé respuestas correctas. }\end{array}$ \\
\hline \multirow[t]{3}{*}{$\begin{array}{lll}\begin{array}{l}\text { Partes } \\
\text { prueba }\end{array} & \text { de la }\end{array}$} & $\begin{array}{l}\text { Forma: este apartado nos da información sobre la fonología y la } \\
\text { morfosintaxis del niño. }\end{array}$ \\
\hline & $\begin{array}{l}\text { Contenido: este apartado nos da información sobre el nivel } \\
\text { léxico-semántico comprensivo y expresivo. }\end{array}$ \\
\hline & $\begin{array}{l}\text { Uso: nos da información sobre la pragmática en especial sobre } \\
\text { la expresión espontánea en diferentes momentos de la prueba. }\end{array}$ \\
\hline
\end{tabular}

Fuente: Elaboración propia a partir de los datos obtenidos del Manual PLON-R. Prueba de Lenguaje Oral Navarra-Revisada (Aguinaga, et al., 1990). 
Tabla 3.7.

Características del Registro Fonológico Inducido (RFI) (Juárez y Monfort, 1996a)

\begin{tabular}{|c|c|}
\hline $\begin{array}{l}\begin{array}{l}\text { Nombre de la } \\
\text { prueba }\end{array} \\
\end{array}$ & Registro Fonológico Inducido (RFI) \\
\hline Aplicación & Individual. \\
\hline $\begin{array}{ll}\text { Ámbito } \\
\text { aplicación }\end{array}$ & Niños de tres a seis años y seis meses. \\
\hline Duración & La prueba dura aproximadamente entre 10 y 20 minutos. \\
\hline Finalidad & $\begin{array}{l}\text {-Registrar las peculiaridades del habla del niño, desde un punto } \\
\text { de vista cualitativo, en producción inducida de palabras y en } \\
\text { repetición, si es necesario. } \\
\text {-Comparar cuantitativamente su producción en la producción } \\
\text { media de un grupo de niños de su edad que vive en un entorno } \\
\text { social similar. }\end{array}$ \\
\hline Baremación & $\begin{array}{l}\text { Se puede argumentar que la baremación de una prueba fonética } \\
\text { o fonológica carece de sentido: existe el modelo correcto de la } \\
\text { pronunciación adulta y todo lo que no coincide con ella debe } \\
\text { considerarse como un error. Para ello se puede utilizar el modelo } \\
\text { adulto de cada comunidad. }\end{array}$ \\
\hline $\begin{array}{l}\text { Instrucciones } \\
\text { generales de } \\
\text { aplicación }\end{array}$ & $\begin{array}{l}\text { Se limita a enseñar al niño la tarjeta con el dibujo y a preguntar: } \\
\text { ¿Qué ves aquí? Salvo en el ítem de la palabra fuma, donde se } \\
\text { pregunta ¿qué está haciendo este señor? } \\
\text { Se apunta lo que dice espontáneamente el niño cuando se le } \\
\text { presenta la tarjeta y en caso de error de pronunciación o si omite } \\
\text { la palabra prevista, se le dice: Vamos a intentarlo otra vez. } \\
\text { Escucha. Esto se llama (decimos la palabra en cuestión), y se } \\
\text { apunta en este caso en la columna de repetición. } \\
\text { Al final del test, se solicita al niño una repetición aislada de } \\
\text { aquellos fonemas o sílabas que resultaron erróneos incluso en la } \\
\text { repetición de las palabras. }\end{array}$ \\
\hline $\begin{array}{lll}\begin{array}{l}\text { Partes } \\
\text { prueba }\end{array} & \text { de } & \text { la } \\
\end{array}$ & $\begin{array}{l}\text { Se registra, el habla espontánea de los niños, por lo que optamos } \\
\text { por una prueba de denominación de dibujos, seguida de la } \\
\text { repetición de la palabra correspondiente en casa de error: el } \\
\text { material se compone de } 57 \text { tarjetas con dibujo que cubren el } \\
\text { espectro fonológico fundamental del castellano. }\end{array}$ \\
\hline
\end{tabular}

Fuente: elaboración propia a partir de los datos del Manual del Registro Fonológico Inducido (RFI) (Juárez y Monfort, 1996a). 
Tabla 3.8.

Características del Peabody Picture Vocabulary Test, TVIP (Dunn, et al., 2006)

\begin{tabular}{|c|c|}
\hline $\begin{array}{l}\text { Nombre de la } \\
\text { prueba }\end{array}$ & $\begin{array}{l}\text { PPVT-III PEABODY. Test de vocabulario en imágenes. } \\
\text { Nombre original: Peabody Picture Vocabulary Test (PPVT- } \\
\text { III) }\end{array}$ \\
\hline Aplicación & Individual. \\
\hline $\begin{array}{l}\text { Ámbito } \\
\text { aplicación }\end{array}$ & De dos años y medio a noventa años. \\
\hline Duración & $\begin{array}{l}\text { Variable, entre } 10 \text { y } 20 \text { minutos, situándose la media entre } 11 \text { y } \\
12 \text { minutos. }\end{array}$ \\
\hline Finalidad & $\begin{array}{l}\text { Evaluación del nivel de vocabulario receptivo y screening de la } \\
\text { aptitud verbal. }\end{array}$ \\
\hline Baremación & $\begin{array}{l}\text { Puntuaciones CI, eneatipos, percentiles y edades equivalentes } \\
\text { para } 85 \text { grupos de edad desde los dos años y medio y siete años, } \\
\text { de dos meses entre siete y diecinueve años, de dos años entre } \\
\text { diecinueve y veinticinco años, de cinco años entre veintiséis y } \\
\text { cuarenta y uno años y de diez años hasta los noventa años. }\end{array}$ \\
\hline $\begin{array}{l}\text { Instrucciones } \\
\text { generales de } \\
\text { aplicación }\end{array}$ & $\begin{array}{l}\text { Tiempo de aplicación: no se debe apresurar al examinado a } \\
\text { contestar, sin embargo, después de } 15 \text { segundos se debe animar } \\
\text { a que responda. } \\
\text { Entorno y condiciones de aplicación: estancia tranquila y } \\
\text { privada y libre de distracciones, con dos sillas y una mesa. } \\
\text { Se debe utilizar el cuaderno de estímulos con el atril, para que el } \\
\text { sujeto pueda ver las cuatro imágenes y el examinador pueda ver } \\
\text { en el dorso las instrucciones que le debe de dar y lo que debe de } \\
\text { decir en voz alta. }\end{array}$ \\
\hline $\begin{array}{lll}\begin{array}{l}\text { Partes } \\
\text { prueba }\end{array} & \text { de } & \text { la } \\
\end{array}$ & $\begin{array}{l}\text { La prueba consiste en enseñar al sujeto cuatro imágenes cada } \\
\text { vez, y el examinador debe decir en voz alta el nombre de una de } \\
\text { ellas que viene predeterminada en la prueba. El niño debe } \\
\text { señalar la imagen correcta, se apunta en la hoja de registro de la } \\
\text { prueba. }\end{array}$ \\
\hline
\end{tabular}

Fuente: elaboración propia a partir de los datos obtenidos del manual de del Peabody Picture Vocabulary Test, TVIP (Dunn, et al., 2006).

\subsubsection{Entrevistas}

La entrevista en profundidad es junto a la observación y el focusgroup, una de las principales técnicas de investigación cualitativa (Fàbregues, et al., 2016). También es la más utilizada independientemente del área de conocimiento en el que nos situemos. De manera general, podemos definirla como una interacción entre dos personas, planificada y que pretende conseguir un objetivo con la opinión que el entrevistado aporta sobre alguna cuestión (Aranda y Araújo, 2009).

Olabuénaga (2012) la define de la siguiente manera: 
La segunda gran técnica de investigación cualitativa viene representada por la llamada Entrevista en Profundidad, que no es otra cosa que una técnica de obtener información, mediante una conversación profesional con una o varias personas para un estudio analítico de investigación o para contribuir en los diagnósticos o tratamientos sociales. (p. 165)

Podemos encontrar diferentes modalidades de agrupar y diferenciar las entrevistas; Olabuénaga (2012) lo divide en tres modalidades: entrevistas sostenidas con un solo individuo (individual) o con un grupo de personas (de grupo); entrevistas que cubren un amplio espectro de temas (biográficas); entrevistas dirigidas (estructuradas) en las que el entrevistador lleva la iniciativa de la conversación o aquellas en la que el entrevistador sigue un esquema cerrado y flexible de preguntas. También encontramos otras maneras de agruparlo, Cerón (2006) diferencia otras tres modalidades de entrevistas cualitativas según su nivel de estructuración: entrevista conversacional informal, entrevista basada en un guion y entrevista semiestructurada. A continuación, explicamos cada una de ellas:

- La entrevista conversacional informal: son entrevistas totalmente abiertas en las que las preguntas fluyen dependiendo del curso natural de las interacciones sociales, pueden ser tan largas como sea la interacción con ese individuo.

- La entrevista basada en un guion: se elabora una guía de temas que se quieren discutir con el entrevistado, pero siempre teniendo en cuenta que existe una gran flexibilidad y libertad para ordenar las preguntas y elaborar otras nuevas según vaya surgiendo en la interacción.

- La entrevista semiestructurada o entrevista estandarizada abierta: se elaboran unas preguntas ordenadas y redactadas por igual para todos los entrevistados pero la respuesta es abierta, ellos pueden responder con total libertad.

En esta tesis doctoral se utilizará la entrevista semiestructurada, por adecuarse mejor al objetivo conocer la opinión de diversos participantes en relación con el diseño de PELEO y a sus resultados. Fàbregues, et al., (2016) nos explican cómo desarrollar las entrevistas: (a) elegir correctamente las preguntas, y reducir el número de categorías temáticas y cuestiones vinculadas, de esta manera el entrevistado dispondrá de más libertad en las respuestas. (b) Se comenzará la entrevista por cuestiones descriptivas, para poco a poco ir conduciendo la entrevista a cuestiones más complejas. (c) se evitará formular las preguntas de manera tendenciosa condicionando la respuesta del entrevistado. En los Anexos 6,7 y 8 se encuentran las entrevistas realizadas. 
En la entrevista semiestructurada el investigador crea un clima y da la posibilidad al entrevistado de que se exprese con total libertad, el entrevistado dispone de un trazado en el que reconoce los temas que debe tratar, pero puede cambiar el orden de las preguntas y la manera de formular las mismas dependiendo de su opinión (Tonon, 2009). Por este motivo decidimos realizar un guion basado en las categorías que queríamos entrevistar para poder basarnos en ellos, y dejar un espacio para abordar algunas sugerencias que nos pudieran ofrecer las entrevistadas (Anexo 6, 7 y 8).

Además, se empleó la grabadora del móvil como instrumento para recoger las entrevistas, la grabación proporciona "datos duros" que a veces se necesitan para demostrar que una investigación es rigurosa y ofrece un registro exacto de los datos recogidos, y además de esta manera otras personas pueden volver a examinar dichas entrevistas (Descombe, 1984, citado en Durán, 2012). Por este motivo, en nuestra investigación grabaremos las entrevistas que se han realizado para poder recoger los datos.

\subsubsection{Cuestionario tipo Likert}

Elaborar cuestionarios no es una ciencia exacta, ya que tiene un componente creativo y artesanal, para evaluar con cuestionarios es necesario realizar una formulación adecuada de las preguntas y las posibles respuestas que forman parte de esta. Esta técnica es adecuada para el desarrollo de trabajos de campo que requieran la recogida sistemática y estructurada de información aportada por un número importante de participantes (Meneses y Rodríguez-Gómez, 2011).

Muñoz (2003) describe el cuestionario como:

Un procedimiento considerado clásico en las ciencias sociales para la obtención y registro de datos. Su versatilidad permite utilizarlo como instrumento de investigación y como instrumento de evaluación de personas, procesos y programas de formación. Es una técnica de evaluación que puede abarcar aspectos cuantitativos y cualitativos. Su característica singular radica en que, para registrar la información solicitada a los mismos sujetos, ésta tiene lugar de una forma menos profunda e impersonal, que el "cara a cara" de la entrevista. Al mismo tiempo, permite consultar a una población amplia de una manera rápida y económica. (p.2)

Existen diferentes tipos de cuestionario, entre ellos está el cuestionario tipo Likert, también llamado escala de clasificación, de juicio absoluto, 
cerrada, de valoración resumida, de múltiple elección entre otros (Cañadas-Osinski y Sánchez-Bruno, 1998); conviene diferenciar entre escala y elemento. La escala es el total de las respuestas de todos los elementos del cuestionario, y los elementos son las afirmaciones que van acompañados por las opciones de respuesta, generalmente indicando el nivel de acuerdo o desacuerdo (Bisquerra y Pérez, 2015).

El cuestionario tipo Likert hace referencia a "un procedimiento de escalamiento en el que el sujeto asigna los estímulos a un conjunto específico de categorías o cuantificadores lingüísticos en su mayoría de frecuencia (siempre, a veces, nunca, etc.,) o de cantidad (todo, algo, nada, etc.)" (Cañadas-Osinski y Sánchez-Bruno, 1998, p.623).

La cantidad de elementos ha estado muy cuestionada; principalmente se utilizan 5 puntos, sin una fundamentación metodológica que lo justifique, Bisquerra y Pérez (2015) recomiendan utilizar escalas de 11 puntos (de 0 a 10), que son las que utilizamos nosotros en el estudio previo, como se puede ver en el Anexo 1.

\subsection{Metodologías de recogida y análisis de datos}

Existen tres principales metodologías de recogida de datos, la metodología cuantitativa -que es la que vamos a utilizar en el Estudio Piloto (EP)-, la metodología cualitativa, y la metodología mixta -que es la que vamos a utilizar en el segundo estudio que constituye la investigación principal-. En este apartado nos centraremos en profundizar en la metodología cuantitativa y mixta de recogida de datos.

\subsubsection{Metodología cuantitativa de recogida de datos}

En el estudio previo se llevó a cabo una intervención con los bits de inteligencia del Método Doman sin realizar ninguna adaptación, con una metodología de recogida de datos cuantitativa. Cadena et al. (2017) explican las características de la metodología cuantitativa, que se fundamenta en el positivismo como fuente epistemológica. Esta metodología se basa en la precisión de los procedimientos de recogida de datos y medición; la distinción más obvia de esta metodología es que se produce el conocimiento a partir de datos numéricos. Galeano (2020) explica que en la metodología cuantitativa los datos son concebidos como rigurosos, duros y confiables. Las matemáticas son la base en la que se afianzan este tipo de metodologías. 
Galindo-Domínguez (2020) diferencia ocho pasos para desarrollar de una manera ordenada una investigación a través de un diseño cuantitativo: (a) determinar cuál será el tema de investigación; (b) concretar cuáles son los objetivos que se pretenden buscar; (c) diseño metodológico, se debe elegir cómo se va a recoger y analizar la información para responder a las preguntas de investigación; (d) diseño de la investigación, se debe elegir qué metodología utilizar; en el caso del Estudio Piloto (EP), que es en el que vamos a utilizar una metodología cuantitativa, será el estudio cuasi experimental; (e) describir el proceso de selección muestral; (f) se debe aportar información sobre cuáles son los instrumentos empleados; (g) describir el procedimiento completo de recolección de datos; (h) conocer cuáles son los resultados teniendo en cuenta los objetivos planteados; (i) el último paso es la discusión.

Según Galeano (2020) existen varios objetivos de investigación que demandan este tipo de metodologías:

- La medición de variables que pueden ser cuantificadas, como pueden ser las dimensiones del lenguaje que pueden ser medidas con pruebas estandarizadas.

- La verificación de hipótesis que tienen como soporte una teoría aceptada por la comunidad científica.

- La definición de investigaciones que tengan como soporte: cubrir servicios, establecimiento de necesidades, niveles laborales, variables demográficas...

- El comportamiento humano o comportamientos sociales como puede ser el lenguaje.

- Probar teorías

- Generalizar los resultados a poblaciones más amplias.

Podemos encontrar más características de la metodología cuantitativa en la Tabla 3.9, que se encuentra en el siguiente subapartado.

\subsubsection{Metodología mixta de recogida de datos}

Los métodos mixtos se han consolidado en la segunda década del S. XXI como una tercera ruta, aproximación o enfoque de investigación en todos los campos de conocimiento incluido en el educativo (HernándezSampieri, 2018; Molina-Azorín \& Fetters, 2020). En esta tercera vía se entrelazan la ruta cuantitativa y cualitativa mezclándolas, sumándolas y 
logrando su interacción y potenciación (Torres, 2019). Esta metodología es ideal para el campo de las ciencias sociales donde la realidad es cambiante e incierta, y el contexto es complejo; con esta vía el investigador se puede acercar al objeto de estudio y obtener un conocimiento de la realidad social (Del Canto y Silva, 2013).

Los métodos mixtos representan un conjunto de procesos sistemáticos, empíricos y críticos de investigación e implican la recolección y el análisis de datos cuantitativos y cualitativos, así como su integración y discusión conjunta para realizar inferencias producto de toda la información recabada (metainferencias) y lograr un mayor entendimiento del fenómeno bajo estudio. (Hernández-Sampieri, 2018, p.612)

El hecho de que en diferentes ciencias se comenzaran a utilizar más los métodos mixtos radica en la complejidad de la gran mayoría de cuestiones exploradas en la investigación. Estos están constituidos por dos realidades, una objetiva y otra subjetiva (Hernández-Sampieri, 2018). El método mixto a menudo (pero no siempre) supone el uso de métodos cuantitativos o cualitativos para medir la misma característica, pero en algunas ocasiones dentro de una investigación se miden diferentes dimensiones, y para cada dimensión se usa un enfoque diferente cuantitativo o cualitativo (Morse, 2016). En nuestro estudio, algunas dimensiones como las características del lenguaje de los niños se van a medir siguiendo un enfoque cuantitativo, mientras que el contexto de intervención o el diseño del método se medirá desde un enfoque cualitativo. Corr et al. (2020) proponen utilizar métodos mixtos para realizar investigaciones con niños con necesidades educativas especiales, y precisamente los niños con trastorno del lenguaje tienen estas dificultades.

A continuación, vamos a describir las principales metodologías del estudio cuantitativo y cualitativo para comprender en profundidad la metodología mixta (Tabla 3.9). 
Tabla 3.9.

Comparación entre las rutas cuantitativa y cualitativa

\begin{tabular}{|c|c|c|}
\hline & Ruta cuantitativa & Ruta cualitativa \\
\hline $\begin{array}{l}\text { Planteamiento } \\
\text { del problema }\end{array}$ & $\begin{array}{l}\text { Específico, acotado, centrado en } \\
\text { variables medibles } \\
\text { observables. }\end{array}$ & $\begin{array}{l}\text { Abierto, emergente y se } \\
\text { enfoca conforme se desarrolla } \\
\text { el proceso en cuestiones que } \\
\text { nos permitan entender el } \\
\text { fenómeno estudiado. } \\
\text { Orientado hacia explorar, } \\
\text { describir y comprender. }\end{array}$ \\
\hline $\begin{array}{l}\text { Revisión de la } \\
\text { literatura }\end{array}$ & $\begin{array}{l}\text { Direcciona el proceso y justifica } \\
\text { el planteamiento y la necesidad } \\
\text { del estudio. }\end{array}$ & $\begin{array}{l}\text { Contextualiza el proceso y } \\
\text { justifica el planteamiento y la } \\
\text { necesidad del estudio. }\end{array}$ \\
\hline Hipótesis & $\begin{array}{l}\text { Se establecen antes de recolectar } \\
\text { los datos y se pretende probarlas } \\
\text { (aceptar-rechazar). }\end{array}$ & $\begin{array}{l}\text { Emergentes: se generan y van } \\
\text { cobrando sentido según se va } \\
\text { investigando. }\end{array}$ \\
\hline Diseños & $\begin{array}{l}\text { Son preestablecidos y se } \\
\text { implementan al pie de la letra. }\end{array}$ & $\begin{array}{l}\text { Emergentes, son abordajes } \\
\text { que se aplican según van } \\
\text { apareciendo } \\
\text { circunstancias. }\end{array}$ \\
\hline Muestra & $\begin{array}{l}\text { El tamaño depende de cómo de } \\
\text { grande y heterogénea sea la } \\
\text { población, pues debe lograr un } \\
\text { número representativo de casos. } \\
\text { Se determina a partir de } \\
\text { fórmulas y estimaciones de } \\
\text { probabilidad. }\end{array}$ & $\begin{array}{l}\text { El tamaño depende de que } \\
\text { comprendamos el fenómeno } \\
\text { bajo estudio. La muestra viene } \\
\text { determinada por el contexto y } \\
\text { las necesidades. }\end{array}$ \\
\hline $\begin{array}{l}\text { Recolección de } \\
\text { datos }\end{array}$ & $\begin{array}{l}\text { Instrumentos predeterminados y } \\
\text { estandarizados que nos ofrecen } \\
\text { datos numéricos. }\end{array}$ & $\begin{array}{l}\text { Instrumentos que se van } \\
\text { afinando y uniformando poco } \\
\text { a poco. La recolección se } \\
\text { orienta a proveer un mayor } \\
\text { entendimiento de los } \\
\text { significados y experiencias de } \\
\text { las personas. }\end{array}$ \\
\hline $\begin{array}{l}\text { Análisis de los } \\
\text { datos }\end{array}$ & Estadísticos sobre una matriz. & $\begin{array}{l}\text { Análisis temático y de } \\
\text { narrativas usando una base de } \\
\text { datos }\end{array}$ \\
\hline $\begin{array}{l}\text { Presentación } \\
\text { de resultados }\end{array}$ & $\begin{array}{l}\text { Distribución de variables, } \\
\text { coeficientes, tablas y figuras que } \\
\text { relacionan variables. }\end{array}$ & $\begin{array}{l}\text { Categorías, temas y patrones: } \\
\text { tablas y figuras que asocian } \\
\text { categorías, materiales } \\
\text { simbólicos... }\end{array}$ \\
\hline $\begin{array}{ll}\text { Reporte } & \text { de } \\
\text { resultados } & \end{array}$ & $\begin{array}{l}\text { Basado en un estilo de } \\
\text { publicaciones estándar con un } \\
\text { tono impersonal y muy objetivo. }\end{array}$ & $\begin{array}{l}\text { Basado en un estilo de } \\
\text { publicaciones emergente, } \\
\text { flexible, tono personal, } \\
\text { incluye tendencias del } \\
\text { investigador clarificadas. }\end{array}$ \\
\hline
\end{tabular}

Fuente: Elaborado a partir de los datos de Torres (2019, p.21). 
La temporalización de la recogida de datos puede variar, pueden recogerse previamente los datos cualitativos y posteriormente los cuantitativos, puede realizarse al revés o simultáneamente (Creswell \& Creswell, 2017), podemos encontrar un esquema de los principales diseños de investigación según Creswell (2015) en la Tabla 3.10.

Tabla 3.10.

Esquema de los tipos de metodología mixta

\begin{tabular}{ll}
\hline Diseños básicos & Convergente (síncrono). \\
\cline { 2 - 2 } & Exploratorio secuencial (diacrónico). \\
\cline { 2 - 2 } & $\begin{array}{l}\text { Explicativo secuencial (primero datos cuantitativos, luego } \\
\text { datos cualitativos. Los primeros datos explican los segundos. }\end{array}$ \\
\hline $\begin{array}{l}\text { Diseños avanzados } \\
\text { (Diseño básico con } \\
\text { otro elemento) }\end{array}$ & $\begin{array}{l}\text { Intervención: estudiar problemas llevando a cabo un } \\
\text { experimento o ensayo de intervención y sumar datos } \\
\text { cualitativos. }\end{array}$ \\
\cline { 2 - 2 } & $\begin{array}{l}\text { Justicia social: agregar la perspectiva teórica general de } \\
\text { justicia social a una investigación de métodos mixtos para } \\
\text { aportar una perspectiva teórica. }\end{array}$ \\
\cline { 2 - 2 } & $\begin{array}{l}\text { Evaluación por múltiples etapas: consiste en evaluar a lo } \\
\text { largo del tiempo la implantación de un programa. }\end{array}$ \\
\hline
\end{tabular}

Fuente: Creswell (2015).

Teniendo en cuenta esta clasificación podemos determinar que este estudio se basa en una recogida de datos mixta de diseño avanzado de intervención, ya que llevamos a cabo una intervención con PELEO y añadimos datos cualitativos para comprender en profundidad el programa.

Según Schoonenboom \& Johnson (2017), los estudios mixtos también pueden ser dependientes o independientes; son dependientes cuando el análisis de los datos de un segundo componente depende de los del primer componente; en nuestro caso son independientes ya que los resultados del análisis de datos no dependen unos de otros. Pero, aun así, según Ramírez-Montoya y Lugo-Ocando (2020) hay que destacar que "los métodos mixtos no es la suma de lo cuantitativo con lo cualitativo, 
sino que es la combinación estratégica lo que marca su diseño de aporte a la investigación" (p.10).

Uno de los modelos de diseño más utilizados en la metodología cuantitativa es la de Mertens (2015), consiste en: (a) analizar el problema y planificar el proceso que se va a llevar a cabo incluyendo los objetivos y las etapas que se van a seguir; (b) diseñar y desarrollar la documentación que se va a utilizar justificando las decisiones; como haremos en el capítulo 4, y desarrollar los resultados como se puede observar en el capítulo 5 (c) evaluación del diseño, en el que se valorará si los métodos mixtos son los adecuados y (d) inferencias y generalizaciones, comunicaremos los resultados, es decir observamos la explicación de este modelo.

\subsubsection{Ventajas del método mixto}

Las tres rutas metodológicas (cuantitativa, cualitativa y mixta) han aportado un gran conocimiento en todas las ciencias; ninguna es intrínsecamente mejor que la otra, solo constituyen diferentes aproximaciones al estudio de una cuestión (Torres, 2019). Pero es una realidad que los métodos mixtos nos permiten profundizar en los fenómenos que se quieren estudiar de manera más específica y complementaria para responder preguntas descriptivas y más objetivas (Morse, 2016).

Algunas de las ventajas de utilizar este método, explicadas por (Hernández-Sampieri, 2018), son:

- Lograr una perspectiva más amplia y profunda del fenómeno: ya que se incrementa la evidencia al utilizar diferentes enfoques metodológicos que nos proporcionan mayor generalización y certeza sobre las conclusiones que saquemos de los resultados. Además, si utilizamos dos métodos que tienen debilidades y fortalezas y nos ayudan a llegar al mismo resultado, podremos aumentar nuestra confianza en que estos son una representación fiel de la realidad, por lo que tener información cuantitativa (pre y postest del lenguaje), y la observación de los videos de intervención, puede hacernos ver desde una perspectiva más amplia cómo ha mejorado el lenguaje en estos niños; y tener los resultados de las entrevistas y las observaciones nos puede ayudar a comprender en profundidad PELEO. 
- Producir datos más ricos y variados gracias a multiplicar las observaciones y las fuentes y tipos de datos; esto ocurre en esta investigación ya que observamos el lenguaje de diferentes maneras, observamos la motivación de los niños a través de preguntas a las logopedas, a las maestras y en los videos de nuestra intervención.

- Potenciar la creatividad en la teoría a través de diferentes procesos críticos de valoración; utilizamos diferentes procesos: observación, entrevistas, test... lo que aporta en esta investigación ese imprescindible proceso crítico.

- Apoyar con mayor solidez las inferencias que se realicen en las conclusiones.

- Permitir una mejor exploración y generalización de los datos que obtengamos.

- La posibilidad de éxito aumenta al tener más enfoques y no nos centramos solo en uno.

- Ayuda a desarrollar nuevas destrezas o competencias dentro del ámbito de la investigación.

Además, está demostrado que los métodos mixtos ayudan a resolver problemas sociales y podemos potenciar los beneficios para lograrlo si seguimos lo que propone Molina-Azonrin \& Fetters (2019): (a) mediante el uso de un kit completo de herramientas metodológicas como el que usamos en esta investigación; (b) al integrar diferentes experiencias de los dos enfoques metodológicos; (c) al comprometer a los interesados, involucrándolos en la creación de conocimiento; (d) al producir una evidencia importante y publicándola; y por último, (e) difundiendo, evaluando y demostrando el impacto de la investigación.

\subsection{Cuestiones ético-metodológicas}

En el marco de la ética de la investigación cualitativa, encontramos un debate que se centra en la idea de que utilizar métodos afines a este paradigma hace que la investigación se considere moralmente superior al tener un carácter más humano (Noreña-Peña, et al., 2012). Las cuestiones ético-metodológicas consisten en evitar daños a las personas que participan en las investigaciones, cuidando de su integridad, autonomía y dignidad, por lo cual los siguientes tres principios son básicos: el consentimiento informado, la confidencialidad de la información y el respeto al anonimato de las personas participantes (Miguélez, 2016). 


\subsubsection{Consentimiento}

Toda investigación social lleva implícita una tensión asociada a la participación de personas como un medio para lograr un fin propio, esta tensión se ha intentado resolver utilizando un consentimiento informado. Estas personas deben recibir información acerca de los objetivos de la investigación, el tipo de participación demandada o esperada, el origen de la financiación del proyecto o el respaldo institucional del mismo, así como el uso que se hará de los resultados obtenidos (Miguélez, 2016). "El consentimiento informado como herramienta normalizada en la investigación es la declaración expresa del voluntario que manifiesta haber entendido cuál va a ser su participación y en la que se deja constancia de su libre colaboración" (Pardo-Caballos y Echarte-Alonso, 2015, p.208). En el caso de los menores, es conveniente realizar un consentimiento informado que firmen los padres o los tutores legales de este (Vicente, 2015). El consentimiento informado del EP se puede observar en el Anexo 2, el consentimiento informado del ECE de PELEO que debían rellenar las logopedas está en el Anexo 10, el de las familias de los niños y los centros en el Anexo 11.

\subsubsection{Confidencialidad}

Hay un acuerdo de respetar estos dos principios; podemos vincular la confidencialidad con privacidad. Sin embargo, en las investigaciones sociales este principio es problemático al ser obligatorio dar a conocer los hallazgos. Este problema se puede resolver con la petición de un permiso explícito de uso de los datos recabados durante la investigación, dando la posibilidad a los participantes de renovar dicho permiso (Miguélez, 2016), en esta investigación se ha dado la posibilidad a los participantes de eliminar el permiso otorgado poniéndose en contacto con la investigadora principal, como se puede observar en todos los consentimientos informados (Anexo 2, 10 y 11). Pero podemos encontrar los problemas éticos que tienen que ver con los límites en el mantenimiento de la confidencialidad, por lo que el participante como titular de la información debe saber y autorizar qué información personal va a ser proporcionada a otras personas, con qué objetivo y con qué amplitud (Vicente, 2015). 


\subsubsection{Anonimato}

La garantía del anonimato tiene sus limitaciones en la investigación cualitativa, ya que en este paradigma la contextualización es imprescindible. En investigaciones sobre grupos sociales muy delimitados, la mención del contexto es necesaria, y esto dificulta el anonimato máxime cuando el análisis hace necesaria la utilización de fragmentos que representen citas directas y literales (Miguélez, 2016). Por ejemplo, en nuestro estudio en algunas ocasiones es necesario describir algunas frases que han dicho los participantes; $y$, probablemente, con algunas de las cosas que pueden decir se puede rastrear la identidad de cada participante, lo que entra en colisión con el hecho de que algunas personas podrían cuestionar la validez del estudio si eliminamos estas palabras. Por ello es importante atender a las características particulares y específicas de cada participante con el fin de respetarlos y proteger la información brindada por ellos de la mejor manera posible (Santi, 2016). En este sentido, en este estudio se han numerado a los participantes (niños, centros colaboradores, logopedas y maestras) por números en vez de por sus iniciales; y además se ha omitido información en la que los niños dijeran su propio nombre o la logopeda nombrara a los niños, para evitar su identificación. 



\section{Capítulo 4 \\ Metodología de investigación}

En este capítulo describiremos la metodología de investigación de la tesis doctoral, concretamente nos centraremos en la descripción detallada del fenómeno que queremos analizar y conocer en profundidad, que es el Programa de Estimulación Lingüística de Expresión Oral (PELEO).

Para mejor comprensión de este capítulo, tenemos que aclarar que hemos realizado dos estudios, el primero que denominamos "Estudio Piloto" (EP), que sigue la metodología cuasi experimental y representa los antecedentes del segundo estudio, de evaluación de PELEO. En este EP nos centraremos en especial en los criterios de selección de los participantes, la contextualización de la recogida de datos, los objetivos del estudio, las técnicas de análisis de datos e instrumentos que se han utilizado y las fases de aplicación que se han seguido, para finalizar con la explicación del análisis de los errores cometidos, para poder diseñar el segundo estudio que denominamos ECE en el que nos centraremos en el siguiente apartado.

El ECE consiste en la aplicación, evaluación y comprensión de PELEO, que al igual que en el apartado anterior, vamos a profundizar en los criterios de selección de los participantes, en la contextualización de la intervención, en los objetivos del estudio, en las técnicas de análisis de datos e instrumentos y, por último, en las fases de aplicación. Para este caso empleamos un diseño de investigación basado en el ECE desde un paradigma mixto. 


\subsection{Objetivos de la investigación}

Los objetivos del trabajo en general ya han sido planteados en el Capítulo 1:

a) Diseñar el Programa de Estimulación Lingüística de Expresión Oral (PELEO).

b) Evaluar el diseño de PELEO en niños con trastorno del lenguaje de tres, cuatro y cinco años.

c) Valorar y analizar la aplicación de PELEO en niños de tres, cuatro y cinco años con trastorno del lenguaje.

Hemos determinado los siguientes como objetivos específicos:

a) Comprobar la eficacia de los bits de inteligencia del Método Doman en los niños con trastorno del lenguaje y valorar si son útiles para el nuevo programa que vamos a crear.

b) Valorar qué características de los bits de inteligencia del Método Doman, podemos utilizar para crear PELEO.

c) Proponer una serie de recomendaciones y sugerencias que realizar en el diseño de PELEO, tras realizar una evaluación exhaustiva al diseño y a la utilización de este.

d) Comprobar cómo ha cambiado la articulación, el vocabulario y la morfosintaxis de los niños que han utilizado PELEO.

La consecución de estos objetivos se materializa en dos diseños de investigación: el diseño cuasi experimental (que se lleva a cabo en el Estudio Piloto) y el ECE (que se lleva a cabo en la investigación posterior). Según Duran (2002), los Estudios de Caso comprenden numerosos objetivos, entre los que destacamos: comprender el fenómeno que se está estudiando desde el punto de vista de las personas que forman parte de él, proporcionar información sobre el objeto de estudio, describir situaciones o hechos, obtener conclusiones sustanciales y analizar de manera intensiva y profunda el o los fenómenos que sean el objeto de estudio. De esta manera, consideramos que se trata de un diseño perfecto para analizar el Programa de Estimulación Lingüística de Expresión Oral (PELEO), al igual que creemos que el diseño cuasi experimental (Campbell \& Stanley, 2005) sirve para valorar la eficacia de un programa de intervención, que era lo que queríamos lograr en el Estudio Piloto (EP). 


\subsection{Diseño de investigación}

Según Olabuénaga (2012), en el diseño de investigación "se unen conceptos y técnicas que luego se aplicarán a los hechos reales." (p.92), también podemos definirlo como "planificación que guía los diversos métodos y técnicas empleados coordinadamente para lograr los objetivos de investigación" (González-Díaz y Hernández-Royett, 2017, p.15). En esta tesis se van a utilizar dos diseños de investigación dependiendo del estudio que realicemos. Ver Figura 4.2.

\section{Estudio piloto: bits de inteligencia del Método Doman}

\section{Estudio cuasi experimental}

\section{Estudio 2: Programa de Estimulación Lingüística de Expresión Oral (PELEO)}

\section{Estudio de caso evaluativo}

Figura 4.2. Síntesis de los diseños de investigación que se utilizarán en esta tesis. Fuente: Elaboración propia.

La explicación de estos dos diseños ya se explicó el apartado 3.2 y 3.3 que se encuentran en el capítulo 3.

\subsection{Descripción del estudio de investigación}

A continuación, se explican los dos estudios de investigación llevados a cabo, pues a través de estos estudios se han conseguido los datos necesarios para realizar el posterior análisis. 


\subsubsection{Estudio 1: Estudio piloto (EP)}

Como ya se ha comentado anteriormente, el Estudio Piloto (EP) consiste en la puesta en marcha de un programa de los bits de inteligencia de Glenn Doman con ocho participantes con retraso del lenguaje, cuatro que forman parte del grupo experimental con los que vamos a utilizar los bits de inteligencia durante un tiempo que oscila entre las 9 a las 15 semanas. Y otro grupo de otros cuatro participantes que ha formado parte del grupo control, son niños a los que no se les ha intervenido y se les ha evaluado dejando pasar el mismo tiempo que a los niños del grupo experimental.

Para el diseño de este programa se tiene en cuenta fielmente la metodología seguida por Doman y Doman (1998) sin ningún cambio ni modificación, ya que lo que queremos es comprobar su efectividad en infantes con trastorno del lenguaje.

\subsubsection{Objetivos del estudio}

En este Estudio Piloto (EP), perseguimos los siguientes objetivos generales:

- Determinar el efecto de los bits de inteligencia del Método Doman en el lenguaje de los niños con trastorno del lenguaje que acuden a un gabinete privado de Palencia.

- Analizar los elementos que podemos utilizar en el nuevo programa que vamos a diseñar, PELEO.

Para perseguir estos objetivos determinamos una serie de hipótesis. En primer lugar, determinamos la siguiente hipótesis general: la aplicación de los bits de inteligencia del Método Doman tiene un efecto positivo en el desarrollo del lenguaje de los niños con trastorno del lenguaje que acuden a un gabinete privado de Palencia. A partir de esta hipótesis general nacen las siguientes hipótesis específicas:

- La aplicación de los bits de inteligencia del Método Doman tiene un efecto positivo en la dimensión fonético-fonológico de los niños con trastorno del lenguaje que acuden a un gabinete privado de Palencia.

- La aplicación de los bits de inteligencia del Método Doman tiene un efecto positivo en la dimensión semántica de los niños con trastorno del lenguaje que acuden a una consulta de logopedia de Palencia. 
- La aplicación de los bits de inteligencia del Método Doman tiene un efecto positivo en la dimensión sintáctica de los niños con trastorno del lenguaje que acuden a una consulta de logopedia de Palencia.

- La aplicación de los bits de inteligencia del Método Doman tiene un efecto positivo en la dimensión pragmática de los niños con trastorno del lenguaje que acuden a una consulta de logopedia de Palencia.

\subsubsection{Contextualización}

El estudio se llevó a cabo por la propia investigadora que trabaja como logopeda en un gabinete privado. Al centro acuden personas con discapacidad o sin ella de cualquier rango de edad que presenten la necesidad o decidan de acudir al centro a cualquiera de los servicios que se prestan. Los profesionales que trabajan en él y los servicios o funciones que tienen cada uno de ellos son:

- El director que se encarga de coordinar todos los servicios.

- La trabajadora social que se encarga del ámbito cognitivo y social.

- Dos fisioterapeutas que se encargan de la fisioterapia y actividades físicas.

- El maestro de pedagogía terapéutica que se encarga de impartir las clases de apoyo escolar y técnicas de estudio.

- Dos educadoras sociales y una animadora sociocultural que se encargan del ámbito cognitivo, físico y social.

- Dos técnicos en atención a personas en situación de dependencia que se encargan del centro de día.

- Dos logopedas cuya función es encargarse del tratamiento de las personas, de cualquier edad que acudan al centro, con dificultades en el lenguaje oral, escrito, habla, voz y deglución.

- Dos conserjes, que se encargan de la entrada y salida de las personas de manera ordenada, y de la desinfección del centro.

En total trabajan en el centro 14 personas, aunque algunas de las personas que trabajan en él no tienen dedicación a jornada completa ni exclusiva.

\subsubsection{Participantes del Estudio Piloto (PEP) y criterios de selección}


Inicialmente, los participantes del estudio son todos los niños y niñas que acuden al servicio de la consulta de logopedia, pero de ellos solo nos interesan aquellos que presentan los siguientes criterios de inclusión:

- Que sean niños diagnosticados de dificultades del lenguaje (hablantes tardíos) o trastorno del desarrollo del lenguaje.

- Que tengan entre tres y seis años.

- Que antes de comenzar este estudio ya acudieran a rehabilitación del lenguaje.

Se excluye a aquellos que presentan previamente algún problema de pérdida auditiva, infecciones respiratorias y otitis media de repetición, que pudieran ser causantes del problema.

Llevando a cabo este cribado inicial seleccionamos a ocho participantes, y se les dividió para que cuatro de ellos formaran parte del grupo experimental y otros cuatro del grupo control. Se les dividió siguiendo el criterio de la edad, logrando que hubiera niños de las mismas edades en ambos grupos, siendo todos del mismo sexo: varones.

La media de la edad de los participantes se puede observar en la Tabla 4.2.

Tabla 4.1.

Edad media de los Participantes del Estudio Piloto (PEP)

\begin{tabular}{llllll} 
& $\mathrm{N}$ & Mínimo & Máximo & Media & $\begin{array}{l}\text { Desviación } \\
\text { estándar }\end{array}$ \\
\hline Edad en meses & 8 & 50,00 & 79,00 & 66,0000 & 10,36478 \\
\hline N válido (por lista) & 8 & & & \\
\hline \multicolumn{5}{c}{ Fuente: elaboración propia. }
\end{tabular}

\subsubsection{Técnicas e instrumentos utilizados}

En este Estudio Piloto (EP), se han utilizado tres tipos de técnicas e instrumentos: el primero, los bits de Inteligencia del Método Doman; el segundo, las pruebas estandarizadas; $y$, en tercer lugar, las entrevistas a las familias. Con el grupo experimental se han utilizado todos los instrumentos, y con el grupo control solamente las pruebas estandarizadas. 
1) Bits de Inteligencia del Método Doman.

Para diseñar los bits de inteligencia del Método Doman se han seguido las líneas determinadas por Doman y Doman (1998), pero se han adaptado a las nuevas tecnologías, como también se realizó en el estudio de Bautista (2010), utilizando la herramienta PowerPoint, añadiendo a cada diapositiva una imagen real y la palabra escrita debajo con el concepto que se pretende representar. Cada PowerPoint está compuesto por 10 ítems, donde se incluyen 10 categorías semánticas, divididos en un total 20 PowerPoint. La duración de estos PowerPoint será de una semana por cada PowerPoint, es decir 20 semanas. Sin embargo, advertimos que aunque programamos esta intervención, no se llegó a utilizar por completo el método. El tiempo máximo de intervención ha sido de 15 semanas, con una duración de las sesiones de 45 minutos, como se podrá ver explicado más adelante. Podemos ver un ejemplo de un bit de inteligencia en la Figura 4.3., y el resto de las imágenes utilizadas están disponibles en el Anexo 12.

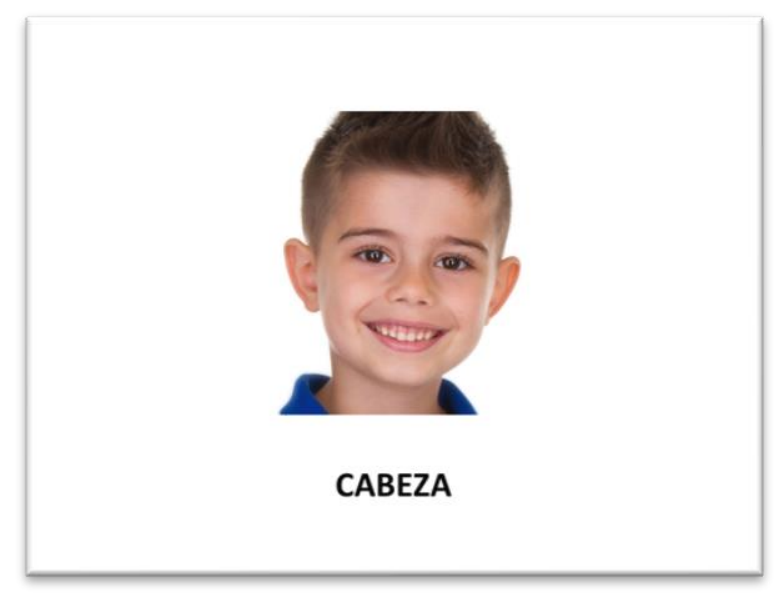

Figura 4.3. Ejemplo de Bit de inteligencia creado para este Estudio Piloto. Se pueden ver el resto de las imágenes en el Anexo 12.

Fuente de la imagen: Pixabayhttps://pixabay.com/es/photos/en-lacabeza-ni\%C3\%B1o-sonrisa-2644201/

Con el objetivo de homogeneizar la aplicación del programa y asegurarnos que no haya sesgos respecto a las diferencias de las voces o de la manera de decirlo, y siempre sea igual, se añade la misma voz a cada categoría semántica, usando el mismo tono de voz y misma 
metodología de intervención con todos los niños. Este material se compone de las siguientes categorías: partes del cuerpo, prendas de vestir, frutas, verduras, carne, otros alimentos, objetos, animales de la granja, transportes y opuestos. En la Tabla 4.2 se muestran las categorías y las palabras que forman parte del programa.

Tabla 4.2.

Vocabulario de los PowerPoint

\begin{tabular}{|c|c|c|}
\hline Categoría & $\begin{array}{l}\mathrm{N}^{\mathrm{o}} \text { de } \\
\text { PowerPoint de } \\
\text { cada categoría }\end{array}$ & Palabras \\
\hline $\begin{array}{ll}\text { Partes del } \\
\text { cuerpo }\end{array}$ & 2 & $\begin{array}{l}\text { Cabeza, boca, ceja, mejilla, barbilla, nariz, ojos, } \\
\text { oreja, cuello, dientes, frente, garganta, lengua, } \\
\text { párpados, pestañas, brazo, codo, hombro, mano, } \\
\text { dedos, uña, pierna, dedos de los pies, muslo, pie, } \\
\text { rodilla, tobillo, culo, espalda, barriga. }\end{array}$ \\
\hline $\begin{array}{l}\text { Prendas de } \\
\text { vestir }\end{array}$ & 2 & $\begin{array}{l}\text { Abrigo, chaqueta, pantalón, jersey, camisa, falda, } \\
\text { bufanda, gorro, leotardos, botas, camiseta, } \\
\text { chándal, zapatos, chanclas, calcetines, } \\
\text { calzoncillos, bragas, bañador, sombrero, playeras. }\end{array}$ \\
\hline Frutas & 2 & $\begin{array}{l}\text { Albaricoque, caqui, cereza, ciruela, fresa, } \\
\text { granada, higo, kiwi, limón, mandarina, mango, } \\
\text { manzana, melocotón, melón, naranja, pera, piña, } \\
\text { plátano, sandía, uva. }\end{array}$ \\
\hline Verduras & 2 & $\begin{array}{l}\text { Ajo, alcachofa, berenjena, seta, calabaza, cebolla, } \\
\text { champiñón, maíz, calabacín, zanahoria, coliflor, } \\
\text { espárrago, guisante, judía, lechuga, patata, } \\
\text { pepino, pimiento, puerro, tomate. }\end{array}$ \\
\hline Carne & 1 & $\begin{array}{l}\text { Filete, hamburguesa, beicon, costilla, jamón, } \\
\text { chorizo, salchichón, mortadela, pollo, salchicha. }\end{array}$ \\
\hline $\begin{array}{l}\text { Otros } \\
\text { alimentos }\end{array}$ & 2 & $\begin{array}{l}\text { Pescado, pizza, cereales, magdalenas, bollo, tarta, } \\
\text { patatas fritas, gominolas, pepinillos, aceitunas, } \\
\text { leche, batido, agua, zumo, Coca-cola, yogurt, } \\
\text { galletas. }\end{array}$ \\
\hline Objetos & 2 & $\begin{array}{l}\text { Puerta, ventana, silla, mesa, cama, cuchara, } \\
\text { tenedor, cuchillo, plato, vaso, servilleta, lámpara, } \\
\text { televisión, cuento, juguete, parque, columpio, } \\
\text { tobogán, teléfono, casa, llaves, gafas. }\end{array}$ \\
\hline Animales & 3 & $\begin{array}{l}\text { Gallina, gallo, cerdo, vaca, caballo, burro, pollito, } \\
\text { conejo, oveja, pato, elefante, tigre, león, cebra, } \\
\text { mono, serpiente, ciervo, oso, lobo, cocodrilo, } \\
\text { perro, gato, rana, mosca, pájaro, mariposa, jirafa, } \\
\text { canguro, leopardo, hipopótamo. }\end{array}$ \\
\hline Transportes & 2 & $\begin{array}{l}\text { Coche, autobús, avión, barco, bicicleta, camión, } \\
\text { camioneta, moto, furgoneta, globo aerostático, } \\
\text { helicóptero, lancha motora, metro, monopatín, }\end{array}$ \\
\hline
\end{tabular}




\begin{tabular}{lll}
\hline & motocicleta, moto de agua, patines, patinete, taxi, \\
& tren. \\
\hline Opuestos & 2 & $\begin{array}{l}\text { Día-noche, frío-calor, encima-debajo, dentro- } \\
\text { fuera, llena-vacía, limpia-sucia, lento-rápido, } \\
\text { largo- corto, joven-viejo, feliz-triste. }\end{array}$ \\
\hline
\end{tabular}

Fuente: Elaboración propia, publicada en Ayuso-Lanchares et al. (2019).

2) Pruebas estandarizadas

Las pruebas empleadas son las que nos han permitido evaluar el nivel del lenguaje de los Participantes del Estudio Piloto (PEP); entre las que existen actualmente hemos seleccionado las que se pueden observar en la Tabla 4.3. Todas las pruebas se han aplicado antes y después de la intervención en el siguiente orden: primero se aplicó el PLON-R -Prueba de Lenguaje Oral Navarra-Revisada- (Aguinaga et al., 1990), después el PEABODY - Picture Vocabulary Test, TVIP-(Dunn et al., 2006) y, finalmente, el Registro Fonológico Inducido (RFI) (Juárez y Monfort, 1996a).

Tabla 4.3.

Pruebas estandarizadas

Test
El PLON-R. Prueba de
Lenguaje Oral Navarra-
Revisada (Aguinaga, et al.,
1990).

\section{Descripción}

Esta prueba se divide en

subpruebas:

Contenido y Uso.

La subprueba Forma

incluye los aspectos

relacionados con los

aspectos formales, es decir,

de la topografía de la

expresión verbal, sin tener

en cuenta los otros niveles

léxicos o pragmáticos. En

esta descripción se incluye

la fonología, morfología y

la sintaxis. La subprueba

Contenido hace referencia a

los aspectos relacionados

con el estudio del

significado de las palabras;

es decir, la semántica.

\section{Objetivo de la prueba}

Se utiliza con el

objetivo de evaluar el desarrollo del lenguaje oral de los niños y, de esta manera, comparar sus resultados. 


\begin{tabular}{|c|c|c|}
\hline & $\begin{array}{l}\text { La subprueba Uso se } \\
\text { incluye la funcionalidad del } \\
\text { lenguaje oral, es decir, el } \\
\text { nivel pragmático del } \\
\text { lenguaje. }\end{array}$ & \\
\hline $\begin{array}{l}\text { El Registro Fonológico } \\
\text { Inducido (RFI) (Juárez y } \\
\text { Monfort, 1996a). }\end{array}$ & $\begin{array}{l}\text { Esta prueba incluye un } \\
\text { material de } 57 \text { tarjetas para } \\
\text { la evaluación fonológica, en } \\
\text { expresión espontánea y en } \\
\text { repetición. }\end{array}$ & $\begin{array}{l}\text { Esta prueba nos aporta } \\
\text { información } \\
\text { cuantitativa de los } \\
\text { aspectos fonológicos } \\
\text { en repetición y } \\
\text { expresión espontánea. }\end{array}$ \\
\hline $\begin{array}{l}\text { El Peabody Picture } \\
\text { Vocabulary Test, TVIP } \\
\text { (Dunn, et al., 2006). }\end{array}$ & $\begin{array}{l}\text { Evalúa el nivel de } \\
\text { vocabulario receptivo (nivel } \\
\text { semántico). }\end{array}$ & $\begin{array}{l}\text { Los resultados de esta } \\
\text { prueba nos hacen } \\
\text { conscientes de si existe } \\
\text { algún cambio en su } \\
\text { nivel de vocabulario, } \\
\text { juntamente con la } \\
\text { subprueba de } \\
\text { Contenido del PLON. }\end{array}$ \\
\hline
\end{tabular}

Fuente: Elaboración propia, publicada en Ayuso-Lanchares et al. (2019).

3) Cuestionario

Para conocer la opinión de las familias del grupo experimental sobre la metodología seguida en las intervenciones se ha decidido utilizar el cuestionario. Al finalizar la intervención con los bits de inteligencia se aplicó el mismo cuestionario elaborados ad hoc a cada familia.

El tipo de cuestionario empleado (véase Anexo 1) emplea una escala tipo Likert (Cañadas-Osinski y Sánchez-Bruno, 1998). La escala que utilizamos es de 11 puntos, en el que (0) representa la puntuación más baja/lo menos frecuente, y el (10) la máxima frecuencia. El cuestionario consta de los siguientes 11 ítems:

1. Mejora debida al servicio de intervención en general.

2. Uso con diferentes personas.

3. Mejora del niño gracias al método.

4. Expresión de las palabras utilizadas en el método en otros ámbitos.

5. Expresión espontánea de las palabras utilizadas en el método en otros ámbitos. 
6. Denomina esas palabras fuera del ámbito de actuación (en momentos diferentes a los que se están enseñando los bits).

7. Comprende las palabras que se han utilizado con el método.

8. Asistencia a las sesiones de logopedia.

9. Frecuencia de utilización de los bits de inteligencia en casa.

10. Conocía de forma previa las palabras.

11. Y, por último, observaciones.

Los familiares tienen que marcar con una $X$ la frecuencia que consideren más apropiada. Los cuestionarios se llevan a cabo durante la última sesión de intervención que, al igual que el resto de las sesiones, tiene una duración de 45 minutos. Los cuestionarios valoran la importancia que atribuyen los familiares a los especialistas del lenguaje, la eficacia del método, la frecuencia con la que aplican los bits en casa y la estimación de la mejora que encuentran en sus hijos. Solo se ha aplicado este cuestionario a las familias del grupo experimental, pues las familias del grupo control no conocen ni han utilizado el Método por lo que no pueden ofrecer su opinión sobre este, por lo que disponemos de un total de 4 cuestionarios que son los que corresponden al grupo experimental.

\subsubsection{Fases de aplicación. Procedimiento}

El programa de intervención en el lenguaje, que emplea los bits de inteligencia del Método Glen Doman, se lleva a cabo durante un mínimo de 9 semanas y un máximo de 15 semanas, a lo largo de tres fases secuenciadas: Fase 1: evaluación inicial; Fase 2: rehabilitación del lenguaje y Fase 3: evaluación final.

Las fases seguidas con el grupo experimental fueron las siguientes:

- Fase 1. Evaluación inicial: en esta fase se les explica a las familias las tres pruebas estandarizadas (descritas en el apartado de técnicas e instrumentos) que se les van a aplicar a sus hijos y cómo va a ser el proceso de aplicación: individual y en el aula de la consulta. Se les dice que existe la posibilidad paralelamente de ir aplicando los bits en casa, por lo que se les explican las orientaciones para llevarlo a cabo: deben mostrar a sus hijos las diapositivas una vez al día y que lo realicen los días que no acudan a la sesión, puesto que los días que el niño acude a la sesión lo hará el logopeda. Esta posibilidad de aplicarlo en casa 
no será obligatoria, evitando dar a la familia más responsabilidad de la que quieran o sean capaces de desarrollar; este aspecto de no obligatoriedad difiere de lo explicado por Doman y Doman (1998), ya que para él era una pieza clave en el tratamiento, y no abarca la posibilidad de que este programa lo lleven a cabo profesionales, pero la American Academy for Cerebral Pals et $a l$. , (1968) opina que este método puede ser bastante exigente, por lo que se da a los padres la posibilidad de elegir, y así valorar sus opciones.

En nuestro caso, consideramos que, aunque se les dé a elegir, y algunos decidan no llevarlo a cabo en casa, la comunicación con la familia siempre será continua, directa y muy personal, convirtiéndose en un pilar angular en nuestra intervención.

Para cumplir con los criterios de credibilidad, transferibilidad y confirmabilidad (Noreña-Peña, et al., 2012) de los menores, elaboramos un consentimiento informado (Miguélez, 2016) (véase Anexo 2) que los padres tuvieron que firmar como prerrequisito para poder comenzar la intervención.

Posteriormente, se aplicaron las pruebas estandarizadas a los niños, primero se aplicó el PLON-R (Aguinaga et al., 2004), después el PEABODY (Dunn et al., 2006). y finalmente, el RFI (Juárez y Monfort, 1996a).

- Fase 2. Rehabilitación del lenguaje: Los niños acudirán a las sesiones logopédicas 2 días a la semana durante 45 minutos de manera individual. La sesión comienza mostrando a los niños las láminas en PowerPoint, con una duración de aproximadamente 1 minuto; en caso de que la motivación o la atención no sean adecuadas en ese momento, se podrá posponer. Posteriormente, se realizará una intervención logopédica normalizada y sin llevar a cabo ninguna actividad relacionada con esos bits.

Durante una semana se muestra a los niños el mismo PowerPoint. Como los niños acuden con el logopeda dos sesiones semanales, se muestra el mismo PowerPoint durante una semana. Recordamos que los otros cinco días de la semana la familia puede encargarse de enseñar el mismo PowerPoint que hemos trabajado en la sesión en casa. La realidad fue que solo dos familias quisieron realizar esta actividad en casa, las otras dos no lo realizaron. 
- Fase 3. Evaluación final: en esta fase se vuelven a aplicar las tres pruebas estandarizadas que se pasaron en la Fase 1, para comprobar si los niños han mejorado en el nivel fonológicofonético, semántico y pragmático, esta evaluación se realiza desde 9 a 15 semanas después de haber realizado la primera evaluación, como se puede observar en la Tabla 4.4. En esta misma fase, y una vez finalizada la intervención, se les presenta a los padres el cuestionario para que valoren el proceso llevado a cabo. Cuatro familias rellenan el cuestionario por lo que obtenemos cuatro cuestionarios iguales para proceder a realizar el análisis.

Las fases que se llevaron a cabo con el grupo control fueron las siguientes:

- Fase 1. Evaluación inicial: en esta fase se les explica a las familias las tres pruebas estandarizadas (descritas en el apartado de técnicas e instrumentos) que se les van a aplicar a sus hijos y cómo va a ser el proceso de aplicación, individual y en la sala de la consulta. Se les explica que no se va a realizar ninguna intervención durante ese tiempo, aprovechando el periodo estival. El resto de las acciones a realizar son iguales a la fase 1 del grupo experimental, los padres firman el consentimiento informado y se aplican las mismas pruebas de evaluación.

- Fase 2. Fase de espera: No se realiza ningún tipo de rehabilitación con los niños, y los infantes no acuden a ningún otro centro. Este tiempo de espera será el correspondiente a los niños del grupo experimental (entre 9 y 15 semanas).

- Fase 3. Evaluación final: en esta fase se vuelven a aplicar las tres pruebas estandarizadas que se pasaron en la Fase 1, con la finalidad de comprobar la mejora espontánea que tienen estos niños sin intervención.

En la Figura 4.4 podemos observar detalladamente el proceso de Estudio Piloto. 


\section{FASES DE INTERVENCIÓN}

\section{Estudio piloto}

\section{Fase 1 (Grupo control y}

experimental):

evaluación inicial

Reunión con las familias

-Consentimiento informado

-Explicación como llevar a cabo la

intervención en casa

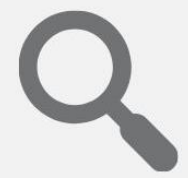

Evaluación

PLON-R

Peabody

Registro Fonológico Inducido

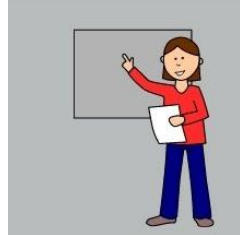

Fase 2:

rehabilitación del lenguaje (Solo grupo experimental)

Los niños acuden 2 sesiones a la semana con la

logopeda, durante 45 minutos de manera

individual. Durante la sesión se enseñan los

PowerPoint

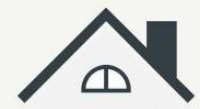

Intervención en casa

Los otros cinco dias a la semana, la familia tiene la oportunidad de enseñar los PowerPoint en $\square \square$ casa, no es obligatorio la realización de este paso

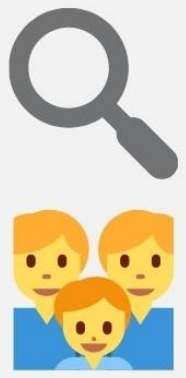

Fase 3:

evaluación final (Grupo control y experimental)

PLON-R

Peabody

Registro Fonológico Inducido.

Cuestionario a las familias (solo grupo experimental)

Nos reunimos con las familias para rellenar el cuestionario tipo Likert

Figura 4.4. Fases de intervención del Estudio Piloto. Fuente: Elaboración propia. 
La temporalización de estas fases fue diferente en cada caso, ya que dependió del momento en el que comenzaron la intervención en el gabinete. Ver Tabla 4.4.

Tabla 4.4.

Temporalización del Estudio Piloto (EP)

\begin{tabular}{lllll}
\cline { 2 - 5 } & Grupo & $\begin{array}{l}\text { Evaluación } \\
\text { inicial }\end{array}$ & $\begin{array}{l}\text { Tiempo } \\
\text { intervención }\end{array}$ & $\begin{array}{l}\text { de } \\
\text { Evaluación } \\
\text { final }\end{array}$ \\
\hline $\begin{array}{l}\text { PEP } \\
1\end{array}$ & Experimental & $30 / 04 / 2018$ & 9 semanas & $28 / 06 / 2018$ \\
\hline PEP 2 & Experimental & $08 / 05 / 2018$ & 15 semanas & $28 / 08 / 2018$ \\
\hline PEP 3 & Experimental & $07 / 05 / 2018$ & 14 semanas & $06 / 08 / 2018$ \\
\hline PEP 4 & Experimental & $02 / 05 / 2018$ & 10 semanas & $11 / 07 / 2018$ \\
\hline PEP 5 & Control & $18 / 05 / 2020$ & 9 semanas & $23 / 07 / 2020$ \\
\hline PEP 6 & Control & $20 / 05 / 2020$ & 15 semanas & $31 / 08 / 2020$ \\
\hline PEP 7 & Control & $25 / 05 / 2020$ & 14 semanas & $31 / 08 / 2020$ \\
\hline PEP 8 & Control & $03 / 06 / 2020$ & 10 semanas & $12 / 08 / 2020$ \\
\hline
\end{tabular}

Fuente: Elaboración propia.

Teniendo en cuenta esto, y que el mismo PowerPoint se utiliza durante una semana, podemos determinar que el Participante Estudio Piloto (PEP) 1 llega a utilizar el PowerPoint de la carne, el PEP 2 hasta el PowerPoint de los animales 2, el PEP 3 hasta el PowerPoint de los animales 1, y el PEP 4 hasta el PowerPoint de otros alimentos 1. Por lo que ninguno de los PEP utiliza todos los PowerPoint que han sido diseñados por una cuestión de tiempo. Recordamos que se han diseñado suficientes para ser utilizados durante 20 semanas, pero esto no ha sido posible ya que la mayoría de los PEP dejan de acudir en verano a las sesiones de logopedia y finalizan el tratamiento.

\subsubsection{Análisis de los resultados}

Para el análisis y el tratamiento de los datos hemos utilizado en programa estadístico SPSS (Statistical Package for Social Sciences) en su versión para Windows.

Primero realizamos la prueba Shapiro Wilk, para comprobar si nuestros datos provienen de una distribución normal o no, y determinar si

\footnotetext{
${ }^{4}$ PEP $=$ Participante del Estudio Piloto
} 
realizamos un análisis paramétrico o no paramétrico. Posteriormente, realizamos dos tipos de análisis:

- Análisis intergrupal: En este primer análisis observamos las diferencias del pretest en el grupo experimental y en el grupo control, y realizamos la misma operación en el postest.

- Análisis intragrupal: Observamos si existen diferencias en el grupo experimental entre el pretest y el postest, y realizamos la misma operación en el grupo control.

Podemos observar un esquema de la explicación en la Figura 4.5.

\section{GRUPO EXPERIMENTAL}

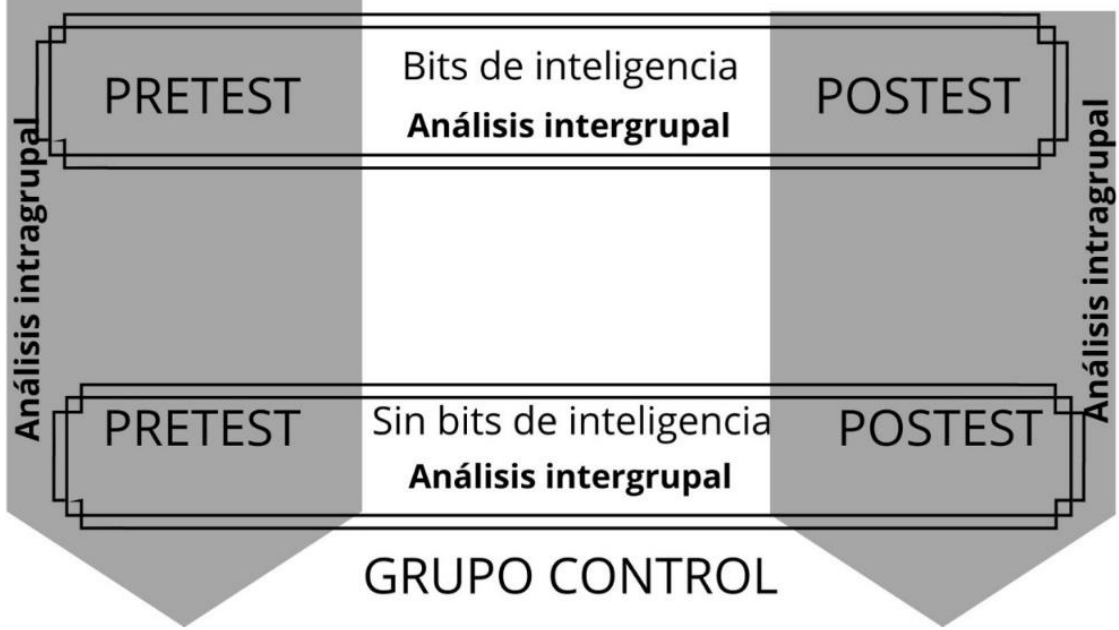

Figura 4.5. Explicación análisis intergrupal e intragrupal. Fuente: elaboración propia.

En el análisis intergrupal realizamos la Prueta T-student para muestras independientes, para observar si hay una diferencia significativa entre el grupo control y el grupo experimental. En el análisis intragrupal realizamos la Prueta T-student para muestras relacionadas. Posteriormente realizamos Kappa de Cohen, para medir el efecto del azar y la intensidad de la significancia. 
4.3.1.7. Resultados iniciales del EP y recomendaciones para diseñar PELEO

Aunque los resultados de este estudio se muestran detalladamente en el capítulo 5, nos gustaría hacer algunas reflexiones sobre los resultados de este primer estudio, ya que son los que nos aportan luz para poder hacer los cambios que posteriormente se harán sobre el Programa de Estimulación Lingüística de Expresión Oral (PELEO). Finalizado este primer estudio podemos señalar que es aceptable el uso de los bits de inteligencia en niños con trastorno del lenguaje con la finalidad de mejorar su nivel fonológico y fonético; pero se rechaza su utilización, tal y como Doman lo propuso, con el objetivo de mejorar los niveles morfosintáctico, semántico y/o pragmático del lenguaje en esta población.

Consecuencia del proceso de intervención y de las opiniones obtenidas de las familias a través de los cuestionarios, haremos una síntesis de las ideas que nos hemos encontrado y que nos ayudarán a plantear el siguiente estudio: tras evaluar el proceso de intervención, hemos determinado que es mejor enseñar y explicar las palabras presentadas en los bits de inteligencia que los niños desconozcan, no solo presentarlas y seleccionar los bits de inteligencia según su frecuencia de uso (no enmarcados dentro de unas categorías semánticos).

Valorando lo señalado por las familias en los cuestionarios, se ha llegado a la determinación de ampliar el número de diapositivas, es decir, de bits de inteligencia que se enseñan a los niños, y eliminar la participación directa en la intervención de la familia sabiendo que esto no significa excluirla del proceso de intervención por completo.

\subsubsection{Estudio 2: Programa de Estimulación Lingüística de Expresión Oral (PELEO)}

Antes hemos explicado detalladamente el primer estudio realizado para esta tesis, en este epígrafe nos centraremos en explicar el segundo estudio, que hemos denominado Estudio 2: Programa de Estimulación Lingüística de Expresión Oral (PELEO). Para el diseño de este programa se han considerado las recomendaciones obtenidas del Estudio Piloto (EP), ya que lo que queremos es utilizar algunas ideas del Método Doman que fueran válidas para que los infantes con trastorno del lenguaje dispongan de una intervención logopédica específica y centrada 
en sus dificultades. Este segundo estudio se ha implementado con 33 participantes con trastorno del lenguaje de un rango de edad comprendido entre los tres años y cero meses y los cinco años y siete meses con trastorno del lenguaje, en la Tabla 4.5, se puede observar la edad media de los participantes.

Tabla 4.5.

Edad media de los participantes del estudio 2: Programa de Estimulación Lingüística de Expresión Oral (PELEO)

\begin{tabular}{lccccc} 
& $\mathrm{N}$ & Mínimo & Máximo & Media & $\begin{array}{c}\text { Desviación } \\
\text { estándar }\end{array}$ \\
\hline Edad & 33 & 36 & 67 & 51,13 & 11,036 \\
\hline N válido (por lista) & 33 & & & & \\
\hline \multicolumn{7}{c}{ Fuente: elaboración propia. }
\end{tabular}

A continuación, se presentan los objetivos del estudio, la contextualización, los criterios de selección de participantes, los objetivos del trabajo, las técnicas e instrumentos de recogida de datos y, finalmente, el procedimiento llevado a cabo.

\subsubsection{Objetivos del estudio}

En este segundo estudio, perseguimos los siguientes objetivos:

- Evaluar la utilización del Programa de Estimulación Lingüística de Expresión Oral (PELEO) en la intervención con la población con trastorno del lenguaje de un rango de edad comprendido entre los tres y cinco años y siete meses.

- Conocer las opiniones de las familias, maestras y logopedas sobre los resultados y el procedimiento de PELEO.

- Determinar los errores o los posibles aciertos de este método para diseñar otro más enfocado a conseguir los objetivos pretendidos en las intervenciones con los infantes con trastorno del lenguaje.

\subsubsection{Contextualización}


La intervención logopédica se lleva a cabo en diferentes contextos en los que han intervenido como logopedas seis profesionales del entorno laboral de la doctoranda. En la Tabla 4.6 se especifican los lugares de actuación de las logopedas y los niños atendidos por cada una de ellas.

Tabla 4.6.

Logopedas encargadas de aplicar el método y su contexto

\begin{tabular}{|c|c|c|c|c|c|}
\hline Logopedas & $\begin{array}{l}\text { Años de } \\
\text { experiencia } \\
\text { como } \\
\text { logopedas }\end{array}$ & Ciudades & Lugares & $\begin{array}{l}\text { Curso en el } \\
\text { que se ha } \\
\text { llevado a } \\
\text { cabo }\end{array}$ & Infantes \\
\hline 1. Logopeda & 6 años & Valladolid & $\begin{array}{l}\text { Gabinete } \\
\text { privado }\end{array}$ & $2018 / 2019$ & 1 \\
\hline $\begin{array}{l}\text { 2. Logopeda } \\
2\end{array}$ & 6 años & $\begin{array}{l}\text { Provincia } \\
\text { de Badajoz }\end{array}$ & $\begin{array}{l}\text { Gabinete } \\
\text { privado }\end{array}$ & $\begin{array}{l}2018 / 2019 \\
2019 / 2020\end{array}$ & 2 \\
\hline $\begin{array}{l}\text { 3. Logopeda } \\
3\end{array}$ & 8 años & Palencia & $\begin{array}{l}\text { Gabinete } \\
\text { privado }\end{array}$ & $2018 / 2019$ & 1 \\
\hline $\begin{array}{l}\text { 4. Logopeda } \\
4\end{array}$ & 4 años & Palencia & $\begin{array}{l}\text { Gabinete } \\
\text { privado }\end{array}$ & $2018 / 2019$ & 1 \\
\hline 5. Logopeda & 6 años & $\begin{array}{l}\text { Provincia } \\
\text { de } \\
\text { Valladolid }\end{array}$ & $\begin{array}{l}\text { Gabinete } \\
\text { privado }\end{array}$ & $2018 / 2019$ & 1 \\
\hline $\begin{array}{l}\text { 6. Logopeda } \\
6\end{array}$ & 2 años & Palencia & $\begin{array}{l}\text { Gabinete } \\
\text { privado }\end{array}$ & $2019 / 2020$ & 1 \\
\hline \multirow[t]{5}{*}{ 7. Doctoranda } & 6 años & Palencia & $\begin{array}{l}\text { Gabinete } \\
\text { privado }\end{array}$ & $\begin{array}{l}2018 / 2019 \\
2019 / 2020\end{array}$ & 6 \\
\hline & & & Centro A & $2019 / 2020$ & 4 \\
\hline & & & Centro B & $2019 / 2020$ & 6 \\
\hline & & & Centro C & $2019 / 2020$ & 4 \\
\hline & & & $\begin{array}{l}\text { Escuela } \\
\text { infantil } \\
\text { privada }\end{array}$ & $2018 / 2019$ & 2 \\
\hline
\end{tabular}

Fuente: Elaboración propia.

En total participan seis gabinetes privados, tres centros educativos y una Escuela Infantil, situados en Palencia capital, ya que es la residencia de la doctoranda, ya que estos centros permitían a ésta el acceso al campo 
de investigación. A continuación, explicamos las características de cada uno de ellos.

Los seis gabinetes privados. Cinco de los seis gabinetes son centros en los que únicamente se ofrece el servicio de logopedia, a excepción del gabinete privado donde trabaja la doctoranda, que se trata de un gabinete multidisciplinar (sus características se explicaron en el contexto del Estudio Piloto (EP), apartado 4.3.1.2.

- El Centro A es un centro concertado, mixto y bilingüe de Educación Infantil, Educación Primaria, Educación Secundaria y Apoyo a alumnos con necesidades educativas específicas, que se distingue por ofrecer una educación integral de calidad. Tiene entre su profesorado una maestra de audición y lenguaje que además también es graduada en logopedia. En Educación Infantil hay 17 niños en primero, 24 niños en segundo y en tercero hay 23 niños. Este centro propuso la utilización del Programa de Estimulación Lingüística de Expresión Oral (PELEO) con 17 niños a quienes se evalúan, pero solo 6 niños cumplieron los criterios de inclusión del estudio, por lo que se realiza un informe de exclusión a los 11 participantes eliminados, como devolución de los resultados obtenidos en su investigación y como premio por haber querido formar parte del estudio (Anexo 16).

- El Centro B es un colegio concertado, mixto de Educación Infantil, Educación Primaria y Educación Secundaria. Tiene entre su profesorado una maestra de audición y lenguaje que ofrece apoyo a los niños de tercero de Educación Infantil y Primaria. Es un colegio de dos líneas. En Educación Infantil hay 32 niños en primero, 44 niños en segundo y en tercero hay 49 niños. En este colegio se evalúan a 5 niños que proponen las maestras de educación infantil, y solo cumplen los criterios de inclusión 4 niños, por lo que se realiza un informe de exclusión determinando los motivos y los resultados de la evaluación de la alumna excluida.

- El Centro $C$ es un colegio concertado, mixto de Educación Infantil de Educación Primaria y Educación Secundaria. No cuenta con maestra de audición y lenguaje ni de pedagogía terapéutica. En el curso 2019/2020, en Educación Infantil tiene 16 niños en primero, 24 niños en segundo y 22 niños en tercero. En este colegio se procede a realizar la valoración a 8 niños que proponen las maestras de educación infantil, y solo cumplen los criterios de inclusión 4 niños, por lo que al igual que en los 
colegios anteriores se redactan informes de exclusión para facilitarlos a las familias de los niños descartados, como devolución de los resultados obtenidos en su investigación y como premio por haber querido formar parte del estudio.

- La Escuela Infantil que participó en el estudio se sitúa en Palencia. Es una escuela que forma parte de una entidad sin ánimo de lucro. En esta Escuela Infantil se imparte el primer ciclo de Educación Infantil (de cero a tres años). La doctoranda escogió directamente los casos y solo se evaluaron 3 niños que fueron admitidos en el estudio, en esta ocasión, tuvimos en cuenta la opinión de las técnicos de educación infantil, que identificaron a los niños que ellas pensaban que tenían alguna necesidad, se observó a estos niños en el aula y se observó que cumplían con los criterios de inclusión que se describen en el siguiente apartado, para poder incluirlos en el estudio.

\subsubsection{Participación y criterios de selección de los participantes}

En la investigación participan diferentes personas y centros, por lo que a continuación, se va a explicar con detenimiento el proceso de selección de los centros, de los logopedas y de los infantes a los que se les iba a intervenir.

1) Proceso de selección de centros

Participan en el estudio seis gabinetes y una Escuela Infantil que tienen colaboración en régimen laboral con las logopedas seleccionadas para el estudio. Por lo que realmente no se diseña un proceso de selección per sé para estos centros. Pero sí que existe para los otros tres centros concertados que participaron. El proceso de selección de estos tres centros es el siguiente:

- Inicialmente se realiza una búsqueda por internet de todos los centros educativos de Palencia, al ser esta ciudad la residencia de la doctoranda, y se encuentran 20 centros escolares. Se contacta vía telefónica con todos ellos, y ocho centros de Palencia capital responden queriendo hablar con nosotros, mientras que el resto desde el inicio se muestran reticentes de formalizar cualquier tipo de colaboración. En este primer contacto con estos ocho centros a los que se explica de manera detallada el proceso de realización 
de la investigación, seis de ellos mostraron interés en establecer una colaboración, y los otros dos declinaron la oferta.

- Posteriormente, se envía por correo electrónico toda la información relativa al estudio de interés, tanto para los profesionales del colegio (Anexo 4), como para las posibles familias que participan en la investigación (Anexo 5).

- Finalmente, solo tres centros concertados deciden participar, y los otros tres declinan la oferta.

2) Proceso de selección de logopedas

El proceso para encontrar las diferentes logopedas es el siguiente:

- Inicialmente se contacta vía telefónica con siete logopedas del entorno laboral de la doctoranda a las que se les explica el proyecto. Una de las logopedas renuncia a la participación en el estudio por motivos de tiempo y logística, por lo que finalmente participan 6 logopedas.

- Posteriormente, se envía por correo electrónico toda la información y material necesario para llevar a cabo el estudio (Anexo 3).

- Se comprueba que todas las logopedas están familiarizadas con la aplicación de los tests que se van a utilizar.

- Para verificar la comprensión de todo el proceso y del material, una semana más tarde se las vuelve a llamar, para poder responder sus posibles dudas y repasar juntos las pautas y el proceso de intervención explicado en el Anexo3.

Por lo que finalmente aplicaron PELEO, las 6 logopedas y la doctoranda. 5 de las 6 logopedas realizaron esta aplicación durante el curso 20182019; la otra logopeda durante el curso 2019-2020; y la doctoranda durante ambos cursos escolares (véase Tabla 4.7).

Tabla 4.7.

Relación de participantes del grupo experimental, edad al inicio de la intervención, logopedas que les atienden y contexto de intervención

\begin{tabular}{lllll}
\hline Participante & $\begin{array}{l}\text { Edad al inicio } \\
\text { de la } \\
\text { intervención }\end{array}$ & $\begin{array}{l}\text { Logopeda que } \\
\text { le atendió }\end{array}$ & $\begin{array}{l}\text { Contexto de } \\
\text { intervención }\end{array}$ & $\begin{array}{l}\text { Curso } \\
\text { escolar }\end{array}$ \\
\hline P3E-1 & Tres años & Doctoranda & Escuela infantil & $2018-$ \\
& & & & 2019 \\
\hline
\end{tabular}




\begin{tabular}{|c|c|c|c|c|}
\hline P3E-2 & Tres años & Doctoranda & Escuela infantil & $\begin{array}{l}2018- \\
2019\end{array}$ \\
\hline P3E-3 & Tres años & Doctoranda & Escuela infantil & $\begin{array}{l}2018- \\
2019 \\
\end{array}$ \\
\hline P3E-4 & $\begin{array}{l}\text { Tres años y tres } \\
\text { meses }\end{array}$ & Doctoranda & Centro A & $\begin{array}{l}2019- \\
2020 \\
\end{array}$ \\
\hline P3E-5 & $\begin{array}{l}\text { Tres años y } \\
\text { cuatro meses }\end{array}$ & Doctoranda & Centro A & $\begin{array}{l}2019- \\
2020 \\
\end{array}$ \\
\hline P3E-6 & $\begin{array}{l}\text { Tres años y } \\
\text { cuatro meses }\end{array}$ & Doctoranda & Centro A & $\begin{array}{l}2019- \\
2020 \\
\end{array}$ \\
\hline P3E-7 & $\begin{array}{ll}\text { Tres años } & \text { y } \\
\text { cinco meses }\end{array}$ & Doctoranda & Centro A & $\begin{array}{l}2019- \\
2020 \\
\end{array}$ \\
\hline P3E-8 & $\begin{array}{ll}\text { Tres años } & \text { y } \\
\text { siete meses }\end{array}$ & Doctoranda & Centro C & $\begin{array}{l}2019- \\
2020 \\
\end{array}$ \\
\hline P3E-9 & $\begin{array}{ll}\text { Tres años } & \text { y } \\
\text { nueve meses }\end{array}$ & Doctoranda & Centro $\mathrm{C}$ & $\begin{array}{l}2019- \\
2020 \\
\end{array}$ \\
\hline P3E-10 & $\begin{array}{l}\text { Tres años y } \\
\text { cuatro meses }\end{array}$ & Doctoranda & $\begin{array}{l}\text { Gabinete } \\
\text { privado }\end{array}$ & $\begin{array}{l}2018- \\
2019 \\
\end{array}$ \\
\hline P3E-11 & Tres años & Doctoranda & $\begin{array}{l}\text { Gabinete } \\
\text { privado }\end{array}$ & $\begin{array}{l}2018- \\
2019 \\
\end{array}$ \\
\hline P4E-1 & $\begin{array}{l}\text { Cuatro años y } \\
\text { tres meses }\end{array}$ & Doctoranda & $\begin{array}{l}\text { Gabinete } \\
\text { privado }\end{array}$ & $\begin{array}{l}2019- \\
2020 \\
\end{array}$ \\
\hline P4E-2 & $\begin{array}{l}\text { Cuatro años y } \\
\text { cinco meses }\end{array}$ & Logopeda 1 & $\begin{array}{l}\text { Gabinete } \\
\text { privado }\end{array}$ & $\begin{array}{l}2018- \\
2019 \\
\end{array}$ \\
\hline P4E-3 & $\begin{array}{l}\text { Cuatro años y } \\
\text { seis meses }\end{array}$ & Logopeda 4 & $\begin{array}{l}\text { Gabinete } \\
\text { privado }\end{array}$ & $\begin{array}{l}2018- \\
2019 \\
\end{array}$ \\
\hline P4E-4 & $\begin{array}{l}\text { Cuatro años y } \\
\text { seis meses }\end{array}$ & Doctoranda & $\begin{array}{l}\text { Gabinete } \\
\text { privado }\end{array}$ & $\begin{array}{l}2018- \\
2019 \\
\end{array}$ \\
\hline P4E-5 & $\begin{array}{l}\text { Cuatro años y } \\
\text { dos meses }\end{array}$ & Doctoranda & $\begin{array}{l}\text { Gabinete } \\
\text { privado }\end{array}$ & $\begin{array}{l}2018- \\
2019 \\
\end{array}$ \\
\hline P4E-6 & Cuatro años & Doctoranda & Centro A & $\begin{array}{l}2019- \\
2020 \\
\end{array}$ \\
\hline P4E-7 & $\begin{array}{l}\text { Cuatro años y } \\
\text { dos meses }\end{array}$ & Doctoranda & $\begin{array}{l}\text { Gabinete } \\
\text { privado }\end{array}$ & $\begin{array}{l}2019- \\
2020 \\
\end{array}$ \\
\hline P4E-8 & $\begin{array}{l}\text { Cuatro años y } \\
\text { tres meses }\end{array}$ & Doctoranda & Centro C & $\begin{array}{l}2019- \\
2020 \\
\end{array}$ \\
\hline P4E-9 & $\begin{array}{l}\text { Cuatro años y } \\
\text { cinco meses }\end{array}$ & Doctoranda & Centro C & $\begin{array}{l}2019- \\
2020 \\
\end{array}$ \\
\hline P4E-10 & $\begin{array}{l}\text { Cuatro años y } \\
\text { siete meses }\end{array}$ & Logopeda 6 & $\begin{array}{l}\text { Gabinete } \\
\text { privado }\end{array}$ & $\begin{array}{l}2019- \\
2020 \\
\end{array}$ \\
\hline P4E-11 & $\begin{array}{l}\text { Cuatro años y } \\
\text { siete meses }\end{array}$ & Doctoranda & $\begin{array}{l}\text { Gabinete } \\
\text { privado }\end{array}$ & $\begin{array}{l}2018- \\
2019 \\
\end{array}$ \\
\hline P5E-1 & $\begin{array}{l}\text { Cinco años y } \\
\text { cinco meses }\end{array}$ & Logopeda 2 & $\begin{array}{l}\text { Gabinete } \\
\text { privado }\end{array}$ & $\begin{array}{l}2018- \\
2019 \\
\end{array}$ \\
\hline P5E-2 & $\begin{array}{l}\text { Cinco años y } \\
\text { cuatro meses }\end{array}$ & Logopeda 1 & $\begin{array}{l}\text { Gabinete } \\
\text { privado }\end{array}$ & $\begin{array}{l}2018- \\
2019 \\
\end{array}$ \\
\hline P5E-3 & $\begin{array}{l}\text { Cinco años y } \\
\text { seis meses }\end{array}$ & Logopeda 3 & $\begin{array}{l}\text { Gabinete } \\
\text { privado }\end{array}$ & $\begin{array}{l}2018- \\
2019\end{array}$ \\
\hline
\end{tabular}




\begin{tabular}{|c|c|c|c|c|c|}
\hline P5E-4 & $\begin{array}{l}\text { Cinco años } \\
\text { cuatro meses }\end{array}$ & $\mathrm{y}$ & Logopeda 5 & $\begin{array}{l}\text { Gabinete } \\
\text { privado }\end{array}$ & $\begin{array}{l}2018- \\
2019\end{array}$ \\
\hline P5E-5 & $\begin{array}{l}\text { Cinco años } \\
\text { dos meses }\end{array}$ & $\mathrm{y}$ & Logopeda 2 & $\begin{array}{l}\text { Gabinete } \\
\text { privado }\end{array}$ & $\begin{array}{l}2018- \\
2019\end{array}$ \\
\hline P5E-6 & $\begin{array}{l}\text { Cinco años } \\
\text { dos meses }\end{array}$ & $y$ & Doctoranda & Centro B & $\begin{array}{l}2019- \\
2020\end{array}$ \\
\hline P5E-7 & $\begin{array}{l}\text { Cinco años } \\
\text { Cinco meses }\end{array}$ & $\mathrm{y}$ & Doctoranda & Centro B & $\begin{array}{l}2019- \\
2020\end{array}$ \\
\hline P5E-8 & $\begin{array}{l}\text { Cinco años } \\
\text { dos meses }\end{array}$ & $\mathrm{y}$ & Doctoranda & Centro B & $\begin{array}{l}2019- \\
2020\end{array}$ \\
\hline P5E-9 & $\begin{array}{l}\text { Cinco años } \\
\text { cinco meses }\end{array}$ & $\mathrm{y}$ & Doctoranda & Centro B & $\begin{array}{l}2019- \\
2020\end{array}$ \\
\hline P5E-10 & $\begin{array}{l}\text { Cinco años } \\
\text { siete meses }\end{array}$ & $\mathrm{y}$ & Doctoranda & $\begin{array}{l}\text { Gabinete } \\
\text { privado }\end{array}$ & $\begin{array}{l}2018- \\
2019 \\
\end{array}$ \\
\hline P5E-11 & $\begin{array}{l}\text { Cinco años } \\
\text { siete meses }\end{array}$ & $\mathrm{y}$ & Doctoranda & Centro A & $\begin{array}{l}2019- \\
2020\end{array}$ \\
\hline
\end{tabular}

Fuente: Elaboración propia.

3) Proceso de selección de niños con trastorno del lenguaje

Los criterios de inclusión de los niños con trastorno del lenguaje han sido los siguientes:

- Que sean niños y niñas diagnosticados de retraso del lenguaje y/o trastorno del desarrollo del lenguaje.

- Que tengan entre tres y seis años.

Como criterios de exclusión: que tengan algún problema de pérdida auditiva, infecciones respiratorias y otitis media de repetición que pudieran ser causantes del problema.

La muestra es no probabilística, ya que la manera de encontrar esta población es muy diferente y está relacionada con los diferentes contextos en los que se llevó a cabo el estudio:

- 17 alumnos que acuden a los colegios con los que colaboramos cumplen los criterios de selección. Recordamos que primero las maestras eligieron a los posibles participantes, y posteriormente la doctoranda realizó la evaluación a estos niños para conocer los que cumplían los criterios de inclusión, se evaluó a un total de 33 niños en los centros educativos, pero finalmente participaron 17, porque los otros 16 no cumplían los criterios de inclusión. 
- 16 pacientes que acuden a las clínicas donde las logopedas trabajan y cumplan los requisitos de selección anteriormente mencionados, en este caso la logopeda que trabajaba en dicho centro decidía los niños que podían entrar en el estudio, teniendo en cuenta los diagnósticos previos realizados, y el conocimiento que éstas tenían sobre los niños. Aun así se realizaron las pruebas necesarias para comprobar que cumplían los requisitos de inclusión.

Por lo que en total se han obtenido 33 participantes, cada uno de ellos ha sido atendido por una logopeda y un contexto de los anteriormente señalados. En la Tabla 4.7 se puede observar la relación de participantes, edad al inicio de la intervención, logopedas que le atendieron y contexto donde se realizó la acción.

\subsubsection{Técnicas e instrumentos utilizados}

Para la recogida de información del segundo estudio, se seleccionan cinco tipos de técnicas e instrumentos, tanto de carácter cuantitativo como cualitativo.

En primer lugar, las láminas del propio PELEO, empleando como recurso tecnológico el PowerPoint; en segundo lugar, las pruebas estandarizadas para evaluar el nivel de lenguaje de los participantes: los test empleados son: el PLON-R, Prueba de Lenguaje Oral NavarraRevisada (Aguinaga et al., 1990), el Registro Fonológico Inducido (Juárez y Monfort, 1996a), y el Peabody Picture Vocabulary Test, TVIP (Dunn et al., 2006); en tercer lugar, la técnica de análisis de datos visuales a través de los vídeos de las sesiones (Bonetto, 2016); en cuarto lugar, la observación participante, empleando como instrumento la lista de control donde hemos organizado las observaciones a lo largo del tiempo (Anexo 9); y en último lugar, las entrevistas semiestructuradas a través de cuestionarios creados ad hoc para las familias (Anexos 6, 7 y $8)$.

1) Láminas del Programa de Estimulación Lingüística de Expresión Oral (PELEO)

Las láminas de PELEO están diseñadas con PowerPoint, al igual que en el Estudio Piloto (EP), aparece en cada lámina una imagen y la palabra escrita; pero existen diferencias significativas entre las láminas de PELEO y los bits de inteligencia utilizados anteriormente; por ejemplo, 
en estas láminas no está grabada la voz, sino que tiene que ser la propia logopeda quien utilice su voz en cada intervención nombrando las palabras de dicha sesión. Las palabras utilizadas se escogen entre aquellos nombres que más veces dicen y escuchan los niños de tres, cuatro y cinco años. Para su selección utilizamos el listado de "nombres" del Corpus de Habla Infantil Espontánea del Español (CHIEDE) (Garrote, 2008). Con estas palabras se crean diferentes PowerPoint con unas 20 diapositivas cada uno, incluye un símbolo pictográfico, propiedad del Gobierno de Aragón y creados por Sergio Palao para ARASAAC, que los distribuye bajo licencia CreativeCommons (BYNC-SA), junto con la palabra escrita en mayúsculas en la parte superior. La cantidad de palabras y las palabras presentadas varía de una edad a otra, como se puede observar en las Tablas 4.8, 4.9 y 4.10.

Tabla 4.8.

Láminas de creación propia edad tres años

\begin{tabular}{ll}
\hline $\begin{array}{l}\text { PowerPoint } \\
1\end{array}$ & $\begin{array}{l}\text { Niño, mamá, papá, abuelo, amigos, elefante, perro, lobo, cerdito, } \\
\text { gato, casa, pis, día, cosas, juguetes, coche, semáforo, pupa, pala, } \\
\text { pelota, cuchara, números. }\end{array}$ \\
\hline $\begin{array}{l}\text { PowerPoint } \\
2\end{array}$ & $\begin{array}{l}\text { Pollo, mariposa, tigre, caballo, pato, traje, bebé, rey, cabeza, } \\
\text { varicela, silla, ordenador, cuento, tenedor, frutas, agua, parque, } \\
\text { piscina, martes, vez. }\end{array}$ \\
\hline $\begin{array}{l}\text { PowerPoint } \\
3\end{array}$ & $\begin{array}{l}\text { Oso, oveja, rinoceronte, conejito, gallina, huevo, tarta, boca, señor, } \\
\text { juego, yayo, tío, corazón, baño, pelo, peine, ese, tacón, dibujo. }\end{array}$ \\
\hline $\begin{array}{l}\text { PowerPoint } \\
4\end{array}$ & $\begin{array}{l}\text { Viento, cristal, cuello, lunes, animal, ratón, pájaro, campo, cole, } \\
\text { acera, pila, payaso, magia, barco, fútbol, gimnasio, castillo, cocina, } \\
\text { pescado, caramelo. }\end{array}$ \\
\hline $\begin{array}{l}\text { PowerPoint } \\
5\end{array}$ & $\begin{array}{l}\text { Habitación, sopa, garbanzos, pan, galletas, macarrones, cuchillo, } \\
\text { culontana, mayor, lengua, collar, globo. }\end{array}$ \\
\hline $\begin{array}{l}\text { PowerPoint } \\
6\end{array}$ & $\begin{array}{l}\text { Montón, pantera, barba, supermercado, pueblo, bolsillo, piso, rosa, } \\
\text { muñeco, plátano, cajita, aire, perdón, espada, cara, taza, ardilla, } \\
\text { calcetín, león, truco. }\end{array}$ \\
\hline PowerPoint & $\begin{array}{l}\text { Arroz, burro, grúa, río, letra, puzle, grano, sol, suelo, café, ducha, } \\
\text { copa, puerta, tobogán, queso, lápiz, abrigo, pata, vaca, charco. }\end{array}$ \\
\hline $\begin{array}{l}\text { PowerPoint } \\
8\end{array}$ & $\begin{array}{l}\text { Leche, cuna, mochila, pie, selva, fecha, hipopótamo, gallo, rana, } \\
\text { fresa, diez, espalda, anillo, bolso, cometa, anular, bata, paseo, } \\
\text { navidad. }\end{array}$ \\
\hline PowerPoint & $\begin{array}{l}\text { Careta, agujero, manguitos, salón, médico, ballena, gusano, bici, } \\
\text { arena, antena, aro, botón, barbilla, regalo, comida, tomate, hoja, } \\
\text { piano, clase. }\end{array}$ \\
\hline $\begin{array}{l}\text { Portuga, erizo, vacaciones, patata, tiburón, diablo, palo, círculo, } \\
\text { carnaval, zapatilla, señorita, fuego, punta, cuerpo, pulgar, papel, } \\
\text { jardín, cuerda, sábado, espejo. }\end{array}$ \\
\hline 0
\end{tabular}




\begin{tabular}{ll}
\hline $\begin{array}{l}\text { PowerPoint } \\
11\end{array}$ & $\begin{array}{l}\text { Siete, lavabo, frente, ficha, flecha, cuidado, cielo, patinete, chalé, } \\
\text { teléfono, ala, delfín, sitio, mando, miedo, reloj, hambre, polvorón, } \\
\text { fideos, vaso. }\end{array}$ \\
\hline $\begin{array}{l}\text { PowerPoint } \\
12\end{array}$ & $\begin{array}{l}\text { Lana, carrito, moto, ceras, borrador, foca, radio, color, pasillo, pirata, } \\
\text { columpio, chicle, peces, cama, trozo, jaula, pajita, nombre, peluca, } \\
\text { bigote. }\end{array}$ \\
\hline $\begin{array}{l}\text { PowerPoint } \\
13\end{array}$ & $\begin{array}{l}\text { Lago, nana, canción, música, cacahuetes, mago, pierna, árbol, } \\
\text { maletín, policía, patio, sal, camión, caca, toallero, hueso, pijama, } \\
\text { llave, rueda, mano. }\end{array}$ \\
\hline $\begin{array}{l}\text { PowerPoint } \\
14\end{array}$ & $\begin{array}{l}\text { Montaña, braguita, calle, limón, gorra, pulsera, muñeca, monstruo, } \\
\text { tijera, pera, mosca, pintura, recreo, merienda, barriga, meñique, uno, } \\
\text { dos, miga, tele. }\end{array}$ \\
\hline
\end{tabular}

\section{Fuente: Elaboración propia publicado en Ayuso-Lanchares y Ruiz-Requies (2020).}

\section{Tabla 4.9.}

\section{Láminas de creación propia edad cuatro años}

\begin{tabular}{ll}
\hline $\begin{array}{l}\text { PowerPoint } \\
1\end{array}$ & $\begin{array}{l}\text { Casa, niño, madre, padre, primos, hermano, abuelo, amigos, vez, } \\
\text { agua, lobo, perro, tortuga, jaula, patio, año, clase, futbol, piedra, } \\
\text { coche. }\end{array}$ \\
\hline $\begin{array}{l}\text { PowerPoint } \\
2\end{array}$ & $\begin{array}{l}\text { Tele, payaso, castillo, cosa, película, cumple, número, cuento, disco, } \\
\text { ojo, pierna, mano, camión, noche, gato, rana, pájaro, día, lunes, } \\
\text { martes. }\end{array}$ \\
\hline $\begin{array}{l}\text { PowerPoint } \\
3\end{array}$ & $\begin{array}{l}\text { Jueves, viernes, sábado, domingo, animal, ratón, monstruo, pantalón, } \\
\text { cole, piscina, pera, café, tobogán, trabajo, hijo, pelota, cuello, nueve, } \\
\text { cartera. }\end{array}$ \\
\hline $\begin{array}{l}\text { PowerPoint } \\
4\end{array}$ & $\begin{array}{l}\text { Contenedor, piso, dragón, cama, once, dibujo, chico, lápiz, cuadra, } \\
\text { comida, manzana, camiseta, montón, carnaval, ficha, lila, sitio, } \\
\text { estuche. }\end{array}$ \\
\hline $\begin{array}{l}\text { PowerPoint } \\
5\end{array}$ & $\begin{array}{l}\text { Pato, paloma, pata, bota, vaso, juguete, barco, libro, biberón, febrero, } \\
\text { sol, tarta, leche, cajón, pintalabios, nido, cometa, profesor, tío, bebé. }\end{array}$ \\
\hline PowerPoint & $\begin{array}{l}\text { Juego, logopeda, gente, calendario, miércoles, huevo, arena, playa, } \\
\text { gusano, piano, oveja, varicela, tarjeta, gafa, palo, silla, boli, cabeza, } \\
\text { canasta, colegio. }\end{array}$ \\
\hline PowerPoint & $\begin{array}{l}\text { Fuego, vuelta, susto, quince, papel, hora, colchoneta, pala, chupete, } \\
\text { campo, escuela, luna, escondite, pastel, abeja, serpiente, foca, liebre, } \\
\text { pelo, obra. }\end{array}$ \\
\hline $\begin{array}{l}\text { Powero, maestro, columpio, plancha, estufa, doce, cara, bigote, taza, } \\
8\end{array}$ & $\begin{array}{l}\text { mujer, chupachús, pantano, empresa, canción, portería, dedo, llave, } \\
\text { horario. }\end{array}$ \\
\hline PowerPoint & $\begin{array}{l}\text { Río, calle, móvil, zapato, familia, enanito, maestra, cazador, grano, } \\
\text { conejo, tijera, suelo, furgoneta, verano, pollito, carpa, boca, pie, } \\
\text { cuna, etiqueta. }\end{array}$ \\
\hline PowerPoint & $\begin{array}{l}\text { Fecha, pajarito, oso, señor, doctor, labio, rato, fuente, plus, espalda, } \\
\text { angina, bicicleta, gatito, paseo, sueño, mayo, tirachinas, terraza, } \\
\text { trece, dieciocho. }\end{array}$ \\
\hline
\end{tabular}




\begin{tabular}{ll}
\hline $\begin{array}{l}\text { PowerPoint } \\
11\end{array}$ & $\begin{array}{l}\text { Patito, elefante, avispa, ballena, osito, panda, dóberman, } \\
\text { extraterrestre, camino, tela, careta, salto, cohete, cesta, manguitos, } \\
\text { nube, herida, aro, regalo, babi. }\end{array}$ \\
\hline $\begin{array}{l}\text { PowerPoint } \\
12\end{array}$ & $\begin{array}{l}\text { Rotulador, pico, cochinillo, cola, paz, coca-cola, enamorados, } \\
\text { purpurina, zapatilla, puente, diente, pis, guardería, daño, tambor, } \\
\text { fantasma, quema, cena, tres, siete. }\end{array}$ \\
\hline $\begin{array}{l}\text { PowerPoint } \\
13\end{array}$ & $\begin{array}{l}\text { Tacón, subibaja, bolsillo, cuidado, siesta, derecha, brazo, corazón, } \\
\text { ala, pila, disfraz, sapo, carro, moco, carpeta, té, misa, correcaminos, } \\
\text { balonmano, alfombra. }\end{array}$ \\
\hline $\begin{array}{l}\text { PowerPoint } \\
14\end{array}$ & $\begin{array}{l}\text { Colonia, moto, ceras, estantería, radio, control, color, compañeros, } \\
\text { muchacho, trozo, colorete, izquierda, nombre, peluca, espada, } \\
\text { televisión, carrito, balón, bola, borra. }\end{array}$ \\
\hline $\begin{array}{l}\text { PowerPoint } \\
15\end{array}$ & $\begin{array}{l}\text { Gimnasio, tripa, nave, león, habitación, carretera, policía, brujo, } \\
\text { señora, crema, gol, bocadillo, ese, sofá, subida, granja, rueda, } \\
\text { empate, foto, porche. }\end{array}$ \\
\hline PowerPoint & $\begin{array}{l}\text { Apellido, gomina, abril, uno, dos, 14, 26, oreja, responsable, } \\
\text { camionero, redondel, polvo, ropa, ordenador, demonio, mosca, }\end{array}$ \\
& zumo, jarabe, permiso, recreo, basura, gata. \\
\hline
\end{tabular}

Fuente: Elaboración propia.

Tabla 4.10.

Láminas de creación propia edad cinco años

\begin{tabular}{ll}
\hline PowerPoint 1 & $\begin{array}{l}\text { Casa, padre, madre, hermano, chico, abuelo, niño, señorita, cosa, } \\
\text { cama, sol, cuento, lobo, galletas, euro, céntimo, perro, vez, día, } \\
\text { jueves. }\end{array}$ \\
\hline PowerPoint 2 & $\begin{array}{l}\text { Tío, primo, amigo, señorito, lunes, martes, miércoles, sábado, } \\
\text { domingo, leche, ColaCao, año, vaso, guerra, patio, dos, ocho, } \\
\text { nueve, fútbol, ropa. }\end{array}$ \\
\hline PowerPoint 3 & $\begin{array}{l}\text { Cumpleaños, verano, febrero, cabeza, cara, escalera, cole, coche, } \\
\text { gol, viernes, diez, hucha, hoja, partido, sólido, campo, chuche, } \\
\text { portero, león, cabrito. }\end{array}$ \\
\hline PowerPoint 4 & $\begin{array}{l}\text { Líquido, tele, casita, piedra, bebé, pelota, comida, piano, colegio, } \\
\text { flor, animal, elefante, ratón, tambor, fantasma, ojo, brazo, pie, } \\
\text { diciembre, tiempo. }\end{array}$ \\
\hline PowerPoint 5 & $\begin{array}{l}\text { Moto, balón, invierno, casco, pijama, ramo, litera, enero, uno, tarta, } \\
\text { agua, mesa, diario, regalo, hijo, clase, duende, rey, pico, dinero. }\end{array}$ \\
\hline PowerPoint 6 & $\begin{array}{l}\text { Zapatilla, periódico, cinco, fuego, chocolate, bombón, hora, daño, } \\
\text { madera, malo, sillón, cereal, juguetes, escondite, humo, morro, } \\
\text { pelo, tripa, culo. }\end{array}$ \\
\hline PowerPoint 7 & $\begin{array}{l}\text { Patito, caballo, barbacoa, chimenea, calle, ordenador, puerta, } \\
\text { sangre, soldado, cuna, bosque, película, noche, mayor, patata, } \\
\text { castaño, juego, marzo, camino, careta. }\end{array}$ \\
\hline PowerPoint 8 & $\begin{array}{l}\text { Baloncesto, salto, vuelta, araña, cachorro, cerdito, colar, camiseta, } \\
\text { gafas, coleta, sierra, palo, pino, enamorados, silla, dientes, armario, } \\
\text { tres, chupete, pueblo. }\end{array}$ \\
\hline
\end{tabular}




\begin{tabular}{|c|c|}
\hline PowerPoint 9 & $\begin{array}{l}\text { Flecha, albañil, cartel, sitio, castañas, rosa, dragón, hámster, } \\
\text { pepino, gorro, septiembre, octubre, noviembre, doce, espada, taza, } \\
\text { castillo, abeto, caballero, gimnasio. }\end{array}$ \\
\hline $\begin{array}{l}\text { Pow } \\
10\end{array}$ & $\begin{array}{l}\text { Mechero, nave, seis, colorín colorado, árbol, carretera, camión, } \\
\text { agosto, sofá, rueda, mano, golpe, río, bolsa, zapato, } 28 \text {, pulsera, } \\
\text { pavo, rinoceronte, peluche. }\end{array}$ \\
\hline $\begin{array}{l}P o n \\
11\end{array}$ & $\begin{array}{l}\text { Conejo, perdiz, julio, dibujo, reina, cero, basura, caja, voltereta, } \\
\text { equipo, pata, maestra, boca, beso, tazón, mariposa, charco, plato, } \\
\text { cajón, miel. }\end{array}$ \\
\hline $\begin{array}{l}\text { Pon } \\
12\end{array}$ & $\begin{array}{l}\text { Caramelo, cuadro, fecha, trabajo, doctor, profesor, señor, cresta, } \\
\text { ventana, masaje, nieve, pedal, desayuno, sombra, rana, buhardilla, } \\
\text { restaurante, sueño, mayo. }\end{array}$ \\
\hline $\begin{array}{l}\text { Pon } \\
13\end{array}$ & $\begin{array}{l}\text { Tela, farmacia, moneda, parte, cesta, sombrero, nube, huevo, } \\
\text { magdalena, manzana, piruleta, rascacielos, noticia, superhéroe, } \\
\text { corbata, botón, video, babi, tren. }\end{array}$ \\
\hline $\begin{array}{l}\text { Pow } \\
14\end{array}$ & $\begin{array}{l}\text { Oveja, búho, gallina, perrito, cuarto, chaqueta, varicela, cosquillas, } \\
\text { montón, baile, cañón, cartera, idioma, jota, pincho, carnaval, } \\
\text { tractor, horquilla, manga, columna. }\end{array}$ \\
\hline $\begin{array}{l}P o n \\
15\end{array}$ & $\begin{array}{l}\text { Cáscara, guantes, punto, pis, helicóptero, punta, hembra, junio, } \\
\text { contenedor, abeja, cinta, bollo, cola, cena, pala, torre, pantalón, } \\
\text { petardo, deporte. }\end{array}$ \\
\hline Pon & $\begin{array}{l}\text { olsillo, cuidado, violín, zanahoria, fin de } \\
\text { dor, lista, canguro, yegua, lechuza, carretilla, } \\
\text { co. }\end{array}$ \\
\hline $\begin{array}{l}\text { Pow } \\
17\end{array}$ & $\begin{array}{l}\text { Nariz, teléfono, nuez, alcachofa, teletexto, payaso, churrería, } \\
\text { muñeco, barra, mando, trampa, caza, carro, caperuza, compra, } \\
\text { ruido, pulga, violonchelo, barco, póster. }\end{array}$ \\
\hline $\begin{array}{l}\text { Pon } \\
18\end{array}$ & $\begin{array}{l}\text { Colonia, falda, pastel, chicle, roscón, zancadilla, rectángulo, } \\
\text { expresión, banda, cuenta, color, edad, arbusto, jaula, nombre, rama, } \\
\text { medio, lío, esponja, jefe. }\end{array}$ \\
\hline $\begin{array}{l}\text { Pon } \\
19\end{array}$ & $\begin{array}{l}\text { Piel, cerebro, leotardo, bola, hospital, par, mancha, canción, } \\
\text { habitación, fiesta, voz, colgante, 24, mayúscula, cebra, olivo, } \\
\text { vocal, llave, naranja, cartón. }\end{array}$ \\
\hline $\begin{array}{l}\text { PowerPoint } \\
20\end{array}$ & $\begin{array}{l}\text { Otoño, frío, goma, ciprés, gomina, abril, letra, cuatro, cocodrilo, } \\
\text { oreja, gorra, aparato, cuenta cuentos, muñeco, dios, monstruo, } \\
\text { garaje, pera, zumo, ruiseñor. }\end{array}$ \\
\hline $\begin{array}{l}\text { Pon } \\
21\end{array}$ & ganchado, ducha, barriga, vampiro, nota, rastrillo. \\
\hline
\end{tabular}

Fuente: elaboración propia.

En la Tabla 4.9 se puede observar que en el PowerPoint 16 se incluyen 22 conceptos y en la Tabla 4.10 en el PowerPoint 21 se incluyen solo 7 conceptos, esto viene determinado por el número de palabras totales que estaban presentes en el Corpus de Habla Infantil Espontánea del Español (CHIEDE) (Garrote, 2008). Para las diferentes edades, al fraccionar las palabras en diferentes PowerPoint, observamos que había dos palabras en el PowerPoint 16 de la edad de tres años, y se decidió no crear otro 
PowerPoint con solo dos conceptos; y ocurrió lo contrario en el PowerPoint 21 de la edad de cinco años, por lo que se acordó crear ese PowerPoint con solo 7 palabras, en vez de incluir 27 conceptos en el PowerPoint 20, que quizás iban a ser demasiadas palabras para los niños de nuestra población.

Estas imágenes se han utilizado tanto en formato PowerPoint como impresas en tamaño cuartilla, es decir 215 x 157,5mm, como se explicará en el apartado 4.3.2.4.

En la fase de aplicación, estas palabras se enseñarán de manera rápida al comienzo de la intervención; posteriormente, se trabajará con los conceptos que consideremos que los niños desconocen a través de estas láminas imprimidas y plastificadas y, finalmente, se volverá a enseñar a los niños rápidamente todas las palabras. Se puede encontrar un ejemplo de estas láminas y PowerPoint en la Figura 4.6. y el resto de las imágenes en el Anexo 13 (imágenes de los niños de tres años), Anexo 14 (imágenes de los niños de cuatro años) y Anexo 15 (imágenes de los niños de cinco años).

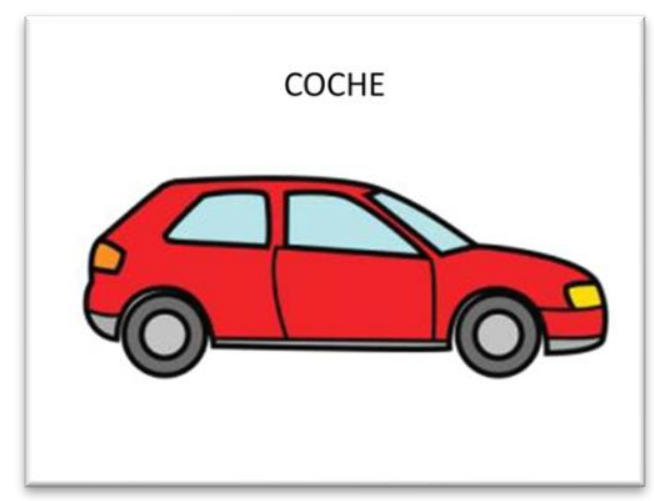

Figura 4.6. Ejemplo de Lámina del Programa de Estimulación Lingüística de Expresión Oral (PELEO) ad hoc.

Fuente: Los símbolos pictográficos utilizados son propiedad del Gobierno de Aragón y han sido creados por Sergio Palao para ARASAAC (http://arasaac.org) que los distribuye bajo licencia Creative Commons (BY-NC-SA). 
2) Pruebas estandarizadas

Las Pruebas estandarizadas utilizadas son las mismas que en el Estudio Piloto (EP), por lo que su descripción se puede encontrar en el apartado 3.1.3. Al igual que en el primer estudio, todas las pruebas se aplican antes y después de la intervención en el siguiente orden: primero se aplica el PLON-R (Aguinaga et al., 2004), después el PEABODY (Dunn et al., 2006) y finalmente el RFI (Juárez y Monfort, 1996a).

La responsabilidad de aplicar estas pruebas estandarizadas recae sobre cada una de las logopedas que participan en este estudio, cada una de ellas debe evaluar a los niños que están a su cargo, tanto al inicio de la intervención como al final, y cuando finaliza la intervención deben facilitar estas pruebas a la doctoranda, es por ello por lo que como ya se ha comentado anteriormente, se comprobó que todas las logopedas conocieran cómo se aplicaba y se evaluaban cada una de las pruebas que tenían que aplicar.

3) Datos visuales a través de vídeos de las sesiones

Esta técnica se empieza a emplear durante el curso académico 2019/2020 porque se cree necesario profundizar en el proceso de aplicación y, para ello, podría ser necesario observar los vídeos y poder categorizar diferentes parámetros y abordar las características del método de manera más fiable; además, también sirve como doble registro del lenguaje de los niños, tanto en los cuadernos de campo como en las grabaciones.

Se obtienen un total de 371 grabaciones de vídeo de 23 participantes; se pueden observar en la Tabla 4.11, la relación de edades, lugares, niños y número de grabaciones.

Tabla 4.11.

Relación de edades, lugares, participantes y cantidades de grabaciones

\begin{tabular}{|c|c|c|c|}
\hline Edad & $\begin{array}{ll}\text { Lugar } & \text { de } \\
\text { intervención }\end{array}$ & Participante & $\begin{array}{ll}\text { N. }{ }^{\circ} & \text { de } \\
\text { grabaciones }\end{array}$ \\
\hline \multirow{7}{*}{$\begin{array}{l}\text { Edad } \\
\text { años }\end{array}$} & \multirow[t]{4}{*}{ Centro A } & P3-1 & 14 \\
\hline & & P3-5 & 14 \\
\hline & & P3-6 & 14 \\
\hline & & P3-7 & 14 \\
\hline & \multirow[t]{2}{*}{ Centro C } & P3-8 & 14 \\
\hline & & P3-9 & 14 \\
\hline & Escuela infantil & P3-3 & 14 \\
\hline
\end{tabular}




\begin{tabular}{|c|c|c|c|}
\hline & & P3-4 & 9 \\
\hline & & P3-2 & 12 \\
\hline & Gabinete privado & P3-10 & 14 \\
\hline \multirow{7}{*}{$\begin{array}{l}\text { Edad cuatro } \\
\text { años }\end{array}$} & Centro A & P4-6 & 16 \\
\hline & \multirow[t]{2}{*}{ Centro B } & P4-9 & 16 \\
\hline & & P4-8 & 16 \\
\hline & \multirow[t]{4}{*}{ Gabinete privado } & $\mathrm{P} 4-5$ & 16 \\
\hline & & P4-1 & 16 \\
\hline & & P4-7 & 16 \\
\hline & & P4-4 & 16 \\
\hline \multirow{6}{*}{$\begin{array}{l}\text { Edad cinco } \\
\text { años }\end{array}$} & Gabinete privado & P5-10 & 21 \\
\hline & Centro A & P5-11 & 21 \\
\hline & \multirow[t]{4}{*}{ Centro B } & P5-6 & 21 \\
\hline & & P5-7 & 21 \\
\hline & & P5-8 & 21 \\
\hline & & P5-9 & 21 \\
\hline
\end{tabular}

Fuente: Elaboración propia.

La responsabilidad de realizar las grabaciones recae sobre la logopeda e investigadora de esta tesis por lo que solo se obtendrán vídeos de los participantes intervenidos por ésta. Esta decisión tiene que ver con la logística y la dificultad que suponía para el resto de las logopedas grabar las sesiones en sus gabinetes privados. Todos los tutores de los participantes a los que se les grabó firmaron un consentimiento informado (véase Anexo 11).

Para la organización y el análisis de los videos se ha utilizado el programa ATLAS.ti 9 para Windows, y se han creado diferentes códigos: sesiones con muchas palabras desconocidas, sesiones con pocas palabras desconocidas, motivación positiva, motivación negativa...

A continuación, explicamos cada una de ellas:

- Consideramos sesiones con muchas palabras desconocidas, las que el número de palabras desconocidas se sitúa por encima de la media de palabras desconocidas por sesión (Tabla 5.11 del capítulo 5); es decir cuando las palabras desconocidas son superiores a 12 para los niños de tres años, superiores a 5 en los niños de cuatro años, y superiores a 4 en los niños de cinco años.

- Consideramos sesiones con pocas palabras desconocidas, cuando éstas son inferiores a la media de palabras desconocidas por sesión (Tabla 5.11 del capítulo 5); es decir cuando las palabras desconocidas son inferiores a 12 para los niños de tres años, 
inferiores a 5 en los niños de cuatro años, e inferiores a 4 en los niños de cinco años.

- Entendemos motivación positiva cuando en la sesión aparecen acciones que incluyen un nivel de activación alto (hacer la señal de victoria, reirse ante una actividad...), la prevalencia de la elección de esa actividad (cuando el niño verbaliza que le gusta la actividad, cuando se apena por no hacer o terminar una actividad), la concentración alta ante esa actividad y la perseverancia con la actividad (Núñez, 2009).

- Entendemos motivación negativa cuando en la sesión aparecen las acciones explicadas anteriormente pero en negativo; es decir, las acciones que incluían un nivel de activación bajo, la negativa ante la elección de la actividad, baja concentración, y las acciones que incluían no querer continuar con la actividad (Núñez, 2009).

Otro tipo de códigos serán la reacción de los niños y su respuesta ante diferentes palabras:

- Partes del cuerpo: reacción de los niños ante las láminas que se incluyen partes del cuerpo humano y animal y su respuesta ante determinadas palabras.

- Conceptos de tiempo: reacción de los niños ante las láminas de los días de la semana, fiestas (navidad, carnaval...), hora, meses, estaciones... y su respuesta ante determinadas palabras.

- Prendas de vestir: reacción de los niños ante las láminas de las prendas de vestir y complementos y su respuesta ante determinadas palabras.

- Alimentos: reacción de los niños ante las láminas de bebidas y comidas y su respuesta ante determinadas palabras.

- Transportes: reacción de los niños ante cualquier medio de transporte ya sea por tierra, mar, aire... y su respuesta ante determinadas palabras.

- Juguetes: reacción de los niños ante las láminas de cualquier juguete desde cuentos, hasta toboganes y su respuesta ante determinadas palabras.

- Objetos: reacción de los niños ante láminas de utensilios, objetos del hogar, objetos que están en la calle... y su respuesta ante determinadas palabras.

- Seres vivos: reacción de los niños ante láminas de animales y plantas y su respuesta ante determinadas palabras.

- Personas, profesiones y personajes: reacción de los niños ante láminas que muestren relaciones familiares (mamá, papá...), personas (niño, bebé, señor...), profesiones (policía, mago...), 
personajes (pirata, fantasma...) y su respuesta ante determinadas palabras.

- Conceptos abstractos: reacción de los niños ante las láminas de algo que no se puede percibir por ningún sentido, que es solo una idea, por ejemplo: paz, pobreza, imaginación... y su respuesta ante determinadas palabras.

- Conceptos de cantidad: reacción de los niños ante las láminas de los números, elementos de comparación (mayor) y su respuesta ante determinadas palabras.

- Lugares: reacción de los niños ante las láminas de la casa, parque, piscina... y su respuesta ante determinadas palabras.

- Medioambiente: reacción de los niños ante las láminas de cualquier elemento relacionado con la naturaleza: sol, suelo, aire, hoja... y su respuesta ante determinadas palabras.

Para la explicación de los resultados se recurre a una serie de siglas: V= video, $\mathrm{PP}=$ PowerPoint, $\mathrm{M}=$ minuto; esto nos ayudará a explicar en qué momento de los videos y en qué video hemos encontrado el fragmento que explicamos en el capítulo 5 de resultados.

\section{4) Observación participante}

La observación participante consiste en recoger las interacciones del niño, sobre todo su expresión espontánea, dedicando especial atención en las palabras que desconoce, y en relatar lo sucedido en las actividades realizadas con las láminas impresas. Una vez dentro del aula, se intenta reflejar con la mayor precisión posible la realidad. Estas observaciones nos aportan una información muy significativa y valiosa para realizar el análisis. Para poder realizar estas observaciones se diseña una lista de control (Anexo 9), que se componen de los siguientes apartados:

- Fecha del día de la intervención.

- Tabla de las palabras que se les enseña cada día, con dos apartados: conoce y desconoce, para poner una cruz en el que corresponda y otro apartado con la expresión espontánea que realiza el participante.

- Un apartado con observaciones, para escribir las actividades que realizamos o lo que considere oportuno la logopeda.

Se consiguen un total de 33 listados de control, uno por cada niño, que se obtienen durante la realización de la Fase 2, que corresponde a la fase de aplicación. Se rellena una hoja de esa lista de control cada día 
intervención (Anexo 9), siendo 14 listas de control para los niños de 3 años; 16 listas de control para los niños de 4 años; y 21 listas de control para los niños de 5 años:

- Como han participado 11 niños de 3 años, tenemos 154 listas de control para ellos, cada una se corresponde con un día de intervención.

- Como han participado 11 niños de 4 años, hemos obtenido 176 listas de control, cada una se corresponde con un día de intervención.

- Como han participado 11 niños de 5 años, hemos obtenido 231 listas de control, cada una se corresponde con un día de intervención.

En total obtenemos 561 listas de control que cada una de ellas corresponde a una sesión de intervención con estos niños.

\section{5) Entrevistas semiestructuradas}

Se han llevado a cabo un total de 28 entrevistas semiestructuradas con los diferentes participantes: las logopedas (Anexo 6), las maestras de los niños (Anexo 8), y las familias participantes en el estudio (Anexo 7). La finalidad de las entrevistas es conocer la valoración de estas profesionales y de las familias sobre el método.

- Las entrevistas a las logopedas (Anexo 6) se han centrado en conocer la opinión respecto al diseño de los bits, la aplicación del método, el lenguaje y la motivación del niño durante la fase de aplicación; además de ofrecerles la opción de realizar cualquier otra aportación que consideraran importante. Las preguntas que realizamos son las siguientes: a) ¿te han parecido las palabras seleccionadas apropiadas?; b) ¿te han parecido las imágenes seleccionadas para esas palabras apropiadas?, c) ¿te ha parecido adecuado el orden en el que se han presentado?, d) ¿te ha parecido adecuado el número de palabras presentadas cada día?, e) ¿cómo te has sentido durante la aplicación?; f) ¿qué dificultades te has encontrado; g) ¿cuándo has realizado la aplicación de los bits? ¿en qué orden?; h) ¿te ha parecido fácil o difícil la aplicación del programa? ¿por qué?; i) ¿crees que ha sido útil para tu paciente la utilización de este programa? ¿por qué?; j) ¿crees que es un programa que vas a utilizar en el futuro con otros casos? ¿por qué?; k) ¿tienes alguna sugerencia o alguna observación que realizar? 
Todas las entrevistas se realizaron vía telefónica, y la fecha, hora y duración de cada una de ellas se puede encontrar en la Tabla 4.12.

Tabla 4.12.

Relación de entrevistas realizadas a las logopedas fecha, hora y duración

\begin{tabular}{llll}
\hline $\begin{array}{l}\text { Logopedas } \\
\text { entrevistadas }\end{array}$ & Fecha & Hora & Duración \\
\hline Logopeda 1 & $02 / 07 / 2019$ & $19: 30$ & 14 minutos \\
\hline Logopeda 2 & $04 / 04 / 2019$ & $12: 19$ & 12 minutos \\
\hline Logopeda 3 & $06 / 07 / 2019$ & $12: 38$ & 9 minutos \\
\hline Logopeda 4 & $02 / 07 / 2019$ & $18: 45$ & 10 minutos \\
\hline Logopeda 5 & $16 / 07 / 2019$ & $13: 15$ & 13 minutos \\
\hline Logopeda 6 & $27 / 11 / 2020$ & $10: 44$ & 8 minutos \\
\hline
\end{tabular}

Fuente: elaboración propia.

- Las entrevistas a las maestras de los niños (Anexo 7) se han centrado en conocer la opinión sobre el nivel del lenguaje oral de los niños y su actitud social, y la opción de realizar cualquier otra aportación u observación que consideraran necesaria. Las preguntas que realizamos a este colectivo son las siguientes: a) ¿has notado que el niño utiliza más vocabulario desde que utiliza el programa?; b) ¿has notado los cambios en la cantidad de expresiones que realiza el niño en la escuela?; c) ¿el niño socializa más desde que utiliza el método?; d) el centro escolar puede decir alguna expresión nueva que tengo el niño ahora que antes no tenía?; e) ¿tenéis alguna inquietud o alguna sugerencia?

La fecha, hora, duración y lugar de cada una de las entrevistas con las maestras se puede observar en la Tabla 4.13.

Tabla 4.13.

Relación de entrevistas realizadas a las maestras fecha, hora y lugar.

\begin{tabular}{lllll}
\hline $\begin{array}{l}\text { Maestras } \\
\text { entrevistadas }\end{array}$ & Fecha & Hora & Duración & Lugar \\
\hline Maestra 1 & $14 / 08 / 2019$ & $10: 30$ & $00: 04$ & $\begin{array}{l}\text { Escuela } \\
\text { infantil }\end{array}$ \\
\hline Maestra 2 & $16 / 12 / 2019$ & $10: 30$ & $00: 05$ & Centro A \\
\hline Maestra 3 & $17 / 12 / 2019$ & $10: 00$ & $00: 05$ & Centro A \\
\hline Maestra 4 & $18 / 12 / 2019$ & $10: 00$ & $00: 04$ & Centro A \\
\hline Maestra 5 & $13 / 01 / 2020$ & $10: 30$ & $00: 06$ & Centro B \\
\hline Maestra 6 & $13 / 01 / 2020$ & $10: 50$ & $00: 05$ & Centro B \\
\hline Maestra 7 & $15 / 01 / 2020$ & $11: 15$ & $00: 04$ & Centro B \\
\hline
\end{tabular}




\begin{tabular}{lllll}
\hline Maestra 8 & $16 / 01 / 2020$ & $11: 15$ & $00: 05$ & Centro B \\
\hline Maestra 9 & $12 / 03 / 2020$ & $11: 00$ & $00: 06$ & Centro C \\
\hline Maestra 10 & $12 / 03 / 2020$ & $11: 15$ & $00: 07$ & Centro C \\
\hline
\end{tabular}

Fuente: elaboración propia.

- Las entrevistas a las familias (Anexo 8) se han centrado en conocer la motivación de los niños cuando acudían a la consulta y el nivel del lenguaje, además de darles la opción de manifestar cualquier inquietud o sugerencia. Las preguntas que realizamos a las familias son las siguientes: a) ¿desde que ha comenzado a utilizarse el programa con su hijo, considera que su hijo ha mejorado? b) ¿ha aumentado el número de palabras que dice su hijo?; c) ¿ha mejorado la articulación de su hijo?; d) ¿tenéis alguna inquietud o sugerencia?

Todas las entrevistas realizadas a la familia se hicieron telefónicamente, la relación de fecha, hora y duración de cada una de ellas se puede observar en la Tabla 4.14.

Tabla 4.14.

Relación de entrevistas realizadas a las familias fecha, hora y duración.

\begin{tabular}{llll}
\hline $\begin{array}{l}\text { Familias } \\
\text { entrevistadas }\end{array}$ & Fecha & Hora & Duración \\
\hline Familia 1 & $14 / 08 / 2019$ & $17: 00$ & $00: 04$ \\
\hline Familia 2 & $14 / 08 / 2019$ & $17: 30$ & $00: 07$ \\
\hline Familia 3 & $14 / 08 / 2019$ & $18: 00$ & $00: 05$ \\
\hline Familia 4 & $16 / 12 / 2019$ & $16: 00$ & $00: 06$ \\
\hline Familia 5 & $16 / 12 / 2019$ & $20: 30$ & $00: 06$ \\
\hline Familia 6 & $17 / 12 / 2019$ & $16: 00$ & $00: 05$ \\
\hline Familia 7 & $17 / 12 / 2019$ & $16: 30$ & $00: 04$ \\
\hline Familia 8 & $18 / 12 / 2019$ & $16: 00$ & $00: 04$ \\
\hline Familia 9 & $18 / 12 / 2019$ & $20: 45$ & $00: 05$ \\
\hline Familia 10 & $13 / 01 / 2020$ & $17: 45$ & $00: 04$ \\
\hline Familia 11 & $13 / 01 / 2020$ & $20: 45$ & $00: 04$ \\
\hline Familia 12 & $13 / 01 / 2020$ & $21: 00$ & $00: 05$ \\
\hline Familia 13 & $15 / 01 / 2020$ & $20: 45$ & $00: 07$ \\
\hline Familia 14 & $16 / 01 / 2020$ & $18: 45$ & $00: 08$ \\
\hline Familia 15 & $16 / 01 / 2020$ & $19: 30$ & $00: 04$ \\
\hline Familia 16 & $12 / 03 / 2020$ & $21: 00$ & $00: 05$ \\
\hline Familia 17 & $13 / 03 / 2020$ & $16: 00$ & $00: 08$ \\
\hline
\end{tabular}

Fuente: elaboración propia.

4.3.2.4. Fases de aplicación 
Primero y antes de comenzar la intervención, los logopedas firman el consentimiento informado (Anexo 10), al igual que lo realizan los tutores legales de los participantes del estudio y el responsable de los distintos centros donde se lleva a cabo la intervención (Anexo 11), posteriormente comenzamos la intervención. Es importante detallar que todas las logopedas llevan a cabo desde la Fase 1 hasta la Fase 3 incluidas, siendo una logopeda la única en realizar la Fase 4. A continuación explicamos en profundidad cada una de dichas fases.

- Fase 1. Fase de evaluación inicial: al igual que en el Estudio Piloto (EP), se evalúa a los participantes en una primera sesión de una hora de duración. La primera prueba que se aplica es el PLON-R (Aguinaga et al., 2004), después el PEABODY (Dunn et al., 2006), y finalmente el RFI (Juárez y Monfort, 1996a). Aunque, como señalamos, esta fase dura alrededor de una hora, en algunas ocasiones es necesario realizar descansos y jugar con el infante entre prueba y prueba antes de continuar.

- Fase 2. Fase de intervención: Esta fase subdivide en tres subfases:

- Primera subfase: se enseña a los niños las láminas en PowerPoint preguntándoles "¿Qué es lo que ves?". Cuando el niño desconoce la palabra, se apunta en la lista de control (Anexo 9), se le explica el significado de la palabra y se le pide que lo repita correctamente. Cuando el niño comete muchos errores fonético-fonológicos, repetimos en voz alta correctamente la palabra.

- Segunda subfase: dura unos 10-15 minutos, donde realizamos diferentes actividades con las palabras, que no hayan conocido o no hayan pronunciado correctamente, registradas anteriormente. Para estas actividades se utilizan las láminas en una cuartilla que corresponde a $215 \times 157,5 \mathrm{~mm}$ plastificadas. Las actividades con cartulinas, que utilizamos con los participantes por separado, son las siguientes:

- Colocar en diferentes rincones del aula las láminas y cuando denominamos en voz alta uno de ellos, el niño corre y lo coge; una vez que lo tiene en la mano, le preguntamos ¿Qué es lo que has encontrado?, esperando que nombre correctamente la palabra; cuando no lo hace, se le nombra y se le insta a repetirla. 
- Se colocan encima de la mesa las láminas y se describe una, esperando que el niño acierte la que estamos describiendo. Se le nombra y la debe repetir.

- Se juega al memory ${ }^{5}$ con las láminas de las palabras desconocidas que correspondan a ese día. Para realizar esta actividad es necesario tener imprimidas dos veces las láminas de PowerPoint, se ponen boca abajo las imágenes que hayan desconocido en la Fase 1, de manera descolocada, tienen que dar la vuelta a una y decir su nombre, posteriormente debe dar la vuelta a otra y decir su nombre, si son idénticas el niño se queda con la pareja y le preguntaremos cosas sobre la imagen. El juego continúa, si se equivoca es el turno de la logopeda, el juego finaliza cuando se hayan dado la vuelta todas las imágenes.

- Tercera subfase: comienza nada más finalizar la fase anterior, dura alrededor de 2 minutos, ya que consiste en volver a mostrar los bits a los infantes, pero en esta ocasión pronunciamos las palabras en alto y se van mostrando los bits más rápido que en la primera fase, unos 3 segundos cada uno. Una vez finalizada la sesión, comienza la preparación para la siguiente sesión, cuyo planteamiento varía dependiendo de la evolución de cada niño. Existen dos posibilidades: continuar con el mismo PowerPoint, o avanzar al siguiente.

1. Si el niño ha cometido demasiados errores (de 10 a 15 errores), se debe continuar con el mismo PowerPoint -cada PowerPoint se puede utilizar un máximo de dos días- la decisión final, de pasar o no al siguiente PowerPoint, recae sobre el profesional que lo aplica.

2. En el caso de que el niño no haya cometido demasiados errores, se puede avanzar al siguiente PowerPoint.

\footnotetext{
${ }^{5} \mathrm{El}$ juego del memory, es una actividad que se puede jugar en pareja o en grupo y consiste en tener una serie de parejas de cartas iguales boca abajo en una mesa, los participantes deben voltear dos cartas, recordando la ubicación de las mismas. Cuando se encuentran dos cartas iguales, el jugador se las lleva, si las dos cartas que voltea no son iguales, las tiene que volver a dejar en el sitio boca abajo, y sigue volteando las cartas el siguiente participante. La partida termina cuando no queden más cartas sobre la mesa, gana la persona que haya recogido más cartas.
} 
- Fase 3. Fase de evaluación final: consiste en volver a aplicar las tres pruebas ya aplicadas en la evaluación inicial. En esta fase, las logopedas que llevaban a cabo este proceso tenían que enviar la información a la persona encargada de recopilar toda la información (en este caso la doctoranda).

- Fase 4. Fase de entrevistas semiestructuradas: momento en el que se realizan las entrevistas semiestructuradas a los que participan en el estudio (logopedas, maestras y familias). Algunas de las entrevistas se realizaron por teléfono y otras de manera presencial.

Se puede encontrar un esquema de las fases en la Figura 4.7. 


\section{FASES DE INTERVENCIÓN}

\section{PELEO (Programa de Estimulación Lingüistica de Expresión Oral)}

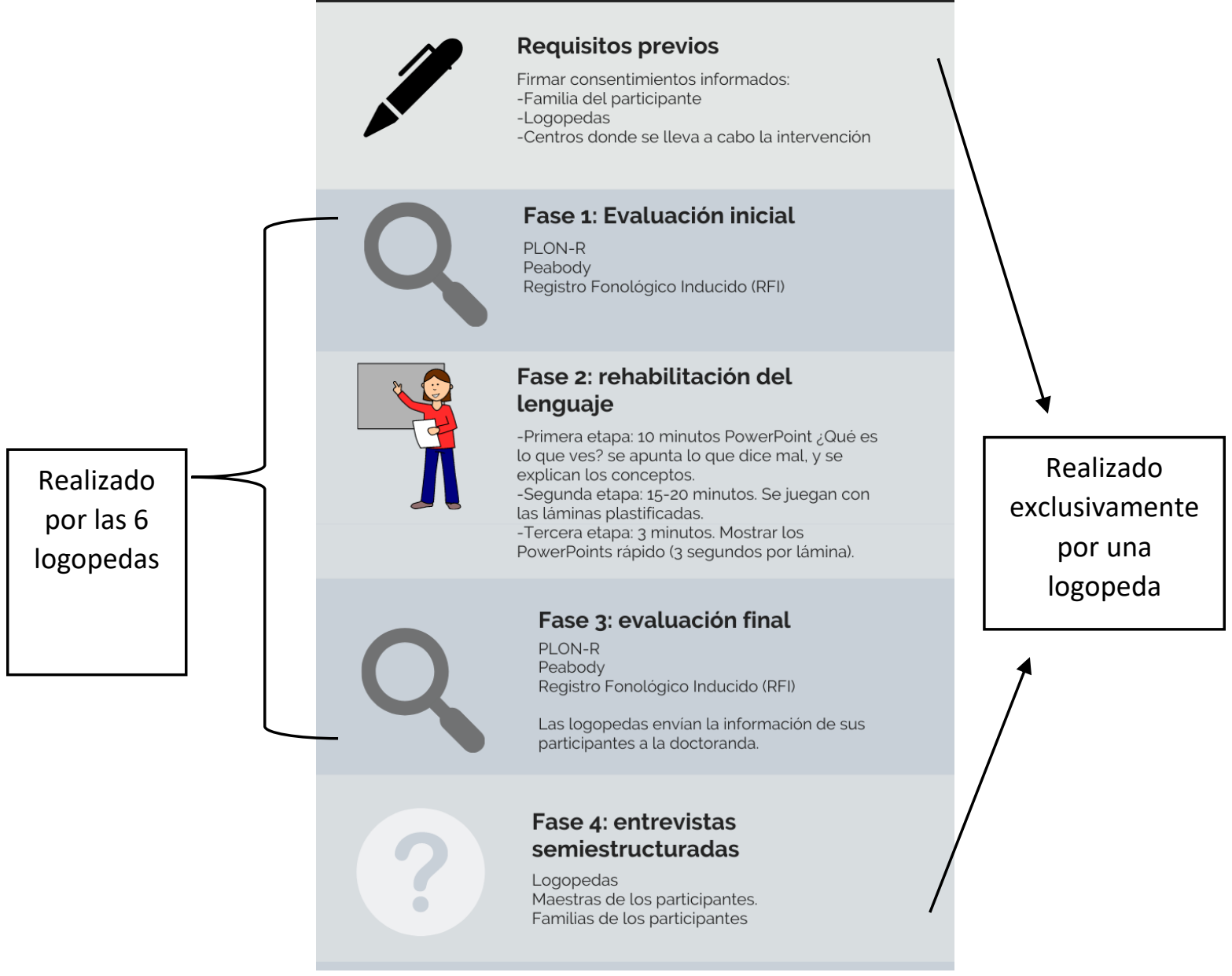

Figura 4.7. Proceso de intervención del Estudio 2: PELEO Fuente: elaboración propia. 



\section{Capítulo 5}

\section{Análisis e interpretación de los datos obtenidos}

En el presente capítulo presentamos el análisis de resultados de los dos estudios realizados. El primero, es el Estudio Piloto (EP) cuyo objetivo principal es comprobar la eficacia de los bits de inteligencia del Método Doman en los niños con trastorno del lenguaje y valorar si son útiles para el nuevo programa y qué cambios podemos implementar para diseñar el Programa de Estimulación Lingüística de Expresión Oral (PELEO). El segundo estudio es un Estudio de Caso Evaluativo (ECE) que consiste en analizar el diseño y la aplicación de PELEO en niños con trastorno del lenguaje de tres, cuatro y cinco años con trastorno del lenguaje. En el EP se presentan los resultados teniendo en cuenta el tipo de análisis (intergrupal e intragrupal) y las pruebas estandarizadas realizadas; mientras que en el segundo estudio de ECE, se presentan los resultados según las preguntas de investigación.

En el primer apartado de este capítulo se explican los resultados obtenidos en el Estudio Piloto (EP); para ello, como se ha comentado en capítulos anteriores, se sigue un diseño cuasi experimental con grupo control desde un paradigma cuantitativo. Como ya explicamos en el apartado 4.3.1 del capítulo 4, se realizan dos tipos de análisis el análisis intergrupal, y en el análisis intragrupal. Empezamos por el análisis intergrupal que consiste en analizar las diferencias del pretest y del postest en el grupo experimental - grupo de niños con los que utilizamos los bits de inteligencia-, y con el grupo control - grupo de niños con los que no se ha realizado ningún tipo de intervención logopédica-; de esta manera conseguimos observar si en un principio la población tenía rasgos similares, y también observamos la diferencia del postest que nos servirá para conocer si existen cambios significativos con los bits de inteligencia. Una vez finalizado este análisis, pasamos al análisis 
intragrupal, en él observamos si existen diferencias en el grupo experimental entre el pretest y el postest, y realizamos la misma operación en el grupo control, de esta manera comprobamos si dentro de cada grupo ha existido una mejoría.

Para realizar este análisis se utiliza el software SPSS (Statistical Package for Social Sciences) versión 24.0 en su versión para Windows, y con él realizamos diferentes análisis estadísticos, Comenzamos con la prueba de normalidad de Shapiro Wilk ya que el tamaño muestral es pequeño (Moreno-González, 2008), teniendo en cuenta los resultados mostrados por esta prueba, consideramos oportuno utilizar estadísticos paramétricos; realizamos estadísticos descriptivos que serán útiles para conocer la media, la mediana y la desviación típica de cada variable, además de la Prueta T-student para muestras independientes (análisis intergrupal) y la Prueta T-student para muestras relacionadas (muestra intragrupal); ambas Pruebas T-student sirven para comparar medias y declarar si existe una diferencia significativa o no entre dos variables (Moreno-González, 2008), por último se aplica Kappa de Cohen, cuando las Pruebas T-Student arrojen una significancia entre los valores, con fin de ajustar el efecto del azar en la concordancia observada, y valorar la intensidad de la diferencia entre las dos variables (Carletta, 1996).

Para finalizar el análisis de los resultados de este primer estudio, analizamos los resultados del cuestionario tipo Likert sobre la opinión de las familias que han utilizado los bits de inteligencia. Y, para terminar, desarrollamos un apartado sobre los resultados del Estudio Piloto (EP), con ello pretendemos explicar a los lectores los cambios realizados y las partes recogidas para crear el nuevo Programa de Estimulación Lingüística de Expresión Oral (PELEO).

En el segundo apartado del capítulo se explican los resultados del ECE que, tal y como hemos indicado previamente, sirve para comprender, y analizar en profundidad el diseño y la aplicación de PELEO, el diseño de investigación de este estudio viene explicado en el apartado 4.3.2 del capítulo 4. Contestaremos a una serie de preguntas relativas a este estudio, que son: ¿cómo es el diseño de PELEO en relación con la cantidad, el orden y el tipo de vocabulario utilizado? ¿Cómo es el diseño de PELEO en relación con las actividades y la motivación de los infantes? ¿Cómo ha cambiado el vocabulario de los niños que han utilizado PELEO? ¿Cómo ha cambiado la articulación de los niños que han utilizado PELEO? ¿Cómo ha cambiado la morfosintaxis de los niños que han utilizado PELEO? Para dar respuesta a estas preguntas, 
empleamos la técnica de triangulación de datos con un enfoque mixto. Entendiendo la triangulación de datos como la utilización de diferentes técnicas de recogida de datos (observación, entrevistas, pruebas estandarizadas, videos) para responder a una pregunta de investigación (García et al., 2016).

\subsection{Resultados del Estudio Piloto (EP)}

La primera prueba estadística que hemos realizado es la prueba de normalidad de Shapiro Wilk, ya que se han obtenido menos de 50 datos. Esta prueba nos indicó si nuestra muestra tenía una distribución normal o no, para decidir si posteriormente realizabamos estadísticos paramétricos o no paramétricos (Moreno-González, 2008). El nivel de significancia que establecimos es de 0.05 y seleccionamos las hipótesis para realizar la prueba, establecimos dos hipótesis: (a) H0: Las variables provienen de una distribución normal y (b) H1: Las variables no provienen de una distribución normal. Y determinamos que si $\mathrm{p}>0.05$ aceptamos H0, y si p<0.05 aceptamos H1. Los resultados y la decisión tomada se pueden observar en la Tabla 5.1.

Tabla 5.1.

Pruebas de normalidad para las variables del primer estudio

\begin{tabular}{|c|c|c|c|}
\hline & \multicolumn{3}{|c|}{ Shapiro-Wilk } \\
\hline & Estadístico & Gl Sig. & Decisión \\
\hline Edad en meses & ,925 & $8 \quad, 476$ & $\begin{array}{l}\mathrm{p}=0.476>0.05 \\
\text { Aceptamos H0 }\end{array}$ \\
\hline Tiempo de intervención en semanas & ,791 & $8 \quad, 023$ & $\begin{array}{l}\mathrm{p}=0.23>0.05 \\
\text { Aceptamos H0 }\end{array}$ \\
\hline $\begin{array}{l}\text { PLON. Evaluación inicial. Puntuación } \\
\text { típica. Forma }\end{array}$ & ,840 & $8 \quad, 075$ & $\begin{array}{l}\mathrm{p}=0.75>0.05 \\
\text { Aceptamos H0 }\end{array}$ \\
\hline $\begin{array}{l}\text { PLON. Evaluación inicial. Puntuación } \\
\text { típica. Contenido }\end{array}$ & ,858 & $8 \quad, 113$ & $\begin{array}{l}\mathrm{p}=0.113>0.05 \\
\text { Aceptamos H0 }\end{array}$ \\
\hline $\begin{array}{l}\text { PLON. Evaluación inicial. Puntuación } \\
\text { típica. Uso }\end{array}$ & ,899 & $8 \quad, 285$ & $\begin{array}{l}\mathrm{p}=0.285>0.05 \\
\text { Aceptamos H0 }\end{array}$ \\
\hline $\begin{array}{l}\text { PLON. Evaluación inicial. Puntuación } \\
\text { típica. Total }\end{array}$ & ,926 & $8 \quad, 481$ & $\begin{array}{l}\mathrm{p}=0.481>0.05 \\
\text { Aceptamos H0 }\end{array}$ \\
\hline $\begin{array}{l}\text { PLON. Evaluación final. Puntuación } \\
\text { típica. Forma }\end{array}$ & ,950 & $8 \quad, 711$ & $\begin{array}{l}\mathrm{p}=0.711>0.05 \\
\text { Aceptamos H0 }\end{array}$ \\
\hline $\begin{array}{l}\text { PLON. Evaluación final. Puntuación } \\
\text { típica. Contenido }\end{array}$ &, 850 & 8,096 & $\begin{array}{l}\mathrm{p}=0.96>0.05 \\
\text { Aceptamos H0 }\end{array}$ \\
\hline $\begin{array}{l}\text { PLON. Evaluación final. Puntuación } \\
\text { típica. Uso }\end{array}$ & ,905 & $8 \quad, 321$ & $\begin{array}{l}\mathrm{p}=0.321>0.05 \\
\text { Aceptamos H0 }\end{array}$ \\
\hline
\end{tabular}




$\begin{aligned} & \text { PLON. Evaluación final. Puntuación ,925 } \\ & \text { típica. Total }\end{aligned}$
$\begin{aligned} & \text { PEABODY. Evaluación inicial. Edad } \\ & \text { equivalente en meses }\end{aligned}$

Fuente: elaboración propia.

Todos los resultados fueron superiores a 0.05 , por lo que decidimos aceptar H0, y decidimos que las variables provenían de una distribución normal. Este resultado nos fue de gran ayuda, ya que de esta manera todas las pruebas estadísticas que hemos utilizado en el análisis intergrupo e intragrupo han sido pruebas paramétricas ya que nuestros datos tenían una distribución normal.

\subsubsection{Análisis intergrupo}

El análisis intergrupal consiste en observar las diferencias del pretest en el grupo experimental y en el grupo control y en realizar la misma operación en el postest. Este tipo de análisis y lo que conlleva, viene explicado en el Capítulo 4 en el apartado 4.3.1.6.

Para conocer las características de las variables en cada grupo, hemos realizado lo estadísticos descriptivos (Tabla 5.2), en esta tabla conoceremos la media, desviación estándar y la media de error estándar de los resultados del PLON-R (Aguinaga et al., 2004), del PEABODY (Dunn et al., 2006), y del RFI (Juárez y Monfort, 1996a).

Tabla 5.2.

Estadísticos descriptivos del análisis intergrupal

\begin{tabular}{|c|c|c|c|c|c|}
\hline & Grupo & $\mathrm{N}$ & Media & $\begin{array}{r}\text { Desviación } \\
\text { estándar }\end{array}$ & $\begin{array}{r}\text { Media de } \\
\text { error } \\
\text { estándar }\end{array}$ \\
\hline $\begin{array}{ll}\text { PLON. } & \text { Evaluación } \\
\text { inicial. } & \text { Puntuación }\end{array}$ & $\begin{array}{l}\text { Grupo } \\
\text { Experimental }\end{array}$ & 4 & 28,75 & 12,69 & 6,34 \\
\hline típica. Forma & Grupo control & 4 & 19,75 & 12,28 & 6,14 \\
\hline \multirow{2}{*}{$\begin{array}{l}\text { PLON. } \quad \text { Evaluación } \\
\text { inicial. } \\
\text { típica. Contentuación }\end{array}$} & $\begin{array}{l}\text { Grupo } \\
\text { Experimental } \\
\end{array}$ & 4 & 29,250 & 11,62 & 5,81 \\
\hline & Grupo control & 4 & 20,75 & 4,72 & 2,36 \\
\hline
\end{tabular}




\begin{tabular}{|c|c|c|c|c|c|}
\hline \multirow{2}{*}{$\begin{array}{ll}\text { PLON. Evaluación } \\
\text { inicial. Puntuación } \\
\text { típica. Uso }\end{array}$} & $\begin{array}{l}\text { Grupo } \\
\text { Experimental }\end{array}$ & 4 & 35,75 & 12,45 & 6,22 \\
\hline & Grupo control & 4 & 34,00 & 10,42 & 5,21 \\
\hline \multirow{2}{*}{$\begin{array}{l}\text { PLON. Evaluación } \\
\text { inicial. Puntuación } \\
\text { típica. Total }\end{array}$} & $\begin{array}{l}\text { Grupo } \\
\text { Experimental }\end{array}$ & 4 & 23,75 & 8,85 & 4,42 \\
\hline & Grupo control & 4 & 11,75 & 6,95 & 3,47 \\
\hline \multirow{2}{*}{$\begin{array}{l}\text { PLON. Evaluación } \\
\text { final. } \quad \text { Puntuación } \\
\text { típica. Forma }\end{array}$} & $\begin{array}{l}\text { Grupo } \\
\text { Experimental }\end{array}$ & 4 & 31,25 & 14,10 & 7,05 \\
\hline & Grupo control & 4 & 26,00 & 10,55 & 5,27 \\
\hline \multirow{2}{*}{$\begin{array}{lr}\text { PLON. } & \text { Evaluación } \\
\text { final. } & \text { Puntuación } \\
\text { típica. } & \text { Contenido } \\
\end{array}$} & $\begin{array}{l}\text { Grupo } \\
\text { Experimental }\end{array}$ & 4 & 38,25 & 10,84 & 5,42 \\
\hline & Grupo control & 4 & 26,25 & 4,71 & 2,35 \\
\hline \multirow{2}{*}{$\begin{array}{ll}\text { PLON. } & \text { Evaluación } \\
\text { final. } & \text { Puntuación } \\
\text { típica. Uso } & \\
\end{array}$} & $\begin{array}{l}\text { Grupo } \\
\text { Experimental }\end{array}$ & 4 & 37,50 & 13,50 & 6,75 \\
\hline & Grupo control & 4 & 47,50 & 8,35 & 4,17 \\
\hline \multirow{2}{*}{$\begin{array}{l}\text { PLON. Evaluación } \\
\text { final. Puntuación } \\
\text { típica. Total }\end{array}$} & $\begin{array}{l}\text { Grupo } \\
\text { Experimental }\end{array}$ & 4 & 28,25 & 15,95 & 7,97 \\
\hline & Grupo control & 4 & 22,00 & 5,77 & 2,89 \\
\hline \multirow{2}{*}{$\begin{array}{l}\text { PEABODY. } \\
\text { Evaluación inicial. } \\
\text { Edad equivalente en } \\
\text { meses }\end{array}$} & $\begin{array}{l}\text { Grupo } \\
\text { Experimental }\end{array}$ & 4 & 55,00 & 8,25 & 4,12 \\
\hline & Grupo control & 4 & 53,25 & 8,42 & 4,21 \\
\hline \multirow{2}{*}{$\begin{array}{l}\text { PEABODY. } \\
\text { Evaluación final. } \\
\text { Edad equivalente en } \\
\text { meses. }\end{array}$} & $\begin{array}{l}\text { Grupo } \\
\text { Experimental }\end{array}$ & 4 & 59,75 & 11,56 & 5,77 \\
\hline & Grupo control & 4 & 54,00 & 8,68 & 4,33 \\
\hline \multirow{2}{*}{$\begin{array}{l}\text { RFI. Evaluación } \\
\text { inicial. Total de } \\
\text { fonemas erróneos. }\end{array}$} & $\begin{array}{l}\text { Grupo } \\
\text { Experimental } \\
\end{array}$ & 4 & 56,00 & 19,41 & 9,70 \\
\hline & Grupo control & 4 & 62,25 & 18,23 & 9,11 \\
\hline \multirow{2}{*}{$\begin{array}{l}\text { RFI. Evaluación final. } \\
\text { Total de fonemas } \\
\text { erróneos. }\end{array}$} & $\begin{array}{l}\text { Grupo } \\
\text { Experimental } \\
\end{array}$ & 4 & 29,50 & 20,66 & 10,33 \\
\hline & Grupo control & 4 & 64,25 & 17,65 & 8,82 \\
\hline
\end{tabular}

Fuente: elaboración propia.

En la Tabla 5.2, se observa la media de cada variable, podemos ver cómo en los resultados pretest, los resultados fueron muy bajos, por lo que pudimos determinar que tenían grandes dificultades en todas las áreas; sin embargo, en el RFI los resultados fueron altos, lo que quiere decir que no pronunciaban muchos fonemas y palabras, y que a simple vista los resultados mejoraron con la intervención.

Para realizar correctamente la Prueta T-student para muestras independientes, tuvimos que conocer si las varianzas eran iguales o no, para elegir correctamente la sig. bilateral. Por ello hemos realizado la prueba de Levene, y para esta prueba se determinaron dos hipótesis: (a) 
H0: Se asumen varianzas iguales; (b) H1: No se asumen varianzas iguales. Al igual que hemos realizado en ocasiones anteriores, si p>0.05 aceptamos H0, y si $\mathrm{p}<0.05$ aceptamos H1. Así pues, una vez aplicada, decidimos aceptar $\mathrm{H} 0$, es decir se asumieron varianzas iguales en las variables de PLON evaluación inicial PT forma (0.979>0.05), PLON evaluación inicial PT uso (0.708>0.05), PLON evaluación inicial PT total (0.899>0.05), PLON evaluación final PT forma (0.279>0.05), PLON evaluación final PT contenido (0.238>0.05), PLON evaluación final PT uso (0.087>0.05), PLON evaluación final PT total (0.381>0.05), PEABODY evaluación inicial, edad equivalente $(0.798>0.05)$, PEABODY evaluación final edad equivalente (0.144), RFI evaluación inicial total fonemas erróneos $(0.829>0.05)$ y RFI evaluación final total de fonemas $(0.646>0.05)$. En cambio, en una variable no ocurrió lo mismo; aceptamos $\mathrm{H} 1$, es decir no se asumieron varianzas iguales en la variable PLON evaluación inicial PT contenido $(0.017<0.05)$.

Para conocer si existía una diferencia significativa entre las medias de ambos grupos, se realizó la Prueta T-student para muestras independientes (Tabla 5.3), al igual que en la otra prueba estadística, establecimos dos hipótesis: (a) H0: Las variables son iguales, (b) H1: Las variables son diferentes. La decisión que tomamos para aceptar o rechazar la $\mathrm{H} 0$; dependió del resultado de sig. bilateral, determinamos que si p>0.05 aceptamos H0, y si p<0.05 aceptamos H1.

Tabla 5.3.

Prueta T-student para muestras independientes

\begin{tabular}{llrr}
\hline & Sig. (bilateral) & $\begin{array}{r}\text { Diferencia de } \\
\text { medias }\end{array}$ & $\begin{array}{r}\text { Diferencia de } \\
\text { error estándar }\end{array}$ \\
\hline $\begin{array}{l}\text { PLON. Evaluación } \\
\text { inicial. Puntuación } \\
\text { típica. Forma }\end{array}$ & 0,347 & 9,00 & 8,83 \\
\hline $\begin{array}{l}\text { PLON. Evaluación } \\
\text { inicial. Puntuación } \\
\text { típica. Contenido }\end{array}$ & 0,247 & & 6,27 \\
\hline $\begin{array}{l}\text { PLON. Evaluación } \\
\text { inicial. Puntuación } \\
\text { típica. Uso }\end{array}$ & 0,836 & 8,50 & 8,12 \\
\hline $\begin{array}{l}\text { PLON. Evaluación } \\
\text { inicial. Puntuación } \\
\text { típica. Total }\end{array}$ & 0,077 & 1,75 & 5,62 \\
\hline $\begin{array}{l}\text { PLON. Evaluación } \\
\text { final. Puntuación } \\
\text { típica. Forma }\end{array}$ & 0,573 & 12,00 & 8,80 \\
\hline
\end{tabular}




\begin{tabular}{|c|c|c|c|}
\hline $\begin{array}{ll}\text { PLON. } & \text { Evaluación } \\
\text { final. } & \text { Puntuación } \\
\text { típica. } & \text { Contenido }\end{array}$ & 0,089 & 12,00 & 5,91 \\
\hline $\begin{array}{l}\text { PLON. Evaluación } \\
\text { final. } \quad \text { Puntuación } \\
\text { típica. Uso }\end{array}$ & 0,254 & $-10,00$ & 7,93 \\
\hline $\begin{array}{ll}\text { PLON. } & \text { Evaluación } \\
\text { final. } & \text { Puntuación } \\
\text { típica. Total }\end{array}$ & 0,489 & 6,25 & 8,47 \\
\hline $\begin{array}{l}\text { PEABODY. } \\
\text { Evaluación inicial. } \\
\text { Edad equivalente en } \\
\text { meses }\end{array}$ & 0,777 & 1,75 & 5,89 \\
\hline $\begin{array}{l}\text { PEABODY. } \\
\text { Evaluación final. } \\
\text { Edad equivalente en } \\
\text { meses. }\end{array}$ & 0,457 & 5,75 & 7,22 \\
\hline $\begin{array}{l}\text { RFI. Evaluación } \\
\text { inicial. Total de } \\
\text { fonemas erróneos. }\end{array}$ & 0,655 & $-6,25$ & 13,31 \\
\hline $\begin{array}{l}\text { RFI. Evaluación } \\
\text { final. Total de } \\
\text { fonemas erróneos. }\end{array}$ & 0,043 & $-34,75$ & 13,58 \\
\hline
\end{tabular}

Fuente: Elaboración propia.

En la Tabla 5.3 observamos que el único resultado significativo positivo intergrupal es el del Registro Fonológico Inducido postest $(0.043<0.05)$, por lo que para esta variable se aceptó H1 y se consideró que las variables eran significativamente diferentes, y en el resto de las variables aceptamos $\mathrm{H} 0$ y se consideró que las variables eran iguales.

Como conclusión en este análisis intergrupal, pudimos determinar que en las variables analizadas en el momento inicial la muestra era similar, y por lo tanto era una muestra bien recogida, aunque eran muy pocos participantes. Por otro lado, pudimos determinar que no había diferencias significativas en ambos grupos a excepción de la variable del Registro Fonológico Inducido, por lo que a priori, el tratamiento con los bits de inteligencia no parecía demostrar que estos eran eficaces, con la excepción de su uso para mejorar la articulación. Aun así, decidimos continuar con el análisis intragrupal, para profundizar en la eficacia de estos en esta población. 


\subsubsection{Análisis intragrupal}

En este apartado se van a explicar los resultados del grupo experimental y del grupo control por separado, observando las diferencias entre el pretest y el postest de cada grupo. Se ha realizado este análisis al grupo experimental para conocer si encontramos diferencias significativas y saber si los niños mejoraron tras aplicarles los bits de inteligencia; se realizó el mismo análisis al grupo control, para conocer y comprender cómo fue la evolución de los niños con trastorno de lenguaje que no recibieron tratamiento.

\subsubsection{Grupo experimental}

Para comenzar, se realizaron los estadísticos descriptivos de las muestras, emparejando éstas según la subprueba que se había utilizado y el resultado inicial y final, de esta manera conocimos la media, la desviación estándar y la media de error estándar (Tabla 5.4).

Tabla 5.4.

Estadísticos descriptivos de las muestras emparejas en el grupo experimental

\begin{tabular}{|c|c|c|c|c|c|}
\hline & & Media & $\mathrm{N}$ & $\begin{array}{r}\text { Desviación } \\
\text { estándar }\end{array}$ & $\begin{array}{r}\text { Media de } \\
\text { error estándar }\end{array}$ \\
\hline \multirow[t]{2}{*}{ Par 1} & $\begin{array}{lr}\text { PLON. } & \text { Evaluación } \\
\text { inicial. } & \text { Puntuación } \\
\text { típica. Forma }\end{array}$ & 28,75 & 4 & 12,68 & 6,34 \\
\hline & $\begin{array}{l}\text { PLON. Evaluación } \\
\text { final. Puntuación típica. } \\
\text { Forma }\end{array}$ & 31,25 & 4 & 14,10 & 7,05 \\
\hline \multirow[t]{2}{*}{ Par 2} & $\begin{array}{l}\text { PLON. Evaluación } \\
\text { inicial. } \\
\text { típica. Contenido }\end{array}$ & 29,25 & 4 & 11,61 & 5,81 \\
\hline & $\begin{array}{l}\text { PLON. Evaluación } \\
\text { final. Puntuación típica. } \\
\text { Contenido }\end{array}$ & 38,25 & 4 & 10,84 & 5,42 \\
\hline \multirow[t]{2}{*}{ Par 3} & $\begin{array}{ll}\text { PLON. } & \text { Evaluación } \\
\text { inicial. } & \text { Puntuación } \\
\text { típica. Uso } & \\
\end{array}$ & 35,75 & 4 & 12,44 & 6,22 \\
\hline & $\begin{array}{l}\text { PLON. Evaluación } \\
\text { final. Puntuación típica. } \\
\text { Uso }\end{array}$ & 37,50 & 4 & 13,50 & 6,75 \\
\hline Par 4 & $\begin{array}{lr}\text { PLON. } & \text { Evaluación } \\
\text { inicial. } & \text { Puntuación } \\
\text { típica. Total } & \end{array}$ & 23,75 & 4 & 8,84 & 4,42 \\
\hline
\end{tabular}




\begin{tabular}{llllll}
\hline & $\begin{array}{l}\text { PLON. Evaluación } \\
\text { final. Puntuación típica. } \\
\text { Total }\end{array}$ & 28,25 & 4 & 15,94 & 7,97 \\
\hline Par 5 & $\begin{array}{l}\text { PEABODY. Evaluación } \\
\text { inicial. 55,00 }\end{array}$ & 4 & 8,24 & 4,12 \\
& equivalente en meses \\
& $\begin{array}{l}\text { PEABODY. Evaluación } \\
\text { final. Edad equivalente } \\
\text { en meses. }\end{array}$ & 59,75 & 4 & 11,55 & 5,77 \\
\hline Par 6 & $\begin{array}{l}\text { RFI. Evaluación inicial. } \\
\text { Total de fonemas } \\
\text { erróneos. 56,00 }\end{array}$ & & & & \\
\hline & $\begin{array}{l}\text { RFI. Evaluación final. } \\
\text { Total de fonemas } \\
\text { erróneos. 29,50 }\end{array}$ & 4 & 20,66 & 10,33 \\
\hline
\end{tabular}

a. Grupo = Grupo Experimental.

Fuente: elaboración propia.

En la Tabla 5.4 comprobamos cómo todas las medias del PLON-R (Aguinaga et al., 2004) y del PEABODY (Dunn et al., 2006) eran superiores en el post-test en comparación con el pretest; esto era positivo quería decir que los niños habían mejorado en las características que medían estas pruebas. Observamos que, en el RFI, esta puntuación media era menor en el postest; esto también era positivo ya que lo que medía el RFI era la cantidad de fonemas erróneos, por lo que esto indicaba que los niños decían menos fonemas mal al finalizar la intervención.

En la Tabla 5.5 mostramos los resultados de la Prueta T-student para muestras relacionadas, esta prueba servía para valorar si existía una diferencia significativa entre las medidas pretest y postest del grupo experimental. Al igual que en las otras pruebas estadísticas, establecimos dos hipótesis: (a) H0: Las variables son iguales, (b) H1: Las variables son diferentes. La decisión que tomamos para aceptar o rechazar la H0 dependió del resultado de sig. bilateral; determinamos que si p>0.05 aceptábamos H0, y si p<0.05 aceptábamos H1. 
Tabla 5.5.

Prueta T-student para muestras relacionadas

Diferencias emparejadas

\begin{tabular}{|c|c|c|c|c|c|c|c|c|c|}
\hline & & \multirow[b]{3}{*}{ Media } & \multirow{3}{*}{$\begin{array}{l}\text { Desviación } \\
\text { estándar }\end{array}$} & \multirow{3}{*}{$\begin{array}{l}\text { Media de } \\
\text { error estándar }\end{array}$} & \multirow{2}{*}{\multicolumn{2}{|c|}{$\begin{array}{l}95 \% \text { de intervalo de confianza } \\
\text { de la diferencia }\end{array}$}} & \multirow[b]{3}{*}{$\mathrm{t}$} & \multirow[b]{3}{*}{$\mathrm{gl}$} & \multirow{3}{*}{$\begin{array}{l}\text { Sig. } \\
\text { (bilateral) }\end{array}$} \\
\hline & & & & & & & & & \\
\hline & & & & & Inferior & Superior & & & \\
\hline Par 1 & $\begin{array}{lr}\text { PLON. } & \text { Evaluación } \\
\text { inicial. } & \text { Puntuación } \\
\text { típica. Forma } & - \text { PLON. } \\
\text { Evaluación } & \text { final. } \\
\text { Puntuación } & \text { típica. } \\
\text { Forma } & \\
\end{array}$ & $-2,50$ & 11,09 & 5,54 & $-20,14$ & 15,14 &,- 451 & 3 & ,683 \\
\hline Par 2 & $\begin{array}{l}\text { PLON. } \\
\text { inicial. } \\
\text { típica. Puntuación } \\
\text { PLON. Evaluantenido } \\
\text { Puntuación final. } \\
\text { Contenido típica. }\end{array}$ & $-9,00$ & 9,27 & 4,63 & $-23,75$ & 5,75 & $-1,941$ & 3 & ,148 \\
\hline Par 3 & 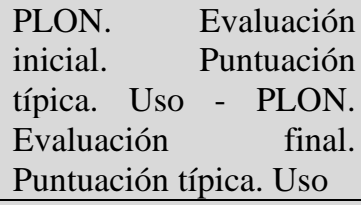 & $-1,75$ & 3,50 & 1,75 & $-7,319$ & 3,81 & $-1,000$ & 3 & ,391 \\
\hline Par 4 & 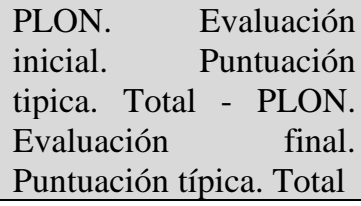 & $-4,50$ & 7,93 & 3,96 & $-17,12$ & 8,12 & $-1,134$ & 3 & ,339 \\
\hline
\end{tabular}




\begin{tabular}{|c|c|c|c|c|c|c|c|c|c|}
\hline Par 5 & $\begin{array}{l}\text { PEABODY. Evaluación } \\
\text { inicial. Edad equivalente } \\
\text { en meses - PEABODY. } \\
\text { Evaluación final. Edad } \\
\text { equivalente en meses. }\end{array}$ & $-4,75$ & 5,12 & 2,56 & $-12,90$ & 3,40 & $-1,854$ & 3 &, 161 \\
\hline Par 6 & $\begin{array}{l}\text { RFI. Evaluación inicial. } \\
\text { Total de fonemas } \\
\text { erróneos. }- \text { RFI. } \\
\text { Evaluación final. Total } \\
\text { de fonemas erróneos. }\end{array}$ & 26,50 & 4,43 & 2,21 & 19,44 & 33,55 & 11,951 & 3 & ,001 \\
\hline
\end{tabular}

Fuente: elaboración propia. 
Observamos en la Tabla 5.5 que solo existía una significancia en la prueba pre-postest del RFI en el grupo experimental, el nivel de significancia es de $0.001<0.05$, por lo que aceptamos $\mathrm{H} 1$ en esas variables. Y asumimos que no existía una diferencia significativa en el resto de las variables, al ser el resto de significancia mayores de 0.05 .

Se realizó el estadístico Kappa de Cohen, para conocer la intensidad de la diferencia entre los resultados de la cantidad de fonemas erróneos en la prueba RFI inicial y la cantidad de fonemas erróneos en la prueba RFI final. Los resultados se pudieron observar en la Tabla 5.6.

Tabla 5.6.

Kappa de Cohen entre los fonemas erróneos en la prueba RFI final pretest y postest

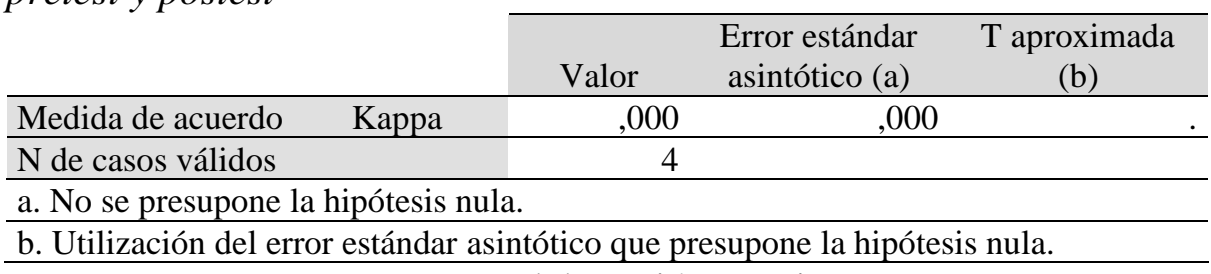

Fuente: elaboración propia.

En la Tabla 5.6 observamos como el valor de Kappa de Cohen era de 0,000 , por lo que pudimos decir que existía una ínfima diferencia entre las dos variables.

\subsubsection{Grupo control}

A continuación, se realizó el mismo análisis que habíamos hecho anteriormente en el grupo experimental, pero esta vez en el grupo control. Para comenzar mostramos la estadística de muestras emparejadas (Tabla 5.7).

Tabla 5.7.

Estadísticos de muestras emparejadas

\begin{tabular}{|c|c|c|c|c|c|}
\hline & & Media & $\mathrm{N}$ & $\begin{array}{l}\text { Desviación } \\
\text { estándar }\end{array}$ & $\begin{array}{l}\text { Media de error } \\
\text { estándar }\end{array}$ \\
\hline \multirow[t]{2}{*}{ Par 1} & $\begin{array}{l}\text { PLON. Evaluación inicial. } \\
\text { Puntuación típica. Forma }\end{array}$ & 19,75 & 4 & 12,28 & 6,14 \\
\hline & $\begin{array}{l}\text { PLON. Evaluación final. } \\
\text { Puntuación típica. Forma }\end{array}$ & 26,00 & 4 & 10,55 & 5,27 \\
\hline
\end{tabular}




\begin{tabular}{|c|c|c|c|c|c|}
\hline \multirow[t]{2}{*}{ Par 2} & $\begin{array}{l}\text { PLON. Evaluación inicial. } \\
\text { Puntuación } \\
\text { Contenido }\end{array}$ & 20,75 & 4 & 4,72 & 2,35 \\
\hline & $\begin{array}{l}\text { PLON. Evaluación final. } \\
\text { Puntuación } \\
\text { Contenido }\end{array}$ & 26,25 & 4 & 4,72 & 2,35 \\
\hline \multirow[t]{2}{*}{ Par 3} & $\begin{array}{l}\text { PLON. Evaluación inicial. } \\
\text { Puntuación típica. Uso }\end{array}$ & 34,00 & 4 & 10,42 & 5,21 \\
\hline & $\begin{array}{l}\text { PLON. Evaluación final. } \\
\text { Puntuación típica. Uso }\end{array}$ & 47,50 & 4 & 8,34 & 4,17 \\
\hline \multirow[t]{2}{*}{ Par 4} & $\begin{array}{l}\text { PLON. Evaluación inicial. } \\
\text { Puntuación típica. Total }\end{array}$ & 11,75 & 4 & 6,94 & 3,47 \\
\hline & $\begin{array}{l}\text { PLON. Evaluación final. } \\
\text { Puntuación típica. Total }\end{array}$ & 22,00 & 4 & 5,77 & 2,88 \\
\hline \multirow[t]{2}{*}{ Par 5} & $\begin{array}{l}\text { PEABODY. } \\
\text { Evaluación } \\
\text { inicial. Edad equivalente } \\
\text { en meses }\end{array}$ & 53,25 & 4 & 8,42 & 4,21 \\
\hline & $\begin{array}{l}\text { PEABODY. Evaluación } \\
\text { final. Edad equivalente en } \\
\text { meses. }\end{array}$ & 54,00 & 4 & 8,67 & 4,33 \\
\hline \multirow[t]{2}{*}{ Par 6} & $\begin{array}{l}\text { RFI. Evaluación inicial. } \\
\text { Total de fonemas erróneos. }\end{array}$ & 62,25 & 4 & 18,22 & 9,11 \\
\hline & $\begin{array}{l}\text { RFI. Evaluación final. } \\
\text { Total de fonemas erróneos. }\end{array}$ & 64,25 & 4 & 17,65 & 8,82 \\
\hline
\end{tabular}

a. Grupo = Grupo control.

Fuente: elaboración propia.

Si examinamos las medias y la desviación estándar, observamos que la desviación estándar era mayor en los resultados del RFI, siendo el inicial (18.22) y el final (17.65), lo que quiere decir que en esta variable la dispersión de la población era mayor que en otras variables.

En la Tabla 5.8, mostramos los resultados de la Prueta T-student para muestras relacionadas, esta prueba sirve para valorar si existe una diferencia significativa entre las medidas pretest y postest del grupo control; al igual que en las otras pruebas estadísticas, establecimos dos hipótesis: (a) H0: Las variables eran iguales, (b) H1: Las variables eran diferentes. La decisión que tomamos para aceptar o rechazar la $\mathrm{H0}$; dependió del resultado de sig. Bilateral, determinamos que si $\mathrm{p}>0.05$ aceptábamos H0, y si p<0.05 aceptábamos H1. 
Tabla 5.8

Prueta T-student para muestras dependientes

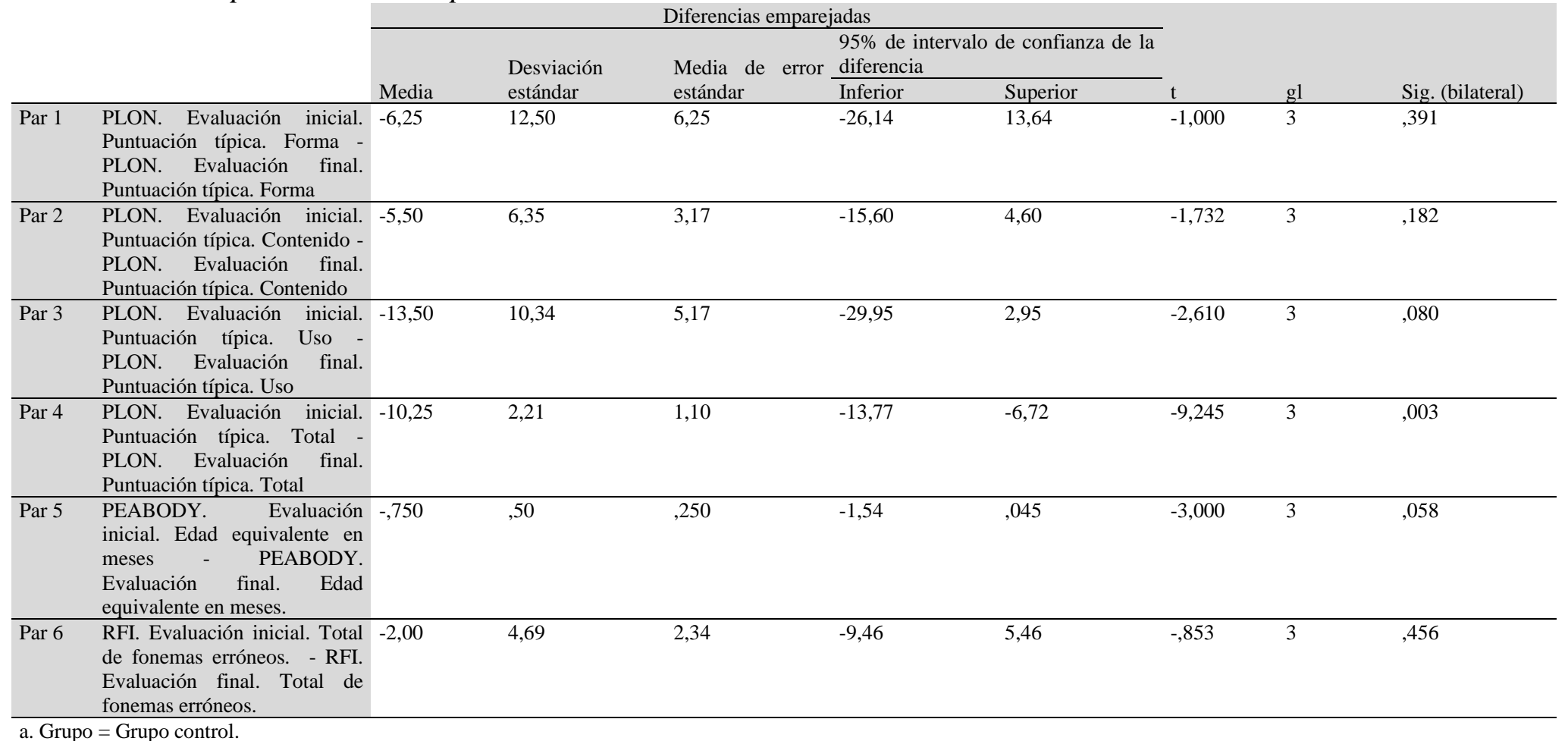

Fuente: elaboración propia. 
En la Tabla 5.8 podemos comprobar cómo en el grupo control aceptamos $\mathrm{H} 0$ en todas las variables al ser p>0.05 en todas ellas, con la excepción del PLON total $(0.003<0.05)$ en la que aceptamos H1; es decir, existía una diferencia significativa entre el PLON total inicial y final, lo que significa que los niños mejoraron su lenguaje en general, pero no mejoraron en lo demás; aunque parecía algo difícil de comprender, es probable que esto se produjo por pequeñas mejoras en otras áreas, que no se consideraron mejoras significativas por separado, pero sí en la suma final.

En la Tabla 5.9 analizamos Kappa de Cohen, en las variables de la Puntuación Típica de la evaluación inicial del PLON-R y de la evaluación final, para valorar la intensidad de la diferencia entre las variables.

Tabla 5.9.

Kappa de Cohen de las variables de la Puntuación Típica de la evaluación inicial del PLON-R y de la evaluación final

\begin{tabular}{|c|c|c|c|c|}
\hline & & Valor & $\begin{array}{c}\text { Error estándar } \\
\text { asintótico (a) }\end{array}$ & $\begin{array}{c}\mathrm{T} \text { aproximada } \\
\text { (b) }\end{array}$ \\
\hline Medida de acuerdo & Kappa & ,000 &, 000 & \\
\hline $\mathrm{N}$ de casos válidos & & 4 & & \\
\hline \multicolumn{5}{|c|}{ a. No se presupone la hipótesis nula. } \\
\hline \multicolumn{5}{|c|}{ b. Utilización del error estándar asintótico que presupone la hipótesis nula. } \\
\hline
\end{tabular}

Fuente: elaboración propia.

Como se puede comprobar en la Tabla 5.9, el resultado de Kappa de Cohen es de 0.000 por lo que la intensidad de la diferencia era insignificante.

Para finalizar este apartado, concluimos con la diferencia que existe entre el estudio del grupo experimental y del grupo control, ya que en el grupo experimental observamos cómo solo mejoraron en la fonética $\mathrm{y}$, en cambio, los niños del grupo control, sí que mejoraron de manera global en su lenguaje. Por lo que podemos determinar que utilizar los bits de inteligencia con los niños con trastorno de lenguaje no es más beneficioso si lo comparamos con no utilizar ningún tipo de tratamiento logopédico. 


\subsubsection{Resultados del cuestionario tipo Likert}

Una vez valorados todos los resultados del lenguaje de los niños, vamos a profundizar en la opinión de las familias sobre la utilización de los bits de inteligencia, para ello plasmamos los resultados del cuestionario que cumplimentaron las familias (Anexo 1).

La explicación de este cuestionario ya la hemos realizado en el apartado 4.3.1.4, a modo de recordatorio vamos a explicar las diversas cuestiones sobre las que se ha preguntado: (a) conocía, de forma previa a la utilización del método, las palabras expuestas; (b) ha enseñado al niño los bits en casa; (c) la asistencia a la intervención logopédica; (d) el niño comprende, en contextos diferentes a la aplicación de los bits, las palabras del método; (e) denomina, fuera de la aplicación del método, las palabras que se han utilizado; (f) utiliza de forma espontánea las palabras de los bits de inteligencia; (g) utiliza esas palabras con diferentes personas; (h) le ha servido la utilización del PowerPoint en casa; (i) el niño estaba motivado con la utilización de los PowerPoint y (j) el niño ha mejorado después de la utilización del método. Las respuestas a estas preguntas se pueden ver en la Figura 5.1.

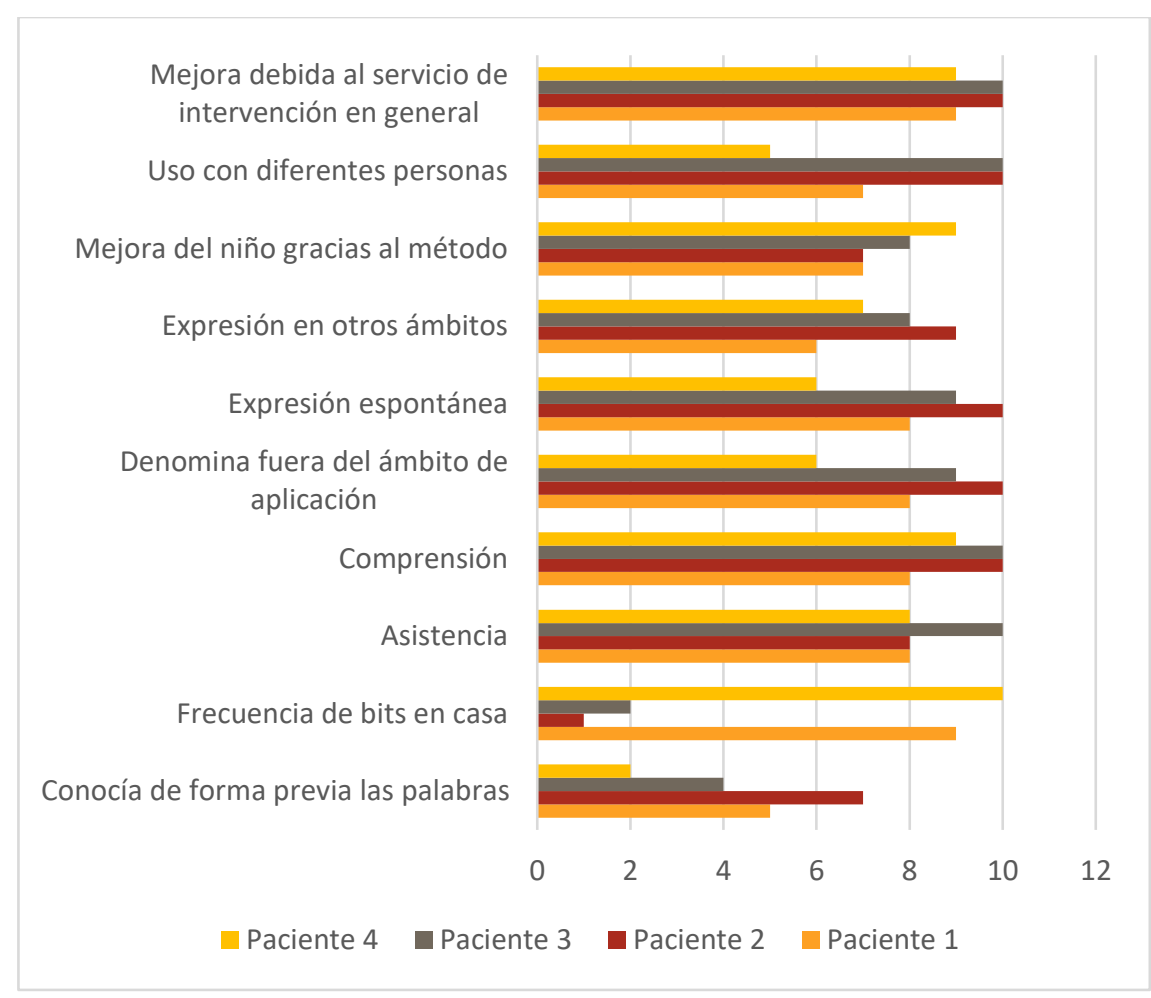

Figura 5.1. Cuestionario para las familias. Elaboración propia. 
Así pues, ante la pregunta del cuestionario que se encuentra en la Figura 5.1 ¿Conocía de forma previa a la utilización del método las palabras expuestas?, la media de las palabras que los padres consideraban que sus hijos conocían anteriormente es de 4.5, por lo que la mayoría de las palabras que aparecían en los PowerPoint no eran conocidas. Pero es cierto que un $75 \%$ de las familias hacían referencia a que esas categorías semánticas se han trabajado en la Escuela Infantil a la que acudían los niños.

Respecto a la cuestión frecuencia de aplicación de los bits en casa, los datos nos muestran una desviación estándar muy alta $(\sigma=4.65)$, que es debido a la diferencia entre los resultados, ya que el 50\% de las familias no participaron en la aplicación de los bits en casa.

Respecto a la asistencia, la media es de 8.50. Teniendo en cuenta que la última parte de la intervención se realizó en verano, estimamos que la asistencia ha sido bastante alta.

La media de la comprensión de las palabras en distintos ámbitos (cuarto ítem) era muy cercana a $10(9.25)$ con una desviación típica baja $(\sigma$ $=9.57$ ), lo que significa que las respuestas de los participantes fueron similares.

Si comparamos la media de las respuestas del apartado de comprensión (9.25) con los de la expresión espontánea de las palabras (8.25) y la expresión de las palabras en diferentes ámbitos (8.25), comprobamos que fue menor la percepción de la mejora en expresión que en comprensión por parte de las familias; es decir, creían que los niños habían mejorado más en la comprensión que en la expresión. Y la valoración de la expresión de estas palabras en otros ámbitos (7.50) fue aún más baja que el del resto de ítems; es decir, los niños habían aprendido las palabras y las utilizaban en su ámbito más cercano, pero la familia no creía que las utilizaban en otros ámbitos o con otras personas.

A su vez, llamaba la atención la diferencia en la media ponderada entre la mejoría que atribuía la familia al método (7.75), respecto a su opinión sobre la intervención logopédica en general (9.50); esto quiere decir que tenían una mejor opinión sobre la intervención en general que sobre el método en particular. 


\subsection{Discusión de los resultados del Estudio Piloto (EP)}

Todos los niños de nuestro estudio eran niños de ambientes favorecidos socioculturalmente, por lo que a priori tienen oportunidades parecidas para el desarrollo del lenguaje (Contreras-González y SorianoFerrer, 2007), pero encontramos diferencias entre el grupo control y el experimental. El uso de los bits de inteligencia incrementa la articulación de los niños con los que lo hemos utilizado. Esto es posible, porque cuando los niños tienen dificultades de articulación se suelen realizar actividades de repetición (De las Heras y García, 2015). Sin embargo, aunque en la articulación sí que se encuentra mejoría, no encontramos mejoras significativas en otros niveles. Los resultados parecen demostrar que el uso de los bits, sin utilizar esas palabras en frases e integrándolo en una conversación o en un juego, no favorece el lenguaje ya que no sigue uno de los principios explicados en Roth (1996) y citados en Carballo y Fresneda (2005). Este principio es que el lenguaje se adquiere con un propósito comunicativo, y que debe enseñarse en ese contexto y no aislado de él. El proceso de utilización de los bits requiere enseñar a los niños las láminas diciendo el nombre de éstas y en ningún momento se enmarca esta enseñanza de las láminas dentro de un contexto comunicativo. No es impactante que enseñando palabras y pidiendo a los niños que las repitan no se mejore la semántica sino otra área, ya que según Good et al. (2015), trabajando un área del lenguaje se pueden mejorar otras, como por ejemplo enseñando palabras se puede mejorar la conciencia morfológica $\mathrm{u}$ otras áreas.

Aun así, se llega a la misma conclusión que llegan otros autores y otras asociaciones como son la American Academy of Neurology (1967); American Academy of Pediatrics (1965, 1968 y 1982); American Academy for Cerebral Palsy (1965); Canadian Association for Retarded Children (1965); American Academy of Physical Medicine and Rehabilitation (1968), y no aconsejamos el uso de los bits de inteligencia tal y como diseñó Doman (Doman y Doman, 1998) en niños con trastorno del lenguaje. Teniendo en cuenta las hipótesis planteadas para el Estudio Piloto (EP), podemos decir que:

- La aplicación de los bits de inteligencia tiene un efecto positivo en el nivel fonético-fonológico de los niños con trastorno del lenguaje que acuden a un gabinete privado de Palencia.

- La aplicación de los bits de inteligencia no tiene un efecto positivo en los niveles semántico sintáctico, pragmático, ni en el lenguaje 
en general de los niños con trastorno del lenguaje que acuden a un gabinete privado de Palencia.

Tras el análisis intergrupal e intragrupal y el análisis de las respuestas del cuestionario tipo Likert, hemos descubierto una serie de debilidades del uso de los bits de inteligencia con niños con trastorno del lenguaje, estas debilidades son las siguientes:

- Con este método no se logra una mejoría en todas las dimensiones, únicamente en la dimensión fonética-fonológica, por lo que es conveniente cambiar el proceso, siguiendo los principios de rehabilitación del lenguaje ya explicados en el apartado del marco teórico.

- Las palabras presentadas no parecen ser las adecuadas, ya que muchos de los niños las conocían con anterioridad, por lo que es conveniente encontrar otro conjunto de palabras adecuadas.

Teniendo en cuenta las debilidades del método y los resultados del EP, se han planteado unas propuestas de mejora para diseñar el nuevo programa y obtener unos resultados fiables.

La primera propuesta para utilizar en PELEO es que se van a mantener el uso de las láminas de los bits de inteligencia, ya que según Gray (2005); Good et al. (2015); Nash \& Donaldson (2005); Riches et al. (2005) y Weismer \& Hesketh (1996), es necesario enseñar explícitamente a los niños el significado de las palabras de una manera lenta.

La segunda propuesta es incluir esas palabras dentro de un contexto comunicativo, por lo que es preciso diseñar este tipo de situaciones comunicativas en el entorno educativo, que es donde adquiere el lenguaje (Roth, 1996; citado en Carballo y Fresneda, 2005). Es determinante la necesidad de usar estas palabras en nuevas oraciones, porque según Gray (2005); Good et al. (2015); Nash \& Donaldson (2005); Riches et al. (2005) y Weismer \& Hesketh (1996) los niños necesitan que se les presenten verbos, y eso lo podemos hacer dentro de frases y necesitan que usemos las palabras desconocidas en oraciones.

La tercera propuesta consiste en cambiar el tipo de palabras que se utilizan, ya que el $75 \%$ de las familias opinan que las palabras presentadas ya han sido utilizadas en la escuela $\mathrm{y}$, además, podemos observar que en la encuesta tipo Likert tenemos un resultado de 9.25 en cuanto a la opinión sobre si los niños comprendían estas palabras en 
distintos ámbitos. Según esto, consideramos imprescindible cambiar de palabras para PELEO, utilizando un listado existente de las palabras que más emplean y escuchan los niños en español, como el que utilizan Wright et al. (2017).

La cuarta propuesta consiste en pedir a los niños que realicen interacciones, no solo que escuchen. Si comparamos la media de las respuestas del apartado de comprensión (9.25) con los de la expresión espontánea de las palabras (8.25) y la expresión de las palabras en diferentes ámbitos (8.25), podemos comprobar que los niños necesitan trabajar más la expresión de lo que se ha hecho hasta ahora. Además, la valoración de la expresión de estas palabras en otros ámbitos (7.50) es aún más baja que el del resto de ítems; por lo que es muy conveniente trabajar la expresión. Además, según Boom \& Lahey, escrito en 1978, (citado en Fernández et al., 2014), los niños logran un lenguaje normalizado cuando alcanzan una utilización adecuada y correcta de las palabras (tanto en expresión como en comprensión), por lo que ambas son igual de importantes.

La quinta propuesta consiste en eliminar la participación directa de las familias, evitando la responsabilidad de utilizar los bits en casa, ya que solamente el $50 \%$ de las familias utilizaron los bits en casa. Además, según American Academy of pediatrics (1982) y la American Academy for Cerebral Pals et al., (1968) el Método Doman es un método demasiado exigente para las familias, y de esta manera no evitamos. Aun así, somos conscientes de la importancia tanto de la actuación con las familias como de la colaboración y trabajo con ellas (Escorcia-Mora et al., 2016), para lo que proporcionaremos a las familias pautas individualizadas de estimulación del lenguaje, teniendo en cuenta cada caso, y dando libertad a las logopedas para dar las pautas que ellas consideren necesario.

\subsection{Resultados del Programa de Estimulación Linguiística de Expresión Oral (PELEO)}

En este apartado se va a presentar los resultados del ECE desde un paradigma de recogida de datos mixto. Se han contestado a las siguientes preguntas ¿cómo es el diseño de PELEO en relación con la cantidad, el orden y el tipo de vocabulario utilizado? ¿Cómo es el diseño de PELEO en relación con las actividades y la motivación de los niños? ¿Cómo ha cambiado el vocabulario de los niños que han utilizado PELEO? ¿Cómo 
ha cambiado la articulación de los niños que han utilizado PELEO? ¿Cómo ha cambiado la morfosintaxis de los niños que han utilizado PELEO? Se han respondido a todas ellas con una triangulación de datos: utilizando datos de las pruebas estandarizadas de los infantes, de las entrevistas a las logopedas, maestras y familias, de los videos grabados, y/o de las observaciones recogidas en la lista de control (Anexo 9). Los datos cualitativos se han presentado empleando la triangulación de técnicas, teniendo en cuenta los criterios de credibilidad y de rigor científico en el estudio de caso. Se ha triangulado los resultados obtenidos de las técnicas de observación, las pruebas estandarizadas, de las entrevistas y de los videos de las sesiones (véase Figura 5.2). Se han escogido tres de estas cuatro técnicas para realizar la triangulación en cada pregunta. Los resultados se muestran empleando una serie de siglas (V=Video, $\mathrm{PP}=$ PowerPoint, y $\mathrm{M}=$ Minuto).

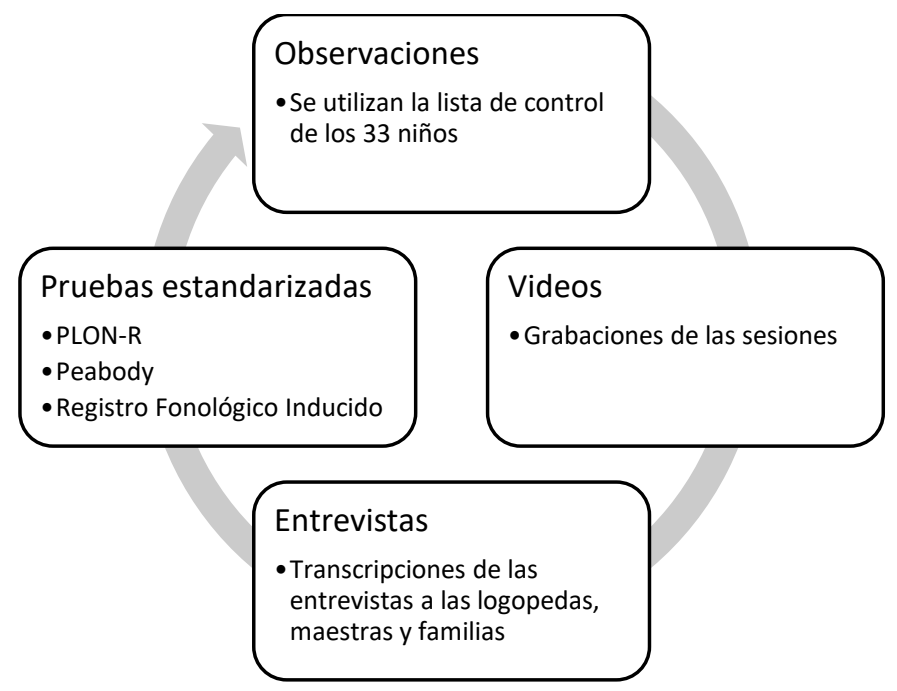

Figura 5.2. Triangulación realizada en el ECE.

Fuente: elaboración propia.

\subsection{1. ¿Cómo es el diseño de PELEO en relación con la cantidad y el orden del vocabulario que se ha utilizado?}

Se ha comenzado con los resultados encontrados en las observaciones lista de control, podemos observar que se han utilizado 279 palabras en los niños de tres años, 297 palabras en los niños de cuatro años, y 404 
palabras en los niños de cinco años, estas palabras están divididas en diferentes PowerPoint, la cantidad mostrada en cada sesión está en la Tabla 5.10.

En el diseño del programa pudimos comprobar que a los niños de tres años los hemos enseñado 279 palabras, a los niños de cuatro años 297 palabras y a los niños de cinco años 404 palabras. Estas palabras se encuentran en el capítulo 4 en el apartado 4.3.2.3 (Técnicas e instrumentos utilizados). En las observaciones se han contabilizado la cantidad de palabras que hemos mostrado en cada sesión y la cantidad de errores cometidos (Tabla 5.10).

Tabla 5.10.

Cantidad de palabras en cada PowerPoint según la edad

\begin{tabular}{|c|c|c|c|c|c|c|}
\hline & \multicolumn{2}{|c|}{ Edad tres años } & \multicolumn{2}{|c|}{ Edad cuatro años } & \multicolumn{2}{|c|}{ Edad cinco años } \\
\hline & Total & $\begin{array}{l}\text { Media } \\
\text { de } \\
\text { errores }\end{array}$ & Total & $\begin{array}{l}\text { Media } \\
\text { de } \\
\text { errores }\end{array}$ & Total & $\begin{array}{l}\text { Media } \\
\text { de } \\
\text { errores }\end{array}$ \\
\hline PowerPoint 1 & $\begin{array}{l}22 \\
\text { palabras }\end{array}$ & 6.45 & $\begin{array}{l}20 \\
\text { palabras }\end{array}$ & 5.15 & $\begin{array}{l}20 \\
\text { palabras }\end{array}$ & 4.4 \\
\hline PowerPoint 2 & $\begin{array}{l}20 \\
\text { palabras }\end{array}$ & 9.18 & $\begin{array}{l}20 \\
\text { palabras }\end{array}$ & 5.30 & $\begin{array}{l}20 \\
\text { palabras }\end{array}$ & 5.1 \\
\hline PowerPoint 3 & $\begin{array}{l}19 \\
\text { palabras }\end{array}$ & 9.36 & $\begin{array}{l}19 \\
\text { palabras }\end{array}$ & 5.47 & $\begin{array}{l}20 \\
\text { palabras }\end{array}$ & 3.4 \\
\hline PowerPoint 4 & $\begin{array}{l}20 \\
\text { palabras }\end{array}$ & 9.36 & $\begin{array}{l}18 \\
\text { palabras }\end{array}$ & 6.55 & $\begin{array}{l}20 \\
\text { palabras }\end{array}$ & 4 \\
\hline PowerPoint 5 & $\begin{array}{l}20 \\
\text { palabras }\end{array}$ & 11.54 & $\begin{array}{l}20 \\
\text { palabras }\end{array}$ & 4.35 & $\begin{array}{l}20 \\
\text { palabras }\end{array}$ & 3.75 \\
\hline PowerPoint 6 & $\begin{array}{l}20 \\
\text { palabras }\end{array}$ & 11.45 & $\begin{array}{l}20 \\
\text { palabras }\end{array}$ & 6.05 & $\begin{array}{l}20 \\
\text { palabras }\end{array}$ & 3 \\
\hline PowerPoint 7 & $\begin{array}{l}20 \\
\text { palabras }\end{array}$ & 12.82 & $\begin{array}{l}20 \\
\text { palabras }\end{array}$ & 5.55 & $\begin{array}{l}19 \\
\text { palabras }\end{array}$ & 4.9 \\
\hline PowerPoint 8 & $\begin{array}{l}19 \\
\text { palabras }\end{array}$ & 12.64 & $\begin{array}{l}18 \\
\text { palabras }\end{array}$ & 5.89 & $\begin{array}{l}20 \\
\text { palabras }\end{array}$ & 2.75 \\
\hline PowerPoint 9 & $\begin{array}{l}19 \\
\text { palabras }\end{array}$ & 13.73 & $\begin{array}{l}20 \\
\text { palabras }\end{array}$ & 4.55 & $\begin{array}{l}20 \\
\text { palabras }\end{array}$ & 5.25 \\
\hline PowerPoint 10 & $\begin{array}{l}20 \\
\text { palabras }\end{array}$ & 14.55 & $\begin{array}{l}20 \\
\text { palabras }\end{array}$ & 6.15 & $\begin{array}{l}21 \\
\text { palabras }\end{array}$ & 4.24 \\
\hline PowerPoint 11 & $\begin{array}{l}20 \\
\text { palabras }\end{array}$ & 13.82 & $\begin{array}{l}20 \\
\text { palabras }\end{array}$ & 5.6 & $\begin{array}{l}20 \\
\text { palabras }\end{array}$ & 2.65 \\
\hline PowerPoint 12 & $\begin{array}{l}20 \\
\text { palabras }\end{array}$ & 13.73 & $\begin{array}{l}20 \\
\text { palabras }\end{array}$ & 4.55 & $\begin{array}{l}19 \\
\text { palabras }\end{array}$ & 4.95 \\
\hline PowerPoint 13 & $\begin{array}{l}20 \\
\text { palabras }\end{array}$ & 12.73 & $\begin{array}{l}20 \\
\text { palabras }\end{array}$ & 5.75 & $\begin{array}{l}19 \\
\text { palabras }\end{array}$ & 3.47 \\
\hline
\end{tabular}




\begin{tabular}{|c|c|c|c|c|c|}
\hline PowerPoint 14 & $\begin{array}{ll}20 & 11.64 \\
\text { palabras } & \\
\end{array}$ & $\begin{array}{l}20 \\
\text { palabras }\end{array}$ & 5 & $\begin{array}{l}20 \\
\text { palabras }\end{array}$ & 4.85 \\
\hline PowerPoint 15 & & $\begin{array}{l}20 \\
\text { palabras }\end{array}$ & 4.75 & $\begin{array}{l}19 \\
\text { palabras }\end{array}$ & 4.58 \\
\hline PowerPoint 16 & & $\begin{array}{l}22 \\
\text { palabras }\end{array}$ & 6.5 & $\begin{array}{l}19 \\
\text { palabras }\end{array}$ & 4.74 \\
\hline PowerPoint 17 & & & & $\begin{array}{l}20 \\
\text { palabras }\end{array}$ & 4.95 \\
\hline PowerPoint 18 & & & & $\begin{array}{l}20 \\
\text { palabras }\end{array}$ & 5.7 \\
\hline PowerPoint 19 & & & & $\begin{array}{l}20 \\
\text { palabras }\end{array}$ & 3.75 \\
\hline PowerPoint 20 & & & & $\begin{array}{l}21 \\
\text { palabras }\end{array}$ & 4.52 \\
\hline PowerPoint 21 & & & & $\begin{array}{l}7 \\
\text { palabras }\end{array}$ & 4.86 \\
\hline $\begin{array}{l}\text { Media de } \\
\text { palabras } \\
\text { desconocidas }\end{array}$ & 11.64 & 5.45 & & 4.27 & \\
\hline
\end{tabular}

Fuente: elaboración propia.

Para valorar si hemos escogido la cantidad y el orden adecuado se analizaron las 33 listas de control recogidas. En estas plantillas se apuntaron las palabras que al principio de la sesión desconocían los niños. En la Tabla 5.10, podemos comprobar que la media de palabras desconocidas descendía con la edad. El rango de palabras desconocidas de los niños de tres años estaba entre 6.45 y 14.55; el de los niños de cuatro años estaba entre 4.35 y 6.50 y el de los niños de cinco años entre 2.75 y 5.70 , lo que significa que algunas sesiones tenían muchas palabras desconocidas para estos niños, aunque existía una constante en muchas de ellas.

Por otro lado, se valoran las respuestas de las entrevistas semiestructuradas de las logopedas, en relación con el vocabulario y la cantidad de vocabulario que se utilizaba, y se observan tres respuestas positivas y dos respuestas negativas o que proponen mejoras, por lo que no hay un consenso (Tabla 5.11).

Tabla 5.11.

Respuestas de las entrevistas de las logopedas en relación con el tipo y la cantidad de vocabulario que se utiliza

Opiniones sobre la LOGOPEDA 2: Quizás yo... Mmm yo tenía la sensación de inadecuación de la que para el de cuatro años quizás eran muchas. Pues no lo cantidad de palabras sé, a los más pequeños en vez de 20 ponerles 15 , sobre todo presentadas cada día. si no entiende unos cuentos deberías de tratar esos 


\begin{tabular}{ll}
\hline & $\begin{array}{l}\text { conceptos en una sesión, si son 20 y no saben 5, puuff pues } \\
\text { es muy difícil hablar de todos los conceptos que no sabe. }\end{array}$ \\
& $\begin{array}{l}\text { LOGOPEDA 5: Si, no eran muchas la verdad lo que pasa } \\
\text { que el niño se cansaba... }\end{array}$ \\
\hline $\begin{array}{l}\text { Opiniones sobre la } \\
\text { adecuación de la } \\
\text { cantidad de palabras }\end{array}$ & $\begin{array}{l}\text { LOGOPEDA 1: Sí, me han parecido adecuadas, por lo } \\
\text { mismo que antes, para los más pequeñitos eran más cortos, } \\
\text { porque se cansaban antes, y había que ir enseñándoles } \\
\text { poco a poco, pero los que eran más mayores, que por lo } \\
\text { menos en mi caso sabían más conceptos, pues eran más } \\
\text { palabras y se podía seguir muy bien el ritmo. }\end{array}$ \\
\hline & $\begin{array}{l}\text { LOGOPEDA 3: Si, eran poquitas y se hacía en poco } \\
\text { tiempo. }\end{array}$ \\
& LOGOPEDA 4: Si \\
& $\begin{array}{l}\text { LOGOPEDA 5: Si, no eran muchas la verdad lo que pasa } \\
\text { que el niño se cansaba... }\end{array}$ \\
\hline
\end{tabular}

Fuente: elaboración propia.

También se preguntó a los logopedas por el orden en el que se han presentado las palabras, y encontramos la siguiente respuesta en una de las logopedas:

LOGOPEDA 1: Si, porque además algunas se repetían, y trabajabas con esas imágenes y te dabas cuenta si algunas de las que trabajabas al principio las habían adquirido, y la continuidad, al principio eran muy poco más fáciles. Y las edades me han parecido correctas, se notaba mucho la diferencia entre las de tres años, por ejemplo, y los que eran más mayores, eran mucho más fáciles.

Mientras que las otras cuatro logopedas simplemente dicen que están de acuerdo y no añaden más información.

Por último, también nos fijamos en las grabacaciones de los videos. Para la organización y el análisis de los datos se ha utilizado el programa ATLAS.ti 9 para Windows, creando cuatro códigos: sesiones con muchas palabras desconocidas, sesiones con pocas palabras desconocidas, motivación positiva, motivación negativa.

En las sesiones con muchas palabras desconocidas encontramos conductas asociadas a motivación positiva y a motivación negativa, como se puede observar en la Tabla 5.12, por lo que en las sesiones con muchas palabras desconocidas también encontramos situaciones codificadas como "motivación positiva". 
Tabla 5.12.

Conductas asociadas a motivación positiva y a motivación negativa en las sesiones con muchas palabras desconocidas

\begin{tabular}{|c|c|}
\hline \multirow[t]{2}{*}{$\begin{array}{l}\text { Motivación } \\
\text { positiva }\end{array}$} & $\begin{array}{l}\text { Cuando finaliza la actividad, la participante P3-8 choca las manos } \\
\text { con la investigadora (VPP5-M:15:21). }\end{array}$ \\
\hline & $\begin{array}{l}\text { Cuando finaliza la actividad, la participante P3-5 choca las manos } \\
\text { con la investigadora (VPP8-M:16:31). }\end{array}$ \\
\hline \multirow[t]{2}{*}{$\begin{array}{l}\text { Motivación } \\
\text { negativa }\end{array}$} & $\begin{array}{l}\text { El participante P4-5, se mete debajo de la mesa y no quiere salir } \\
\text { cuando se sacan las láminas de los PowerPoints, se pone a llorar y } \\
\text { a gritar (VPP8 - M: 15:49). }\end{array}$ \\
\hline & $\begin{array}{l}\text { La participante P3-9, se pone a hablar de otras cosas, de su } \\
\text { compañera de clase, y de cosas que estaban haciendo en clase, la } \\
\text { logopeda la insta a continuar con la actividad, pero ella cambia de } \\
\text { tema (VPP } 11-M: 18: 12) \text {. }\end{array}$ \\
\hline
\end{tabular}

Fuente: elaboración propia.

En las sesiones con muchas palabras conocidas encontramos conductas asociadas a motivación positiva y a motivación negativa, algunos ejemplos se pueden observar en la Tabla 5.13.

Tabla 5.13.

Conductas asociadas a motivación positiva y a motivación negativa en las sesiones con pocas palabras desconocidas

\begin{tabular}{ll}
\hline $\begin{array}{l}\text { Motivación } \\
\text { positiva }\end{array}$ & $\begin{array}{l}\text { Cuando finaliza la actividad, la participante P3-5 choca las manos } \\
\text { con la investigadora (VPP8-M:16:31). }\end{array}$ \\
\cline { 2 - 2 } & $\begin{array}{l}\text { El participante P3-7 se pone contento cuando finaliza de repetir } \\
\text { las palabras y choca los } 5 \text { con la logopeda (con ambas manos) } \\
\text { (VPP6 - M: 5:37). }\end{array}$ \\
\hline $\begin{array}{l}\text { Motivación } \\
\text { negativa }\end{array}$ & $\begin{array}{l}\text { La participante P4-6, se tumba encima de la mesa y mira de reojo, } \\
\text { no quiere mirar las imágenes, se niega a continuar (VPP10 - M: } \\
\text { 9:12). }\end{array}$ \\
\hline $\begin{array}{l}\text { La participante P4-9, bosteza y habla de otras cosas, no muestra } \\
\text { interés, se la repite continuamente que esté atenta (VPP11 - M: } \\
\text { 12:18) }\end{array}$ \\
\hline $\begin{array}{l}\text { El participante P5-11, dice lo siguiente: ipuedo escoger yo la } \\
\text { actividad hoy y hacer otra? (VPP13 - M:3:18) }\end{array}$ \\
\hline
\end{tabular}

Fuente: elaboración propia.

Por lo que, teniendo en cuenta los resultados arrojados en Atlas.ti, observamos que tanto en las sesiones con muchas palabras desconocidas, como en las sesiones con pocas palabras conocidas, existían momentos en los que los niños estaban más o menos motivados (Figura 5.3), por lo 
que el hecho de que hubiera más palabras desconocidas en una sesión no parecía afectar a la motivación.

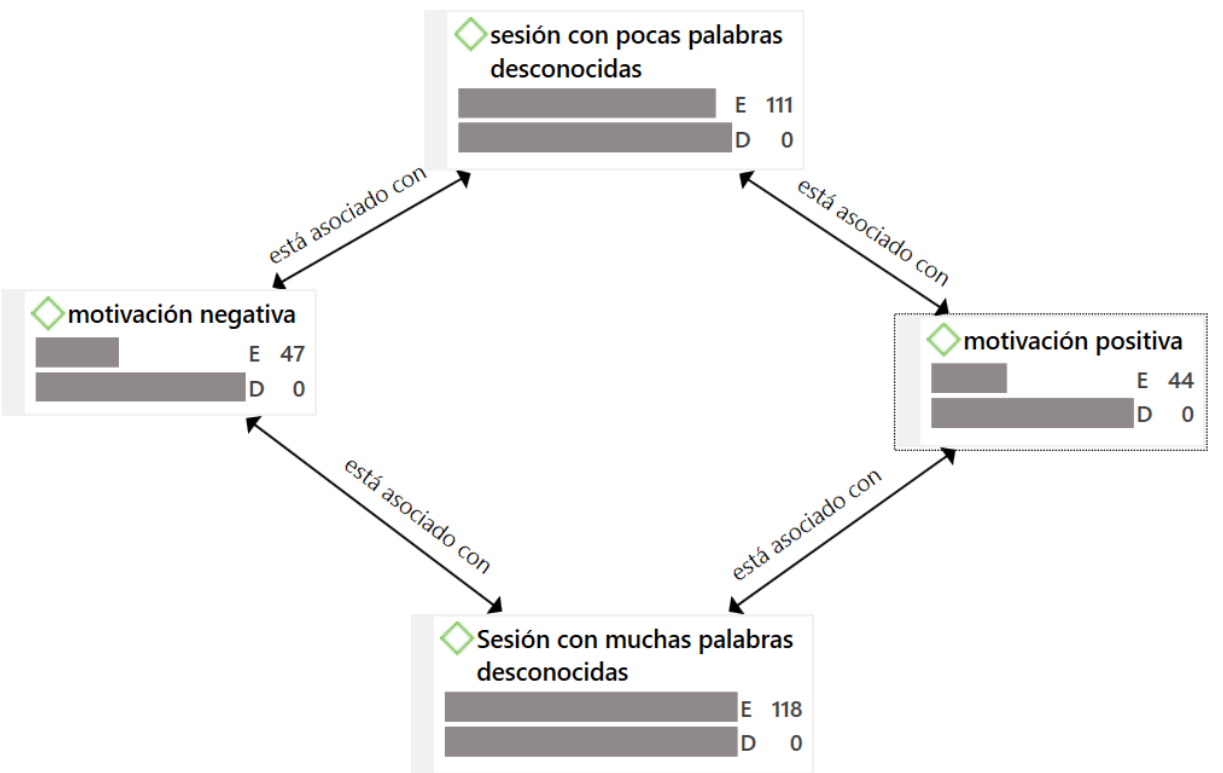

Figura 5.3. Red de asociación de códigos: sesión con pocas y muchas palabras desconocidas y motivación positiva y negativa.

Fuente: elaboración propia.

La Figura 5.3, muestra el enraizamiento (E), es decir, la cantidad de citas enlazadas al código, y la densidad (D) de cada código, que indica el número de códigos asociados a una cita. Gráficamente vemos cómo están interrelacionados todos los códigos entre ellos. Observamos cómo es parecido el enraizamiento (E ) de los códigos "sesión con muchas palabras desconocidas" y "sesión con muchas palabras conocidas"; y lo mismo ocurre con "motivación negativa" y "motivación positiva"; lo que explica que había respuestas parecidas para cada código.

Así pues, teniendo en cuenta todo lo presentado anteriormente, respondiendo a la pregunta planteada ¿cómo es el diseño de PELEO en relación con la cantidad, el orden y el tipo de vocabulario utilizado?, podemos determinar que el diseño de PELEO en cuanto al orden y a la cantidad parece adecuado, pero no ha habido un consenso por parte de las logopedas. 


\subsection{2. ¿Cómo es el diseño de PELEO en relación con el tipo de vocabulario que se ha utilizado?}

Para poder responder a esta pregunta se contabilizaron las palabras de la lista de control, estas palabras se dividieron según su categoría semántica para poder someterlas al análisis estadístico cuantitativo y cualitativo.

En la Tabla 5.14 se describen los porcentajes de las palabras conocidas según estas categorías.

Tabla 5.14.

Porcentaje de palabras conocidas según la categoría en todas las edades Desviación

N Mínimo Máximo Media estándar

\begin{tabular}{llllll}
\hline Partes del cuerpo & 33 & $35 \%$ & $95 \%$ & $67 \%$ &, 16 \\
\hline Conceptos de tiempo & 33 & $0 \%$ & $55 \%$ & $22 \%$ &, 15 \\
\hline Prendas de vestir & 33 & $77 \%$ & $96 \%$ & $59 \%$ & .27 \\
\hline Comida & 33 & $13 \%$ & $93 \%$ & $58 \%$ &, 22 \\
\hline Transportes & 33 & $33 \%$ & $100 \%$ & $75 \%$ &, 17 \\
\hline Juguetes & 33 & $17 \%$ & $100 \%$ & $60 \%$ &, 19 \\
\hline Cosas & 33 & $14 \%$ & $87 \%$ & $55 \%$ &, 17 \\
\hline Seres Vivos & 33 & $26 \%$ & $84 \%$ & $63 \%$ &, 13 \\
\hline Personas & 33 & $21 \%$ & $82 \%$ & $51 \%$ &, 14 \\
\hline Conceptos de cantidad & 33 & $13 \%$ & $95 \%$ & $46 \%$ &, 23 \\
\hline Conceptos abstractos & 33 & $0 \%$ & $75 \%$ & $34 \%$ &, 21 \\
\hline Lugares & 33 & $19 \%$ & $88 \%$ & $44 \%$ &, 17 \\
\hline Medioambiente & 33 & $0 \%$ & $100 \%$ & $72 \%$ &, 28 \\
\hline Otros & 33 & $48 \%$ & $82 \%$ & $46 \%$ &, 20 \\
\hline N válido (por lista) & 33 & & & \\
\hline
\end{tabular}

Fuente: Elaboración propia.

Si tenemos en cuenta los resultados mostrados en la Tabla 5.14, los niños tenían más dificultades en los conceptos de tiempo (22\% de palabras conocidas), conceptos abstractos (34\% de palabras conocidas) y los lugares ( $44 \%$ de palabras conocidas), pero desconocemos si ocurría lo mismo o existía alguna diferencia si nos fijamos en los resultados según la edad del participante, por lo que se procedió a analizar los resultados de los niños de tres años (Tabla 5.15), de los niños de cuatro años (Tabla 5.16) y de los niños de cinco años (Tabla 5.17). 
Tabla 5.15.

Porcentaje de palabras conocidas según la categoría en la edad de tres años

\begin{tabular}{|c|c|c|c|c|c|}
\hline & $\mathrm{N}$ & Mínimo & Máximo & Media & $\begin{array}{l}\text { Desviación } \\
\text { estándar }\end{array}$ \\
\hline Edad en meses & 11 & 36 & 45 & 39,27 & 3,07 \\
\hline $\begin{array}{l}\text { Porcentaje de } \\
\text { palabras conocidas }\end{array}$ & 11 & $24 \%$ & $58 \%$ & $41 \%$ &, 11 \\
\hline $\begin{array}{l}\text { Porcentaje de partes } \\
\text { del cuerpo }\end{array}$ & 11 & $35 \%$ & $70 \%$ & $52 \%$ &, 12 \\
\hline $\begin{array}{l}\text { Porcentaje de } \\
\text { conceptos del tiempo }\end{array}$ & 11 & $0 \%$ & $30 \%$ & $13 \%$ &, 10 \\
\hline $\begin{array}{ll}\text { Porcentaje } & \text { de } \\
\text { prendas de vestir } & \end{array}$ & 11 &, $1 \%$ & $56 \%$ & $35 \%$ &, 15 \\
\hline $\begin{array}{l}\text { Porcentaje de } \\
\text { comida }\end{array}$ & 11 & $13 \%$ & $53 \%$ &, $32 \%$ &, 14 \\
\hline $\begin{array}{ll}\begin{array}{l}\text { Porcentaje } \\
\text { transportes }\end{array} & \text { de } \\
\end{array}$ & 11 & $33 \%$ & $100 \%$ & $74 \%$ & 22 \\
\hline $\begin{array}{ll}\begin{array}{l}\text { Porcentaje } \\
\text { juguetes }\end{array} & \mathrm{de} \\
\end{array}$ & 11 & $17 \%$ & $67 \%$ & $44 \%$ & 18 \\
\hline Porcentaje de cosas & 11 & $14 \%$ & $69 \%$ & $40 \%$ &, 15 \\
\hline $\begin{array}{l}\text { Porcentaje de seres } \\
\text { vivos }\end{array}$ & 11 & $26 \%$ & $79 \%$ & $61 \%$ &, 17 \\
\hline $\begin{array}{ll}\begin{array}{l}\text { Porcentaje } \\
\text { personas }\end{array} & \text { de } \\
\end{array}$ & 11 & $33 \%$ & $55 \%$ & $46 \%$ & ,09 \\
\hline $\begin{array}{l}\text { Porcentaje } \\
\text { conceptos } \\
\text { cantidad }\end{array}$ & 11 & $12 \%$ & $63 \%$ & $33 \%$ & ,17 \\
\hline $\begin{array}{l}\text { Porcentaje de } \\
\text { conceptos abstractos }\end{array}$ & 11 & $0 \%$ & $60 \%$ & $31 \%$ & ,19 \\
\hline Porcentaje de lugares & 11 & $19 \%$ &, $48 \%$ & $32 \%$ &, 11 \\
\hline $\begin{array}{ll}\begin{array}{l}\text { Porcentaje } \\
\text { medioambiente }\end{array} & \text { de } \\
\end{array}$ & 11 & $0 \%$ & $83 \%$ & $42 \%$ & 25 \\
\hline Porcentaje de otros & 11 &, $48 \%$ & $38 \%$ & $27 \%$ &, 12 \\
\hline $\mathrm{N}$ válido (por lista) & 11 & & & & \\
\hline
\end{tabular}

Fuente: elaboración propia.

Los niños de tres años (Tabla 5.15) tienen más dificultades en los conceptos de tiempo (13\% de palabras conocidas), en la categoría otros (27\% de palabras conocidas), en los conceptos abstractos (31\%) y en la comida y lugares ( $32 \%$ de palabras conocidas).

Tabla 5.16.

Porcentaje de palabras conocidas según la categoría en la edad de cuatro años 


\begin{tabular}{|c|c|c|c|c|c|}
\hline & $\mathrm{N}$ & Mínimo & Máximo & Media & $\begin{array}{l}\text { Desviación } \\
\text { estándar }\end{array}$ \\
\hline Edad en meses & 11 & 48 & 55 & 51,91 & 2,11 \\
\hline $\begin{array}{l}\text { Palabras Conocidas } \\
\text { Porcentaje }\end{array}$ & 11 & $37 \%$ & $77 \%$ & $53 \%$ &, 11 \\
\hline $\begin{array}{ll}\text { Partes del cuerpo } \\
\text { Porcentaje }\end{array}$ & 11 & $50 \%$ & $92 \%$ & $70 \%$ & ,13 \\
\hline $\begin{array}{l}\text { Conceptos de tiempo } \\
\text { Porcentaje }\end{array}$ & 11 & $9 \%$ & $55 \%$ & $23 \%$ &, 15 \\
\hline $\begin{array}{l}\text { Prendas de vestir } \\
\text { Porcentaje }\end{array}$ & 11 & $77 \%$ & $92 \%$ & $64 \%$ & ,30 \\
\hline Comida Porcentaje & 11 & $40 \%$ & $93 \%$ & $65 \%$ &, 16 \\
\hline $\begin{array}{l}\text { Transportes } \\
\text { Porcentaje } \\
\end{array}$ & 11 & $44 \%$ & $100 \%$ & $68 \%$ &, 17 \\
\hline Juguetes Porcentaje & 11 & $46 \%$ & $69 \%$ & $55 \%$ & ,08 \\
\hline Cosas Porcentaje & 11 & $30 \%$ & $87 \%$ & $58 \%$ &, 16 \\
\hline $\begin{array}{ll}\text { Seres } & \text { Vivos } \\
\text { Porcentaje } & \\
\end{array}$ & 11 & $42 \%$ & $84 \%$ & $62 \%$ & 13 \\
\hline Personas Porcentaje & 11 & $21 \%$ & $82 \%$ & $50 \%$ &, 18 \\
\hline $\begin{array}{l}\text { Conceptos de } \\
\text { cantidad porcentaje }\end{array}$ & 11 & $20 \%$ & $60 \%$ & $38 \%$ &, 11 \\
\hline $\begin{array}{l}\text { Conceptos abstractos } \\
\text { Porcentaje }\end{array}$ & 11 & $0 \%$ & $67 \%$ & $27 \%$ &, 25 \\
\hline Lugares Porcentaje & 11 & $34 \%$ & $72 \%$ & $46 \%$ &, 10 \\
\hline $\begin{array}{l}\text { Medioambiente } \\
\text { Porcentaje }\end{array}$ & 11 & $50 \%$ & $100 \%$ & $77 \%$ & 13 \\
\hline Otros Porcentaje & 11 & $39 \%$ & $75 \%$ & $52 \%$ &, 12 \\
\hline N válido (por lista) & 11 & & & & \\
\hline
\end{tabular}

Fuente: elaboración propia.

Los niños de cuatro años (Tabla 5.16) tenían mayores dificultades en los conceptos de tiempo ( $23 \%$ de palabras conocidas), conceptos abstractos ( $27 \%$ de palabras conocidas) y conceptos de cantidad (38\% de palabras conocidas).

Tabla 5.17.

Porcentaje de palabras conocidas según la categoría en la edad de cinco años

\begin{tabular}{llllll}
\hline & $\mathrm{N}$ & Mínimo & Máximo & Media & $\begin{array}{l}\text { Desviación } \\
\text { estándar }\end{array}$ \\
\hline Edad en meses & 11 & 62 & 67 & 64,45 & 1,86 \\
\hline $\begin{array}{l}\text { Palabras Conocidas } \\
\text { Porcentaje }\end{array}$ & 11 & $48 \%$ & $80 \%$ & $63 \%$ &, 11 \\
\hline $\begin{array}{l}\text { Partes del cuerpo } \\
\text { Porcentaje }\end{array}$ & 11 & $57 \%$ & $95 \%$ & $80 \%$ &, 11 \\
\hline
\end{tabular}




\begin{tabular}{llllll}
\hline $\begin{array}{l}\text { Conceptos de tiempo } \\
\text { Porcentaje }\end{array}$ & 11 & $0 \%$ & $47 \%$ & $32 \%$ &, 13 \\
\hline $\begin{array}{l}\text { Prendas de vestir } \\
\text { Porcentaje }\end{array}$ & 11 & $58 \%$ & $96 \%$ & $79 \%$ &, 13 \\
\hline $\begin{array}{l}\text { Comida Porcentaje } \\
\text { Transportes }\end{array}$ & 11 & $68 \%$ & $90 \%$ & $77 \%$ &, 07 \\
$\begin{array}{l}\text { Porcentaje } \\
\text { Juguetes Porcentaje }\end{array}$ & 11 & $63 \%$ & $100 \%$ & $83 \%$ &, 12 \\
\hline $\begin{array}{l}\text { Cosas Porcentaje } \\
\text { Seres Vivos }\end{array}$ & 11 & $49 \%$ & $86 \%$ & $66 \%$ &, 10 \\
$\begin{array}{l}\text { Porcentaje } \\
\text { Personas Porcentaje }\end{array}$ & 11 & $52 \%$ & $79 \%$ & $65 \%$ &, 10 \\
\hline $\begin{array}{l}\text { Conceptos de } \\
\text { cantidad porcentaje }\end{array}$ & 11 & $21 \%$ & $95 \%$ & $67 \%$ &, 22 \\
\hline $\begin{array}{l}\text { Conceptos abstractos } \\
\text { Porcentaje }\end{array}$ & 11 & $83 \%$ & $75 \%$ & $44 \%$ &, 18 \\
\hline $\begin{array}{l}\text { Lugares Porcentaje } \\
\text { Medioambiente }\end{array}$ & 11 & $31 \%$ & $88 \%$ & $54 \%$ &, 21 \\
$\begin{array}{l}\text { Porcentaje } \\
\text { Otros Porcentaje }\end{array}$ & 11 & $75 \%$ & $100 \%$ & $95 \%$ &, 10 \\
\hline v válido (por lista) & 11 & & $82 \%$ & $59 \%$ &, 18 \\
\hline
\end{tabular}

Fuente: Elaboración propia.

Los niños de cinco años (Tabla 5.17) tenían mayores dificultades en los conceptos de tiempo (32\% de palabras conocidas), conceptos abstractos (44\% de palabras conocidas) y lugares (54\% de palabras conocidas).

Podemos ver que sí que existía una pequeña variación dependiendo de la edad, pero vemos una constante; por ejemplo, se observa que tenían mayores dificultades en los conceptos abstractos en todas las edades. Podemos comprobar las dificultades que han tenido los niños si revisamos sus fallos. De esta manera, hemos preguntado a las logopedas si les han parecido las palabras seleccionadas apropiadas, y encontramos los resultados en la Tabla 5.18.

Tabla 5.18.

Opinión de las logopedas sobre el tipo de palabras escogidas en PELEO Las palabras LOGOPEDA 1: Las palabras me parecían casi todas escogidas son apropiadas, excepto que algunas eran muy difíciles identificarlo adecuadas con un dibujo, y a los niños les era muy difícil entenderlo, las palabras eran apropiadas, pero a los niños a veces les es difícil identificarlo con un dibujo.

LOGOPEDA 4: $\mathrm{Si}$.

LOGOPEDA 3: Yo creo que sí aunque alguna un poco complicadilla, sobre todo adjetivos, pero bueno... 


\begin{tabular}{|c|c|}
\hline & $\begin{array}{l}\text { LOGOPEDA 6: Sí, creo que son palabras que en su mayoría se } \\
\text { ven casi a diario y que se usan con bastante frecuencia. }\end{array}$ \\
\hline \multirow[t]{2}{*}{$\begin{array}{l}\text { Las palabras } \\
\text { escogidas son } \\
\text { inadecuadas }\end{array}$} & $\begin{array}{l}\text { LOGOPEDA 2: Hay algunas un poco abstractas, sobre } \\
\text { conceptos un poco abstractos, que los niños no sé hasta qué } \\
\text { punto lo pueden comprender, pero que con una imagen es muy } \\
\text { difícil saber si eso lo están comprendiendo, que con la imagen } \\
\text { quizás no les ha servido ¿sabes? }\end{array}$ \\
\hline & $\begin{array}{l}\text { LOGOPEDA 5: Eh... No, me han parecido muchas palabras muy } \\
\text { difíciles, para los niños más pequeños, ¿las de los meses? A ver, } \\
\text { en general yo creo que bien, pero en todos los PowerPoints, en } \\
\text { cada semana, había ciertas palabras que me parecían difíciles, } \\
\text { incluso mi niño las fáciles tampoco se las sabía. }\end{array}$ \\
\hline
\end{tabular}

Fuente: elaboración propia.

Verificamos que las logopedas también observaban dificultades en las palabras abstractas, que son una de las categorías que más dificultades muestran los niños independientemente de su edad.

Para poder responder correctamente a la pregunta planteada al inicio, se han analizado los videos de las sesiones. Los vídeos nos han ayudado a vislumbrar qué respuestas dan cuando fallan. En algunas ocasiones los infantes no dicen nada, otras dicen "no sé" y otras veces se equivocan y dicen otras palabras diferentes. Para valorar lo que ocurre en cada categoría semántica, hemos analizado las veces que los niños dicen otras palabras diferentes.

Tabla 5.19.

Respuestas observadas en los vídeos de las palabras que desconocen según la categoría semántica

\begin{tabular}{|c|c|}
\hline \multirow[t]{3}{*}{ Partes del cuerpo } & $\begin{array}{l}\text { El participante P3-6 dice "pupa" en vez de "cuello" (VPP4 } \\
\text { - M: 03:58). }\end{array}$ \\
\hline & $\begin{array}{l}\text { El participante P3-6 dice "pierna" en vez de "pie" (VPP8 } \\
- \text { M: 6:52). }\end{array}$ \\
\hline & $\begin{array}{l}\text { El participante P3-6 dice "barriga" en vez de "espalda" } \\
\text { (VPP -M: 7:35). }\end{array}$ \\
\hline \multirow[t]{5}{*}{ Conceptos de tiempo } & $\begin{array}{l}\text { El participante } P 3-4 \text {, dice "sol" en vez de "día" (VPPI - } \\
\text { M: } 2: 46) \text {. }\end{array}$ \\
\hline & $\begin{array}{l}\text { La participante P4-9 dice "sol" en vez de "día" (VPP2 - } \\
\text { M: 3:40). }\end{array}$ \\
\hline & $\begin{array}{l}\text { El participante P5-11 dice "vacaciones" cuando se le } \\
\text { enseña "verano" (VPP3 - M: 3:10). }\end{array}$ \\
\hline & $\begin{array}{l}\text { El participante P5-11 dice "año" cuando se le enseña } \\
\text { "febrero"(VPP3-M: 3:25). }\end{array}$ \\
\hline & $\begin{array}{l}\text { El participante P5-11 dice "jueves" cuando se le enseña } \\
\text { "viernes (VPP3 - M: 3:40). }\end{array}$ \\
\hline
\end{tabular}




\begin{tabular}{|c|c|}
\hline & $\begin{array}{l}\text { El participante P4-6 dice "Halloween" cuando se le enseña } \\
\text { "carnaval"(VPP4 - M: 12:30). }\end{array}$ \\
\hline \multirow[t]{5}{*}{ Prendas de vestir } & $\begin{array}{l}\text { El participante P3-4 dice "reloj" en vez de decir "pulsera" } \\
\text { (VPP14-M: 15:12). }\end{array}$ \\
\hline & $\begin{array}{l}\text { La participante P4-6 dice "traje" en vez de decir "disfraz" } \\
\text { (VPP13 - M: } 11: 49) \text {. }\end{array}$ \\
\hline & $\begin{array}{l}\text { La participante P4-6 dice "ropa" en vez de "camiseta" } \\
\text { (VPP4 - M:5:10). }\end{array}$ \\
\hline & $\begin{array}{l}\text { El participante P3-6 dice "chaqueta" en vez de abrigo } \\
\text { (VPP7-M: 6:40). }\end{array}$ \\
\hline & $\begin{array}{l}\text { El participante P3-6 dice "para dormir" en vez de } \\
\text { "pijama" (VPP13-M: } 14: 20) \text {. }\end{array}$ \\
\hline \multirow[t]{4}{*}{ Alimentos } & $\begin{array}{l}\text { El participante P3-6 dice "comida" en vez de decir } \\
\text { "pescado"(VPP4-M: 4:22). }\end{array}$ \\
\hline & $\begin{array}{l}\text { El participante P3-6 dice "comida" en vez de decir "sopa" } \\
\text { (VPP5 - M: 4:51). }\end{array}$ \\
\hline & $\begin{array}{l}\text { El participante P3-6 dice "beber" en vez de "leche" (VPP8 } \\
\text { - M: 7:10). }\end{array}$ \\
\hline & $\begin{array}{l}\text { La participante P3-8 dice "pollo" en vez de "huevo" } \\
\text { (VPP3 - M: 4:40). }\end{array}$ \\
\hline Transportes & $\begin{array}{l}\text { El participante P5-11 dice "cohete" en vez de nava (VPP10 } \\
-M: 9: 10) \text {. }\end{array}$ \\
\hline Juguetes & $\begin{array}{l}\text { El participante P5-11 dice "parchís/cuadrados" en vez de } \\
\text { decir "juego" (VPP7 - M: 5:50). }\end{array}$ \\
\hline \multirow[t]{7}{*}{ Objetos } & $\begin{array}{l}\text { El participante P3-5 dice "agua" cuando se le enseña la } \\
\text { lámina de "lavabo" (VPP11-M: 10:30). }\end{array}$ \\
\hline & $\begin{array}{l}\text { El participante P5-11 dice "sombrero" cuando se le enseña } \\
\text { la lámina "casco" (VPP5 - M: 4:10). }\end{array}$ \\
\hline & $\begin{array}{l}\text { El participante P5-11 dice "puerta" en vez de "ventana" } \\
(V P P 12-M: 9: 50) \text {. }\end{array}$ \\
\hline & $\begin{array}{l}\text { La participante P4-6 dice "chupete" en vez de "biberón" } \\
\text { (VPP5 - M: 5:40). }\end{array}$ \\
\hline & $\begin{array}{l}\text { La participante P4-6 dice "lapicero" en vez de "boli" } \\
\text { (VPP6 - M: 6:30). }\end{array}$ \\
\hline & $\begin{array}{l}\text { El participante P3-6 dice "vaso" en vez de "copa" (VPP7 } \\
\text { - M: 6:43). }\end{array}$ \\
\hline & $\begin{array}{l}\text { La participante P3-8 dice "cuchara" en vez de "tenedor" } \\
\text { (VPP2 - M: 4:25). }\end{array}$ \\
\hline \multirow[t]{5}{*}{ Seres vivos } & $\begin{array}{l}\text { El participante P3-4 dice "guauguau" cuando se le está } \\
\text { enseñando la lámina de "perro".(VPP1 - M: 2:31). }\end{array}$ \\
\hline & $\begin{array}{l}\text { El participante P3-5 dice "guau guau" cuando se le está } \\
\text { enseñando la lámina del "perro"( } V P P 1-M: 2: 40) \text {. }\end{array}$ \\
\hline & $\begin{array}{l}\text { El participante P3-5 dice "pio" cuando se le está } \\
\text { enseñando la lámina del "pollo" (VPP2 - M: } 3: 20) \text {. }\end{array}$ \\
\hline & $\begin{array}{l}\text { El participante P4-6 dice "pájaro" cuando se le está } \\
\text { enseñando la lámina de "paloma" (VPP5 - M: 5:57). }\end{array}$ \\
\hline & $\begin{array}{l}\text { El participante P3-6 dice "gatito" en vez de "pantera" } \\
\text { (VPP6 - M: 5:20). }\end{array}$ \\
\hline
\end{tabular}




\begin{tabular}{|c|c|}
\hline & $\begin{array}{l}\text { El participante P3-6 dice "caballo" en vez de "burro" } \\
\text { (VPP7 - M: 6:50). }\end{array}$ \\
\hline & $\begin{array}{l}\text { La participante P3-8 dice "pato" en vez de "pollo" (VPP2 } \\
-M: 4: 31) \text {. }\end{array}$ \\
\hline & $\begin{array}{l}\text { La participante P3-8 dice "hipopótamo" en vez de } \\
\text { "rinoceronte" (VPP3 - M: 5:10). }\end{array}$ \\
\hline \multirow[t]{5}{*}{$\begin{array}{l}\text { Personas, profesiones y } \\
\text { personajes }\end{array}$} & $\begin{array}{l}\text { El participante P3-4 dice "mamá" cuando se le está } \\
\text { enseñando la lámina de "amigos". (VPPl-M: } 2: 10) \text {. }\end{array}$ \\
\hline & $\begin{array}{l}\text { El participante P3-5 dice "niño" cuando se le está } \\
\text { enseñando la lámina del "médico"(VPP9-M: 8:10). }\end{array}$ \\
\hline & $\begin{array}{l}\text { El participante P5-11 dice "ladrillo" cuando se le está } \\
\text { enseñando la lámina de "albañil".(VPP9-M: 7:50). }\end{array}$ \\
\hline & $\begin{array}{l}\text { La participante P4-6 dice "primo" en vez de "hijo" (VPP3 } \\
-M: 4: 20) \text {. }\end{array}$ \\
\hline & $\begin{array}{l}\text { La participante P3-8 dice “mamá y papá” en vez de } \\
\text { "amigos" }(V P P 1-M: 3: 10) \text {. }\end{array}$ \\
\hline \multirow[t]{5}{*}{ Conceptos abstractos } & $\begin{array}{l}\text { El participante P5-11 dice "agua" cuando se le enseña } \\
\text { "líquido" (VPP4 - M: 3:50). }\end{array}$ \\
\hline & $\begin{array}{l}\text { El participante P5-11 dice "casados" cuando se le enseña } \\
\text { "enamorados" (VPP8 - M: 7:10). }\end{array}$ \\
\hline & $\begin{array}{l}\text { La participante P4-9 dice "casados" cuando se le enseña } \\
\text { "enamorados"(VPP12 - M: 12:10). }\end{array}$ \\
\hline & $\begin{array}{l}\text { La participante P4-6 dice "paloma" cuando se le enseña la } \\
\text { lámina de "paz"(VPP12 - M: 10:30). }\end{array}$ \\
\hline & $\begin{array}{l}\text { El participante P3-6 dice "tubo" cuando se le enseña la } \\
\text { lámina del "circulo" (VPP10-M: 11:30). }\end{array}$ \\
\hline \multirow[t]{3}{*}{ Conceptos de cantidad } & $\begin{array}{l}\text { El participante P3-4 dice “manos" en vez de "diez” (VPP8 } \\
-M: 7: 26) \text {. }\end{array}$ \\
\hline & $\begin{array}{l}\text { El Participante P5-11 dice "uvas" en vez de "montón" } \\
\text { (VPP14-M: ). }\end{array}$ \\
\hline & $\begin{array}{l}\text { La participante P4-6 dice "uva" en vez de "montón" } \\
(V P P 4-M: 4: 50) \text {. }\end{array}$ \\
\hline \multirow[t]{6}{*}{ Lugares } & $\begin{array}{l}\text { El participante P3-4 dice "árbol" en vez de "campo" } \\
(V P P 4-M: 5: 41) \text {. }\end{array}$ \\
\hline & $\begin{array}{l}\text { El participante P3-5 dice "agua" en vez de "piscina" } \\
(V P P 2-M: 3: 40) \text {. }\end{array}$ \\
\hline & $\begin{array}{l}\text { El participante P5-11 dice "mar" en vez de "río" (VPP10 } \\
\text { - M: 9:30). }\end{array}$ \\
\hline & $\begin{array}{l}\text { La participante P4-6 dice "pizarra" en vez de "mar" } \\
(V P P 1-M: 3: 10) \text {. }\end{array}$ \\
\hline & $\begin{array}{l}\text { El participante P3-6 dice "casitas" en vez de "pueblo" } \\
\text { (VPP6 - M: 5:38). }\end{array}$ \\
\hline & $\begin{array}{l}\text { La participante P3-8 dice "patio" en vez de "parque" } \\
(V P P 2-M: 4: 20) \text {. }\end{array}$ \\
\hline Medioambiente & $\begin{array}{l}\text { El participante P3-4 dice "árbol" cuando se le está } \\
\text { enseñando la lámina de "árbol" (VPP4 - M: 5:58). }\end{array}$ \\
\hline
\end{tabular}

Fuente: elaboración propia. 
Como se puede ver en la Tabla 5.19, existían diferentes tipos de errores, cometen errores de sobreextensión ${ }^{6}$ (Nelson, 1988), como cuando La participante P4-6 decía "ropa" en vez de "camiseta" (VPP4 - M: 5:10); o también como cuando el participante P3-6 decía "comida" en vez de decir "pescado" (VPP4 - M: 4:22).

También se observa cómo algunas veces no conocían el nombre de lo que representaba la lámina, pero sí su uso, como por ejemplo cuando el participante P3-6 decía "para dormir" en vez de "pijama" (VPP13 - M: 14:20).

En otras ocasiones, se observa que decían una palabra que podía ser similar, o de un uso parecido, como cuando el participante P5-11 decía "sombrero" cuando se le enseñaba la lámina "casco" (VPP5 - M: 4:10), o cuando el participante P5-11 decía "mar" en vez de "río" (VPP10 $M: 9: 30$ ). Por lo que a priori podían saber para qué podía servir, aunque desconocieran su nombre.

En los conceptos relacionados con el tiempo, debido a la dificultad que entraña representar correctamente conceptos de tiempo a través de láminas, nos cuesta verificar si se trata de un error el no reconocer lo que representa la lámina o sencillamente que no ha utilizado la palabra que se pretendía que dijera. Esto se puede observar cuando La participante P4-9 dice "sol" en vez de "día" (VPP2 - M: 3:40). Para entender esta dificultad, a continuación, ilustramos la lámina que representa la palabra "día":

\footnotetext{
${ }^{6}$ La sobreextensión consiste en ampliar el campo semántico de una palabra, por ejemplo, llamar "guau" a todos los animales; también cometen infraextensión, tratando de ponerle un nombre a un objeto para referirse solo a ese, y aunque podría generalizarlo no lo hace, por ejemplo "trapito" es su trapo con el que duerme, pero no son el resto de los trapos (Nelson, 1988).
} 


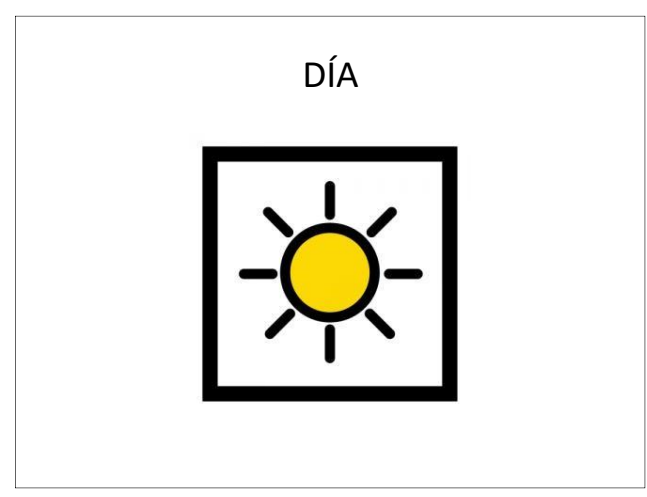

Figura 5.4. Lámina que representa la palabra "dia”.

Fuente: Los símbolos pictográficos utilizados son propiedad del

Gobierno de Aragón y han sido creados por Sergio Palao para ARASAAC (http://arasaac.org) que los distribuye bajo licencia Creative Commons (BY-NC-SA).

Esto mismo ocurre con las láminas relacionadas con los conceptos abstractos. Por ejemplo, esto lo vemos cuando El participante P5-11 decía “agua” cuando se le enseña "líquido" (VPP4 - M: 3:50). Esta respuesta es entendible, si extrapolamos la dificultad que existía en la Figura 5.5, pues es obvio lo complicado y arbitrario que resulta representar correctamente en imágenes conceptos abstractos. Esta dificultad, implícita en lo abstracto, es lo que genera la gran cantidad de errores que hemos encontrado.

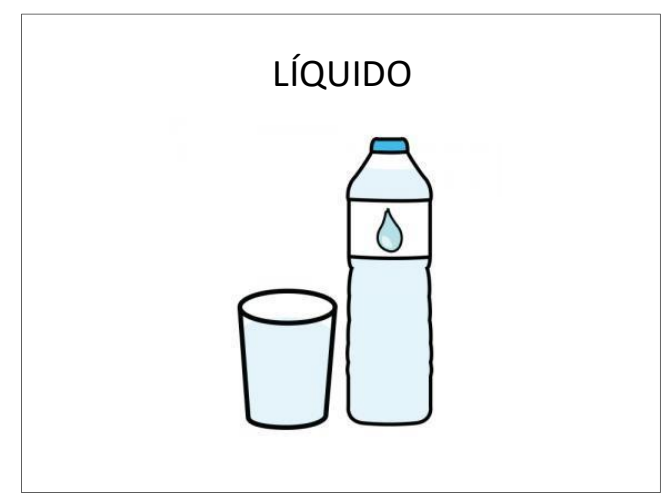

Figura 5.5. Lámina que representa la palabra “líquido”.

Fuente: Los símbolos pictográficos utilizados son propiedad del

Gobierno de Aragón y han sido creados por Sergio Palao para ARASAAC (http://arasaac.org) que los distribuye bajo licencia Creative Commons (BY-NC-SA). 
Una vez expuestos los resultados en torno a la segunda pregunta, podemos concluir que, los conceptos abstractos y de tiempo son las categorías semánticas donde más dificultades mostraban los infantes; y estos conceptos, además, tenían la dificultad añadida de que probablemente no se encuentre la imagen más adecuada para representarlos.

\subsection{3. ¿Cómo es el diseño de PELEO en relación a las actividades y a la motivación de los niños?}

Hemos presentado la motivación de los niños teniendo en cuenta la fase de PELEO en la que estaban; para ello se ha analizado el contenido de las entrevistas semiestructuradas a las logopedas y las grabaciones de las sesiones en las que se realizaban las actividades lúdicas y las actividades de repetición.

Ante las preguntas: ¿cómo era la motivación de los niños ante las actividades de repetición? y ¿cómo era la motivación de los niños ante las actividades lúdicas? las respuestas se encuentran en la Tabla 5.20.

Tabla 5.20.

Opinión de las logopedas sobre las actividades de la fase 1 y 3 (actividades relacionadas con el PowerPoint) y la fase 2 (actividades lúdicas con las palabras desconocidas)

Opinión de las LOGOPEDA 1: Pues en mi caso, yo se lo ponía en el ordenador actividades de las imágenes, y les dejaba ir pasando a ellos las imágenes, y les la fase 1 y 3 gustaba mucho el ordenador, y como cuando se lo sabían yo les dejaba ir pasando, ellos les encantaba, y luego cuando ya íbamos mirando las que ya se habían aprendido, pues les hacía mucha ilusión.

LOGOPEDA 2: Mmm ... La del niño de cuatro años regular, poca la motivación, me cuesta mucho que centre la atención, se va por todos lados y no para, entonces claro el tenerlo ahí un ratito enseñándole tal, y yo escribiendo... igual que las pruebas me cuesta la propia vida porque no para, no es que sea con eso, es que es con todo, como no sea jugando, así como muy de pelota o demás. La de la niña bien.

LOGOPEDA 3: Las actividades de repetir al principio algunos días sí, otros decías uff ¿se acaba ya? Pero en general sí, porque sabía que se terminaba y después iba a jugar.

LOGOPEDA 4: Siempre está activo y participativo, pero es verdad, que al inicio no le importaba repetir, y en las últimas sesiones ya se le hacía más cuesta arriba. 


\begin{tabular}{ll}
\hline & $\begin{array}{l}\text { LOGOPEDA 5: Pésima antes durante y después, pero con eso y } \\
\text { con todo habido y por haber, es su forma, su característica. }\end{array}$ \\
& LOGOPEDA 6: Al principio era tímido, y ahora cada vez está más \\
suelto y con más ganas de hablar. Noto diferencias en la parte \\
lúdica de los juegos está más motivado que en la parte de \\
repetición, aunque a las dos está más motivado.
\end{tabular}

Fuente: elaboración propia.

En la Tabla 5.20 observamos cómo las logopedas 2 y 5 tenían una opinión negativa de la motivación de los niños, en la fase 2 como en las fases 1 y 3 , mientras que el resto de las logopedas parecían estar contentas con ambas actividades, pero mostraban una especial predilección por las actividades lúdicas.

Encontramos fragmentos en los que observamos una motivación positiva por parte de los participantes. Por ejemplo, al finalizar las actividades, la mayor parte de los niños tenían las siguientes actitudes $\mathrm{o}$ comportamientos:

- Cuando finaliza la actividad, la participante P4-4 choca las manos con la investigadora (VPP11-M:14:367).

- El participante P5-10, al finalizar la parte de repetición choca los 5 con la logopeda (VPP1: M: 12:30).

$7 *$ V=Video, *PP=PowerPoint, *M=Minuto 
- El participante P4-5 se pone contento cuando finaliza de repetir las palabras y choca los 5 con la logopeda (con ambas manos) (VPP4 - M: 7:02).

Además, encontramos diferencias en el volumen de su habla como puede ser en el siguiente fragmento:

- La participante P4-4 habla muy bajito durante todas las actividades, pero en las actividades de repetición habla muy alto (VPP1-M: 9:31).

Por otro lado, en las actividades de la fase 1 y 3 , también podemos observar conductas codificadas como "motivación negativa":

- La participante P4-4 al final de la actividad de repetición (VPP11-M: 13:48).

Doctoranda: manguitos.

Participante P4-4: manguitos.

Doctoranda: nubes.

Participante P4-4: (bostezando): nubes.

Doctoranda: qué sueño...

- El participante P3-1, se quiere levantar de la silla porque no quiere hacer la actividad, y la investigadora le sienta encima de sus rodillas (VPP4-M: 20:54).

- El participante P3-4. (VPP1-M: 4:20)

Logopeda: Elefante.

Niño: fante.

Logopeda: No, escucha Ele-fante.

Niño: se queda mirando a la pantalla y no quiere responder.

La motivación que se ha observado en la fase 2 , material procedente de las grabaciones de los vídeos, comenzando por los segmentos que incluyen un nivel de activación alto y una motivación positiva:

- La participante P4-4 está jugando a un juego de adivinanzas con el vocabulario que desconocía (VPP4 - M: 11:42).

Logopeda: Una cosa hecha con tela.

La niña lo coge y sonríe: dice "Pijama" y pone las manos hacia arriba en señal de victoria y se ríe. 
- La participante P3-3 es una niña muy tímida y seria, está jugando a los sonidos que hacen los diferentes animales y tiene que decir el nombre (VPP1 - M: 1:42).

Logopeda: ¿Este cuál es? Hace oing-oing.

Niña: se ríe y se acerca a la logopeda para hacerla una carantoña dice: Cerdo.

- El participante P4-1: la logopeda canta una canción para que el niño aprenda la palabra "calle" (VPP3: M. 3:52).

Logopeda: La calle es donde vamos a salir por esa puerta, cuando nos ponemos el abrigo y los zapatos y hay una canción mira:

Logopeda dando palmas al ritmo: "en la calle-lle, veinticuatrotro, ha habido-do, un asesinato-to..." canta conmigo el precio "en la calle-lle..." eso es la calle ¿has visto?

El participante: Se ríe, sonríe y dice: sí, calle.

- La participante P4-7. La logopeda está enseñándola los días de la semana y canta una canción (VPP6: M. 4:43).

Logopeda y participante P4-7 (cantando a la vez y realizando gestos con las manos): lunes, martes, miércoles, jueves, viernes, sábado y domingo, son siete días de la semana, cinco en el cole y dos en casa.

Logopeda: Sabiendo esto, ¿qué día es hoy?

Participante P4-7 riéndose: jueves

- Participante P5-7 está jugando a decir poesías, que tienen escritas con pictogramas (VPP2 - M. 2:59).

Logopeda: Ayer hemos empezado el otoño.

Participante: Hoy.

Logopeda: Vamos a jugar a decir poesías. ¿Te sabes alguna poesía del otoño?

Participante: No.

Logopeda (acompañándolo con gestos): Abrí la ventana, saqué la maceta, y vi caer una hoja triste y seca.

Participante se ríe.

Logopeda continúa: mi hermana pequeña que en el balcón estaba me dijo: ¿es que el otoño llega mañana?

Las situaciones en las que había una motivación positiva debido a la prevalencia de la elección de esa actividad son las siguientes: 
- Participante P5-6 está jugando a un juego de adivinar la palabra que describe la logopeda entre varias imágenes que está viendo (VPP8 - M. 5:12):

Logopeda: ¿Tú tienes una más mayor? ¿Una qué?

Participante: Una hermana, si, una más mayor que va al último curso.

Logopeda: Si, y en esa imagen hay muchas...

Participantes: Cosas.

Logopeda: ¡Muy bien! Eres un crack.

Participante: Me gusta, porque yo me sé las cosas, los juguetes...

- Participante P5-9. Estamos recogiendo unos juegos que hizo él el día anterior (VPP8 - M: 2:47).

El participante: ¡Mira! (sonriendo) los dibujos que vi yo antes, pero ya no los hacemos. ¿Qué pena!

- El participante P5-8 está jugando a adivinar qué imagen es la que se refiere la logopeda (VPP1 - M: 8:45).

Logopeda: Coge una cosa.

El participante: lo coge.

Logopeda: Un céntimo.

El participante lo coge.

El participante: Vaya, se ha acabado.

Solo encontramos conductas con motivación negativa en tres participantes, que son los participantes P3-4, P4-5 y P4-9. Éstos mostraban problemas de conducta en la intervención (durante todo el tiempo), se tiraban al suelo, se levantaban, se ponían encima de la mesa, por lo que era complicado valorar si realmente se sientían motivados o no en las diferentes fases. Todo el tiempo mantenían una conducta disruptiva, aunque no estaban diagnosticados de otras dificultades que no fuera retraso de lenguaje.

Hemos hallado diferencias en la motivación en las tres fases, encontrando más conductas de motivación positiva en las actividades de la fase 2 que en las actividades de las fases 1 y 3 .

Los resultados en torno a las observaciones realizadas se encuentran en la Tabla 5.21. 
Tabla 5.21.

Observaciones encontradas en las listas de control relacionadas con la motivación de los niños ante las actividades

\begin{tabular}{|c|c|}
\hline \multirow[t]{4}{*}{$\begin{array}{l}\text { Motivación } \\
\text { positiva }\end{array}$} & $\begin{array}{l}\text { Está muy tranquila, y habladora, nos cuenta que va a tener un } \\
\text { hermanito, está muy contenta con la situación, hace todo } \\
\text { especialmente bien, dice que tiene que enseñarle a sufuturo hermano } \\
\text { a hablar y que lo tiene que hacer muy bien (Participante P3-3_lista } \\
\text { de control_PP5). }\end{array}$ \\
\hline & $\begin{array}{l}\text { Viene muy contento a la sesión, van a venir los Reyes dentro de poco, } \\
\text { y le han dicho sus padres que tiene que portarse bien para que le } \\
\text { traigan cosas, lo cuenta por el camino antes de ir a la sesión } \\
\text { (Participante } \mathrm{P} 5-6 \text { _lista de control_PP12). }\end{array}$ \\
\hline & $\begin{array}{l}\text { Hoy cuando hemos ido a buscarla por el camino, le he dicho que era } \\
\text { el último día que venía, y se ha puesto a llorar, quiere continuar, dice } \\
\text { que le gusta mucho las sesiones y que se lo pasa muy bien, dice que } \\
\text { quiere seguir aprendiendo, en seguida se la pasa y realiza la sesión } \\
\text { muy contenta (Participante P5-7_lista de control_PP21). }\end{array}$ \\
\hline & $\begin{array}{l}\text { Está muy contenta, le ha gustado mucho la sesión quería seguir, } \\
\text { cuando ha terminado, no se quería ir, hoy es el primer día y se ha } \\
\text { adaptado muy bien a la sesión (Participante P4-7_lista de } \\
\text { control_PP1). }\end{array}$ \\
\hline \multirow[t]{4}{*}{$\begin{array}{l}\text { Motivación } \\
\text { negativa }\end{array}$} & $\begin{array}{l}\text { No ha querido sentarse en la silla, se muestra nervioso, da vueltas } \\
\text { alrededor de la silla, ordena compulsivamente las láminas y no } \\
\text { responde a lo que se le plantea, no quiere colaborar.(Participante } \\
\text { P3-4_lista de control_PP4). }\end{array}$ \\
\hline & $\begin{array}{l}\text { Se mete todo el rato debajo de la mesa, no quiere salir, le fuerzo a } \\
\text { salir y le siento sobre mis piernas, cuando salimos de la sesión les } \\
\text { dice a los padres "ella me ha pegado", me dice su madre que en el } \\
\text { colegio está recibiendo muchos partes de incidencias, y que es algo } \\
\text { que dice cuando le fuerzas a hacer algo que no quiere (Participante } \\
\text { P4-5_lista de control_PP9). }\end{array}$ \\
\hline & $\begin{array}{l}\text { Habla todo el tiempo de otras cosas, hay que preguntarle de cinco a } \\
\text { seis veces como se llama cada lámina, dice claramente que no quiere } \\
\text { continuar, que quiere volver a clase con sus compañeros y que quiere } \\
\text { tocar la pandereta. Habla mucho sobre el resto de sus compañeros, } \\
\text { sobre uno en especial que le hace rabiar, y se queja todo el rato, se } \\
\text { evade, y no sigue la conversación (Participante P4-9_lista de } \\
\text { control_PP8). }\end{array}$ \\
\hline & $\begin{array}{l}\text { Se ha pillado los dedos de la mano con la bisagra de la puerta antes } \\
\text { de comenzar, desde ese momento ha comenzado a llorar, ha sido muy } \\
\text { difícil seguir la sesión, le he puesto hielo, pero aun así se le han } \\
\text { hinchado los dedos un poco, aunque no parece que sea nada } \\
\text { importante, ha sido muy difícil seguir la sesión no mostraba ningún } \\
\text { interés (Participante P3-7_lista de control_PP10). }\end{array}$ \\
\hline
\end{tabular}
Fuente: elaboración propia. 
Los participantes P3-4, P4-5 y P4-9 tenían comportamientos de motivación negativa en las observaciones (estas son algunas de las observaciones, pero se han realizado, pero hay muchas más).

Existía, además, una observación negativa debida a un motivo externo, (no por un motivo interno del diseño ni de la intervención en sí), que fue la del participante P3-7.

Hemos querido dejar constancia también por escrito de algunas observaciones de motivación positiva debidas a motivos externos: como pudo ser la llegada de un hermano (participante P3-3), o que iban a llegar los Reyes (participante P5-6); mientras que los dos últimos (participante P5-7 y P4-7) sí que tenían que ver con la intervención.

Por lo que podemos decir que la motivación no era exactamente igual entre la fase 1 y 3 y la fase 2; ya que existían mayores situaciones de motivación positiva en la fase 2 .

\subsection{4. ¿Cómo ha cambiado el vocabulario de los niños que han utilizado PELEO?}

Los resultados obtenidos giran en torno a las pruebas estandarizadas ya que analizamos las respuestas del PLON-R Contenido, los resultados del PEABODY (Dunn et al., 2006), las respuestas de las entrevistas semiestructuradas a las logopedas, las familias y las profesoras.

Los resultados del PLON-R Contenido y del PEABODY, nos ofrecieron una visión sobre la situación inicial y final en el vocabulario de los niños, y nos ayudaron a comprender cómo este ha cambiado (Tabla 5.22).

Tabla 5.22.

Estadísticos descriptivos de la prueba pre-postest

\begin{tabular}{lllllc}
\hline & $\mathrm{N}$ & Mínimo & Máximo & Media & $\begin{array}{l}\text { Desviación } \\
\text { estándar }\end{array}$ \\
\hline $\begin{array}{l}\text { PLON-R Contenido } \\
\text { pretest }\end{array}$ & 33 & 0 & 5 & 2,84 & 1,526 \\
\hline $\begin{array}{l}\text { PLON-R contenido } \\
\text { postest }\end{array}$ & 33 & 3 & 6 & 4,88 &, 871 \\
\hline Peabody PD pretest & 33 & 7 & 67 & 31,66 & 19,582 \\
\hline Peabody PD postest & 33 & 11 & 105 & 41,13 & 22,098 \\
\hline Peabody CI pretest & 33 & 24 & 116 & 86,34 & 22,090 \\
\hline Peabody CI postest & 33 & 62 & 123 & 94,91 & 16,187 \\
\hline N válido (por lista) & 33 & & & & \\
\hline
\end{tabular}

Fuente: elaboración propia. 
Los resultados de la prueba $W$-Wilcoxon nos sirvieron para comparar el rango medio de las variables y de esta manera pudimos determinar si existieron diferencias entre ellas.

Tabla 5.23.

Resultados de la prueba W-Wilcoxon

\begin{tabular}{llll}
\hline & $\begin{array}{l}\text { PLON contenido } \\
\text { postest-pretest }\end{array}$ & $\begin{array}{l}\text { Peabody PD } \\
\text { postest-pretest }\end{array}$ & $\begin{array}{l}\text { Peabody CI } \\
\text { postest-pretest }\end{array}$ \\
\hline $\mathrm{Z} \quad-4,763 \mathrm{~b}$ & $-4,222 \mathrm{~b}$ & $-2,781 \mathrm{~b}$ \\
\hline $\begin{array}{l}\text { Sig. asintótica } \\
\text { (bilateral) }\end{array}$ &, 000 &, 000 &, 005 \\
\hline a. Prueba de rangos con signo de Wilcoxon & & \\
\hline b. Se basa en rangos negativos & & \\
\hline c. Se basa en rangos positivos & & \\
\hline
\end{tabular}

Fuente: elaboración propia.

En la Tabla 5.23 observamos cómo la Sig. asintótica (bilateral) era menor de 0.05 en todas las relaciones de las variables, por lo que podemos determinar que existieron diferencias significativas en todas ellas.

En la Tabla 5.24 se observa Kappa de Cohen para las mismas categorías que hemos estudiado en la prueba W-Wilcoxon y han arrojado un resultado de significación positiva.

Tabla 5.24.

Resultados de Kappa de Cohen

\begin{tabular}{|c|c|c|c|c|}
\hline & Valor & $\begin{array}{l}\text { Error estándar } \\
\text { asintóticoa }\end{array}$ & $\begin{array}{l}\mathrm{T} \\
\text { aproximadab }\end{array}$ & $\begin{array}{l}\text { Significación } \\
\text { aproximada }\end{array}$ \\
\hline \multirow{2}{*}{$\begin{array}{l}\text { PLON-R contenido } \\
\text { pretest y PLON-R } \\
\text { contenido postest }\end{array}$} &,- 040 & ,050 &,- 701 & ,484 \\
\hline & & & & \\
\hline $\begin{array}{l}\text { Peabody PD inicial y } \\
\text { Peabody PD final }\end{array}$ & 050 & ,041 & 2,475 & ,013 \\
\hline $\begin{array}{l}\text { Peabody CI inicial y } \\
\text { Peabody CI final }\end{array}$ & ,107 & ,054 & 4,333 & ,000 \\
\hline
\end{tabular}


Fuente: elaboración propia.

En la Tabla 5.24, observamos que el valor del PLON-R era de -0.40 y el del Peabody PD era de 0.50, lo que indica una intensidad de la diferencia moderada, mientras que el Peabody CI tenía un valor de 0.107 lo que indica una ínfima diferencia.

Una vez realizado este análisis, en el que comprobamos que PELEO ayudaba a incrementar el vocabulario de los niños que utilizaron el programa. Para profundizar y conocer cómo cambió el vocabulario de estos niños que utilizan PELEO, valoramos la opinión de las logopedas (Tabla 5.25), familias (Tabla 5.26) y maestras (Tabla 5.27) sobre cómo ha afectado PELEO al vocabulario de los niños que han utilizado PELEO.

Tabla 5.25.

Opinión de las logopedas sobre cómo afecta al nivel semántico PELEO Conoce o dice las palabras LOGOPEDA 1: Si, hay veces que al principio había presentadas en los muchas que no se sabían, porque todos tenían PowerPoint muchas dificultades, pero después sí que las usaban, de hecho, con alguno que no tenía mucha dificultad y hemos trabajado los días de la semana y los meses del año, luego sí que notaba que se lo iban aprendiendo mucho mejor, con otros no los he aplicado porque no podía, pero había otros que sí, y yo creo que sí que lo aplicaban después.

LOGOPEDA 2: ¿Antes de enseñárselas? Sí, yo creo que sí, no sé cuánto tanto por ciento, pero la mayoría sí.

LOGOPEDA 3: Sí, la niña las conoce, pero hay errores que sigue cometiendo.

LOGOPEDA 4: Algunas sí, otras según aumentábamos el orden le era más complicado y le costaba más reconocerlas.

LOGOPEDA 5: Muchas sí, pero muchas no. Conoce muchas, pero debería de conocer muchas más.

LOGOPEDA 6: Algunas de ellas, la mayoría.

¿Consideras que el niño LOGOPEDA 1: Yo creo que sí que las van a usar, generaliza el uso de las porque luego al final las identificaban muy rápido, palabras con las actividades según las veían, y cuando se los ponía en 


\begin{tabular}{|c|c|}
\hline $\begin{array}{l}\text { que realizas en la fase } 2 \text { ? } \\
¿ \text { Crees que el niño ha }\end{array}$ & $\begin{array}{l}\text { actividades también las identificaban no solo las } \\
\text { identificaban con la imagen del PowerPoint. }\end{array}$ \\
\hline generalizado las palabras en & LOGOPEDA 2: Algunas, pero considero que, si eso \\
\hline $\begin{array}{l}\text { todos los } \\
\text { aplicación? }\end{array}$ & $\begin{array}{l}\text { no lo llevas a cabo en casa, que como esas palabras } \\
\text { luego no se vean... porque en sesión luego no } \\
\text { puedes practicar el uso de determinadas palabras, } \\
\text { si luego esas no se trasladan, pues claro... Pero } \\
\text { algunas sí, porque quizás tienen un sinónimo, pero } \\
\text { si es totalmente nuevo. }\end{array}$ \\
\hline & $\begin{array}{l}\text { LOGOPEDA 3: Generalizar... yo creo que mejora, } \\
\text { pero no termina de generalizar, habría vocabulario } \\
\text { que habría que seguir machacando más adelante, } \\
\text { no solamente con dos sesiones. }\end{array}$ \\
\hline & $\begin{array}{l}\text { LOGOPEDA 4: Si, la mayoría de las palabras sí, } \\
\text { otras están aún en ello. }\end{array}$ \\
\hline & LOGOPEDA 5: No... \\
\hline & LOGOPEDA 6: $\mathrm{No}$, \\
\hline
\end{tabular}

Fuente: elaboración propia.

Tal y como comprobamos, las logopedas tenían opiniones diversas sobre esta pregunta tan concreta y difícil de valorar a priori, por lo que vamos a analizar las respuestas de las familias (Tabla 5.23).

Tabla 5.26.

Opinión de las familias sobre si el número de palabras que dice su hijo ha aumentado al utilizar PELEO

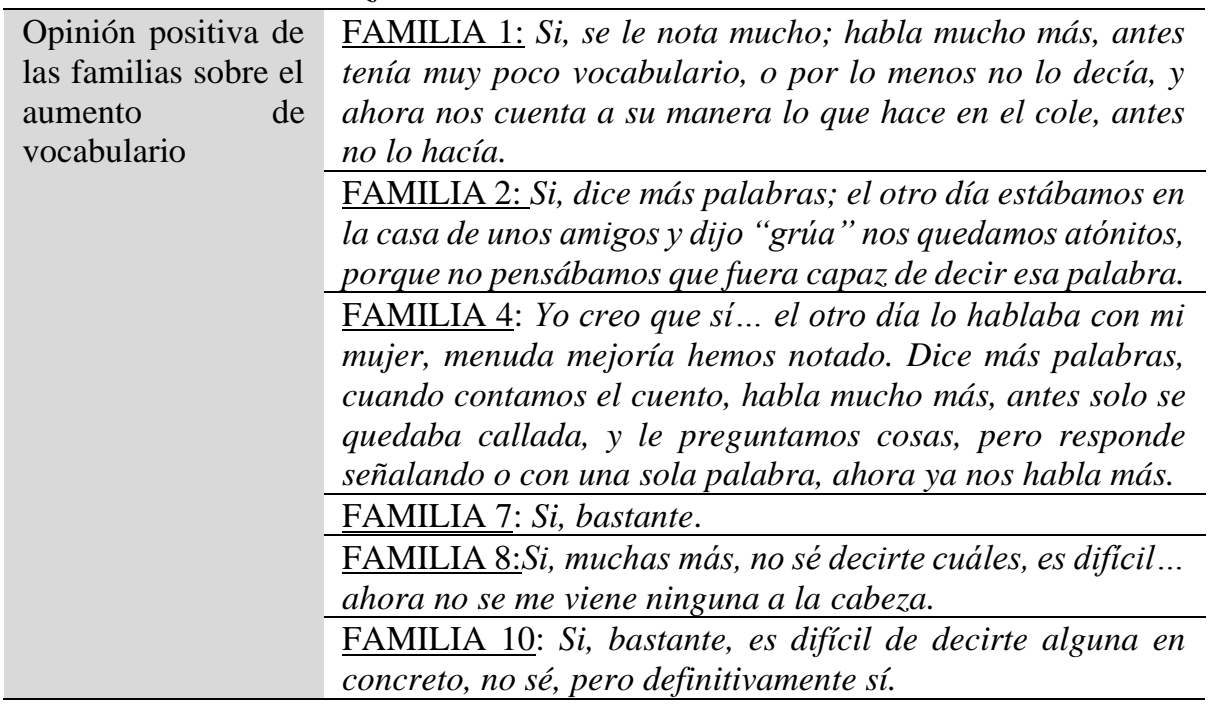




\begin{tabular}{ll}
\hline & $\begin{array}{l}\text { FAMILIA 11: Si, yo creo que de manera global ha mejorado } \\
\text { en todo, no es solo a nivel de vocabulario, es que si me fijo } \\
\text { solo en las palabras tampoco sé decirte. }\end{array}$ \\
\hline FAMILIA 13: Yo creo que sí... pero no sé decirte. \\
\hline FAMILIA 16: Si, sí, porque habla más. \\
\hline $\begin{array}{l}\text { FAMILIA 17: Si... aunque me preguntas por ejemplos, pero } \\
\text { no sé qué decirte. }\end{array}$ \\
\hline Opiniones indecisas & $\begin{array}{l}\text { FAMILIA 3: Supongo que sí, no te sé decir, tampoco nos } \\
\text { hemos dado cuenta de las palabras que dice o las que no, sí } \\
\text { que notamos que habla más, pero hay veces que no se le } \\
\text { entiende si son palabras nuevas o qué es lo que dice. }\end{array}$ \\
\hline $\begin{array}{l}\text { FAMILIA 5: No lo sé la verdad... habla más, pero no sé si } \\
\text { dice más palabras, o son las de antes.... }\end{array}$ \\
\hline $\begin{array}{l}\text { FAMILIA 6: mmm no lo sé, pero podían ser más podría decir } \\
\text { nuevas palabras. }\end{array}$ \\
\hline $\begin{array}{l}\text { FAMILIA 12: No sé decirte, posiblemente sí, porque ha } \\
\text { mejorado en todo. }\end{array}$ \\
\hline $\begin{array}{l}\text { FAMILIA 15: Yo creo que no su vocabulario, aunque sí que } \\
\text { habla más, puede ser que sí, no lo sé. }\end{array}$ \\
\hline $\begin{array}{l}\text { FAMILIA 9: Podría ser más, ha podido decir algo nuevo, } \\
\text { pero ahora ni se me viene a la cabeza, así que creo que no, } \\
\text { no ha mejorado. }\end{array}$ \\
\hline FAMILIA 14: Yo creo que no, en ese sentido sigue igual \\
\hline Opiniones negativas
\end{tabular}

Fuente: elaboración propia.

Analizando estas opiniones podemos afirmar que las familias mostraban una mayor conformidad que disconformidad en este aspecto, pero para continuar analizando si aumentó el vocabulario de los niños que han utilizado PELEO, vamos a considerar también las respuestas de las maestras (Tabla 5.27).

\section{Tabla 5.27.}

Opinión de las maestras sobre si el número de palabras que dice su alumno ha aumentado al utilizar PELEO

\begin{tabular}{ll}
$\begin{array}{l}\text { Opiniones } \\
\text { positivas }\end{array}$ & $\begin{array}{l}\text { MAESTRA 2: De los dos niños, Uno si, aunque cuesta entender lo } \\
\text { que dice, y el otro niño un poco más. }\end{array}$ \\
& $\begin{array}{l}\text { MAESTRA 3: Si, yo creo que sí, porque hablan bastante más, y } \\
\text { claro, eso si no ha aumentado su vocabulario pues no hubiera podido } \\
\text { hacerlo. }\end{array}$ \\
& $\begin{array}{l}\text { MAESTRA 4: Más vocabulario el niño sí, ha añadido más palabras, } \\
\text { la niña no, pero participa en clase mucho más, en la asamblea por la } \\
\text { mañana incluso a veces levanta la mano y participa de manera } \\
\text { espontánea, antes siempre se lo tenía que indicar, y haciendo } \\
\text { preguntas. }\end{array}$ \\
\hline
\end{tabular}




\begin{tabular}{|c|c|}
\hline & $\begin{array}{l}\text { MAESTRA 7: Si, mucho más, es vocabulario específico de clase, me } \\
\text { lo ha dicho también la profesora de inglés, que también lo ha notado } \\
\text { en su asignatura, no sé si está relacionado con lo que haces o no. }\end{array}$ \\
\hline & MAESTRA 8: Si, yo creo que sí. \\
\hline & $\begin{array}{l}\text { MAESTRA 9: Si, pero quizás no es en lo que más se lo he notado, le } \\
\text { noto que habla más en clase, incluso el otro día le tuve que castigar, } \\
\text { porque no callaba con otro niño, nunca me había pasado eso con él. }\end{array}$ \\
\hline & MAESTRA 10: Si, todo lo que has hecho ha sido de mucha utilidad. \\
\hline \multirow[t]{3}{*}{$\begin{array}{l}\text { Opiniones } \\
\text { negativas }\end{array}$} & $\begin{array}{l}\text { MAESTRA 1: De poco para acá, de dos meses para acá, sí que es } \\
\text { verdad, que ella intenta comunicarse mucho más y responde mucho } \\
\text { más a las preguntas que tú le haces, pero voluntariamente ella, } \\
\text { expresar cosas con un nuevo vocabulario... no. }\end{array}$ \\
\hline & $\begin{array}{l}\text { MAESTRA 5: Pues... yo creo que no, pero es verdad que antes que } \\
\text { empezases tú tampoco notaba que le faltaba vocabulario, es sobre } \\
\text { todo su manera de expresarse y su articulación. }\end{array}$ \\
\hline & $\begin{array}{l}\text { MAESTRA 6: Yo creo que no, porque sobre todo en lo que falla es } \\
\text { en la articulación y sigue parecido, ha mejorado, pero no muchísimo. }\end{array}$ \\
\hline
\end{tabular}

Fuente: elaboración propia.

Realmente, las maestras tenían mayor número de opiniones positivas sobre si han aumentado el número de palabras con PELEO.

Como hemos podido comprobar, en general, tanto los resultados de las pruebas estandarizas, la opinión de las logopedas, las familias como de las maestras vertían más opiniones positivas que negativas en cuanto al aumento de vocabulario de los infantes tras el uso de PELEO.

\subsection{5. ¿Cómo ha cambiado la articulación de los niños que han utilizado PELEO?}

Para dar respuesta a esta pregunta se utilizan a las pruebas estandarizadas: el Registro Fonológico Inducido (RFI) (Juárez y Monfort, 1996a), el PLON-R (Aguinaga et al., 2004), las entrevistas semiestructuradas a las logopedas, las familias y las profesoras.

Los resultados del Registro Fonológico Inducido indican que todos los niños fueron capaces de articular correctamente los fonemas /a/, /e/, /i/ tanto al inicio de la intervención como al final de ésta.

En el resto de los fonemas la articulación ha sido diferente dependiendo de la edad, por lo que hemos dividido a los participantes en esta ocasión según su edad, creando tres grupos de 11 participantes en cada uno de ellos. Se analizan los fonemas que son capaces de articular al menos en una posición, ya sea esta posición inicial, final o media. 


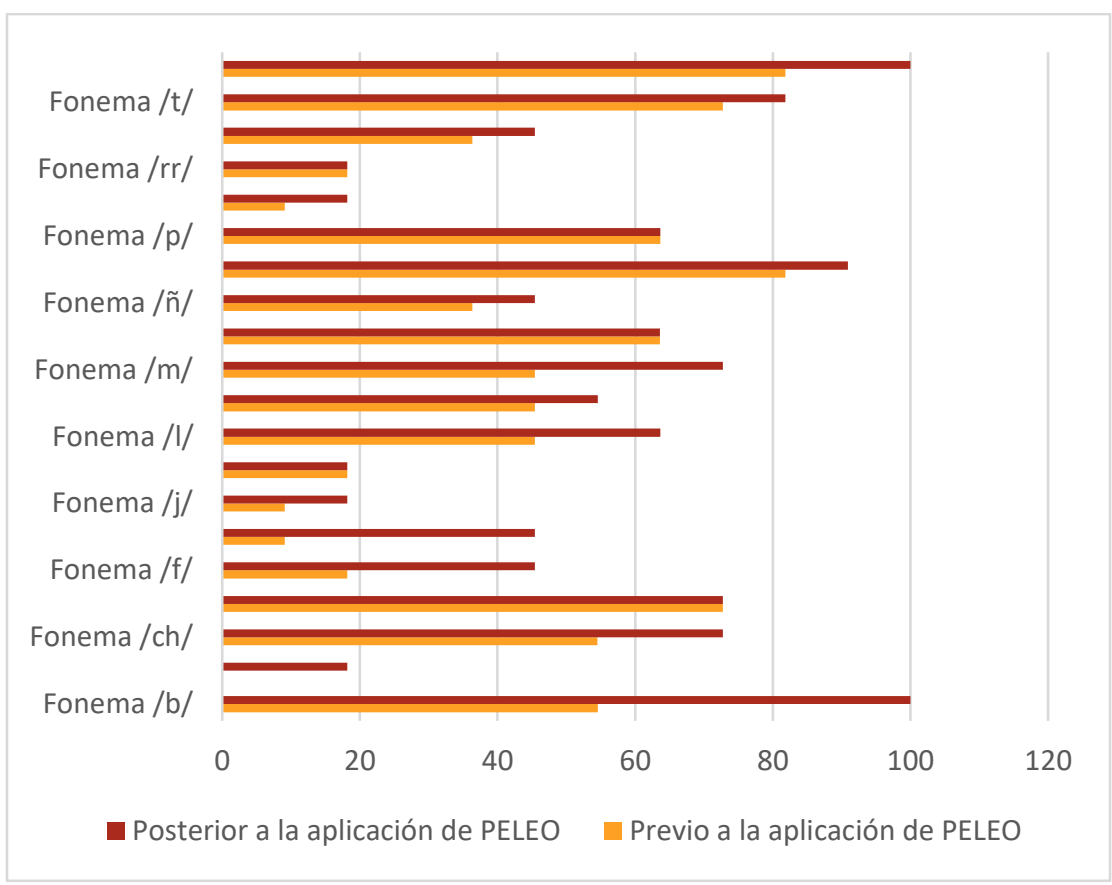

Figura 5.6. Porcentaje de niños de tres años que articulan correctamente los diferentes fonemas al menos en una posición. Fuente: elaboración propia.

En la Figura 5.6. podemos observar cómo no encontramos un gran cambio en algunos fonemas $/ \mathrm{d} /, / \mathrm{k} /, / \mathrm{n} /, / \mathrm{p} / \mathrm{y} / \mathrm{s} /$; encontramos un aumento del 9.09\% en la pronunciación de los fonemas $/ \mathrm{j} /, / 11 /, / \tilde{\mathrm{n}} /, / \mathrm{r} /$, $/ \mathrm{rr} / \mathrm{y} / \mathrm{t} /$; de un $18.18 \%$ en los fonemas / $\mathrm{\Theta} /, / \mathrm{ch} /, / 1 / \mathrm{y} / \mathrm{u} / ;$ de un $27.27 \%$ en el fonema /f/; de un $36.36 \%$ en el fonema /f/, y de un $45.55 \%$ en el fonema $/ \mathrm{b} /$.

Los niños del grupo de cuatro años articulaban correctamente los fonemas /b/, /ch/, /d/, /k/, /l/, /l1/, /m/, /o/, /t/ y /u/ y tenían dificultades en los siguientes fonemas que se observan en la Figura 5.7 


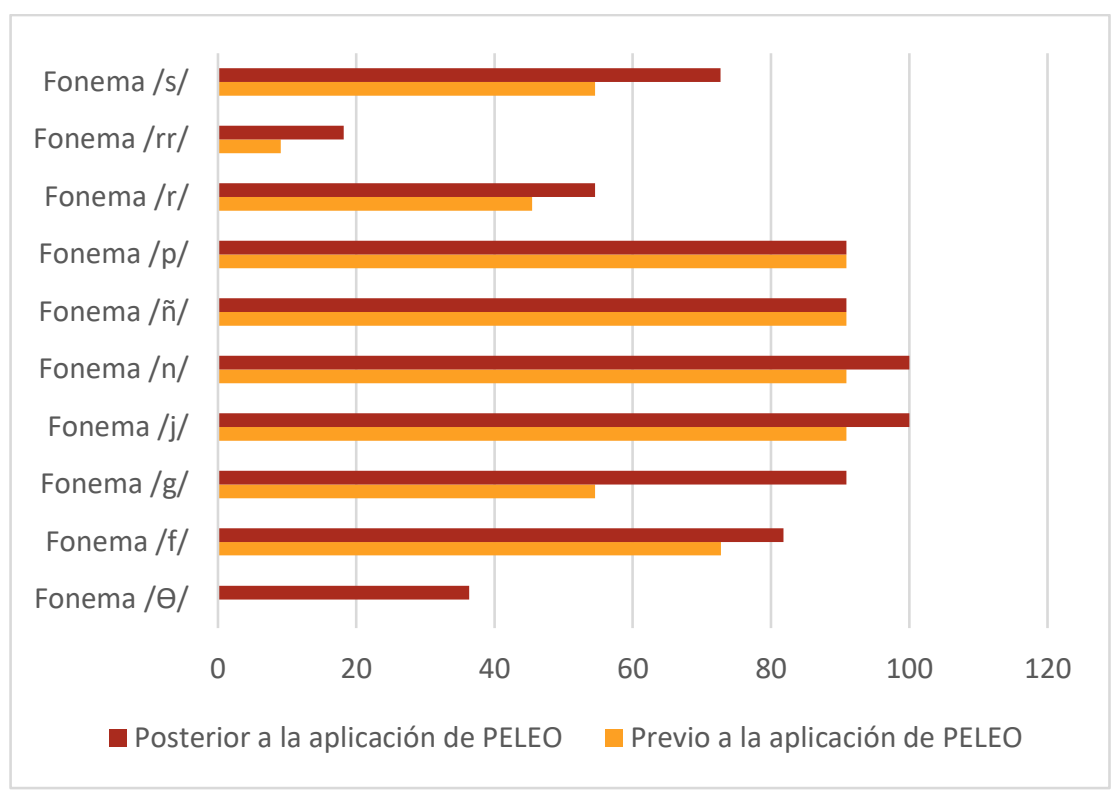

Figura 5.7. Porcentaje de niños de cuatro años que articulan correctamente los diferentes fonemas al menos en una posición.

Fuente: elaboración propia.

En la Figura 5.8 podemos observar cómo no existió una mejoría en algunos fonemas $/ \tilde{\mathrm{n}} /, / \mathrm{p} /$, encontramos una mejoría del $9.09 \%$ en los fonemas $/ \mathrm{f} /, / \mathrm{j} /, / \mathrm{n} /, / \mathrm{r} /, / \overline{\mathrm{r}} /$; una mejoría del $18.32 \%$ en el fonema $/ \mathrm{s} /$, una mejoría del $36.36 \%$ en el fonema $/ \Theta / \mathrm{y} / \mathrm{g} /$.

Todos los niños de cinco años articularon correctamente antes y después de la utilización de PELEO los fonemas /b/, /d/, /f/, /g/, /k/, /l/, /ll/, /m/, $/ \mathrm{n} /, / \mathrm{o} /, / \mathrm{t} /, \mathrm{y} / \mathrm{u} /, \mathrm{y}$ tuvieron dificultades en los fonemas que aparecen en la Figura 5.8. 


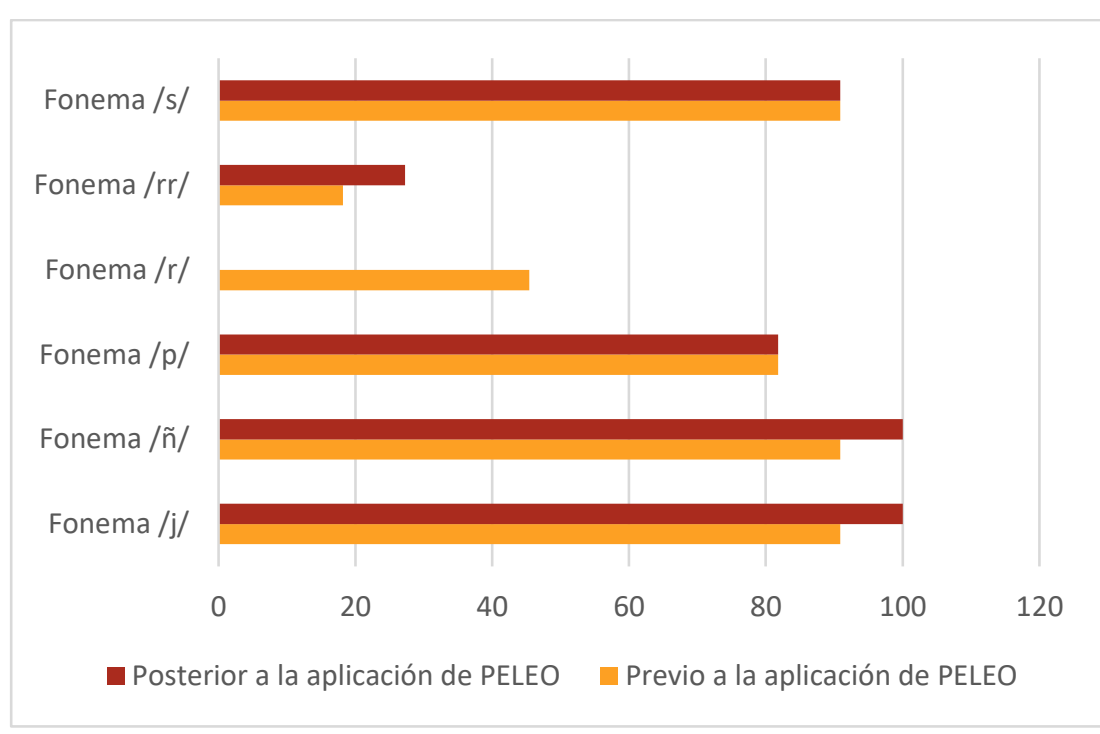

Figura 5.8. Porcentaje de niños de cinco años que articulan correctamente los diferentes fonemas al menos en una posición.

Fuente: elaboración propia.

Si nos fijamos en la Figura 5.8 podemos ver que no existió una mejoría en el fonema /p/, que existió una mejoría del $9.09 \%$ en los fonemas $/ \mathrm{j} /$, $/ \tilde{\mathrm{n}} /, / \mathrm{s} / \mathrm{y} / \overline{\mathrm{r}} / \mathrm{y}$ una mejoría del $18.8 \%$ en el fonema $/ \mathrm{r} /$.

En la Tabla 5.28 encontramos cómo ha sido la evolución de los niños en el PLON-R forma. En este subapartado se analiza la fonética de los niños $\mathrm{y}$ el número de palabras y fonemas que dijeron mal los niños en el Registro Fonológico Inducido.

Tabla 5.28.

Estadísticos descriptivos de la prueba pre-postest

\begin{tabular}{llllll} 
& $\mathrm{N}$ & Mínimo & Máximo & Media & $\begin{array}{l}\text { Desviación } \\
\text { estándar }\end{array}$ \\
\hline PLON-R Forma pretest & 33 & 0 & 4 & 1,53 & 1,436 \\
\hline PLON-R Forma postest & 33 & 0 & 5 & 2,88 & 1,408 \\
\hline RFI fonemas pretest & 33 & 11 & 231 & 74,78 & 62,186 \\
\hline RFI fonemas postest & 33 & 9 & 185 & 49,25 & 38,717 \\
\hline RFI palabras pretest & 33 & 16 & 57 & 39,00 & 11,854 \\
\hline RFI palabras postest & 33 & 7 & 56 & 31,16 & 12,626 \\
\hline N válido (por lista) & 33 & & & & \\
\hline
\end{tabular}

Fuente: elaboración propia. 
En la Tabla 5.28 observamos los resultados de la prueba $W$-Wilcoxon que nos ayudará a comparar el rango medio de las variables y de esta manera determinaremos si existen diferencias entre ellas.

Tabla 5.29.

Resultados de la prueba W-Wilcoxon

\begin{tabular}{llll} 
& $\begin{array}{l}\text { PLON } \\
\text { postest-pretest }\end{array}$ & $\begin{array}{l}\text { RFI fonemas postest- } \\
\text { pretest }\end{array}$ & $\begin{array}{l}\text { RFI palabras postest- } \\
\text { pretest }\end{array}$ \\
\hline$Z \quad-4,427 \mathrm{~b}$ & $-4,938 \mathrm{c}$ & $-4,865 \mathrm{c}$ \\
\hline $\begin{array}{l}\text { Sig. asintótica } \\
\text { (bilateral) }\end{array}$ &, 000 &, 000 \\
\hline a. Prueba de rangos con signo de Wilcoxon & \\
\hline b. Se basa en rangos negativos & \\
\hline c. Se basa en rangos positivos & \\
\hline
\end{tabular}

Fuente: Elaboración propia

En la Tabla 5.29 vemos cómo la Sig. asintótica (bilateral) fue menor de 0.05 en todas las relaciones de las variables, por lo que podemos determinar que exieron diferencias significativas en todas ellas.

En la Tabla 5.30, exponemos los resultados de Kappa de Cohen para las mismas variables que los resultados expuestos en la prueba $W$-Wilcoxon.

Tabla 5.30.

Resultados de la prueba Kappa de Cohen

\begin{tabular}{|c|c|c|c|c|c|}
\hline & Valor & $\begin{array}{l}\text { Error estándar } \\
\text { asintótico (a) }\end{array}$ & $\begin{array}{l}\text { T } \\
\text { aproximada } \\
\text { (b) }\end{array}$ & $\begin{array}{l}\text { Significación } \\
\text { aproximada }\end{array}$ & \\
\hline PLON-R forma pretest- &, 106 &, 082 & 1,504 & &, 133 \\
\hline $\begin{array}{l}\text { postest } \\
\text { RFI fonemas pretest- } \\
\text { postest }\end{array}$ &,- 011 & ,005 &,- 608 & & ,543 \\
\hline $\begin{array}{l}\text { RFI palabras pretest- } \\
\text { postest }\end{array}$ & ,018 & ,030 & ,885 & &, 376 \\
\hline
\end{tabular}

Fuente: elaboración propia.

En la Tabla 5.30 observamos que todos los valores de Kappa de Cohen se situaron en torno a 0 y a 0.2 lo que indica que tenía una intensidad de la diferencia baja. 
Una vez realizado este análisis, en el que comprobamos que sí que existió una mejora en todos los niveles, decidimos realizar un análisis desde la perspectiva cualitativa, para profundizar en los resultados encontrados anteriormente, por ello se analizaron las respuestas de las entrevistas a las logopedas (Tabla 5.31), familias (Tabla 5.32) y maestras (Tabla 5.33).

Tabla 5.31.

Opinión de las logopedas sobre la articulación

\begin{tabular}{|c|c|}
\hline \multirow[t]{4}{*}{$\begin{array}{l}\text { La articulación ha } \\
\text { mejorado }\end{array}$} & $\begin{array}{l}\text { LOGOPEDA 1: Mmmmm Depende del caso, hay casos que } \\
\text { tengo que tiene un retraso del lenguaje, pero en la } \\
\text { pronunciación no tiene ninguna dificultad, hay otro caso en el } \\
\text { que tiene retraso de pronunciación por un problema orgánico, } \\
\text { porque es otra dificultad. Y luego con otra sí que trabajé las } \\
\text { mismas palabras, para trabajar las dislalias, y ahí sí que noté } \\
\text { diferencia. Porque si que íbamos trabajándolo con palabras y } \\
\text { con sílabas, y muchas palabras, al ir conociéndolas } \\
\text { trabajábamos la pronunciación y fue mejorando. }\end{array}$ \\
\hline & $\begin{array}{l}\text { LOGOPEDA 2: ¿Tras la repetición quieres decir por parte } \\
\text { mía? Si, la repetición la he trabajado con ambos, así que sí. }\end{array}$ \\
\hline & LOGOPEDA 4: Mejora progresivamente. \\
\hline & $\begin{array}{l}\text { LOGOPEDA 6: Al principio hacia muchas omisiones de } \\
\text { sílabas, ahora en algunos casos ya dice correctamente la } \\
\text { palabra completa. }\end{array}$ \\
\hline \multirow{2}{*}{$\begin{array}{l}\text { La articulación es } \\
\text { igual en } \\
\text { comparación al } \\
\text { inicio y al final }\end{array}$} & LOGOPEDA 3: Igual, la articulación igual. \\
\hline & $\begin{array}{l}\text { LOGOPEDA 5: Muy mala siempre, no ha mejorado, yo le } \\
\text { entiendo porque le entiendo, ¿cómo va a mejorar si no me } \\
\text { mira? }\end{array}$ \\
\hline
\end{tabular}

Fuente: elaboración propia.

La mayoría de las logopedas opinó que los niños habían mejorado, pero dos de seis opinaron que no habían mejorado o seguía igual. Por otro lado, gran parte de las familias dijeron que los niños habían desarrollado su articulación positivamente, aunque algunas opinaron que no lo suficiente, y un menor número de ellas opinaron que no había existido un desarrollo en este área (Tabla 5.32). 
Tabla 5.32.

\section{Opinión de las familias sobre la articulación}

\section{La articulación ha} mejorado

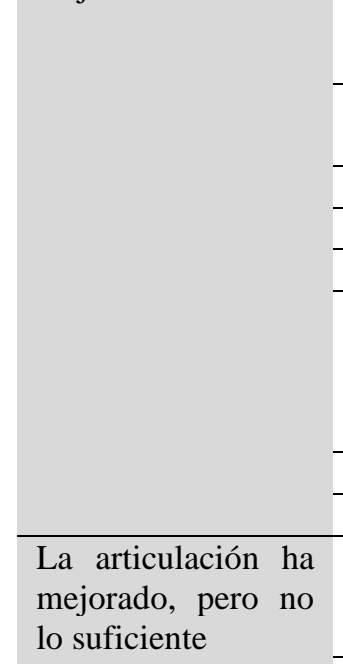

FAMILIA 1: Si, muchísimo, mis padres ahora entienden más al niño; el otro día mi hermana le estuvo cuidando y me lo dijo que se le nota muchísimo. Nosotros nos damos cuenta, pero no tanto como los demás que nos lo dicen.

FAMILIA 5: Si, se le entiende más, yo creo que es en lo que más se le nota.

FAMILIA 7: $\mathrm{Si}$

FAMILIA 11: Ha mejorado bastante.

FAMILIA 12: $\mathrm{Si}$, sí que ha mejorado

FAMILIA 15: Genial, la mejora también se le ha notado, sigue sin decir la $R$ pero nos han dicho que no nos preocupemos, que suelen tardar todos los niños, hay otros niños de su clase que tampoco la dicen.

FAMILIA 16: Si, también se le nota mucho, habla mejor. FAMILIA 17: Si, habla bastante mejor.

FAMILIA 2: Si, pero le queda mucho de mejorar; cuando estamos con sus primos, notamos mucho la diferencia, su primo habla mucho mejor y tiene cuatro meses menos que él.

FAMILIA 3: En este creemos que ha mejorado, pero no mucho, seguimos sin entenderle y ahora que habla más y dice más cosas es más difícil entenderle que antes.

FAMILIA 4: Nuestra hija sigue teniendo su lengua de trapo, pero puff si ha mejorado mucho.

FAMILIA 6: $S i$, pero sigue necesitando mejorar más, no termina de hablar bien.

FAMILIA 8: Si, aunque no tanto como en su lenguaje, sigue equivocándose en muchas letras cuando las dice, ha mejorado más en otras cosas que en eso.

FAMILIA 10: Ha mejorado su articulación también, pero sigue teniendo algún error.

FAMILIA 13: A ver ya es bastante mayorcito, y tenía muchas letras que no decía, ahora son menos, pero sigue teniendo, aun así, sí creo que ha mejorado en este nivel.

No ha mejorado en la articulación
FAMILIA 9: No, seguimos sin entenderle cuando habla.

FAMILIA 14: No lo suficiente, sigue mostrando muchos errores, creo que dice lo mismo mal que al principio.

Fuente: elaboración propia.

La gran mayor parte de las maestras opinaron que había existido un desarrollo en la articulación de los niños que habían utilizado PELEO, y una sola opinón que este desarrollo no había existido (Tabla 5.33). 
Tabla 5.33.

Opinión de las maestras sobre la articulación

\begin{tabular}{|c|c|}
\hline $\begin{array}{l}\text { La articulación ha } \\
\text { mejorado }\end{array}$ & $\begin{array}{l}\text { MAESTRA 1: Muchísimo, mira, antes en la asamblea no } \\
\text { le entendía nada de lo que decía, ahora le entiendo } \\
\text { muchísimo más. }\end{array}$ \\
\hline & $\begin{array}{l}\text { MAESTRA 2: Pues de los dos niños, uno muchísimo, el } \\
\text { otro un poquito menos pero también ha mejorado. }\end{array}$ \\
\hline & $\begin{array}{l}\text { MAESTRA 3: Si, mucho más habla más y también se la } \\
\text { entiende mejor. }\end{array}$ \\
\hline & $\begin{array}{l}\text { MAESTRA 4: Pues... si, definitivamente sí, mira hemos } \\
\text { tenido la actuación de navidad y tenía que decir una frase, } \\
\text { y la diferencia es incréble. Así que me alegro mucho por } \\
\text { eso, la familia también nos lo ha dicho que lo notan. }\end{array}$ \\
\hline & $\begin{array}{l}\text { MAESTRA 5: La articulación sí, es en lo único en lo que } \\
\text { lo he visto mejoría, ha sido una pasada la verdad. }\end{array}$ \\
\hline & MAESTRA 8: $\mathrm{Si}$. \\
\hline & MAESTRA 10: Si, se le entiende mucho mejor. \\
\hline $\begin{array}{l}\text { La articulación ha } \\
\text { mejorado, pero podía } \\
\text { haber mejorado más }\end{array}$ & $\begin{array}{l}\text { MAESTRA 6: Sí, es en lo que más fallaba, sigue } \\
\text { cometiendo errores, y podría mejorar más yo creo, porque, } \\
\text { aunque ha mejorado cuando lo comparo con los demás } \\
\text { pues se le nota esa lengua de trapo que tiene. }\end{array}$ \\
\hline & $\begin{array}{l}\text { MAESTRA 9: Si, ha mejorado mucho en ese sentido, } \\
\text { aunque le queda todavía mucho de mejorar. }\end{array}$ \\
\hline $\begin{array}{l}\text { No ha mejorado en la } \\
\text { articulación }\end{array}$ & $\begin{array}{l}\text { MAESTRA 7: Pues no... pero la articulación estaba } \\
\text { bastante bien yo creo. }\end{array}$ \\
\hline
\end{tabular}

Fuente: elaboración propia.

En general, si examinamos todos los resultados que ya hemos explicado, podemos deducir que los niños que utilizaron PELEO desarrollaron muy positivamente su articulación. Esta mejoría fue mayor en los niños que tuvieron grandes dificultades en esta área, ya que había niños con trastorno del lenguaje que tenían otras dimensiones del lenguaje más afectadas que esta. Algunas familias pusieron de manifiesto la necesidad de continuar con el tratamiento, lo que pone en evidencia que PELEO no fue la solución definitiva, por lo que es necesario continuar durante más tiempo de intervención.

\subsection{6. ¿Cómo ha cambiado la morfosintaxis de los niños que han utilizado PELEO?}

Para dar respuesta a esta pregunta se analizaron los resultados de la lámina 1 del cuaderno de estímulos tres años, cuatro años y cinco años de la Prueba de Lenguaje Oral de Navarra Revisada PLON-R (Aguinaga 
et al., 2004). En dicha lámina aparece un parque, en el que un niño se ha caído del tobogán y un adulto se acerca andando, además hay varios elementos: pájaros, columpios, otros niños realizando otras acciones, la lámina para los niños de tres y cuatro años se observa en la Figura 5.9, y la lámina para los niños de cinco años se observa en la Figura 5.10.

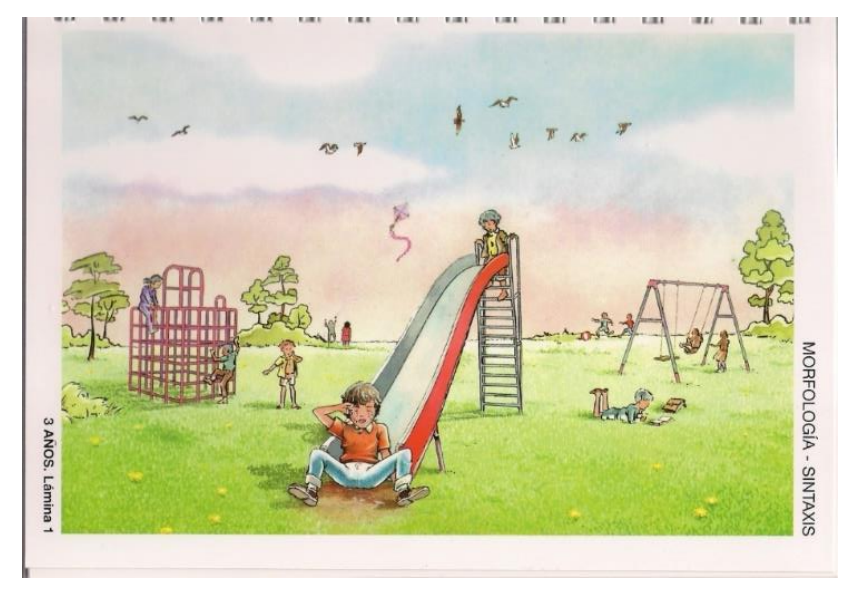

Figura 5.9. Lámina 1 del cuaderno de estímulos tres años, cuatro años. Fuente: Prueba de Lenguaje Oral de Navarra Revisada PLON-R (Aguinaga et al., 2004).

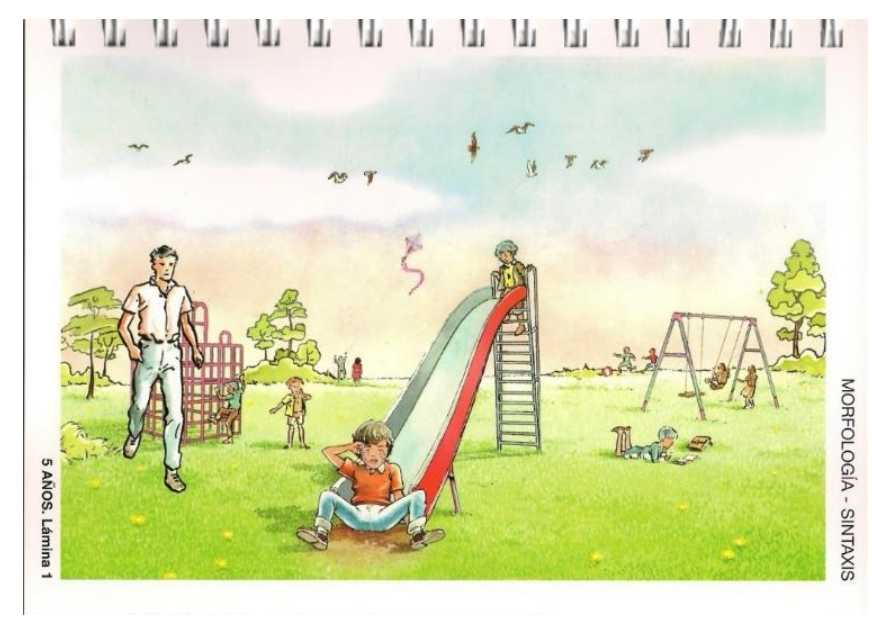

Figura 5.10. Lámina 1 del cuaderno de estímulos cinco años. Fuente: Prueba de Lenguaje Oral de Navarra Revisada PLON-R (Aguinaga et al., 2004). 
Se cuantificó el número de palabras utilizadas en cada frase (longitud media de la frase) y se contabilizó el número de frases realizadas, el resultado del análisis descriptivo se puede observar en la Tabla 5.34.

Tabla 5.34.

Estadísticos descriptivos de las pruebas inicial-final sobre sintaxis

\begin{tabular}{lllllll}
\cline { 3 - 6 } & & $\mathrm{N}$ & Mínimo & Máximo & Media & $\begin{array}{l}\text { Desviación } \\
\text { estándar }\end{array}$ \\
\hline $\begin{array}{l}\text { Cantidad de } \\
\text { inicial }\end{array}$ & oraciones & 33 &, 00 & 3,00 & 1,18 & 1,09 \\
\hline $\begin{array}{l}\text { Cantidad de } \\
\text { final }\end{array}$ & oraciones & 33 &, 00 & 4,00 & 1,87 & 1,07 \\
\hline $\begin{array}{l}\text { Cantidad de } \\
\text { inicial }\end{array}$ & palabras 33 &, 00 & 2,00 & 1,18 &, 644 \\
\hline $\begin{array}{l}\text { Cantidad de } \\
\text { final }\end{array}$ & palabras 33 &, 00 & 6,00 & 2,84 & 1,29 \\
\hline N válido (por lista) & 33 & & & & \\
\hline
\end{tabular}

Fuente: elaboración propia.

En relación con la cantidad de subordinadas que realizaron los niños, en la prueba inicial ningún niño las realizó en la prueba. En cambio, en la evaluación final observamos que 4 de los niños (12.5\%) sí fueron capaces de realizarlo, los cuatro niños tenían cinco años.

Como los datos no tenían una distribución normal, tuvimos que realizar una prueba no paramétrica, empleamos la prueba de Wilcoxon para muestras relacionadas (Tabla 5.35).

Tabla 5.35.

Resultados de la prueba W-Wilcoxon

\begin{tabular}{lll} 
& $\begin{array}{l}\text { Cantidad de oraciones Cantidad de palabras } \\
\text { final - Cantidad de } \\
\text { oraciones inicial }\end{array}$ & $\begin{array}{l}\text { final Cantidad de } \\
\text { palabras inicial }\end{array}$ \\
\hline$Z$ & $-4,119^{\mathrm{b}}$ & $-4,702^{\mathrm{b}}$ \\
\hline Sig. asintótica (bilateral) &, 000 &, 000 \\
\hline a. Prueba de rangos con signo de Wilcoxon & \\
\hline b. Se basa en rangos negativos. &
\end{tabular}

Fuente: elaboración propia.

Como podemos observar en la Tabla 5.35 el nivel de significancia asintótica fue menor a 0.05 por lo que aceptamos que existió una 
diferencia entre la cantidad de oraciones y de palabras que los niños decían al inicio y la cantidad dicha al final.

En la Tabla 5.36, analizamos Kappa de Cohen para valorar la intensidad de esa diferencia, se comprobó que la intensidad de la diferencia fue escasa, pero sí que existió.

Tabla 5.36.

Resultados de la prueba Kappa de Cohen

\begin{tabular}{lrrrrr}
\cline { 2 - 5 } & \multicolumn{3}{c}{$\begin{array}{c}\text { Error estándar } \\
\text { Valor }\end{array}$} & $\begin{array}{c}\text { T } \\
\text { asintóticoa }\end{array}$ & \multicolumn{2}{c}{$\begin{array}{c}\text { Significación } \\
\text { aproximadab }\end{array}$} \\
\hline $\begin{array}{l}\text { Cantidad de oraciones } \\
\text { inicial - cantidad de } \\
\text { oraciones final }\end{array}$ &, 238 &, 097 & 2,862 &, 004 \\
\hline $\begin{array}{l}\text { Cantidad de palabras } \\
\text { inicial - cantidad de } \\
\text { palabras final }\end{array}$ &,- 030 &, 060 &,- 597 &, 551 \\
$\begin{array}{l}\text { a. No se presupone la hipótesis nula. } \\
\text { b. Utilización del error estándar asintótico que presupone la hipótesis nula. }\end{array}$ \\
\hline
\end{tabular}

Fuente: elaboración propia.

Se les pregunta a las logopedas cómo era la sintaxis del niño, y se existió algún cambio durante el proceso, su opinión se puede observar en la Tabla 5.37.

Tabla 5.37.

Opinión de las logopedas sobre la mejora de la sintaxis de los niños que utilizan PELEO

\begin{tabular}{ll}
\hline $\begin{array}{l}\text { Opiniones } \\
\text { positivas }\end{array}$ & $\begin{array}{l}\text { LOGOPEDA 1: Pues depende de cada caso, la verdad es que es } \\
\text { más difícil darse cuenta de esto, yo diría que ha mejorado, pero } \\
\text { tampoco se te decir. }\end{array}$ \\
\cline { 2 - 2 } & $\begin{array}{l}\text { LOGOPEDA 2: Pues no estoy segura de que decirte sobre esto, yo } \\
\text { creo que sí que ha mejorado en ese aspecto, aunque no era un } \\
\text { aspecto en el que tuviera que mejorar tanto. }\end{array}$ \\
\cline { 2 - 2 } & $\begin{array}{l}\text { LOGOPEDA 6: Ha mejorado en este aspecto pues dice frases más } \\
\text { largas que antes no hacía. }\end{array}$ \\
\cline { 2 - 2 } & LOGOPEDA 4: Ha mejorado. \\
\hline Opiniones & LOGOPEDA 3: Yo creo que igual \\
\cline { 2 - 2 } negativas & LOGOPEDA 5: Pues mal como todo, es que es muy inatento no \\
& mira y asíno se puede. \\
\hline
\end{tabular}

Fuente: elaboración propia. 
En la Tabla 5.37 hallamos información muy dispar sobre este aspecto, pero hay una predominancia de resultados positivos. Además, desde la lista de control verificamos las situaciones de expresión sintáctica que aparecen, y solo encontramos tres situaciones de expresión sintáctica negativa y ninguna observación sobre expresión sintáctica positiva:

- He sacado las láminas, se reía y decía solo una palabra (un verbo), no hacía la frase correspondiente, el verbo podía ser el adecuado para utilizar con la lámina, pero no realizaba la frase completa (Participante P3-4_lista de control_PP5).

- Dice solo onomatopeyas, y a veces una palabra unida a una onomatopeya, es difícil comprenderle, hay veces que la onomatopeya se corresponde al animal que está viendo, por ejemplo, y apoya esa comunicación con gestos (Participante P31_lista de control_PP1).

- Ha hablado mucho, sobre la operación que la han hecho, y habla en futuro de la operación, no conjuga bien los verbos, no habla y no se expresa tanto con las láminas como lo ha hecho hablando sobre este tema. (Participante P4-9_lista de control_PP5).

El comentario del participante P3-4, podía ser debido a sus dificultades en su motivación y a los problemas de conducta que manifestaba, ya que no se aprecia ese comportamiento en otras observaciones; en el segundo comentario observamos cómo el participante decía onomatopeyas y gestos apoyándose en ellas para complementar sus dificultades en la sintaxis; y por último, observamos problemas en las formas verbales.

Por lo que, tras la exposición de los resultados obtenidos, podemos decir que PELEO ayudó a ampliar la sintaxis de estos niños, aunque seguían presentando dificultades en este sentido; lamentablemente no es un área en el que las logopedas hayan trabajado expresamente durante el periodo valorado, pero consideramos que se trata de una dimensión que hay estimular más.

\subsection{Discusión de los resultados del segundo estudio: PELEO}

En este apartado vamos a hablar sobre este Estudio de Caso Evaluativo, en el que valoramos el diseño y la utilización de PELEO. Se va a dividir este epígrafe en dos subapartados, uno que trata sobre el diseño de PELEO para estimular el lenguaje de niños con trastorno del 
lenguaje de tres a cinco años, y otro en el que se discuten los resultados relativos a la utilización de PELEO con esta misma población.

Teniendo en cuenta los enfoques de intervención del lenguaje que explican DeVeney et al. (2017), podemos determinar que nuestro programa es de tipo "estimulación focalizada del lenguaje" ya que nos centramos en enseñar una serie de PowerPoints y láminas enseñando vocabulario, y a través de estimular a los niños a través de diversos estímulos en la forma, el contenido o el uso, hemos logrado que mejoren el resto de las dimensiones del lenguaje (Acosta, 2012b). Si tenemos en cuenta los enfoques explicados por Schwartz (2017), podemos decir que PELEO tiene un enfoque de estimulación centrada en el niño. PELEO tiene unas fases y una estructura clara que se repite en cada sesión, esto ayuda a los niños ya que, según las afirmaciones de Khamis-Dakwar (2014), cuando la enseñanza es constante y predecible resulta más eficaz que cuando se están variando las condiciones de aprendizaje y la práctica difiere.

\subsubsection{El diseño de PELEO para estimular el lenguaje de niños con trastorno del lenguaje de tres a cinco años}

En esta investigación se han estudiado distintos aspectos del diseño de PELEO, como son la cantidad, el orden y el tipo de vocabulario utilizado, las actividades y la motivación de los niños durante estas actividades,

La adquisición de un vocabulario básico constituye el pilar fundamental para la gran mayoría de los hablantes tardíos, este pilar será sobre el que después se fundamente el sistema lingüístico. Así pues, la adquisición del vocabulario es clave para activar otros componentes lingüísticos y para el progreso escolar del alumnado con trastorno del lenguaje (Mendoza, 2016; Marulis \& Neuman, 2010); además, el léxico es un elemento más dentro de la interacción social (Gómez, 2019). No hay que perder de vista que los niños con trastorno del lenguaje tienen grandes dificultades para recordar palabras dentro de un listado (Mainela \& Evans, 2005), por lo que precisamos profundizar en el diseño del vocabulario utilizado en PELEO para saber si es adecuado o no y, así, emplearlo con esta población.

Los resultados encontrados respecto a la cantidad de las palabras nos explican que se enseña a los niños alrededor de 20-21 palabras cada día. Observamos que los niños escuchan muchas más palabras cada día, y que la frecuencia con la que escuchan los niños las palabras, en especial 
los sustantivos, está directamente relacionada con las palabras que ellos adquieren, junto a otros factores (Goodman et al., 2008); por ello, no es de extrañar que, autores como Wright et al. (2018), utilicen listados existentes de las palabras más frecuentes para emplearlas en niños con trastorno del desarrollo del lenguaje, tal y como se ha realizado en este estudio, y que se tienda a repetir esas palabras con frecuencia con el objetivo de que las aprendan. Además, el proceso de aprendizaje del vocabulario parte del almacenamiento y procesamiento de las diferentes palabras, que es lo que posibilita una posterior producción (RodríguezMontes, 2020); por lo que es importante que este número sea un número manejable de palabras. En nuestro estudio, consideramos que enseñar 20-21 palabras es una cantidad razonable, teniendo en cuenta que nuestra muestra se sitúa entre los 3 y los 6 años, que a los tres años los niños son capaces de manejar unas mil palabras y a los seis años la mayoría de los niños tiene un vocabulario de entre quince mil y dieciocho mil palabras (Aparicio e Igualada, 2019).

Si nos centramos en la cantidad media de las palabras que desconocen los participantes (los niños de tres años desconocen entre 6.45 y 14.55 , los niños de cuatro años desconocen entre 4.35 y 6.50 y los niños de 5 años desconocen entre 2.75 y 5.70 palabras), por lo que pretendemos que aprendan estas palabras desconocidas en la sesión.

Por otra parte, los niños con retraso del lenguaje tienen dificultades para aprender palabras en comparación con sus compañeros sin dificultades (Wright et al. 2018). Si estudiamos el número de palabras que aprenden los niños observamos una gran disparidad en las publicaciones: una o dos palabras después de 10 horas de intervención (Spencer et al, 2017), dos palabras después de 18 horas (Lubliner \& Smetana, 2005) y cuatro palabras después de 30 horas (Snow et al. 2009). El estudio de Molina (2001), citado en Mohedano (2004), indica que pueden llegar a aprender entre 600 y 800 palabras cada año. En nuestro estudio les estamos pidiendo que aprendan entre 2 a 7 palabras en la sesión, pero esas palabras se utilizan durante toda la sesión, lo que se traduce en muchos ensayos y producciones por nuestra parte y por la suya. Según Gray (2003), los niños con TDL de 4 y 5 años requieren una media de 27 ensayos para comprender una nueva palabra y 49 para producirla, mientras que los niños con desarrollo típico necesitaban solo 13 y 24 ensayos, respectivamente, por lo que realizar tantos ensayos en las distintas fases, es una buena elección de diseño para PELEO. Algunos niños con trastorno del lenguaje tienen mayores dificultades que otros para comprender esas palabras (Mainela \& Evans, 2005), por lo que sería conveniente que los niños que tengan aún más dificultades puedan 
ensayar más con las palabras que desconocen, para aumentar los ensayos y, por lo tanto, la comprensión (Gray, 2003).

Iruela (2002) determina que la cantidad de vocabulario que aprenden los niños depende de la manera en la que sea enseñado, de los intereses del individuo y del tiempo disponible. Para observar esos intereses, hemos analizado las conductas asociadas a motivación positiva y negativa en las sesiones con más y con menos palabras desconocidas y observamos conductas parecidas en ambos tipos de sesiones; por lo que no creemos que sea determinante para la motivación de los niños. Además, también encontramos opiniones de las logopedas muy diferentes sobre cómo ha sido la motivación de los niños durante las diferentes fases de PELEO, por lo que al no tener un resultado claro en este sentido, queremos destacar la importancia de realizar intervenciones individuales acordes a las características de cada sujeto (González-Picarín y CalzadillaGonzález, 2015) y tener en cuenta la cantidad de palabras desconocidas para cada niño, y de esta manera poder repetir el PowerPoint un día más o no, para poder atender a estas características.

Respecto al orden, existen varias posibilidades de enseñar vocabulario a los niños, podemos enseñar primero palabras fáciles, objetos del entorno del alumno, palabras con etiología común..., y posteriormente las más difíciles que son las que indican nociones abstractas o cuya explicación es difícil a través de ilustraciones o de mímica (Iruela, 2002); otros autores proponen comenzar por significados básicos y continuar por conceptos metafóricos y especializados (Morante y Martí, 2002), o incluir las palabras según la frecuencia de utilización y escucha (Molina, 2001, citado en Mohedano, 2004; Wright et al. 2018). El diseño del orden de las palabras de PELEO se realizó según la frecuencia de utilización y escucha, y autores como Molina (2001), citado en Mohedano (2004) y Wright et al. (2018), apuestan por ello; según la opinión de las logopedas de nuestro estudio esta opción es correcta, por lo que opinamos que es adecuado el diseño en cuanto al orden de presentación de las palabras.

Con lo que respecta al tipo de vocabulario que se ha utilizado, podemos decir que la respuesta es diferente teniendo en cuenta la edad de los niños, pero hay una serie de constantes: los niños presentan menores dificultades en las categorías de transportes, medioambiente y partes del cuerpo en todas las edades; esto puede ser debido a que son las palabras más comunes para ellos y además aprenden antes el nombre de los objetos que se mueven que los inmóviles (Gleason \& Ratner, 2010; Sentis et al., 2009). 
Mendoza (2016) recomienda seleccionar el siguiente léxico básico para intervenir con los niños con TDL, (consideramos de utilidad también para los niños con RL); palabras concretas que nombren objetos o acciones específicas; nombres de objetos y personas familiares; nombres de animales y mascotas; verbos; adjetivos para describir objetos y personas; palabras relevantes cultural y socialmente. Si lo comparamos con las categorías que hemos incluido nosotros, vemos que nosotros no hemos incluido verbos que denoten acciones específicas, pero sí que hemos incluido nombres de objetos, personas familiares y animales. Por lo que estas categorías sí que pueden ser adecuadas enseñárselas y, además, podemos observar que el porcentaje de palabras conocidas es mayor en estas categorías que en la de conceptos abstractos, de tiempo y de cantidad.

En este sentido, otra constante que observamos es que existe una mayor dificultad en los conceptos abstractos, los lugares y los conceptos de tiempo, esto puede deberse a que los niños con trastorno del lenguaje tienen grandes dificultades para asimilar los conceptos abstractos (colores, formas, tamaños) además de los conceptos espacio-temporales (Alegre y Pérez, 2008), sabiendo de que es a partir de los seis años cuando comienzan a tener claros estos conceptos (Díaz-Villafáñez, 2016), y la muestra presentada es de niños de tres a seis años. Por lo que, teniendo en cuenta el proceso de aprendizaje del lenguaje, es común que tengan dificultades en este tipo de palabras (Querejeta, 2016), y sabiendo que no están preparados para aprender este tipo de palabras, quizás sería más conveniente eliminarlas del diseño.

Las logopedas explican que los niños tienen grandes dificultades en los conceptos abstractos, de tiempo (los meses), y explican que la causa puede deberse también a la dificultad de interpretar este tipo de palabras en una imagen de ARASAAC. Esta dificultad también la observamos cuando analizamos las respuestas de las palabras que desconocen en esas categorías. Se eligen las imágenes del ARASAAC pues varios artículos (Cabello y Mazón, 2018; Cabello y Bertola, 2015; Paolieri, \& Marful, 2018) demuestran que son símbolos icónicos y de utilidad para el aprendizaje del lenguaje de los infantes. Hübscher \& Prieto (2019) afirman que para comprender el lenguaje abstracto no inferencial es esencial un apoyo visual, por lo que a priori, nos pareció una buena idea utilizar los símbolos del ARASAAC para trabajar estos conceptos que aparecían en el listado de CHIEDE. Ponari et al. (2018) explican que las palabras abstractas que los niños aprenden pronto suelen tender a tener un valor emocional, y la manera en la que enseñamos estas palabras no implica que la enseñanza de estas palabras conlleve ese alto valor emocional. 
En referencia al resto de categorías observamos que cuando se equivocan en estas puede ser por sobreextensión (Nelson, 1988), que es algo común en el desarrollo evolutivo de los niños. También denominan las palabras según su uso en vez de decir la palabra en sí, por el desconocimiento de la palabra; además de decir una palabra similar o de uso parecido. Lo que hacen los niños es tener en cuenta el conocimiento que comparten con el receptor para elaborar un punto de partida, y de esta manera explicar a la logopeda lo que es el objeto que están viendo (Seibel y Jiménez, 2009); por lo que podemos afirmar que los niños desconocían algunas de esas palabras, pero sí que han comprendido lo que representa la imagen de ARASAAC.

Teniendo en cuenta las anteriores consideraciones, nos encontramos en disposición de responder a la pregunta que nos propusimos al principio: ¿cómo es el diseño de PELEO en relación con la cantidad, el orden y el tipo de vocabulario que se ha utilizado?, y podemos decir que es adecuado, pero que es conveniente eliminar las palabras relacionadas con conceptos abstractos, de tiempo y de cantidad. Y es importante diseñar la posibilidad de repetir el PowerPoint durante más de un día en caso de que la logopeda lo considere necesario, ya que cada niño desconoce unas palabras diferentes y de esta manera tendremos en cuenta las características individuales del alumno, y lograr una mayor individualización del programa.

La segunda pregunta que nos planteábamos era ¿cómo es el diseño de PELEO en relación a las actividades y la motivación de los niños?, podemos determinar que las actividades lúdicas son las actividades más motivantes para los niños (que son las que se corresponden a la fase 2 del programa), aunque las actividades de repetición también lo pueden llegar a ser (fase 1 y 3), en menor medida. La opinión de las logopedas no es unánime, todas refieren que es mayor la motivación de los niños ante actividades lúdicas que en actividades de repetición que es la opción esperada (Pérez-Bernal, 1997); excepto dos de ellas que explican que su motivación es baja en ambas actividades, las dos refieren que es debido a problemas de atención y su nivel de activación, que son dos de los problemas que presentan los niños con RL y TDL (Buiza-Navarrete $e t$ al., 2007), por lo que esa dificultad en la motivación sería atribuida a variables internas como dicen Castejón et al. (2005) en su estudio. Esto también lo podemos ver en las observaciones encontradas en las listas de control relacionadas con la motivación de los niños, en los que tres participantes siempre muestran una motivación negativa. Los niños con trastorno del lenguaje suelen tener dificultades en las funciones 
ejecutivas (Riccardi-León et al., 2018), y los niños que tienen estas dificultades suelen tener problemas en su comportamiento y conducta (Lepe-Martínez et al., 2017). Este puede ser el motivo de las conductas mostradas en las sesiones de intervención de estos niños.

En los vídeos observamos una gran cantidad de citas codificadas como motivación positiva durante las actividades lúdicas, por lo que podemos determinar que utilizar el juego para reforzar el aprendizaje del lenguaje es una buena opción (Jarvinen, 2007; Miller, 2008), y por lo tanto las actividades de la Fase 2 están bien diseñadas. También existen citas categorizadas como motivación positiva durante la Fase 1 y 3, por lo que a priori también podría ser una opción que motivase a los niños. De las Heras y García (2015) opinan que las actividades de repetición pueden ser una buena opción para intervenir la articulación de los niños con TDL. Aun así, existen más citas codificadas como motivación negativa durante las actividades de repetición (Fase 1 y 3 ) que en las actividades lúdicas (Fase 2), por lo que podemos determinar que se debe buscar un elemento motivante para ampliar esta, ya que la motivación es básica para lograr un aprendizaje óptimo (Lieury \& Fenouillet, 2016). El acceso al aprendizaje lúdico, desarrollado en ambientes educativos, es un derecho irrenunciable para aprender (Saneleuterio et al., 2019), por lo que realizar actividades motivantes en estos niños se convierte en sencial ya que los niños con TDL suelen tener manifestaciones emocionales negativas (Ibáñez-Rodríguez et al., 2021).

Por lo que, respondiendo a la pregunta formulada inicialmente, podemos decir que las actividades son motivantes, aunque son más motivantes las actividades relacionadas en la Fase 2, que las actividades realizadas en la Fase 1 y 3 . Teniendo todo esto en cuenta, es necesario variar las actividades de la Fase 1 y 3 añadiendo alguna estrategia motivacional para que estas actividades sean más motivadoras para los niños.

\subsubsection{Utilización de PELEO con niños con trastorno del lenguaje de tres a cinco años}

Una vez explicado el diseño de PELEO, y evaluado minuciosamente cada apartado, es conveniente hacer lo mismo con la utilización del programa, para de esta manera discurrir qué efectos tiene su uso sobre los participantes del estudio. Para realizar esta discusión, vamos a seguir el mismo orden presentado en los resultados, y responderemos a todas las preguntas formuladas anteriormente: ¿cómo ha cambiado el vocabulario, la articulación y la morfosintaxis de los niños que utilizan 
PELEO? Una constante en todos los resultados encontrados es que la posibilidad de que los niños evolucionen de manera espontánea sin realizar una correcta o ningún tipo de estimulación existe (Abad et al., 2009). Esto no quiere decir que el planteamiento de esperar y ver si los niños mejoran espontáneamente sea adecuado, al contrario, es obsoleto (Singleton, 2018), pero sí que quiere decir que estos resultados hay que tomarlos con cuidado, y si en un futuro se desea valorar el programa es necesario realizar un diseño cuasiexperimental con grupo postest, y centrarnos en conocer el programa en este estudio, para mejorarlo.

Como el planteamiento de esperar y ver es inadecuado (Singleton, 2018), es fundamental realizar una buena actuación ya que es importante una estimulación del lenguaje temprana para el desarrollo del lenguaje expresivo adecuado (Fisher, 2017), y por lo tanto es importante conocer y evaluar en profundidad la utilidad de los programas como puede ser PELEO. Pero sí que hay que tomar con cautela los resultados presentados. Para paliar esta paradoja, se ha realizado una triangulación observando los resultados desde técnicas de investigación diferentes, analizando las diferentes preguntas desde distintos puntos de vista.

La primera pregunta que nos formulábamos en cuanto a la utilización de PELEO era ¿cómo ha cambiado el vocabulario de los niños que han utilizado PELEO? Determinamos que el aumento del léxico en niños con trastorno del lenguaje que reciben terapia está altamente demostrado (Moreno et al., 2012; Motsch \& Ulrich, 2012), este aumento también lo podemos encontrar en nuestro estudio, tal y como observamos en los resultados de la prueba $W$-Wilcoxon. Profundizamos sobre este aspecto preguntando a las logopedas sobre si los niños generalizaban el uso de las palabras aprendidas. Su opinión es muy dispar, aunque en general es positiva. Una de las logopedas pone de manifiesto la necesidad de una colaboración por parte de la familia para lograr una mayor generalización del léxico. Según Escorcia-Mora et al. (2016) los padres y los cuidadores de los niños tienen una misión especial en el desarrollo del lenguaje de los niños, ya que se sabe que cuando los niños se encuentran en entornos competentes en estímulos, se multiplican las posibilidades de aprendizaje del lenguaje en los niños.

Existen muchos estudios que valoran el papel de la familia en la intervención de las dificultades del lenguaje (Benitez y Domeniconi, 2014; Gortmaker et al., 2007); pero al contrario que lo que opinaban los críticos del Método Doman sobre la idoneidad de la función rehabilitadora que ejercen los propios padres, debido a las altas demandas a las familias del método y de la posibilidad de descuidar otras 
necesidades familiares, y que aumentara la ansiedad de unos padres agobiados y confundidos (American Academy for Cerebral Palsy et al., 1968), actualmente lo que más preocupa es que las familias no se involucran lo suficiente (Stocco \& Thompson, 2015). Si las familias se involucraran lo suficiente podría ser una buena solución para paliar la dificultad que explica una de las logopedas, en las que cuenta que con dos sesiones no es suficiente para lograr una generalización del léxico, ya que la calidad de la intervención se multiplicaría gracias a la acción de las familias en sus hogares (Escorcia-Mora et al., 2016). Por otro lado, la opinión de las familias es muy positiva siendo todos los comentarios favorables en relación al aumento del vocabulario, con la excepción de cinco familias que están indecisas respecto al efecto de PELEO en la semántica de sus hijos. Pero estas familias no manifiestan que la semántica de sus hijos sea exactamente igual que en el inicio de la intervención, sino que muestran dificultades para responder a esas preguntas; por lo que podemos afirmar que en todos los sentidos y desde las tres perspectivas (pruebas estandarizadas, opinión de las logopedas y opinión de las familias) la semántica de los niños ha mejorado. Estos resultados no son nuevos, sino que confirman lo que ya está demostrado: que la intervención logopédica focalizada es eficaz en los niños con TDL (Ellis et al., 1993; Lederer, 2001).

La segunda pregunta sobre la utilización de PELEO, es ¿cómo ha cambiado la articulación de los niños que han utilizado PELEO? Los niños con trastornos fonológicos que reciben intervención logopédica suelen lograr articular fonemas que anteriormente no decían o que no realizaban correctamente (Cervera-Mérida y Ygual-Fernández, 2003). En este sentido, no extraña que los resultados estadísticos de esta tesis sean positivos y determinemos que los niños que utilizan PELEO mejoran su nivel fonético-fonológico. Sin perder de vista que algunas actividades realizadas son actividades de repetición, De las Heras y García (2015) opinan que las actividades de repetición pueden ser una buena opción para intervenir la articulación de los niños con TDL.

Es muy importante valorar esta estimulación en los programas de los niños con trastorno de lenguaje, ya que, según Andreu-Barrachina et al., (2014), los niños con trastorno del lenguaje con dificultades en el nivel fonético presentan menos verbalizaciones, articulan correctamente menos consonantes y vocales y tienen un habla más ininteligible que los niños de su edad. Por ello es importante comprender qué tipo de mejoría ha existido y en qué fonemas ha ocurrido. Los fonemas se adquieren gradualmente (Perelló, 1990) y existe una gran variabilidad intrapersonal, esto significa que un mismo sonido a veces se produce de 
forma correcta y otras veces de forma incorrecta. Para realizar la evaluación de esta estimulación, se analizaron los resultados del Registro Fonológico Inducido en tres edades (tres años, cuatro años y cinco años). Entre un 1 y un $11 \%$ cometen errores en los fonemas $/ \mathrm{b} /, / \mathrm{p} /, / \mathrm{f} /, / \mathrm{d} /, / \mathrm{t} /$, /l/ y /n/ (Perelló, 1990), y algunos de esos fonemas son en los que más mejoran los niños utilizando PELEO, por ejemplo, los niños de tres años mejoran un $45.55 \%$ en el fonema /b/, o un $36.36 \%$ en el fonema /f/. Andreu-Barrachina, et al. (2014) explican cómo los niños con TDL tienen mayores dificultades en los fonemas $/ \mathrm{d} /, / \mathrm{l} / \mathrm{y} / \mathrm{r} /$, en las oclusivas nasales y en las semiconsonantes. En nuestros resultados, en cambio, comprobamos que solo tienen dificultad en el fonema /d/ los niños de tres años y no existe una mejoría en este fonema, y en cambio los niños de cuatro y cinco años no muestran dificultades en las palabras que incorporan el fonema /d/. Pero sí que observamos dificultades en los fonemas /l/ y /r/, encontrando una leve mejoría al utilizar PELEO. En general, no observamos una mayor mejoría en los fonemas que los niños comienzan a articular más temprano, que son los fonemas nasales y oclusivos áfonos, ni menores resultados en los fricativos y róticos que son los que articulan más tarde (Susanibar, et al., 2013; Torres, et al., 2016), por lo que parece que a priori, en nuestra muestra el periodo de adquisición de los fonemas no es determinante para lograr una mejora en estos.

Además de comprobar la mejoría en los estadísticos cuantitativos de las pruebas y en el análisis del Registro Fonológico Inducido, encontramos que la opinión de las logopedas también es muy positiva, todas menos dos advierten que existe una mejoría en la articulación de los niños tras utilizar PELEO. Una de ellas, señala que la mejoría es mayor en los niños que tienen más dificultades en el área fonológica, no hay que olvidar que hace años se dividía a los niños con TDL en diferentes subgrupos, y uno de ellos eran niños que tenían mayores dificultades fonético fonológicas, y estos niños se caracterizaban por presentar un conjunto restringido de sonidos del habla, además de presentar un vocabulario limitado, denominando estas palabras con una sola sílaba, teniendo una persistencia de errores fonéticos y fonológicos más allá de la edad apropiada para cometer esos errores (Mendoza, 2006). Actualmente no se realiza esta división, ya que seguimos la división realizada por el DSM-V y por el CIE-11, pero es conveniente no olvidar que algunos niños tienen mayores dificultades en esta área que otros diagnosticados de trastorno del lenguaje, por lo que estas logopedas en sus comentarios realizan estas diferenciaciones. Una de las dos logopedas que opinan de manera negativa sobre la mejora de los niños en este aspecto dice que el niño que ella atendía era inatento, y no era capaz de mejorar en su 
articulación -ni en nada más, como dice ella misma-. Los niños con trastorno del lenguaje tienen dificultades en algunas funciones ejecutivas como puede ser la memoria y la atención, por lo que no es tan extraña esta opinión (Ahufinger et al., 2021). Una atención adecuada es muy importante para poder llevar a cabo un correcto desarrollo de un aprendizaje (Moraine, 2014), como puede ser el aprendizaje del lenguaje o de la articulación. Pero quizás, como en el apartado anterior, es conveniente mejorar la motivación del niño para quizás ampliar esta atención, ya que ambas, motivación y atención, son condiciones imprescindibles para lograr un correcto aprendizaje (Lozano-Fernández et al., 2020).

Si nos fijamos en la opinión de las familias sobre este aspecto, podemos determinar que un gran número de familias opinan que sus hijos han mejorado, pero no lo suficiente, todos ellos hacen hincapié en que quieren más intervención. Hay que explicar que esta intervención ha sido gratuita para ellos, y quizás es un sesgo para solicitar más intervención gratuita, ya que según Nye et al, (1987), entre las primeras 4-12 semanas de intervención logopédica es donde se producen más avances en los niños y a partir de la $13^{\mathrm{a}}$ semana los beneficios disminuyen. Además, según Alt et al. (2020), no se encuentran diferencias significativas teniendo en cuenta el número de sesiones semanales, por lo que tampoco existe evidencia científica que explique que sea mejor aumentar las sesiones semanales de dos semanales a tres o más. Aunque es cierto, que según Khamis-Dakwar (2014) más terapia es siempre mejor. Dos familias opinan que sus hijos no han mejorado en su articulación, pero es una minoría, teniendo en cuenta la cantidad de ellas que opina que sí ha mejorado.

Teniendo en cuenta todo lo presentado anteriormente, podemos concluir que la utilización de PELEO supone una mejora en la articulación de estos niños, aunque hay que valorar si es conveniente aumentar las sesiones para que sea aún más eficaz en este aspecto, e incluir alguna característica que resulte más motivante en la intervención.

La tercera y última pregunta sobre la utilización es ¿cómo ha cambiado la morfosintaxis en los niños que han utilizado PELEO? Los niños con trastorno del lenguaje tienen mayores dificultades sintácticas que los niños normotípicos, tal y como afirman otros autores como AndreuBarrachina et al. (2014); Law et al. (2019); Del Valle et al. (2018). Según Parada-Salazar (2019), para evaluar la morfosintaxis de los niños podemos tener en cuenta información cualitativa como puede ser: los 
términos de funciones sintácticas, las características morfológicas de las palabras que utilizan, los tipos de oraciones, o los tipos y la frecuencia de los errores producidos. Por otra parte, además, también se puede tener en consideración información cualitativa entre la que incluimos: el promedio de la longitud de los enunciados, el índice de la complejidad sintáctica, los índices de gramaticalidad... Nosotros decidimos analizar la cantidad de oraciones y la longitud de la frase (cantidad de palabras), además de conocer la opinión de las logopedas sobre el tema, y de estudiar las observaciones de las listas de control.

Al revisar los resultados encontrados en los estadísticos, comprobamos que existe una diferencia significativa entre los resultados encontrados al principio y al final de la intervención, por lo que los niños que utilizan PELEO han mejorado su sintaxis. Como en nuestra investigación, el estudio de Acosta et al. (2020) realiza un programa con el objetivo de mejorar la sintaxis de los niños y consigue que los niños obtengan esa ganancia. También en el Plan de Estimulación del Desarrollo Narrativo (EDEN) (Pavez et al. 2008) se consiguen resultados positivos. Comprobamos que la longitud de la frase es menor al inicio del tratamiento que al final, esto ha podido mejorar al utilizar frases $\mathrm{y}$ realizar tantos ensayos durante las sesiones, ya que según AguilarMediavilla et al. (2007) los niños con TDL tienen dificultades y suelen omitir palabras función, y si hemos realizado frases que las incluyen han podido aumentarlas, lo que ha incrementado el número de palabras. Es adecuado el diseño de PELEO en este aspecto ya que se ha expuesto a los niños a una gran cantidad de ensayos de frases y se les ha repetido la frase en más de una ocasión. Sabemos que los niños con trastorno del lenguaje requieren una media de 60 a 120 exposiciones a una característica gramatical antes de aprender a utilizarla espontáneamente (Camarata et al., 1994).

Cabe destacar las respuestas dadas por las logopedas ya que todas ellas tienen una opinión positiva, a excepción de una de ellas que vuelve a mencionar que el niño es inatento, y como hemos visto anteriormente, la atención es un elemento condicionante para el aprendizaje (LozanoFernández et al., 2020). Por otro lado, algunas logopedas comentan que es más difícil darse cuenta de manera subjetiva de esta mejoría. Es posible que tampoco se hayan fijado en esta mejoría ya que PELEO tiene como objetivo aumentar todas las dimensiones del lenguaje, y no es como algunas otras aplicaciones y/o herramientas diseñadas exclusivamente para mejorar la sintaxis de los niños con trastorno del lenguaje (eg. Crisol et al., 2015), por lo que quizás es conveniente añadir alguna estrategia metodológica que aumente la sintaxis de los niños. 
Si observamos los resultados de la lista de control, encontramos que los niños cometen errores gramaticales, no utilizando la forma verbal correcta. Esto puede deberse a que los niños adquieren primero los significados y después empiezan a asumir reglas gramaticales, como los procedimientos de formación de plurales, conjugaciones verbales (como es la conjugación verbal del pasado que la confunde por el futuro en este caso) (Anaya-Reig y Calvo, 2019). En estas observaciones también encontramos cómo un participante utiliza una sola palabra unida a un gesto o a una onomatopeya; esto es más propio de los niños de dos años (Bermeosolo, 2016), no de los niños de tres años, que es lo que tiene este niño en cuestión.

Teniendo en cuenta todo lo comentado, podemos decir que los niños mejoran su sintaxis utilizando PELEO, aunque es conveniente en un futuro realizar un estudio sintáctico con mayor profundidad, para observar otras variables como la existencia de subordinadas, el índice de complejidad sintáctica (Parada-Salazar, 2019). Podemos confirmar que mejora la longitud media de la frase y la cantidad de oraciones realizadas. Aun así, es conveniente añadir más ensayos de una categoría gramatical concreta, para aumentar la práctica de la expresión y la comprensión de esta (Bahamonde et al., 2021).

Como conclusión, consideramos que en general el diseño de PELEO es adecuado, no siendo preciso hacer cambios sustanciales a la estructura del programa, pero sí mejorar algunos aspectos descritos anteriormente, y que recogemos también en el capítulo siguiente. 


\section{Capítulo 6}

\section{Conclusiones, limitaciones y líneas futuras}

Una vez descrita la interpretación de los resultados y su discusión, vamos a desarrollar en este apartado las conclusiones de la tesis doctoral, y una serie de recomendaciones con el fin de mejorar PELEO para su utilización con los niños con trastorno del lenguaje, nos gustaría recalcar que cuando nos referimos a niños con trastorno del lenguaje, nos referimos a niños que presentan Trastorno del Desarrollo del Lenguaje y que presentan habla tardía. Vamos a desarrollar y fijarnos en cada uno de los objetivos generales, sin perder de vista los específicos, para elaborar las conclusiones de esta tesis doctoral. Para finalizar, se van a detallar las limitaciones y las futuras líneas de investigación, que abrirán la posibilidad de continuar con esta investigación, enriqueciendo a la comunidad científica con ella.

\subsection{Conclusiones}

En relación con el primer objetivo general de la tesis doctoral, podemos concluir que hemos diseñado de manera correcta el programa, teniendo en cuenta las debilidades del uso de los bits de inteligencia de Glenn Doman con los niños con trastorno del lenguaje ya que, según la bibliografía encontrada, no tiene una gran evidencia científica y, además, el programa no era del todo eficaz con estos niños, aunque sí que parecía que incrementaba la articulación de los niños que lo utilizaban. Encontramos grandes debilidades al programa tal y como estaba diseñado inicialmente:

- Era un programa que se limitaba exclusivamente a la repetición y no integraba el nuevo vocabulario en frases o en un contexto, por lo que consideramos que era más adecuado mejorar este aspecto. 
- Las palabras presentadas no parecían ser las adecuadas, ya que muchos de los niños las conocían con anterioridad, por lo que era conveniente hallar el conjunto de palabras adecuadas.

- Según la bibliografía, y tal y como lo marcaba Doman, el método de utilización de los bits era muy estricto para las familias.

De esta manera cumplimos el objetivo específico: comprobar la eficacia de los bits de inteligencia del Método Doman en los niños con trastorno del lenguaje y valorar si son útiles para el nuevo programa que vamos a crear, ya que los resultados encontrados y la bibliografía consultada no recomendaba su uso para lograr una mejora global de todas las dimensiones del lenguaje de los niños con trastorno del lenguaje. Esta conclusión, ha supuesto una gran aportación no sólo al ámbito logopédico, sino también al ámbito de la educación infantil; ya que sabemos que actualmente en muchas escuelas infantiles de España se utiliza este programa con el fin de mejorar el lenguaje de estos niños; y con nuestros resultados, y con la información facilitada en el marco teórico de esta tesis, podemos determinar que esta práctica educativa no es correcta, pudiendo mejorarla y eliminar esta de las escuelas.

En esta tesis doctoral se tuvieron en cuenta dichas dificultades y se plantearon seis propuestas para diseñar PELEO, que son las siguientes: a) mantener las láminas de los bits de inteligencia; b) incluir estas palabras dentro de un contexto comunicativo; c) cambiar el tipo de palabras que se utilizan; d) pedir a los niños que realicen interacciones, no solo que escuchen y e) eliminar la participación directa con las familias. Después de analizar todas estas propuestas, escogimos el nuevo vocabulario de PELEO, utilizando las palabras más escuchadas y que más veces dicen los niños de tres, cuatro y cinco años. Se eligen tres listados diferentes para cada uno de ellos. Al escoger el vocabulario delimitamos el número de sesiones para los niños, ya que decidimos enseñar alrededor de 20 láminas por sesión (14 para los niños de tres años, 16 para los de cuatro años y 21 para los de cinco años). Todas las sesiones tuvieron el mismo formato, y se dividieron en tres fases: fase 1: en la que se enseñaron las palabras y explicamos lo que son, integrándolas dentro de una conversación con el niño, ya que era una de las debilidades del método anterior; fase 2: en la que se realizaron diferentes tipos de actividades de conversación y repetición, pero en este caso solo con las palabras que desconocen; y fase 3: en la que se volvieron a enseñar las palabras a los niños, de manera rápida, tal y como dictaba Doman, ya que sabemos que esto sirve para mejorar la articulación. 
De esta manera obtenemos PELEO, que es un programa de estimulación lingüística para niños con trastorno del lenguaje sistematizado, es decir que sigue una serie de fases que se repiten con todos los niños, y que puede ser flexible. Existen pocos programas diseñados para tal fin; y muchos menos por no decir que son casi inexistentes, en la literatura hispana. Por lo que esta investigación ha aportado valor a la comunidad científica siendo pionero en proponer un programa que sea útil con estos niños y pueda ser sistematizado durante una serie de sesiones, aunque debemos continuar trabajando en él para poder generalizar los datos encontrados. También esto supone una revolución para algunas profesiones como puede ser los logopedas y los maestros de audición y lenguaje, porque contarán con un instrumento de intervención diseñado específicamente con estos niños, teniendo en cuenta que la prevalencia del TDL se sitúa en torno a un 7\% (Tomblin et al., 1997), podemos afirmar que ambos profesionales suelen trabajar mucho con estos niños.

En cuanto al segundo objetivo general de la tesis doctoral: evaluar el diseño de PELEO en niños con trastorno del lenguaje de tres, cuatro y cinco años, podemos determinar que también lo hemos cumplido, ya que hemos evaluado el diseño y hemos llegado a la conclusión de que es adecuado enseñar una media de 20-21 palabras por sesión, que de esas palabras suelen desconocer entre 6.45 y 14.55 cuando tienen tres años, entre 4.35 y 6.50 cuando tienen cuatro años y entre 2.75 y 5.70 palabras cuando tienen cinco años. El programa tal y como está diseñado no se ha individualizado, se instó a las logopedas a que repitieran el mismo PowerPoint en caso de que ellas determinasen que existían demasiados errores (entre 10 o 15 palabras desconocidas por sesión); pero la realidad es que ninguna logopeda repitió el PowerPoint al día siguiente, ya que les aclarábamos que la última decisión estaba en su mano. Tras tener en cuenta todos los resultados consideramos que el diseño de PELEO en cuanto a la cantidad de palabras parece correcto, pero no está individualizado, hemos encontrado diferentes opiniones al respecto, en su mayoría positivas. Si bien el diseño en cuanto al orden de las palabras parecía adecuado, no podemos decir lo mismo en cuanto al tipo de vocabulario, ya que se incluyeron palabras para las que los niños no estaban preparados para asimilarlas como pueden ser: conceptos espaciotemporales y los conceptos abstractos y de tiempo, además la utilización de los símbolos del ARASAAC tampoco parece adecuada para estas palabras. Aunque este tipo de palabras no eran adecuadas, en la evaluación del diseño de la clase de palabras encontramos que el resto sí que es adecuado. La evaluación del diseño de las actividades fue positiva, ya que los niños estaban motivados mientras las utilizaban; 
aunque parecía que estaban mejor diseñadas las actividades de la fase 2 que las de la fase 1 y 3 , ya que estas dos últimas eran actividades más repetitivas, y menos motivantes para los niños.

Todas estas conclusiones, han supuesto un aporte positivo a la ciencia, ya que no se ha encontrado en la literatura, estudios que explicasen el tipo de palabras más desconocidas para los niños con trastorno del lenguaje, y esto puede ser de gran interés para diseñar nuevos programas, o para tratar a diferentes niños de manera individualizada. Además, también hemos podido determinar cómo ha sido el cambio de estos niños en esta cantidad de sesiones, y no existe una gran evidencia científica sobre qué cantidad de sesiones es la más adecuada para tratar a estos niños, por lo que todo tipo de estudios que realicen una cantidad específica de sesiones con los niños con trastorno del lenguaje estarán arrojando luz a un ámbito no muy estudiado todavía; por último, los resultados relacionados con la inespecificidad de los símbolos del ARASAAC en los conceptos abstractos y espaciotemporales, también es algo que se ha publicado por primera vez, y abre paso a que los profesionales: logopedas y maestros de audición y lenguaje, busquen otras maneras de representar este tipo de palabras con los niños con trastorno del lenguaje, y desechen el uso de estos con el fin de que los niños adquieran nuevo vocabulario o desarrollen otras dimensiones del lenguaje.

En lo que respecta al tercer objetivo: valorar y analizar la aplicación de PELEO en niños de tres, cuatro y cinco años con trastorno del lenguaje, podemos decir que de manera global también es positiva; aunque es necesario tomar estos datos con cautela y saber que no se ha realizado una validación del programa, sino una evaluación de este para conocerlo en profundidad y valorar los puntos fuertes y débiles del mismo. Si bien es muy beneficiosa la aplicación PELEO para ampliar el vocabulario, la articulación y la morfosintaxis de los niños con trastorno del lenguaje, ya que estas dimensiones de los niños han cambiado después de utilizar PELEO, es necesario realizar una investigación en mayores parámetros de la morfosintaxis de los niños. Teniendo en cuenta esto, podemos determinar que hemos cumplido el objetivo específico: comprobar cómo ha cambiado la articulación, el vocabulario y la morfosintaxis de los niños que han utilizado PELEO. Los resultados mostrados en cómo han cambiado estas dimensiones nos hacen poder afirmar que el número de sesiones aplicadas parece suficiente para lograr muchos resultados. Por otro lado, parece necesario ampliar la utilización de PELEO en el ámbito familiar para lograr una generalización de todos los aprendizajes que se logran con el programa; y además también es preciso individualizar el 
programa, ya que algunos niños con trastorno del lenguaje se muestran inatentos, y esto puede enlentecer el progreso de los niños.

Todo lo comentado en las conclusiones de este tercer objetivo, no solo ha ayudado a PELEO, si no a la ciencia en general, y a la práctica educativa y logopédica en particular, ya que podemos determinar que otros programas que se diseñen, ya sean sistemáticos como este o individualizados para un niño específico, tienen que fijarse en estas características que hemos analizado de PELEO: la necesidad de la colaboración por parte de la familia y la necesidad de valorar si los niños están teniendo una atención suficientemente adecuada para llevar a cabo la actividad. No debemos olvidar la necesidad de conocer cómo cambian las diferentes dimensiones del lenguaje cuando intervenimos con estos niños; por ejemplo, no existen muchos estudios que describan cómo avanza y en cuánto tiempo de media comienzan a articular correctamente los fonemas los niños con trastorno del lenguaje, y nosotros detallamos cómo ha sido esta evolución durante estas semanas de intervención; al igual que realizamos este análisis con las otras dimensiones del lenguaje.

Como conclusión final del desarrollo de la tesis doctoral, hemos sido capaces de identificar una serie de debilidades de PELEO, por lo que queremos elaborar las siguientes recomendaciones para mejorar el programa y, de un modo u otro, lograr mayores resultados al utilizarlo con los niños con trastorno del lenguaje:

- Es importante flexibilidad para decidir la cantidad de palabras nuevas que se enseñan por sesión. Para ello se deberá tener en cuenta la media de palabras desconocidas: para los niños de tres años, 11 palabras; para los niños de cuatro años, 5 palabras; y para los niños de cinco años, 4 palabras. Cuando los niños sobrepasen la media de palabras desconocidas establecida anteriormente, repetiremos el uso del mismo PowerPoint en la próxima sesión. Un mismo PowerPoint no se repetirá durante más de dos días ${ }^{8}$. Realizando esta modificación a PELEO, añadiremos más tiempo de intervención en los niños que realmente lo necesiten, que era una de las preocupaciones que mostraban las familias, y aumentaremos el número de ensayos al repetir las actividades durante más de un día.

- En cuanto al tipo de palabras que se incluyen en las sesiones, eliminaremos las palabras relacionadas con los conceptos de

\footnotetext{
${ }^{8}$ Esta recomendación ya la habíamos hecho anteriormente, pero no habíamos dado un número exacto de palabras en las que tenían que fallar los niños para repetir el PowerPoint al día siguiente.
} 
tiempo, abstractos y de cantidad. Los niños a estas edades (3-4 y 5 años) no están preparados para utilizar correctamente estos conceptos y, de esta manera, eliminaremos la dificultad que existe con los símbolos de ARASAAC.

- Mejora de la motivación de los niños, añadiendo un elemento atractivo en las fases 1 y 3 . Este elemento puede ser una marioneta, el programa de Motsch \& Ulrich (2012) lo incluye para trabajar la semántica de niños con TDL y resulta beneficioso y atrayente para los niños. De esta manera, realizaremos de la misma manera el apartado descrito en las fases 1 y 3, pero pediremos a las logopedas que incluyan el uso de esta marioneta para dar las instrucciones al niño, en vez de hacerlo ellas directamente.

- Solo en el caso de que el niño con TL presente dificultades en la dimensión morfosintáctica y necesite mejorar su gramática, se recomienda trabajar durante cada sesión una forma gramatical (presente, pasado, futuro...) y otras formas morfosintácticas. Las logopedas deben realizar las frases de ejemplo en la Fase 2 con esas fórmulas gramaticales, de esta manera realizarán más ensayos con una misma fórmula gramatical; por ejemplo, si en la fase 1 han fallado en las palabras: elefante, coche, semáforo y cuchara, podrán elegir formular durante ese día todas las frases en presente: "el elefante come fruta", "Mamá y papá van en coche", o en pasado: "el elefante ayer comía fruta", "mamá y papá el otro día iban en coche", o en futuro: "el elefante mañana buscará fruta", "mamá y papá vendrán luego en coche"; de esta manera trabajarán la misma forma gramatical durante un mismo día y las opciones de ensayo se multiplicarán.

- Para lograr una mayor generalización de los aprendizajes se pedirá a las familias que utilicen en situaciones cotidianas las palabras que los niños han desconocido en cada sesión. Esta participación se realizará invitando a las familias a la primera sesión de intervención para que observen cómo se realiza la fase 2; se les instará a que repitan esta fase 2 en casa, con las palabras que han desconocido los niños en la sesión; además de los ejemplos que vean en la sesión, se les dará otros ejemplos por escrito como puede ser: jugar al memory con las palabras que hayan desconocido; si aparece una cuchara en la lámina, pueden utilizar cucharas de verdad para hacer la actividad... Estos juegos se repetirán, dando a las familias cierta libertad para realizarlos cuando mejor les convenga y cuando los niños estén motivados 
para realizarlo, de esta manera individualizaremos y flexibilizaremos el proceso.

Una vez llevadas a cabo estas modificaciones en PELEO, lograremos una mejora del programa, logrando que sea más beneficioso en diferentes niveles (de diseño y utilización), de esta manera hemos cumplido el último de los objetivos específicos: proponer una serie de recomendaciones y sugerencias que realizar en el diseño de PELEO, tras realizar una evaluación exhaustiva al diseño y a la utilización de este. Que también será beneficioso para la comunidad científica, al poder transferir estas recomendaciones para este programa particular a otros diseños, o incluso a otros programas de intervención logopédico individuales.

\subsection{Limitaciones y futuras líneas}

Existen una serie de limitaciones en este estudio que hay que tener en cuenta para comprender el trabajo en su integridad. La primera limitación que nos encontramos fue la cantidad de resultados hallados en los que se desaconsejaba el uso del Método Doman. Esto es debido a que no se trata de un método con gran validez científica, por lo que nos vimos obligados a cambiar el diseño de la investigación original, en el que pretendíamos validar el método Doman con estos niños y a utilizar esa primera muestra que habíamos recogido como un estudio piloto, para partir y desarrollar un programa de intervención diferente que podría ser útil con infantes con trastorno del lenguaje.

Otra de las principales limitaciones de esta investigación es la muestra tan reducida con la que hemos trabajado en el Estudio Piloto (EP) en el que han colaborado 8 participantes, por lo que los resultados encontrados no pueden ser generalizados, pero sí que nos han permitido disponer de una idea de las posibles características que teníamos que cambiar del programa, o que podíamos modificar para diseñar PELEO.

En relación con la muestra, encontramos una limitación que tiene que ver con el género y el contexto sociocultural de los participantes del Estudio de Caso Evaluativo (ECE). En esta investigación no se ha tenido en cuenta las diferencias en este sentido, por lo que no disponemos de datos sobre la posible incidencia del género o del contexto sociocultural en las preguntas que hemos planteado y en sus respuestas.

Otra limitación consiste en la evaluación de los niños, habiendo sido necesario aplicar más pruebas para realizar un diagnóstico más certero, 
que nos diera más información como puede ser CELF Preschool-2 Spanish (Wiig et al., 2009), esta prueba es más acertada para realizar un diagnóstico ya que evalúa la presencia de un trastorno del lenguaje y determina su naturaleza, detalla las habilidades clínicas críticas que subyacen al trastorno y valora cómo afecta al desempeño del aula. Pero en el momento de realizar el diseño de investigación y comenzar con este estudio desconocíamos la existencia de esta prueba. Es necesario tener en cuenta la aplicación de esta prueba para continuar con esta investigación en un futuro.

Encontramos otra limitación en cuanto a que no se ha tenido en cuenta el tipo de TDL, esto es porque, aunque Rapin y Allen (1983) hacían una clasificación de estas, hoy en día no están recogidas en el DSM-V. Sin embargo, en el análisis de los resultados, algunas logopedas hacían diferencias en cuanto a estos subtipos, por lo que en un estudio posterior podría ser interesante añadir estos subtipos; aunque hoy en día muchos investigadores opinan que no es necesario establecer las diferencias entre tipos.

Otra limitación radica en las dimensiones del lenguaje que se han analizado de los niños que han utilizado PELEO. Se han analizado la dimensión fonética, semántica y sintáctica, pero no se ha hecho un análisis de la dimensión pragmática. La causa de esta omisión es debida a la falta de información suficiente para realizar una triangulación adecuada, ya que la triangulación realizada por nosotros ha consistido en la comparación de los resultados de técnicas diferentes (observación, entrevista, pruebas estandarizadas y vídeos), y solo hemos valorado la pragmática a través de la prueba PLON-R, y no se ha recogido información a través de ninguna otra técnica diferente.

La última limitación viene derivada del periodo de realización del doctorado, en febrero de 2020 nos vimos inmersos en un confinamiento debido a la crisis de la COVID-19. En ese momento ya habíamos finalizado la aplicación de los bits en diferentes centros escolares y gabinetes, habiendo recogido datos de 33 niños. El diseño de investigación original incluía la participación de un grupo control con retraso de lenguaje, pero finalizado el confinamiento se decidió no comenzar y eliminar ese grupo control del diseño de investigación, ya que la COVID-19 ha supuesto un hándicap para estos niños. Se ha demostrado, en el estudio de Charney et al. (2020), que el uso de las mascarillas ha resultado un impedimento para los hablantes tardíos y los niños con TDL, debido al obstáculo que supone para ellos no poder observar las expresiones faciales y no tener el apoyo visual del habla de 
su interlocutor; además de encontrarse con menos oportunidades de interacción con sus iguales, al tener menos tiempo de juego libre en los parques públicos y haberse mermado su tiempo en las escuelas. Por ello, no consideramos adecuado comparar unos niños con los que se había llevado a cabo PELEO antes de la pandemia, con niños con las mismas dificultades después de la pandemia; ya que las características de estos habían cambiado y no eran las mismas.

Una vez observadas estas limitaciones, es importante poner la vista en el futuro y considerar otros trabajos o formas en las que podrían formar parte de las perspectivas futuras de nuestro trabajo.

La primera consiste en realizar los cambios propuestos en esta tesis doctoral en PELEO, analizar la eficacia de éste en la población con trastorno del lenguaje, realizando un estudio cuasiexperimental con un grupo control, evaluando la eficacia de PELEO en todas las dimensiones del lenguaje, añadiendo a las variables ya estudiadas: el género, el contexto socioeconómico de los participantes, la comunicación no verbal y si son hablantes tardíos o niños con TDL y de qué tipo, atendiendo a los tipos de Rapin y Allen (1983), de esta manera lograremos validar PELEO. En esta misma línea, también es necesario realizar este estudio en los dos contextos: dentro del aula como una intervención inclusiva, y fuera del aula; de esta manera podremos valorar si puede ser un programa que se puede utilizar de manera grupal o no.

La segunda consiste en analizar la eficacia de PELEO en otros grupos poblacionales: niños con Síndrome de Down, Trastorno del Espectro Autista, niños que aprenden el castellano como su segunda lengua....

La tercera se basa en validar PELEO en otros países hispanohablantes. Para ello será necesario realizar una modificación de las palabras que hemos utilizado, y de las pruebas estandarizadas; ya que es necesario utilizar pruebas validadas en esa muestra objetivo, además las palabras que usan los niños en los distintos países hispanos son diferentes, por lo que habría que adaptar el estudio a ese contexto.

Otra línea futura reside en examinar la comprensión de las distintas categorías semánticas en niños con trastorno del lenguaje y sin trastorno del lenguaje, para valorar si estos niños tienen mayores dificultades en algunas categorías respecto a sus homólogos. Este estudio es más descriptivo, pero nos podría servir para ahondar más en las posibles intervenciones con los niños con trastorno del lenguaje, para que lleguen a un lenguaje más acorde a su edad cronológica. 
También es necesario llevar a cabo investigaciones relacionadas con la frecuencia y la cantidad de sesiones necesarias para lograr una mejoría en el lenguaje de los niños con trastorno del lenguaje.

Y, por último, investigar la comprensión de los símbolos relativos a conceptos de cantidad y espacio-temporales de ARASAAC en niños con un desarrollo típico del lenguaje y en niños con dificultades del lenguaje. 


\section{Referencias bibliográficas}

[Fotografía de una cabeza]. (2019). Recuperado de Pixabay https://pixabay.com/es/photos/en-la-cabeza-ni\%C3\%B1osonrisa-2644201/

Abad, S., Brusasca, M. C. y Labiano, L. M. (2009). Neuropsicología infantil y educación especial. Revista Intercontinental de Psicología y Educación, 11(1), 199-216.

Acosta, V. (2012a). Algunos retos y propuestas en la conceptualización, evaluación e intervención del Trastorno Específico del Lenguaje (TEL). Revista Chilena de Fonoaudiología, 11, 23-36. https://doi.org/10.5354/0719-4692.2012.24525

Acosta, V. (2012b). La intervención logopédica en los trastornos específicos del lenguaje. Revista de Logopedia, Foniatría y Audiología, $32(2)$,

67-74. https://doi.org/10.1016/j.rlfa.2012.03.003

Acosta, V. M., Ramírez, G. M. y Axpe, Á. (2020). Intervención temprana en la organización léxica de alumnado con trastorno del desarrollo del lenguaje. Revista de Psicodidáctica, 25(2), 150157. https://doi.org/10.1016/j.psicod.2020.04.001

Acosta, V. M., Ramírez, G. M., Expósito, S. H. y Caballero, Á. A. (2020). Intervention in Syntactic Skills in Pupils with Developmental Language Disorder. Psicothema, 32(4), 541-548. https://doi.org/10.7334/psicothema2020.160

Acosta, V., Moreno, A. y Axpe, A. (2012) Implicaciones clínicas del diagnóstico diferencial temprano entre Retraso de Lenguaje (RL) y Trastorno Específico del Lenguaje (TEL). Universitas Psychologica 11(1) 279-291.

Adelman, C., Jenkins, D. \& Kemmis, S. (1983). Case study: An overview. Deakin University Press.

Aguado, G. (1989). El desarrollo de la morfosintaxis en el niño. CEPE. 
Aguado, G. (2004): Procesos psicolingüísticos en la comprensión del lenguaje. Intervención. Ponencia presentada en el XVI Congreso de FEPAL, Sevilla, España.

Aguado, G. (2007a). Apuntes acerca de la investigación sobre el TEL. Revista de Logopedia, Foniatría y Audiología, 27(3), 103109.

Aguado, G. (2007b). Repetición de pseudopalabras en el diagnóstico del Trastorno Específico del Lenguaje. Universidad de Navarra.

Aguado, G., Coloma, C., Martínez, A., Mendoza, E. y Montes, A. (2015). Documento de consenso elaborado por el comité de expertos en TEL sobre el diagnóstico. Revista de Logopedia, Foniatría $y \quad$ Audiología, 35(4), $147-149$. https://doi.org/10.1016/j.rlfa.2015.06.004

Aguilar, E. y Serra, M. (2003). A-RE-HA. Análisis del retraso del habla: protocolos para el análisis de la fonética y la fonología infantil. Universidad de Barcelona.

Aguilar, E., Sanz, M. y Serra, M. (2002). A comparative study of the phonology of pre-school children with specific language impairment (SLI), language delay (LD) and normal acquisition. Clinical Linguistics and Phonetics, 16(8), 573-596. https://doi.org/10.1080/02699200210148394

Aguilar-Mediavilla, E., Sanz-Torrent, M., y Serra-Raventós, M. (2007). Influence of phonology on morpho-syntax in Romance languages in children with Specific Language Impairment (SLI). International Journal of Language \& Communication Disorders, 42(3), 325-347. https://doi.org/10.1080/13682820600881527

Aguinaga, G. L., Armentia, M. A., Fraile, A., Olangua, P. y Uriz, N. (2004). Prueba de Lenguaje Oral de Navarra-Revisada (PLON$R$ ). Fondo de Publicaciones del Gobierno de Navarra.

Aguinaga, G., Armentia, M., Fraile, A., Olangua, P. y Uriz, N. (1990). PLON. Prueba de lenguaje oral Navarra. TEA ediciones.

Aguinaga, G., Armentia, M., Fraile, A., Olangua, P. y Úriz, N. (2005). Prueba de lenguaje oral de Navarra Revisada (PLON)-R. TEA ediciones.

Ahufinger, N., Ferinu, L., Pacheco-Vera, F., Sanz-Torrent, M. y Andreu, L. (2021). El trastorno del desarrollo del lenguaje (TDL) más allá 
de las dificultades lingüísticas: memoria y atención. Revista de Logopedia, Foniatría y Audiología, 41(1), 4-16. https://doi.org/10.1016/j.rlfa.2019.12.001

Alegre, J. R. y Pérez, M. (2008). Guía práctica de los trastornos del lenguaje: descripción e intervención. Lebón.

Alonso, J. C. (2003). El estudio de caso simple: un diseño de investigación cualitativa. Pontificia Universidad Javeriana, Facultad de Ciencias Políticas y Relaciones Internacionales.

Alt, M., Mettler, H. M., Erikson, J. A., Figueroa, C. R., Etters Thomas, S. E., Arizmendi, G. D. \& Oglivie, T. (2020). Exploring input parameters in an expressive vocabulary treatment with late talkers. Journal of Speech, Language, and Hearing Research, 63(1), 216-233. https://doi.org/10.1044/2019_JSLHR19-00219

Alt, M., Meyers, C., Oglivie, T., Nicholas, K. \& Arizmendi, G. (2014). Cross-situational statistically based word learning intervention for late-talking toddlers. Journal of Communication Disorders, 52, 207-220. https://doi.org/10.1016/j.jcomdis.2014.07.002

American Academy for Cerebral Palsy, American Academy of Neurology, American Academy of Pediatrics, American Academy for Physical Medicine and Rehabilitation, American Congress of Rehabilitation Medicine, American Academy of Orthopedics..., National Association for Retarded Children (USA) (1968). The Doman-Delacato Treatment of Neurologically Handicapped Children. Developmental Medicine and Child. Neurology, 10, 243-246.

American Academy for Cerebral Palsy. (1965). Statement of Executive Committee. Feb. 15.

American Academy of Neurology. (1967). Joint Executive Board Statement: The Doman Delacato treatment of neurologically handicapped children. Neurology, 637.

American Academy of Pediatrics, Committee on Children With Disabilities. (1982). The Doman-Delacato treatment of neurologically handicapped children. Pediatrics, 70, 810-812.

American Academy of Pediatrics. (1965). Executive Board Statemen: Doman-Delacato Treatment of Neurologically Handicapped Children. Amer. Acad. Pediat. Newsletter, 16(11), 1-6. 
American Academy of Pediatrics. (1968). Joint Statement: The DomanDelacato treatment of neurologically handicapped children. Neurology, $\quad 18(12), \quad 1214-$ https://doi.org/10.1212/wnl.18.12.1214

American Academy of Physical Medicine and Rehabilitation. (1968). Doman-Delacato treatment of neurologically handicapped children. Archives of Physical Medicine and Rehabilitation, 49, 183-186

American Psychiatric Association (2000). Diagnostics and Statistical Manual of Mental Disorders, IV text revision. American Psychiatric Pub.

American Psychiatric Association (2012): DSM-V Development. http://www.dsm5.org/ProposedRevision/Pages/proposedrevisio n.aspx? rid $=488$.

American Speech-Language-Hearing Association. (2005). Evidencebased practice in communication disorders [positionstament]. www.asha.org/members/deskref-journal.

American Speech-Language-Hearing Association. (2006). Introduction to evidence-based practice. www.asha.org

Anaya-Reig N. y Calvo, V. (2019). Desarrollo de habilidades lingüísticas en la educación infantil. Ediciones Paraninfo, SA.

Andreu-Barrachina, L., Gerardo-Aguado, M., Cardona-Pera, M. C., y Sanz-Torrent, M. (2014). El trastorno especifico del lenguaje: diagnóstico e intervención, Vol. 294. UOC.

Aparicio, M. e Igualada, A. (2019). El desarrollo del lenguaje y la comunicación en la infancia. UOC.

Aranda, T. y Araújo, E. G. (2009). Técnicas e instrumentos cualitativos de recogida de datos. Editorial EOS.

Asociación Americana de Psiquiatría (2014) Manual de Diagnóstico y Estadístico de los Trastornos Mentales, 5a Edición. DSM-5. Madrid. Editorial Médica Panamericana.

Auza, B. y Peñaloza, C. (2019). Factores individuales y familiares en el Trastorno del Desarrollo del Lenguaje (TDL). Iztapalapa. Revista de Ciencias Sociales y Humanidades, 40(86), 41-66. https://doi.org/10.28928/ri/862019/atc2/auzaa/penalozacastilloc 
Ayuso-Lanchares, A. y Ruíz-Requies, I. (2020). Intervención lingüística en niños con retraso del lenguaje utilizando los bits de inteligencia. En Felipe, A., Peña, B. y Bobkina, J. (Ed.) Estudios sobre innovaciones educativas (pp. 87-98). Colección: Ediciones Universitarias. Ediciones Pirámide.

Ayuso-Lanchares, A., Ruíz-Requies, I. y Santiago-Ruiz, R.B. (2021). La motivación ante actividades lúdicas o actividades de repetición en niños con Retraso de Lenguaje (RL) o Trastorno del Desarrollo del Lenguaje (TDL). Nuevas formas de aprendizaje en la era digital: en busca de una educación inclusiva. Editorial Dykinson (en prensa).

Ayuso-Lanchares, A., Santiago-Pardo, R. B., y Ruiz-Requies, I. (2019). Método Doman para la inclusión e intervención de niños con Trastorno del Desarrollo del Lenguaje. Revista Internacional de Apoyo a la Inclusión, Logopedia, Sociedad y Multiculturalidad, 5(3), 91-105. https://doi.org/10.17561/riai.v5.n3.9

Bahamonde, C., Serrat, E. y Vilà, M. (2021). Intervención en Trastorno del Desarrollo del Lenguaje (TDL). Una revisión sistemática (2000-2020). Revista de Investigación en Logopedia, 11, 17-34. https://doi.org/10.5209/rlog.71975

Bautista, B. (2010). Utilización de las TIC en educación infantil. El método Doman. Clave XXI. Reflexiones y Experiencias en Educación, Revista Clave 21. http://clave21.ieszaframagon.com/files/articulos/metodo\%20do man.pdf

Benitez, P. \& Domeniconi, C. (2014). Capacitação De Agentes educacionais: proposta de desenvolvimento de estratégias inclusivas. Revista Brasileira de Educação Especial, 20, 371386.

Bermeosolo, J. (2016). Psicología del lenguaje: una aproximación psicopedagógica. Ediciones Universidad Católica de Chile.

Bishop, D. (2003). The Children's Communication Checklist, Version 2 (CCC-2). Psychological Corporation.

Bishop, D., Snowling, M., Thompson, P. \& Greenhalgh, T. (2016). CATALISE: A multinational and multidisciplinary Delphi consensus study. Identifying language impairments in children. PLOS one, 11(7). https://doi.org/10.1371/journal.pone.0158753 
Bisquerra, R. y Pérez, N. (2015). ¿Pueden las escalas Likert aumentar en sensibilidad? REIRE. Revista d'Innovació i Recerca en Educació, 8(2) p. $129-147$.

Blanco, R. (2014). Inclusión educativa en América Latina: Caminos recorridos y por recorrer. En A. Marchesi, R. Blanco, \& L. Hernández (Coords.), Avances y desafíos de la educación inclusiva en Iberoamérica (pp. 11-35). OEI.

Boehm, A. (1990). Test Boehm de conceptos básicos (8.a ed.). TEA.

Bonetto, M. J. (2016). El uso de la Fotografía en la investigación social. Revista Latino-americana de Metodología de la Investigación Social, 11, 71-83.

Bortolini, U. \& Leonard, L. (2000). Phonology and children withspecific language impairment: Status of structural constraints in two languages. Journal of Communication Disorders, 33(2),131-150. http://dx.doi.org/10.1016/s0021-9924(99)00028-3

Bosch, L. (1984). El desarrollo fonológico infantil: una prueba para su evaluación. En M. Siguán (dir.), Estudios sobre psicología del lenguaje infantil (pp. 33-58). Pirámide.

Brito-Torres, C. J. (2018). Inicio tardío del lenguaje: Revisión teórica de la conceptualización a los aspectos generales para la evaluación e intervención. Revista digital EOS Perú, 6(2), 117-128.

Bronckart, J. P. (1980). Teorías del lenguaje. Ed. Herder.

Brumbaugh, K. M. \& Smit, A. B. (2013). Treating children ages 3-6 who have speech sound disorder: a survey. Language, Speech, and Hearing Services in Schools. 44(3), pp. 306-319. https:// doi.org/10.1044/0161-1461(2013/12-0029

Bruner, J, (1986). El habla del niño: aprendiendo a usar el lenguaje. Paidós Ibérica.

Buceta M. J. (2011). Manual de Atención Temprana. Editorial Síntesis.

Buiza-Navarrete, J.J., Adrián-Torres, J.A. y González-Sánchez, M. (2007). Marcadores neurocognitivos en el trastorno específico del lenguaje. Revista de Neurología, 44, 326-33.

Cabello, F. y Bertola, E. (2015). Características formales y transparencia de los símbolos pictográficos de ARASAAC. Revista de 
Investigación en Logopedia, 5(1), 60-70. https://doi.org/10.1016/j.rlfa.2018.04.002

Cabello, F. y Mazón, C., (2018). Iconicidad y facilidad de aprendizaje de los símbolos pictográficos ARASAAC. Revista de Logopedia, Foniatría y Audiología, 38(3), 95-104. https://doi.org/10.1016/j.rlfa.2018.04.002

Cadena, P., Rendón, R., Aguilar, J., Salinas, G., De la Cruz, F. y Sangerman, D. (2017). Métodos cuantitativos, métodos cualitativos o su combinación en la investigación: un acercamiento en las ciencias sociales. Revista Mexicana de Ciencias Agrícolas, 8(7), 1603-1617.

Camarata, S. M. \& Nelson, K. E. (1992). Treatment efficiency as a function of target selection in the remediation of child language disorders. Clinical Linguistics and Phonetics, 6(3), 167-178.

Camarata, S. M., Nelson, K. E., \& Camarata, M. N. (1994). Comparison of conversational-recasting and imitative procedures for training grammatical structures in children with specific language impairment. Journal of Speech, Language, and Hearing Research, 37(6), 1414-1423.

Campbell, D. \& Stanley, J. (2005). Diseños experimentales y cuasi experimentales en la investigación social. Buenos Aires: Amorrortu [ $1^{\text {a }}$ edición en castellano 1973; novena reimpresión].

Campbell, D. T. \& Stanley, J. C. (1966) Experimental and quasiexperimental designs for research. Chicago, Rand-McNally

Canadian Association for Retarded Children (1965). Institutes for the Achievement of Human Potential. Ment. Retardation (Canada), Fall, 27-28.

Cañadas-Osinski, I. y Sánchez-Bruno, A. (1998). Categorías de respuesta en escalas tipo LiLeonard, L. B. (2014). Children with specific language impairment. MIT press.

Carballo, G. (2012). Guía para la evaluación del TEL: algunas consideraciones. Revista de Logopedia, Foniatría y Audiología, 32(2),

87-93. https://doi.org/10.1016/j.rlfa.2012.03.004 
Carballo, G., y Fresneda, M. (2005). Evaluación e Intervención logopédica en el trastorno específico del lenguaje. Revista de Neurología, 41(Supl. 1), S73-S82.

Carletta, J. (1996). Assessing agreement on classification tasks: the kappa statistic. Computional Linguistics 22(2), 1-9.

Carrasco, A., García, R. y Hervás, M. (2015). Revisión de programas de intervención dirigidos a alumnos de infantil y primaria con trastorno específico del lenguaje. ReiDoCrea: Revista Electrónica de Investigación y Docencia Creativa, (4), 156-161.

Castañeda, P.F. (1999). El lenguaje verbal del niño. Fondo Editorial de la UNMSM.

Castejon, L., Núñez, C. y González, J. (2005). Variables cognitivomotivacionales y afectivas e intervención logopédica. Revista Española de Psicología General y Aplicada 57, 299-3I4. https://doi.org/IO.IOI6/S02I4-4603(05)75818-6

Cerdá-Marín, M. C. e Iyanga-Pendi, A. (2017). Evolución legislativa de la educación especial en España de 1970 a 2006 y su aplicación práctica. Revista de Educación Inclusiva, 6(3), 150-163.

Cerón, M. C. y Cerâon, M. C. (2006). Metodologías de la investigación social. LOM ediciones.

Cervera-Mérida, J. F., e Ygual-Fernández, A. (2003). Intervención logopédica en los trastornos fonológicos desde el paradigma psicolingüístico del procesamiento del habla. Revista de Neurología, 36(1), 39-53.

Cifuentes-Lardín, M. S., \& Martínez-Ramón, J. P. (2018). Diseño de un instrumento para el análisis de las competencias del logopeda escolar y del maestro de Audición y Lenguaje. European Journal of Child Development, Education and Psychopathology, 6(1), 4756. https://doi.org/10.30552/ejpad.v6i1.61

Cohen, N. J. (2001). Language impairment and psychopathology in infants, children, and adolescents. Sage Publications.

Coloma, C. J., Pavez, M. M., Maggiolo, M. y Peñaloza, C. (2010). Desarrollo fonológico en niños de 3 y 4 años según la fonología natural: Incidencia de la edad y del género. Revista signos, 43(72), 31-48. $\quad$ https://doi.org/10.4067/S0718$\underline{09342010000100002}$ 
Conferencia Sindical de Comisiones Obreras (2009). Las Funciones del Maestro/a de Audición y Lenguaje. Temas para la Educación. 15. https://www.feandalucia.ccoo.es/indicei.aspx? $\mathrm{p}=62 \& \mathrm{~d}=178$

Consejería de Educación de la Junta de Castilla y León (2007). DECRETO 122/2007, de 27 de diciembre, por el que se establece el currículo del segundo ciclo de la Educación Infantil en la Comunidad de Castilla y León. BOCyL. No 1, 6-16

Contreras-González, M. y Soriano-Ferrer, M. (2007). La morfología flexiva en el trastorno específico del lenguaje y en la deprivación sociocultural. Revista de logopedia, Foniatría y Audiología, 27(3), 110-117. https://doi.org/10.1016/S02144603(07)70080-3

Corr, C., Snodgrass, M. R., Greene, J. C., Meadan, H. \& Santos, R. M. (2020). Mixed methods in early childhood special education research: Purposes, challenges, and guidance. Journal of Early Intervention, 42(1), 20-30. https://doi.org/10.1177/1053815119873096

Crespo, N. y Narbona, J. (2006). Subtipos de trastorno específico del desarrollo del lenguaje: perfiles clínicos en una muestra hispanohablante. Revista de Neurología, 43(1) S193-S200.

Crespo-Allende, N., Alfaro-Faccio, P., Góngora-Costa, B., Alvarado, C. y Marfull-Villanueva, D. (2020). Perfil sintáctico de niños con y sin Trastornos del Desarrollo del Lenguaje: Un análisis descriptivo. Revista signos, 53(104), 619-642. https://doi.org/10.4067/S0718-09342020000300619

Creswell, J. W. (2015). A concise introduction to mixed methods research. SAGE publications.

Creswell, J. W. \& Creswell, J. D. (2017). Research design: Qualitative, quantitative, and mixed methods approaches. Sage publications.

Crisol, E., El Homrani, M. y Fernández, L. (2015). La morfosintaxis con TEL expresivo. Aplicaciones multimedia como propuesta de intervención logopédica: modelo assure. Revista Internacional de Apoyo a la Inclusión, Logopedia, Sociedad y Multiculturalidad, 1(4).

Cuevas-Miranda, C. A., López-Figueroa, M. D. C., Valenzuela-Pezo, M. J. I., Cares-González, J. E. y Quintanilla-Villar, T. A. (2019). Experiencia de aplicación de un programa de estimulación del 
lenguaje realizado en aulas inclusivas de kínder. Revista de Logopedia, Foniatría y Audiología, 39(3), 129-140. https://doi.org/10.1016/j.rlfa.2019.04.002

Charney, S. A., Camarata, S. M. \& Chern, A. (2020). Potential Impact of the COVID-19 Pandemic on Communication and Language Skills in Children. Otolaryngology-Head and Neck Surgery, 1-2. https://doi.org/10.1177/0194599820978247

Chaverra-Fernández, B. E., Gaviria-Cortés, D. F. y González-Palacio, E. V. (2019). El estudio de caso como alternativa metodológica en la investigación en educación física, deporte y actividad física. Conceptualización y aplicación. Retos, (35), 428-433.

Chivite, F. (1998). Lingüística infantil y origen del lenguaje. Cauce, 2021, 873-898.

Chomsky, N. (1972). Language and mind. Harcourt.

Chomsky, N. (1978). Estructuras sintácticas. Siglo XXI.

De las Heras, G. y Rodríguez, L. (2015). Guía de intervención logopédica en las dislalias. Síntesis.

Decreto 12/2008, de 14 de febrero, por el que se determinan los contenidos educativos del primer ciclo de la Educación Infantil en la comunidad de Castilla y León y se establecen los requisitos que deben reunir los centros que impartan dicho ciclo. Boletín Oficial de Castilla y León, 20 de febrero de 2008. Núm. 35, pp. 3022-3025. https://www.educa.jcyl.es/es/resumenbocyl/d-122008-14-02-determinan-contenidos-educativos-primer-cic

Decreto 122/2007, de 27 de diciembre, por el que se establece el currículo del segundo ciclo de la Educación Infantil de Castilla y León. Boletín Oficial de Castilla y León, 2 de enero de 2008. Núm. 1, pp. 6-16. http://bocyl.jcyl.es/

Del Canto, E. y Silva, A. S. (2013). Metodología cuantitativa: abordaje desde la complementariedad en ciencias sociales. Revista de Ciencias Sociales, 141, 25-34. https://doi.org/10.15517/RCS.V0I141.12479

Del Valle Hernández, G., Acosta Rodríguez, V. M. y Ramírez Santana, G. M. (2018). La producción gramatical en el discurso narrativo de alumnado con Trastorno Específico del Lenguaje (TEL). 
Revista signos, 51(98), 264-284. http://dx.doi.org/10.4067/S0718-09342018000300264

Demuth, K. (1996). Collecting spontaneous production data. En D. Mc Daniel, C. McKee \& H. Smith Cairns (Eds.), Methods for assessing children's syntax (pp. 3-22). MIT Press

Denzin, N. y Lincoln, Y. (2012). Manual de metodología cualitativa. Gedisa.

DeVeney, S. L., Hagaman, J. L. \& Bjornsen, A. L. (2017). Parentimplemented versus clinician-directed interventions for latetalking toddlers: A systematic review of the literature. Communication Disorders Quarterly, 39(1), 293-302. http://dx.doi.org/10.1177/1525740117705116

Díaz, S., Mendoza, V. M. y Porras, C. M. (2011). Una guía para la elaboración de estudios de caso, Razón y palabra, 75, 1-26.

Díaz-Villafáñez, M. (2016). El aprendizaje del tiempo y su enseñanza en la Educación Primaria. Tabanque: Revista Pedagógica, (29), 4368.

Doman G., Doman, J. (2012). Cómo enseñar conocimientos enciclopédicos a su bebé. Edaf.

Doman, G. (2000). Cómo enseñar a leer a su bebé. Edaf.

Doman, G., Doman, J. y Aisen, S. (2012). Cómo enseñar conocimientos enciclopédicos a su bebé. La Revolución Pacífica. Edaf.

Doman, G. y Doman, J. (1998). Cómo multiplicar la inteligencia de su bebé: la revolución pacífica (Vol. 7). Edaf.

Domínguez, C. L. y Martínez, H. (2015). Sintaxis y prosodia: el análisis sintáctico de las unidades del discurso oral. Lengua y habla, (19), 149-165.

Domínguez-Montes, J. A. (2016). Paradigmas de investigación educativa en educación física. Revista Española de Educación Física y Deportes, (413), 33-54.

Dunn, L. M., Dunn, L. M. \& Arribas, D. (2006). Peabody, test de vocabulario en imágenes. TEA ediciones.

Durán, M. M. (2002). Auditoría general d'una empresa d'alta tecnología comprocediment inicial en la implementació d'una estratègia de 
formació continuada: la gestió del coneixement (Tesis doctoral). Universidad Autónoma de Barcelona.

Durán, M. M. (2012). El estudio de caso en la investigación cualitativa. Revista Nacional de Administración, 3(1), 121-134.

Ebbels, S. (2014). Effectiveness of intervention for grammar in schoolaged children with primary language impairments: A review of the evidence. Child Language Teaching and Therapy, 30, 7-40. http://dx.doi.org/10.1177/0265659013512321

Echeita, G. (2008). Inclusión y exclusión educativa - Voz y quebranto. REICE - Revista Electrónica Iberoamericana sobre Calidad, Eficacia y Cambio en Educación, 6(2), 9-18.

Eikmeier, V, Alex-Ruf, S., Maienborn, C. \& Ulrich, R. (2015). How strongly linked are mental time and space alongthe left-right axis? Journal of Experimental Psychology: Learning, Memory, and Cognition, 41(6), 1878-1883. https://doi.org/10.1037/xlm0000129

Eisenberg, S. L., Bredin-Oja, S. L. \& Crumrine, K. (2020). Use of imitation training for targeting grammar: A narrative review. Language, Speech, and Hearing Services in Schools, 51(2), 205225. https://doi.org/10.1044/2019_LSHSS-19-00024

Ellis, S. (2007). Language development spectrum? En R. Paul (Ed.), Language disorders from a developmental perspective (pp. 83101). Erlbaum.

Ellis, S., Murray, J. \& Miller, J. (1993). Comparison of two methods for promoting productive Vocabulary in late talkers. Journal of Speech and Hearing Research, 36, 1037-1050

Enrique, A. M. y Barrio Fraile, E. (2018). Guía para implementar el método de estudio de caso en proyectos de investigación. Propuestas de Investigación en Áreas de Vanguardia, 159-168.

Escorcia-Mora, C. T., García-Sánchez, F. A., Orcajada-Sánchez, N. y Sánchez-López, M. C. (2016). Perspectiva de las prácticas de atención temprana centradas en la familia desde la logopedia. Revista de Logopedia, Foniatría y Audiología, 36(4), 170-177. https://doi.org/10.1016/j.rlfa.2016.07.002

Estalayo, V. y Vega, R. (2001). El método de los bits de inteligencia. Edelvives. 
Extracto de la Resolución de 31 de julio de 2020, de la Secretaría de Estado de Educación, por la que se convocan ayudas para alumnos con necesidad específica de apoyo educativo para el curso académico 2020-2021. Boletín Oficial del Estado, 31 de julio de 2020. Núm. 214, p. 34414-34415. https://www.boe.es/diario boe/txt.php?id=BOE-B-2019-33445

Fàbregues, S., Meneses, J., Rodríguez, D. y Paré, M. H. (2016). Técnicas de investigación social y educativa. Editorial UOC.

Falkus, G., Tilley, C., Thomas, C., Hockey, H., Kennedy, A., Arnold, T., ... \& Pring, T. (2016). Assessing the effectiveness of parent-child interaction therapy with language delayed children: A clinical investigation. Child Language Teaching and Therapy, 32(1), 717. https://doi.org/10.1177/0265659015574918

Fernández Martín, F., Arce Calvo, M. T. y Moreno Molina, J. A. (2014). Escuchemos el lenguaje del niño: normalidad versus signos de alerta. Pediatría Atención Primaria, 16, 101-110. http://dx.doi.org/10.4321/S1139-76322013000300014

Fernández, C. (2009). La logopedia en la escuela. Propuestas desde la práctica para una educación más inclusiva (Tesis Doctoral). Las Palmas: Universidad de las Palmas de Gran Canarias.

Fernández, L. C. y Ganzaráin, Y. E. (2004). La colaboración logopedamaestro: hacia un modelo inclusivo de intervención en las dificultades del lenguaje. Revista de Logopedia, Foniatría y Audiología, 24(2), 55-66. https://doi.org/10.1016/S0214$\underline{4603(04) 75781-2}$

Fey, M. E. \& Proctor-Williams, K. (2000). Recasting, elicited imitation, and modelling in grammar intervention for children with specific language impairments. In D. V. H. Bishop \& L. B. Leonard (Eds.), Speech and language impairments in children: Causes, characteristics, intervention, and outcome (pp. 177-194). Psychology Press.

Fey, M. E., Long, S. H. \& Finestack, L. H. (2003). Ten principles of grammar facilitation for children with specific language impairments. American Journal of Speech-Language Pathology $12,3-15$ 
Fikkert, P. (2007). Acquiring phonology. En P. Lacy (ed.), The Camdbridge Handbook of phonology (pp. 537-554) Camdbridge University Press.

Fisher, E. L. (2017). A systematic review and meta-analysis of predictors of expressive-language outcomes among late talkers. Journal of Speech, Language, and Hearing Research, 60(10), 2935-2948. https://doi.org/10.1044/2017_JSLHR-L-16-0310.

Flyvbjerg, B. (2003). Cinco malentendidos acerca de la investigación mediante los estudios de caso. http://www.reis.cis.es/REIS/PDF/ REIS_106_041167998142322.pdf

Galeano, M. E. (2020). Diseño de proyectos en la investigación cualitativa. Universidad Eafit.

Galindo-Domínguez, H. (2020). Estadística para no estadísticos: una guía básica sobre la metodología cuantitativa de trabajos académicos (Vol. 59). Editorial: 3Ciencias.

Gallardo, I. (2016). Inicio tardío del lenguaje: revisión general. Revista Mexicana de Comunicación, Audiología, Otoneurología y Foniatría 5(3), 89-96.

Gallardo, J. R. y Gallardo J. L. (1993). Manual de Logopedia escolar. Un enfoque práctico. Aljibe.

Gallego, C. (Ed.). (2004). Libro Blanco. Título de Grado en Logopedia. Agencia Nacional de Evaluación de la Calidad y Acreditación (ANECA).

García, T., García, L., González, R., Carvalho, J. y Catarreira, S. (2016). Revisión metodológica de la triangulación como estrategia de investigación. [Proceeding] CIAIQ2016, 3.

Garrote, M. (2008). Corpus de Habla Infantil Espontánea del Español. (Tesis doctoral). Universidad Autónoma de Madrid. Madrid.

Gento, S. y Hernández, M. J. (2012). Tratamiento educativo de la diversidad en audición y lenguaje. UNED.

Gil-Álvarez J. (2016). Técnicas e instrumentos para la recogida de información. Editorial UNED.

Gil-Álvarez, J. L., León-González, J. L. y Morales-Cruz, M. (2017). Los paradigmas de investigación educativa, desde una perspectiva crítica. Revista Conrado, 13(58), 72-74. 
Gleason, J. B. \& Ratner, N. B. (2010). El desarrollo del lenguaje. Pearson educacion.

Gómez, D. R. y Roquet, J. V. (2009). Metodología de la investigación. Universitat Oberta de Catalunya.

Gómez, M. B. (2019). A propósito de las redes semánticas en el léxico disponible de escolares de primero de Educación Primaria, Ogigia. Revista Electrónica de Estudios Hispánicos, 25 https://doi.org/10.24197/ogigia.25.2019.165-183

González, J. N. (2003). Alteraciones del habla en la infancia. Aspectos Clínicos. Buenos Aires: Editorial médica Panamericana.

González, L. (2009). Estudio de casos bajo el enfoque transdisciplinar. Multiciencias, 9(3), 303-312.

González-Díaz，R. R. y Hernández-Royett, J. (2017). Diseños de investigación cuantitativos aplicados en las ciencias de la administración y gestión. Globalciencia, 3(1), 15-27.

González-Picarín, A. y Calzadilla-González, O. (2015). El proceso de atención logopédica a escolares del nivel primario desde una perspectiva pedagógica. Didasc@lia: Didáctica y Educación, 6(1), 259-270.

Good, J. E., Lance, D. M. \& Rainey, J. (2015). The effects of morphological awareness training on reading, spelling, and vocabulary skills. Communication Disorders Quarterly, 36, 142151. https://doi.org/10.1177/1525740114548917

Goodman, J., Dale, P. \& Li, P. (2008). Does frequency count? Parental input and the acquisition of vocabulary. Journal of Child Language $35(3)$, 515-31. https://doi.org/10.1017/S0305000907008641

Goodman, K. (1990). El lenguaje integral: un camino fácil para el desarrollo del lenguaje. Revista Lectura y Vida, 11(2), 1-16.

Gortmaker, V. J., Daly, E. J., Mc Curdy, M., Persampieri, M. J. \& Hergenrader, M. (2007). Improving reading outcomes for children with learning disabilities: using brief experimental analysis to develop parent tutoring interventions. Journal of Applied Behavior Analysis, 40, 203-221. https://doi.org/10.1901/jaba.2007.105-05 
Gray, S. (2003). Word-learning by preschoolers with specific language impairment: What predicts success? Journal of Speech, Language, and Hearing Research, 46, 56-67.

Gray, S. (2005) Word learning by preschoolers with specific language impairment: effect of phonological or semantic cues. Journal of Speech, Language and Hearing Research, 48, 1452-1467.

Guba, E. G. (2008). Criterios de credibilidad en la investigación naturalista. En Gimeno, J., y Pérez, Á.I. (Eds.). La enseñanza: su teoría y su práctica (6 ${ }^{a}$ edición). Akal.

Guba, E.G. (1981). Criterios de credibilidad en la investigación naturalista. La enseñanza: su teoría y su práctica. Akal.

Heikkilä, J., Lonka, E., Meronen, A., Tuovinen, S., Eronen, R., Leppänen, P. H., ... \& Tiippana, K. (2018). The effect of audiovisual speech training on the phonological skills of children with specific language impairment (SLI). Child Language Teaching and Therapy, 34(3), 269-287. https://doi.org/10.1177/0265659018793697

Heim, S., Choudhury, N. \& Benasich, A. A. (2016). Electrocortical dynamics in children with a language-learning impairment before and after audiovisual training. Braintopography, 29(3), 459-476. https://doi.org/10.1007/s10548-015-0466-y

Hernández, R., Fernández, C. y Baptista, P. (2006). Metodología de la investigación. ( $4^{\mathrm{a}} \mathrm{Ed}$.). McGraw Hill.

Hernández-Sampieri, R. (2018). Metodología de la investigación: las rutas cuantitativa, cualitativa y mixta. McGraw-Hill.

Hübscher, I. \& Prieto, P. (2019). Gestural and prosodic development act as sister systems and jointly pave the way for children's sociopragmatic development. Frontiers in Psychology, 10, 1259. https://doi.org/10.3389/fpsyg.2019.01259

Ibáñez-Rodríguez, A., Ahufinger, N., Ferinu, L., García-Arch, J., Andreu, L. y Sanz-Torrent, M. (2021). Dificultades sociales, emocionales y victimización específica por el lenguaje en el trastorno del desarrollo del lenguaje. Revista de Logopedia, Foniatría $y \quad$ Audiología, 41(1), 40-48. https://doi.org/10.1016/j.rlfa.2020.03.017 
Ingram, D. (1981). Procedures for the phonological analysis of children's language. University Park Press.

Ingram, D. (1983). Trastornos fonológicos en el niño. Médica y Técnica.

Ingram, D. (1986). Explanation and phonological remediation. Child Language Teaching and Therapy, 2(1), 1-29. https://doi.org/10.1177/026565908600200101

Iruela, A. (2002). La lengua de la especialidad en Mundo Hispánico. Alienta Editorial.

Jackson, D. (2004). El retraso del lenguaje en niños mexicanos: vocabulario y gestos. The UB Journal of Psychology, 35(2), 257277.

Jackson, D., Thal, D., Marchman, V. A., Fenson, L., Newton, T. y Conboy, B. (2003). Inventario de Desarrollo Comunicativo MacArthur. Adaptación Española de López, S., Gallego, C., Gallo, P., Karousou, A., Mariscal, S., y Martínez, M. (2005). Tea Ediciones.

Jarvinen, A. (2007). Games without Frontiers, Theories and Methods for Game Studies and Design. (PhD in Media Culture), University of Tampere, Finland.

Jespersen, O. (1922). Language: its nature, development and origin. Allen and Unwin.

Jiménez, M. G. (2010). Alteraciones del desarrollo del lenguaje y su corrección en niños de cuatro a nueve años. Ethos educativo.

Jiménez-Rodríguez, J. (2010). Adquisición y desarrollo del lenguaje. En. A. Muñóz, Psicología del desarrollo en la etapa de educación infantil), 101-120. Pirámide.

Joffe, V. L., Rixon, L. \& Hulme, C. (2019). Improving storytelling and vocabulary in secondary school students with language disorder: a randomized controlled trial. International Journal of Language \& Communication Disorders. https://doi.org/10.1111/1460$\underline{6984.12471}$

Jornet-Meliá, J. M. (2017). Evaluación estandarizada. Revista Iberoamericana de Evaluación Educativa 10(1), 5-8.

Juárez, A. y Monfort, M. (1996a). Registro fonológico inducido. CEPE. 
Juárez, A., y Monfort, M. (1996b). Estimulación del lenguaje oral. Un modelo interactivo para niños con dificultades (segunda edición). Santillana.

Khamis-Dakwar, R. \& Khattab, G. (2014). Cultural and linguistic considerations in language assessment and intervention for Levantine Arabic speaking children. Perspectives on Communication Disorders and Sciences in Culturally and Linguistically Diverse (CLD) Populations, 21(3), 78-87. https://doi.org/10.1044/cds21.3.78

Kirk, S. A., McCarthy, J. J. \& Kirk, W. D. (2004). Test Illinois de aptitudes psicolingüísticas ITPA. Adaptación española. TEA.

Lara F. y Cabrera M. (2015). Fichas de procedimientos de evaluación educativa UDLA. Universidad de las Américas.

Law, J., McKean, C., Murphy, C. A. \& Thordardottir, E. (2019). Managing Children with Developmental Language Disorder. Routledge.

Lederer, S. (2001). Efficacy of parent-child language group intervention for late-talking toddlers. Infant Toddler Intervention, 11, 223235.

Lenneberg, E. H. (1985). Fundamentos biológicos del lenguaje. Alianza Universidad, 153-216.

Leonard, L. (1998). Children with Specific Language Impairment. MacKeith Press.

Leonard, L. (2009). Is expresive language disorder an accurate diagnostic category? American Journal of Speech-Language Pathology, $\quad 18, \quad 115-122 . \quad$ https://doi.org/10.1044/1058$\underline{0360(2008 / 08-0064)}$

Leonard, L. (2014). Children with specific language impairment and their contribution to the study of language development. Journal of Child Language, 41(S1), 38-47. https://doi.org/0.1017/S0305000914000130

Lepe-Martínez, N., Pérez-Salas, C., Rojas-Barahona, C. A. \& RamosGalarza, C. (2017). Funciones ejecutivas en niños preescolares con y sin trastorno del lenguaje. Revista Ecuatoriana de Neurología, 26(3), 197-202. 
Lewis, M. M. (1951). Infant Speech: a study of the beginning of language. Routledge and Kegan Paul.

Ley 13/1982, de 7 de abril, de integración social de los minusválidos. Boletín Oficial del Estado. Núm 103, pp. 11106-11112. https://www.boe.es/buscar/doc.php?id=BOE-A-1982-9983

Ley 14/1970, de 4 de agosto, General de Educación y Financiamiento de la Reforma Educativa. Boletín Oficial del Estado. 6 de agosto de 1970. Núm. 187, pp. 12525-12546. https://www.boe.es/buscar/doc.php?id=BOE-A-1970-852

Ley 44/2003, de 21 de noviembre de 2003, de ordenación de las profesiones sanitarias. Boletín Oficial Del Estado, núm. 280, pp. 41442-41458. https://www.boe.es/buscar/pdf/2003/BOE-A2003-21340-consolidado.pdf

Ley Orgánica 1/1990, de 3 de octubre, de Ordenación General del Sistema Educativo. Boletín Oficial del Estado. 4 de octubre de 1990. Núm. 238, pp. 28927-28942. https://www.boe.es/buscar/doc.php?id=BOE-A-1990-24172

Ley Orgánica 10/2002, de 23 de diciembre, de Calidad de la Educación. Boletín Oficial del Estado. 24 de diciembre de 2002. Núm. 307, pp. 45188-45220. https://www.boe.es/buscar/doc.php?id=BOEA-2002-25037

Ley Orgánica 11/1983, de 25 de agosto de 1983, de Reforma Universitaria. Boletín Oficial del Estado. 1 de septiembre de 1983, núm. 209, pp. 24034-24042. https://www.boe.es/eli/es/lo/1983/08/25/11

Ley Orgánica 2/2006, de 3 de mayo de 2006, de Educación. Boletín Oficial del Estado. 4 mayo de 2006, núm 106 pp. 1-110. https://www.boe.es/eli/es/lo/2006/05/03/2/con

Ley Orgánica 3/2020, de 29 de diciembre, por la que se modifica la Ley Orgánica 2/2006, de 3 de mayo, de Educación. Boletín Oficial del Estado. 30 de diciembre de 2020. Núm. 340, pp.122868122953.

https://www.boe.es/eli/es/lo/2020/12/29/3

Ley Orgánica 8/2013, de 9 de diciembre de 2013, para la mejora de la calidad educativa. Boletín Oficial del Estado. 10 de diciembre de 2013. Núm. 295, pp. 97858-97921. https://www.boe.es/eli/es/lo/2013/12/09/8 
Lieury, A. y Fenquillet, F. (2016). Motivación y éxito escolar. Fondo de cultura económica.

Ljubešić, M. (1995). Language Impairments in School Children. Školskenovine.

López C. (1990). El discurso y el conector reformulativo: «es decir». Revista de Filología Románica, 7, 87-100.

López, A. (2013). La evaluación como herramienta para el aprendizaje: conceptos, estrategias y recomendaciones. Magisterio.

López, S., Gallego, C., Gallo, P., Karousou, A., Mariscal, S. y Martínez, M. (2005). Inventarios de Desarrollo Comunicativo MacArthur. Manual. Tea Ediciones.

López-González, W. O. (2013). El estudio de casos: una vertiente para la investigación educativa. Educere, 17(56), 139-144.

Lousada, M., Ramalho, M. \& Marques, C. (2016). Effectiveness of the language intervention programme for preschool children. Folia Phoniatrica et Logopaedica, 68(2), 80-85. https://doi.org/10.1159/000448684

Lozano-Fernández, L. M., García-Cueto, E. y Gallo-Álvaro, P. (2000). Relación entre motivación y aprendizaje. Psicothema, 12(Su2), 344-347.

Lubliner, S. \& Smetana, L. (2005). The effects of comprehensive vocabulary instruction on title I students' metacognitive wordlearning skills and reading comprehension. Journal of Literacy Research, 37, 163-200. Doi: https://doi.org/10.1207/s15548430jlr3702_3

Mackenzie, C., Muir, M \& Allen, C. (2010). Non-speech oro-motor exercise use in acquired dysarthria management: regimes and rationales. International journal of language \& communication disorders. $45(6)$,

617-629. https://doi.org/10.3109/13682820903470577

Madueño, I. L y De Sebastián, J. V. (2018). Manual práctico de patología del lenguaje: evaluación e intervención en adultos y niños. Editorial UOC.

Mainela, E \& Evans, J. (2005). Beyond capacity limitations: Determinants of word recall performance on verbal working 
memory span tasks in children with SLI. Journal of Speech, Language \& Hearing Research, 48(4), 897-909.

Maldonado. E. (2018). Metodología de la Investigación social: Paradigmas: cuantitativo, sociocrítico, cualitativo, complementario. Ediciones de la U.

Manterola, C. y Otzen, T. (2015). Estudios experimentales $2^{\mathrm{a}}$ parte: estudios cuasi-experimentales. International Journal of Morphology, 33(1), 382-387.

Marcelo, C., Parilla, A., Mingorance, P., Estebaranz, A., Sánchez M. V. y Llinares, S. (1992). Estudio de casos: una estrategia para la formación del profesorado y la investigación didáctica. Universidad de Sevilla.

Martínez C. y Galán, A. (2014). Técnicas e instrumentos de recogida y análisis de datos. Editorial UNED.

Martínez, A. B. (2015). Identification of two SLI profiles through WISCIV, CELF-4 and FON. Journal of Educational Psychology Propósitos $\quad y \quad$ Representaciones, 3(2), 45-79. https://doi.org/10.20511/pyr2015.v3n2.78

Marulis, L. \& Neuman, S. (2010). The effects of vocabulary intervention on young children's word learning: A metaanalysis. Review of Educational Research, 80(3), 300-335. https://doi.org/10.3102/0034654310377087

McCarthy, D. (2006). Escalas McCarthy de Aptitudes y Psicomotricidad para Niños. Tea Ediciones.

Meltzoff, A. N. \& Williamson, R. A. (2013). Imitation: Social, cognitive, and theoretical perspectives. In P. D. Zelazo (Ed.), Oxford handbook of developmental psychology, Vol. 1, pp. 651-682. Oxford University Press.

Mendoza, E. (2006). Trastorno especifico del lenguaje, TEL. Ediciones Pirámide.

Mendoza, E. (2010). La evaluación del lenguaje: orientaciones alternativas. Revista de Logopedia, Foniatría y Audiología, 30(4), 167-173. https://doi.org/10.1016/S0214-4603(10)70152-2

Mendoza, E. (2016). Trastorno específico del lenguaje (TEL). Avances en el estudio de un trastorno invisible. Pirámide. 
Mendoza, E., Carballo, G., Muñoz, J. y Fresneda, M. D. (2005). Test de comprensión de estructuras gramaticales (CEG). Tea Ediciones.

Meneses, J., y Rodríguez-Gómez, D. (2011). El cuestionario y la entrevista. Editorial UOC.

Merriam, S. B. (1998). Qualitative research and case study applications in education. Jossey-Bass.

Mertens, D. M. (2015). Mixed methods and wicked problems. Journal of Mixed Methods Research, 9(1), 36. https://doi.org/10.1177/1558689814562944

Miguélez, B. A. (2016). Investigación social cualitativa y dilemas éticos: de la ética vacía a la ética situada. EMPIRIA. Revista de Metodología de las Ciencias Sociales, (34), 101-119. https://doi.org/empiria.34.2016.16524

Miller, C.T. (2008). Games: purpose and potential in education (Vol. I). Springer Verlag.

Mohedano, M. M. (2004). La enseñanza del léxico español a través de Internet: análisis y comentarios de páginas Web para la práctica y adquisición de vocabulario (Vol. 3). Editorial Edinumen.

Molina-Azorin, J. F. \& Fetters, M. D. (2020). Virtual Special Issue on Paradigms in Mixed Methods Research. Journal of Mixed Methods Research, 14(1), 6-10. https://doi.org/10.1177/1558689819894741

Montero, I. y León, O. G. (2002). Clasificación y descripción de las metodologías de investigación en Psicología. International Journal of Clinical and Health Psychology, 2(3), 503-508. https://www.redalyc.org/pdf/337/33720308.pdf

Montero, L. A. A. (1991). El informe Warnock. Cuadernos de pedagogía, 197, 62-64.

Moraine, P. (2014). Las funciones ejecutivas del estudiante: Mejorar la atención, la memoria, la organización y otras funciones para facilitar el aprendizaje (Vol. 197). Narcea Ediciones.

Morante, R. y Martí M. A. (2002) EuroWordNet as a resource for leaning the Spanish Verbs. Alienta Editorial.

Moreno, A., Axpe, Á. y Acosta, V. (2012). Efectos de un programa de intervención en el lenguaje sobre el desarrollo del léxico y del 
procesamiento fonológico en escolares de Educación Infantil con Trastorno Específico del Lenguaje. Revista de Investigación Educativa, 30(1), 71-86. https://doi.org/10.6018/rie.30.1.113861

Moreno, R. y Nieva, S. (2021). Intervención logopédica naturalista con familias de hablantes tardíos: efectos en el lenguaje infantil y en los intercambios adultos. Revista de Investigación en Logopedia, 11(1) 61-75. https://doi.org/10.5209/rlog.68157

Moreno-Flagge, N. (2013). Trastornos del lenguaje. Diagnóstico y tratamiento. Revista de Neurología, 57(1), S85-94.

Moreno-González, E. (2008). Manual de Uso de SPSS. UNED.

Moretti, S. \& Greco, A. (2018). Truth is in the head. A nod and shake compatibility effect. Acta Psychologica, 185, 203-218. https://doi.org/10.1016/j.actpsy.2018.02.010

Moriña, A. (2011). Aprendizaje cooperativo para una educación inclusiva: Desarrollo del programa PAC en un aula de Educación Primaria. Estudios sobre Educación, 21, 199-216.

Morse, J. M. (2016). Mixed method design: Principles and procedures (Vol. 4). Routledge.

Morton, J. (2008). Understanding developmental disorders: A causal modelling approach. Editorial: John Wiley \& Sons.

Motsch, H. J. \& Ulrich, T. (2012). Effects of the strategy therapy 'lexicon pirate' on lexical deficits in preschool age: A randomized controlled trial. Child Language Teaching and Therapy, 28(2), 159-175. https://doi.org/10.1177/0265659011432943

Muñoz, T. G. (2003). El cuestionario como instrumento de investigación/evaluación. Centro Universitario Santa Ana. http://cvonline. uaeh. edu. $\mathrm{mx} /$ Cursos/Maestria/MTE/Gen02/seminario_de_tesis/Unidad_4 _anterior/Lect_El_Cuestionario.pdf.

Nash, M. \& Donaldson, M. L. (2005). Word learning in children with vocabulary deficits. Journal of Speech, Language and Hearing Research, 48, 439-458. https://doi.org/10.1044/1092$\underline{4388(2005 / 030)}$

Navarro, M. (2003). Adquisición del lenguaje. El principio de la comunicación. Cauce, 26, 321-347. 
Nelson, K. (1988). El descubrimiento del sentido. La adquisición del significado compartido. Alianza.

Nelson, K. E., Camarata, S. M., Welsh, J., Butkovsky, L. \& Camarata, M. (1996). Effects of imitative and conversational recasting treatment on the acquisition of grammar in children with specific language impairment and younger language-normal children. Journal of Speech and Hearing Research, 39, 850-859. https://doi.org/10.1044/jshr.3904.850

Norbury, C. F. \& Bishop, D. V. (2003). Narrative skills of children with communication impairments. International Journal of Language \& Communication Disorders, 38(3), 287-313. https://doi.org/10.1080/136820310000108133

Noreña-Peña, A., Moreno, N. A., Rojas, J. G. y Rebolledo-Malpica, D. M. (2012). Aplicabilidad de los criterios de rigor y éticos en la investigación cualitativa. Aquichan, 12(3), 263-274. https://doi.org/10.5294/aqui.2012.12.3.5

Núñez, J. C. (2009). Motivación, aprendizaje y rendimiento académico. En Trabajo presentado en el X Congresso Internacional GalegoPortuguês de Psicopedagogia. Braga, Portugal (pp. 41-67).

Nye, C., Foster, S. H. \& Seaman, D. (1987). Effectiveness of language intervention with the language/learning disabled. Journal of Speech and Hearing Disorders, 52(4), 348-357. https://doi.org/10.1044/jshd.5204.348

Oetting, J., Rice, M. \& Swank, L. (1995). Quick incidental learning (QUIL) of words by school-age children with and without SLI. Journal of Speech, Language, and Hearing Research, 38(2), 434445. https://doi.org/10.1044/jshr.3802.434

Olabuénaga, J. I. R. (2012). Metodología de la investigación cualitativa (Vol. 15). Universidad de Deusto.

Oliveira, C.; Lousada, M. \& Jesus, L. M. (2015). 'The clinical practice of speech and language therapists with children with phonologically based speech sound disorders'. Child Language Teaching and Therapy. 31(2), 173-194. https://doi.org/10.1177/0265659014550420

OMS (1992), CIE-10. Décima revisión de la clasificación internacional de las enfermedades. Trastornos mentales y del comportamiento. Descripción clínicas y pautas para el diagnóstico. Ed. Méditor. 
Orden CIN/726/2009, de 18 de marzo de 2009, por la que se establecen los requisitos para la verificación de los títulos universitarios oficiales que habiliten para el ejercicio de la profesión de Logopeda. Boletín Oficial del Estado. 26 de marzo de 2009, núm. 73 , pp. 29159-29163. https://www.boe.es/boe/dias/2009/03/26/pdfs/BOE-A-20095033.pdf

Orden de 9 de diciembre de 1992 por la que se regulan la estructura y funciones de los Equipos de Orientación Educativa y Psicopedagogía. Boletín Oficial del Estado, 18 de diciembre de 1992, núm. 303, pp.42991-42993. https://www.boe.es/buscar/doc.php?id=BOE-A-1992-27998

ORDEN ECI/3960/2007, de 19 de diciembre, por el que se establece el currículo y se regula la ordenación de la educación infantil. Boletín Oficial del Estado. 5 de enero de 2008, núm. 5, pp. 1-36. https://www.boe.es/buscar/pdf/2008/BOE-A-2008-222consolidado.pdf

Orden EDU/1152/2010, de 3 de agosto de 2010, por la que se regula la respuesta educativa al alumnado con necesidad específica de apoyo educativo escolarizado en el segundo ciclo de Educación Infantil, Educación Primaria, Educación Secundaria Obligatoria, Bachillerato y Enseñanzas de Educación Especial, en los centros docentes de la Comunidad de Castilla y León, Boletín Oficial de Castilla y León, 13 agosto 2010, 156. http://bocyl.jcyl.es/

Orden EDU/746/2016, de 19 de agosto, por la que se establecen los equipos de orientación educativa en la comunidad de Castilla y León, así como el ámbito de actuación de los mismos, y se delega la competencia para modificar su ámbito de actuación, 3 de julio de 2017. Boletín Oficial de Castilla y León. Núm. 125. Pp. 26626-26644.

https://www.educa.jcyl.es/es/resumenbocyl/orden-edu-7462016-19-agosto-establecen-equipos-orientacion

Ortiz-Ocaña, A. (2015). Enfoques y métodos de investigación en las ciencias sociales y humanas. Ediciones de la U.

Ortiz-Torres, E. A. (2015). La evaluación del impacto científico en las investigaciones educativas a través de un estudio de caso. Revista Electrónica de Investigación Educativa, 17(2), 89-100. 
Owens, J. (2003). Desarrollo del lenguaje. Traducción, adaptación y autoría parte española Caps. 10 y 12 Escudero, A.J. Pearson Educación.

Palacios, S. G. y Fernández, R. G. (2009). Integración educativa e inclusión de calidad en el tratamiento educativo de la diversidad. Editorial UNED.

Paolieri, D. \& Marful, A. (2018). Norms for a pictographic system: the Aragonese portal of augmentative/alternative communication (ARASAAC) system. Frontiers in Psychology, 9, 2538. https://doi.org/10.3389/fpsyg.2018.02538

Pappas, N. W. \& McLeod, S. (2008). Working with families in speechlanguage pathology. Plural Publishing.

Parada-Salazar, S. (2019). Manual de morfosintaxis. Universidad autónoma de Chile.

Pardo-Caballos, A. y Echarte-Alonso, L.E. (2015). La formalización del consentimiento informado en investigación y la pérdida sentimental del paciente. Persona y bioética, 19(2), 198-226. https://doi.org/10.5294/pebi.2015.19.2.3

Parra-López, P., Olmos-Soria, M., Cabello-Luque, F. y Valero-García, A. V. (2016). Eficacia del entrenamiento en praxias fonoarticulatorias en los trastornos de los sonidos del habla en niños de 4 años. Revista de Logopedia, Foniatría y Audiología, 36(2),

77-84. https://doi.org/10.1016/j.rlfa.2015.05.001

Parrilla, A. (2001). O longo camiño cara a inclusión. Revista Galega do Ensino, 32, 35- 54.

Paul, R. \& Norbury, C. F. (2012). Language disorders from infancy through adolescence: Listening, speaking, reading, writing, and communicating. Elsevier.

Pavez, M., Coloma, C. y Maggiolo, M. (2008). El desarrollo narrativo en niños. Una propuesta práctica para la evaluación y la intervención en niños con trastorno del lenguaje. Ars Médica.

Peña, J. (2014). Manual de logopedia. Masson.

Peñaloza, C. (2017). Desarrollo de la complejidad sintáctica en recontados narrativos de niños preescolares y escolares. Logos (La Serena), 27(2), 334-349. http://dx.doi.org/10.15443/r12726 
Peralta, M. F. y Narbona, J. (1991). Retrasos del desarrollo verbal y problemas de aprendizaje escolar: estudio longitudinal. Bordón. Revista de Pedagogía, 43, 285-98.

Perelló J. (1990). Trastornos del habla: $5^{\text {a }}$ edición. Masson.

Perelló, J., Guixá, J., Leal, M. y Vendrell, J. (1978). Perturbaciones del lenguaje, Científico-Médica.

Pérez, G. (1994). Investigación cualitativa. Retos e interrogantes. La Muralla.

Pérez-Bernal, J. S. (1997). Tratamiento de los retrasos del lenguaje desde la escuela. Revista Interuniversitaria de Formación del Profesorado, (28), 175-188.

Pérez-Hoyos, Ó. I. (2016). Metodología para la elaboración de estudios de caso en responsabilidad social. U. Externado de Colombia.

Piaget, J. (1923). La pensé symbolique et le pensée de l'enfant. Archives de Psychologie, 18; 273-304.

Piaget, J. (1946). La formation du symbole chez l'enfant. Neuchatel. Delachaux et Niestlé.

Piaget, J. (1973). La formación del símbolo en el niño. Editorial Fondo de Cultura Económica.

Ponari, M., Norbury, C. F. \& Vigliocco, G. (2018). Acquisition of abstract concepts is influenced by emotional valence. Developmental $\quad$ Science, 21(2), e12549. https://doi.org/10.1111/desc. 12549

Pons-Bonals, L. y Espinosa-Torres, I. D. J. (2020). Protagonistas de la investigación educativa. Revista Latinoamericana de Metodología de las Ciencias Sociales (RELMECS), 10(1), 1-12. https://doi.org/10.24215/18537863e068

Popham, W. J. (1999). Why standardized tests don't measure educational quality. Educational Leadership, 56(6), 8-15.

Proctor-Williams, K. (2014). Treatment for morphosyntactic deficits: From specific strategies to aholistic approach. Perspectives on Language Learning and Education, 21, 192-202. http://dx.doi.org/10.1044/1le21.4.192 
Puyuelo, M., Wiig, E., Renon, J. y Solanas, A. (1997). Batería de Lenguaje Objetiva y Criterial (BLOC). Masson.

Quecedo, R. y Castaño, C. M. (2002). Introducción a la metodología de investigación cualitativa. Revista de Psicodidáctica, 14, 5-40.

Querejeta, Maira (2016). Vocabulario infantil: comprensión de palabras concretas y abstractas. En el VIII Congreso Internacional de Investigación y Práctica Profesional en Psicología XXIII Jornadas de Investigación XII Encuentro de Investigadores en Psicología del MERCOSUR. Facultad de Psicología Universidad de Buenos Aires, Buenos Aires.

Quintana, E. G. (2008). Las grabaciones en vídeo de secuencias didácticas como instrumento de observación, análisis y reflexión para la evaluación y autoevaluación de la práctica docente. En $L a$ evaluación en el aprendizaje y la enseñanza del español como lengua extranjera/segunda lengua: XVIII Congreso Internacional de la Asociación para la Enseñanza del Español como lengua Extranjera (ASELE): Alicante, 19-22 de septiembre de 2007 (pp. 611-617). Servicio de Publicaciones.

Quinteros, G. D. (2017). La aplicación de los bits de inteligencia, del Glenn Doman y el desarrollo del lenguaje en los niños de tres a cuatro años de la Parroquia el Sucre del Cantón Patate (Tesis doctoral), Universidad Técnica de Ambato-Facultad de Ciencias de la Salud-Carrera de Estimulación Temprana.

Ramírez, D. M. (2011). Estrategias de intervención educativa con el alumnado con trastornos del habla. Revista Digital Innovación y Experiencias Educativas, 48, 1-15.

Ramírez, G. M., Acosta, V. M., Moreno, A. M., del Valle, N. y Axpe, A. (2018). Use of Oral Narrative and Morphosyntactic Activities to Improve Grammar Skills in Pupils with Specific Language Impairment (SLI). Revista de Psicodidáctica, 23(1), 48-55. https://doi.org/10.1016/j.psicoe.2017.07.004

Ramírez-Montoya, M. S. y Lugo-Ocando, J. (2020). Revisión sistemática de métodos mixtos en el marco de la innovación educativa. Comunicar: Revista Científica de Comunicación y Educación, 28(65). https://doi.org/10.3916/C65-2020-01

Ramírez-Santana, G. M., Acosta-Rodríguez, V. M., Moreno-Santana, A. M., del Valle-Hernández, N. y Axpe-Caballero, Á. (2018). El uso 
combinado de narraciones orales y actividades morfosintácticas para mejorar habilidades gramaticales de alumnado con trastorno específico del lenguaje (TEL). Revista de Psicodidáctica, 23(1), 48-55. https://doi.org/10.1016/j.psicod.2017.07.002

Rapin, I. \& Allen, D. A. (1983). Developmental language disorders: Nosologic considerations. En U. Kirk (Ed.), Neuropsychology of Language, Reading and Spelling. Academic Press.

Real Decreto 1277/2003, de 10 de octubre, por el que se establecen las bases generales sobre autorización de centros, servicios y establecimientos sanitarios. Boletín Oficial del Estado. 23 de octubre de 2003, núm. 254, pp. 1-18. https://www.boe.es/eli/es/rd/2003/10/10/1277/con

Real Decreto 1393/2007, de 29 de octubre, por el que se establece la ordenación de las enseñanzas universitarias oficiales. Boletín Oficial del Estado. 30 de octubre de 2007, núm. 260, pp. 1-28. https://www.boe.es/eli/es/rd/2007/10/29/1393/con

Real Decreto 1419/1991, de 30 de agosto, por el que se establece el título universitario oficial de Diplomado en Logopedia y las directrices generales propias de los planes de estudios conducentes a la obtención de aquel. Boletín Oficial del Estado. 10 de octubre de 1991, núm. 243, pp. 32890-32891). https://www.boe.es/eli/es/rd/1991/08/30/1419

Real Decreto 1440/1991, de 30 de agosto, por el que se establece el título universitario, oficial de Maestro, en sus diversas especialidades y las directrices generales propias de los planes de estudios conducentes a su obtención. Boletín Oficial del Estado, 11 de octubre de 1991, núm. 244, pp.33003-33018. https://www.boe.es/eli/es/rd/1991/08/30/1440

Real Decreto 1954/1994, de 30 de septiembre, sobre homologación de títulos a los del Catálogo de Títulos Universitarios Oficiales, creado por el Real Decreto 1497/1987, de 27 de noviembre. Boletín Oficial del Estado. 17 de noviembre de 1994, Núm. 275, pp. 1-11. https://www.boe.es/buscar/pdf/1994/BOE-A-199425190-consolidado.pdf

Real Decreto 334 de ordenación de la Educación Especial. 16 de marzo de 1985. Boletín Oficial del Estado. Núm. 65, pp. 1-12 https://www.boe.es/buscar/pdf/1985/BOE-A-1985-4305consolidado.pdf 
Real Decreto 334/1985, de 6 de marzo, de Ordenación de la Educación Especial. Boletín Oficial del Estado. Núm 65, pp. 6917-6920. https://www.boe.es/eli/es/rd/1985/03/06/334

Real Decreto 696/1995, de 28 de abril, de ordenación de la educación de los alumnos con necesidades educativas especiales. Boletín Oficial del Estado. Núm 131, pp. 16179-16185. https://www.boe.es/eli/es/rd/1995/04/28/696

Renzi, E. y Vignolo, L. (2005). Test Token para niños. Lebón.

Rescorla, L. (1989). The language Developmental Survey (LDS): A screening tool for delayed language in toodlers. Journal of Speech and Hearing Disorders, 54, 587-599. https://doi.org/10.1044/jshd.5404.587

Reynell, J. K., y Gruber, C. P. (1990). Reynell developmental language scales. (Traducción española Pereda, S., Escalas Reynell de desarrollo del Lenguaje). MEPSA.

Reyzábal, M.V. (2001). La comunicación oral y su didáctica (6 ${ }^{\mathrm{a}}$ ed.). La Muralla.

Riccardi-León C.B., Martins-Dias, N. y Luxo-Martins, G.L. (2018). Executive functions in preschool children: development and relationships with language and behabior. Psicologia: Teoria y Prática, 20(3), 121-137. http://dx.doi.org/10.5935/19806906/psicologia.v20n3p121-137.

Rice, M. L. \& Hoffman, L. (2015). Predicting vocabulary growth in children with and without specific language impairment: A longitudinal study from 2; 6 to 21 years of age. Journal of Speech, Language, and Hearing Research, 58(2), 345-359. https://doi.org/10.1044/2015 JSLHR-L-14-0150

Riches, N., Tomasello, M. \& Conti-Ramsden, G. (2005). Verb learning in children with SLI: frequency and spacing effects. Journal of Speech, Language and Hearing Research, 48, 1397- 1411 https://doi.org/10.1044/1092-4388(2005/097)

Rivera, C. (2009). Intervención con alumnos que presentan dislalias. Revista Digital Innovación y Experiencias Educativas, 14, 1-9.

Rodríguez, E. (2010). Alumnos con dislalia: evaluación e intervención. Revista digital: Reflexiones y Experiencias Innovadoras en el Aula, 25, 1-9. 
Rodríguez, N. (2011). Diseños experimentales en educación. Revista de Pedagogía, 32(91), 147-158.

Rodríguez-Montes, T. (2020). El desarrollo de la competencia léxicosemántica a través de la morfología léxica. Revista de Filología, 278-288. https://doi.org/10.25145/j.refiull.2020.40.13

Roper, N \& Dunst, C. J. (2003). Communication intervention in natural learning environments: Guidelines for practice. Infants \& Young Children, 16(3), 215-226.

Ruiz-Quiroga, P. M. (2010). La evolución de la atención a la diversidad del alumnado de educación primaria a lo largo de la historia Temas para la educación. Revista digital para profesionales de la enseñanza, 8, 1-15.

Salas-Blas, E. (2013). Diseños preexperimentales en psicología y educación: una revisión conceptual. Liberabit, 19(1), 133-141.

Salkind, N. J. (1999). Métodos de investigación. Pearson Educación.

Sánchez-Delgado, M. P., Ortuño-Ibáñez, A. y Belda-Galbis, A. C. (2015). De la atención de los problemas de la audición y lenguaje a la logopedia como disciplina. Revista Iberoamericana de Educación, 67(1), 169-186.

Saneleuterio, E., Alonso-Stuyck, P. y García-Ramos, D. (2019). Educar jugando y dialogando. Derechos de la infancia, intencionalidad, familia y lenguaje. Revista sobre la Infancia y la Adolescencia, 17, 40-48. https://doi.org/10.4995/reinad.2019.11781

Sanhueza, D. R., Urrutia, M., Hernández, P. A. \& Marrero, H. (2021). Comprensión del tiempo a través del espacio: Un estudio de plasticidad inducida en niños con trastorno del desarrollo del lenguaje. Revista de Logopedia, Foniatría y Audiología, 1-11. https://doi.org/10.1016/j.rlfa.2020.09.005

Santi, M. F. (2016). Controversias éticas en torno a la privacidad, la confidencialidad y el anonimato en investigación social. Revista de Bioética y Derecho, (37), 5-21. https://doi.org/10.1344/rbd2016.37.16147

Sanz-Torrent, M., Andreu, L., Badia, I. \& Sidera, F. (2011). Argument omissions in preschool Catalan and Spanish speaking children with SLI. Infancia y Aprendizaje, 34(1), 49-66. https://doi.org/10.1174/021037011794390085 
Schoonenboom, J. \& Johnson, R. B. (2017). How to construct a mixed methods research design. Köln Z Soziol, 69(2), 107-131. https://doi.org/10.1007/s11577-017-0454-1

Schwartz, R. G. (Ed.). (2017). Handbook of child language disorders. Psychology press.

Seibel, C. y Jiménez-Hurtado, C. (2009). Definir para todos. La definición como acceso fundamental a la información. M. Tercedor (Ed). En Materiales multimedia para todos: inclusión y accesibilidad en educación, 167-284. Tragacanto.

Semel, E., Wiig, E. H. \& Secord, W. (2006). Clinical Evaluation of Language Fundamentals-fourth edition UK (CELF- 4UK). Harcourt Assessment

Semel, E., Wiig, E. H. \& Secord, W. A. (1997). CELF-3. Clinical Evaluation of Language Fundamentals (Spanish Edition). The Psychological Corporation.

Sentis, F., Nusser, C. \& Acuña, X., (2009). El desarrollo semántico y el desarrollo de la referencia en la adquisición de la lengua materna. Onomázein, 20 (2) 147-191.

Serón, J. M. y Aguilar, M. (1992). Psicopedagogía de la comunicación y el lenguaje. EOS.

Serra-Raventós, M. S. (1991). Procesamiento del lenguaje en el retraso y la disfasia. Revista de Logopedia, Foniatría y Audiología, 11(3), 151-156.

Serra-Raventós, M. S. (2002). Trastornos del lenguaje: preguntas pendientes en investigación e intervención. Revista de Logopedia, Foniatría y Audiología, 22(2), 63-76.

Silva, M. L. (2010). El estudio de la sintaxis infantil a partir del diálogo con niños: Aportes metodológicos. Interdisciplinaria, 27(2), 277-296.

Simons, H. (2011). El estudio de caso: Teoría y práctica. Ediciones Morata.

Singleton, N. C. (2018). Late talkers: Why the wait-and-see approach is outdated. Pediatric Clinics, 65(1), 13-29.

https://doi.org/10.1016/j.pcl.2017.08.018S

Skinner, B. F. (1957). Verbal behavior. Appleton-Century-Crofts. 
Snow, C. E., Lawrence, J. F. \& White, C. (2009). Generating knowledge of academic language among urban middle school students. Journal of Research on Educational Effectiveness, 2, 325-344. https://doi.org/10.1080/19345740903167042

Spencer, S., Clegg, J., Lowe, H. \& Stackhouse, J. (2017). Increasing adolescents' depth of understanding of cross curriculum words: an intervention study. International Journal of Language and Communication Disorders, 52(5), 652-668. https://doi.org/10.1111/1460-6984.12309

Stake, R. E. (1995). The art of case study research. Thousand Oaks, CASAGE Publications.

Stake, R. E. (2005). Qualitative case studies. En Denzin, N. K. y Lincoln, Y. S. (Ed). Sage handbook of qualitative research, $3^{\mathrm{a}}$ ed., 443466. Thousand Oaks, CA: Sage Publications.

Steeve, R. W. (2010). Babbling and chewing: Jaw kinematics from 8 to 22 months. Journal of Phonetics. 38(3), 445-458. https://doi.org/10.1016/j.wocn.2010.05.001

Steeve, R. W.; Moore, C. A.; Green, J. R.; Reilly, K. J. \& McMurtrey, J. R. (2008). Babbling, chewing, and sucking: Oromandibular coordination at 9 months. Journal of Speech, Language, and Hearing Research. 51(6), 1390-1404. htps:// doi.org/10.1044/1092-4388(2008/07-0046)

Stocco, C. S. \& Thompson, R. H. (2015). Contingency analysis of caregiver behavior: implications for parent training and future directions. Journal of Applied Behavior Analysis, 48, 1-19. https://doi.org/10.1002/jaba.206

Susanibar, F. (2015). Trastorno de los sonidos del Habla - TSH: Controversias y Evidencias en el Uso de Ejercicios Oromotores no Verbales en la Intervención. Revista Científica Signos Fónicos, 1(2), 47-49.

Susanibar, F., Dioses, A. y Monzón, K. (2016). El habla y otros actos motores orofaciales no verbales: Revisión parte II. Revista Digital EOS Perú. 8(2), 68-105.

Susaníbar, F., Huamaní, O. \& Dioses, A. (2013). Adquisición fonéticafonológica. Rev. Digit EOS Perú, 1(1), 19-36. 
Swanson, L., Fey, M., Mills, C. \& Hood, L. (2005). Use of narrativebased language intervention with children who have specific language impairment. American Journal of Speech Language Pathology, 14, 131-143. http://dx.doi.org/10.1044/1058$\underline{0360(2005 / 014)}$

Thal, D. (2000). Late talking toddlers: Are they at risk? San Diego State University Press.

Tomblin, J. B., Records, N. L., Buckwalter, P., Zhang, X., Smith, E., \& O'Brien, M. (1997). Prevalence of specific language impairment in kindergarten children. Journal of Speech, Language, and Hearing Research: JSLHR, 40(6), 1245-1260. http://dx.doi.org/10.1044/jslhr.4006.1245

Tonon, G. (2009). La entrevista semi-estructurada como técnica de investigación. En Tonon, G, Alvarado, S., Ospina, H., Lucero, P., Luna, M.T. y Fabris, F. (2009). Reflexiones Latinoamericanas sobre Investigación Cualitativa (p. 47-68).

Toronto, A. S. (1975). Screening Test of Spanish Grammar, STSG (Test Exploratorio de Gramática Española). Northwestern Univ. Press.

Torres, F., Pino, J., Peñaloza, C., Rojas, D., Fernández, M. A., Castro, P., ... \& Hormazábal, K. (2016). Comparación de criterios para determinar la edad de adquisición de fonemas lateral y róticos. Revista Chilena de Fonoaudiología, 15, 1-16. http://dx.doi.org/10.5354/0719-4692.2016.44149

Torres, J. (2003). Trastornos del lenguaje en niños con necesidades educativas especiales. Ceac.

Torres, R. H. (2019). Metodología de la investigación. Las rutas cuantitativa, cualitativa y mixta. McGraw-Hill Interamericana editores S.A.

UNESCO (2004). Temario abierto sobre educación inclusiva. Materiales de apoyo para responsables de políticas educativas. UNESCO.

UNESCO (2008). Educación para Todos en 2015 ¿Alcanzaremos la meta? UNESCO.

Van Wynsberghe, R. \& Khan, S. (2007). Redefining Case Study. International Journal of Qualitative Methods, 6(2), 80-94. 
Vavrik, K. (2016). Gesells chaftliche Effizienz potentiale von Frühd iagnostik und frühz eitiger Therapie von En twick lungs störungen. [Online] http://www.hauptverband.at/cdscontent/load?contentid=10008.6 35848\&version=1480670314 (Accedido 26 diciembre 2019).

Vicente, A. L. (2015). Cuestiones éticas en la intervención con familias y menores. Cuadernos de Trabajo Social,28(1), 127. https://doi.org/10.5209/revCUTS.2015.v28.n1.45727

Von, S., Verdel, M., Barstad, B. G., Gravås, E. M. H., Jahnsen, R., Krabbe, S., ... \& Bang, B. (2013). The effect of interventions based on the programs of The Institutes for the Achievement of Human Potential and Family Hope Center. Developmental neurorehabilitation, 16(4),

217-229. https://doi.org/10.3109/17518423.2012.739211

Vygotski, L. (1979). El desarrollo de los procesos psicológicos superiores. Ed. Crítica.

Vygotski, L. S., Kozulin, A. \& Abadía, P. T. (1995). Pensamiento y lenguaje. Paidós.

Vygotski, L., (2010). Pensamiento y lenguaje (2a ed.). Paidós ibérica.

Warnock, M. (1981). Meeting Special Educational Needs, Britannic Majesty's Stationary Ofice.

Watson, J. B. (1970). Behaviorism. 1925. Reimpresión. Norton \& Company.

Wechsler, D. (1949). Wechsler Intelligence Scale for Children. Psychological Corporation.

Wechsler, D. (2014). Wechsler Intelligence Scale for Children (Fifth Edition). Pearson.

Weismer, S. \& Heseth, L. J. (1996). Lexical learning by children with specific language impairment: effects of linguistic input presented at varying speaking rates. Journal of Speech and Hearing Research, 39, 177-190.

Wetherby, A. \& Prizant, B. (2002). Communication and Symbolic Scales Developmental Profil Paul H. Brookes.

White, H. \& Sabarwal, S. (2014). Diseño y métodos cuasiexperimentales. Síntesis metodológicas: evaluación de 
impacto. Fondo para las naciones Unidas para la infancia (UNICEF).

Wiig, E. H., Secord, W. A. \& Semel, E. (2009). Clinical Evaluation of Language Fundamentals Preschool- 2 Spanish. Pearson.

Wiig, E. H., Secord, W. A. \& Semel, E. (2013). Clinical evaluation of language fundamentals: CELF-5. Pearson.

Wirz, S. (1993). Historical consideration in assessment. En J. R. Beech, L. Harding y D. Hilton-Jones (eds.), Assessment in Speech and Language Therapy. Routledge.

World Health Organization. (2018). International statistical classification of diseases and related health problems (11th Revision). https://icd.who.int/browse11/1-m/en

Wright, L., Pring, T. \& Ebbels, S. (2018). Effectiveness of vocabulary intervention for older children with (developmental) language disorder. International Journal of Language \& Communication Disorders, 53(3), 480-494. https://doi.org/10.1111/1460$\underline{6984.12361}$

Yazan, B. (2015). Three approaches to case study methods in education: Yin, Merriam, and Stake. The Qualitative Report, 20(2), 134152. http://www.nova.edu/ssss/QR/QR20/2/yazan1.pdf

Yela, M. (1996). La evolución del conductismo. Psicothema, 8(Sup), 165-186.

Ygual, A. y Cervera, J. (2016). Eficacia de los programas de ejercicios de motricidad oral para el tratamiento logopédico de las dificultades de habla. Revista de Neurología, 62(Sup11), 59 - 64. http:// www.neurologia.com/pdf/Web/62S01/bpS01S059.pdf

Ygual, A. y Cervera, J. F. (2005). Dispraxia verbal: características clínicas y tratamiento logopédico. Revista de Neurología, 40(1), S121-S126. https://doi.org/10.33588/rn.40S01.2005083

Ygual, A., Cervera, J. F., Baixauli, I. y Meliá, A. (2011). Protocolo de observación del lenguaje para maestros de educación infantil. Eficacia en la detección de dificultades semánticas y morfosintácticas. Revista de Neurología, 52(1), S127-S134. https://doi.org/10.33588/rn.52S01.2011001

Yin, R. K. (2009). Case Study Research: design and methods (4. ${ }^{\mathrm{a}}$ ed.). Thousand Oaks, CA: Sage. 
Zwitserlood, R., Wijnen, F., Van, M. \& Verhoeven, L. (2015). 'MetaTaal': enhancing complex syntax in children with specific language impairment a metalinguistic and multimodal approach. International Journal of Language \& Communication Disorders, 50(3), 273-297. https://doi.org/10.1111/1460-6984.1213 


